Marcelo Luiz Pereira

\title{
MEDIÇÃO, PREDIÇÃO E ANÁLISE DE PARTÍCULAS AÉREAS EM SALAS CIRÚRGICAS
}

São Paulo

2008 
Marcelo Luiz Pereira

\section{MEDIÇÃO, PREDIÇÃO E ANÁLISE DE PARTÍCULAS AÉREAS EM SALAS CIRÚRGICAS}

Tese apresentada à Escola Politécnica da Universidade de São Paulo para obtenção do Título de Doutor em Engenharia

Área de Concentração:

Engenharia Mecânica

Orientador:

Prof. Dr. Arlindo Tribess

São Paulo

2008 
Este exemplar foi revisado e alterado em relação à versão original, sob responsabilidade única do autor e com a anuência de seu orientador.

São Paulo, 07 de novembro de 2008

Assinatura do Autor

Assinatura do Orientador

\section{FICHA CATALOGRÁFICA}

Pereira, Marcelo Luiz

Medição, predição e análise de partículas aéreas em salas cirúrgicas/ M. L. Pereira. - ed. rev. - São Paulo, 2008.

$163 p$.

Tese (Doutorado) - Escola Politécnica da Universidade de São Paulo. Departamento de Engenharia Mecânica.

1. Ar condicionado 2. Qualidade do ar 3. Contaminação aérea 4. Salas cirúrgicas I. Universidade de São Paulo. Escola Politécnica. Departamento de Engenharia Mecânica II. $\mathrm{t}$ 


\section{DEDICATÓRIA}

Dedico este trabalho a uma pessoa que foi muito importante em todas as etapas de minha vida e que, por circunstâncias do destino, teve que nos deixar antes da conclusão desse trabalho, meu pai.

Meu pai, lembrar de você é lembrar seus ensinamentos e exemplos de vida...

É lembrar a sua vida humilde, porém cheia de garra e ternura...

Você partiu sem que eu tivesse tempo de lhe agradecer por tudo.

Você partiu antes do final de mais uma importante conquista dessa vida...

Gostaria muito que você estivesse aqui para compartilharmos esse importante momento

Gostaria muito que você não tivesse nos deixado dessa forma.

Onde quer que você esteja, quero dizer que você faz parte deste caminho...

Quero dizer que ainda sinto o ombro amigo que sempre me estimulou a seguir em frente.

Obrigado pela vida, pelos abraços calorosos ou simplesmente pelos momentos que passamos juntos.

Obrigado pelos exemplos de luta, que perduraram até seus momentos finais em meio a muita dor e sofrimento.

Obrigado pela espera para que eu pudesse lhe dar o último abraço.

Meu pai, aceite esta homenagem em meio a lágrimas e saudades...

Em meio a muito, muito orgulho por ter sido seu filho.

Obrigado por tudo...

Da mesma forma, dedico o trabalho a minha querida mãe, também fundamental nessa caminhada.

E dedico-o à minha esposa e à minha filha, que sempre estiveram ao meu lado.

Sou grato também aos meus irmãos Batista, Luciano, Cesário e Luana e à minha avó Carmem. 


\section{AGRADECIMENTOS}

Ao meu orientador, Prof. Dr. Arlindo Tribess, pela amizade, apoio técnico e pessoal à realização deste trabalho, pelo seu companheirismo e incentivo em todos os momentos.

À Prof a . Dra. Lídia Morawska, do International Laboratory for Air Quality and Health da Queensland University of Technology da Austrália, pela amizade, calor humano e pela orientação no período em que permaneci naquele país.

À Fundação de Amparo à Pesquisa do Estado de São Paulo - FAPESP, pelo suporte financeiro ao projeto.

Ao Conselho Nacional de Desenvolvimento Científico e Tecnológico - CNPq, pelas bolsas concedidas para a realização de estudos no Brasil e na Austrália

Ao Dr. Gustavo Silveira Graudenz pelas importantes discussões e contribuições desde o início do desenvolvimento deste trabalho

Ao Prof. Dr. Jurandir Itizo Yanagihara pelas importantes sugestões ao desenvolvimento da tese

Aos colegas do programa de Pós-Graduação em Engenharia Mecânica da EPUSP, em especial ao colega Eng. Victor Barbosa Felix, e à Bióloga Cristiane Minussi pela amizade e ajuda prestada nos ensaios experimentais.

Ao Prof. Vidomar Silva Filho pela amizade, apoio pessoal e técnico ao longo de todo este trabalho.

Aos Profs. Rogério Vilain, Rubem Toledo Bergamo, Jaci Destri, Felipe Teixeira e Fernando Teixeira, pelo companheirismo, amizade e a presença em momentos importantes de minha vida.

À colega Dra. Patrícia Kawase pelo seu companheirismo e incentivo em todos os momentos.

Aos Profs. Gilson Jandir de Souza e Jesué Graciliano da Silva do Curso Técnico de Refrigeração e Ar Condicionado do CEFETSC, pela dedicação e respeito com a coisa pública.

À Dra. Linda Ferreira Maximiano, ao Prof. Dr. José Pinhata Otoch e à Enfermeira Andréa Tamancoldi Couto pela receptividade, colaboração e apoio nos ensaios realizados no Hospital Universitário da Universidade de São Paulo. 
Ao Prof. Dr. Flávio Galvão, pelo entusiasmo e ajuda prestada para a realização de ensaios na Faculdade de Medicina da Universidade de São Paulo.

Ao Eng. Tomaz Puga Leivas, pela constante disposição e contribuição para a realização dos ensaios no Instituto de Ortopedia e Traumatologia do Hospital das Clínicas.

À Dra. Ivete L. Masukawa pela colaboração e apoio nos ensaios realizados no Hospital Nereu Ramos em Santa Catarina.

Ao Dr. Getúlio Oliveira Filho, Diretor Geral do Hospital Celso Ramos pela colaboração e apoio nos ensaios realizados nessa instituição.

Ao Dr. Didier Roberto Torres Ribas e Dra. Tânia Regina Guedes do Hospital Geral de Itapecerica da Serra, pela colaboração e apoio nos ensaios realizados nessa instituição.

Às amizades que construí na Austrália e aos colegas do International Laboratory for Air Quality and Health da Queensland University of Technology.

Aos funcionários do Laboratório de Máquinas Térmicas do Departamento de Engenharia Mecânica da EPUSP, em especial ao funcionário Wilson Costa Neves pelo apoio a amizade. 


\section{SUMÁRIO}

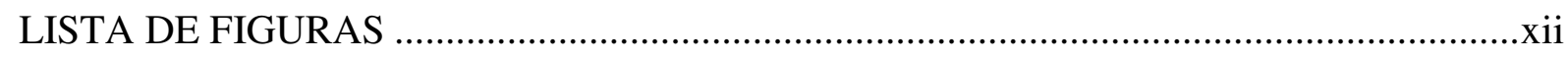

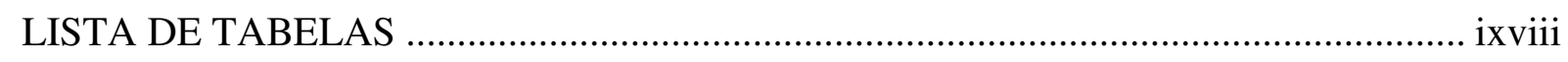

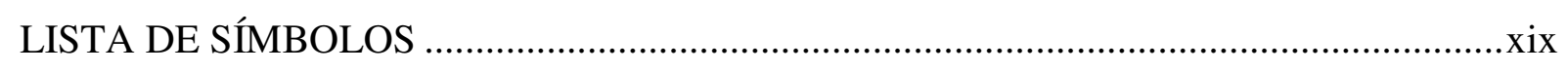

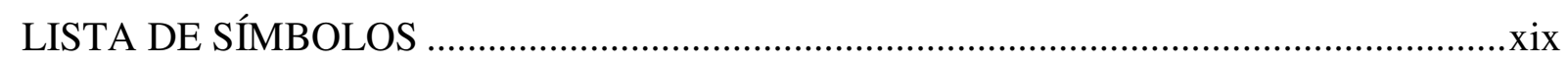

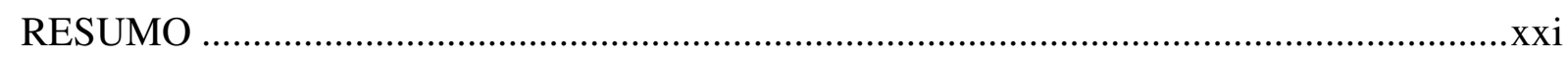

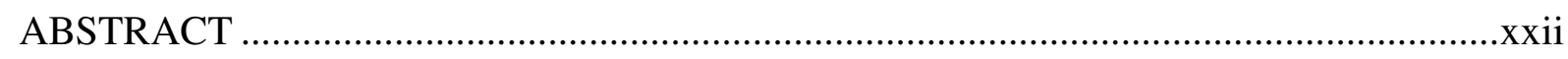

CAPÍTULO 1 - INTRODUÇÃ O ........................................................................................ 1

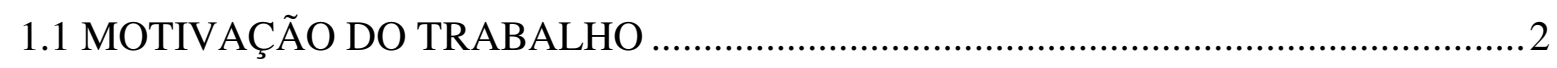

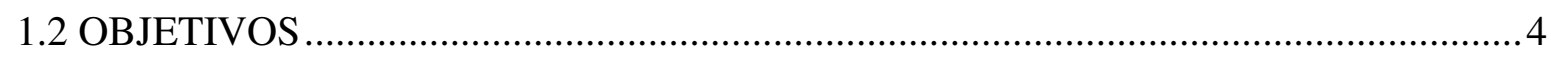

1.3 ESTRUTURA DO TRABALHO ....................................................................... 4

CAPÍTULO 2 - CONTAMINAÇÃO AÉREA EM SALAS CIRÚRGICAS .......................6

2.1 MICROBIOLOGIA DAS SALAS CIRÚRGICAS .................................................. 10

2.1.1 A pele como fonte de microrganismos ............................................................... 10

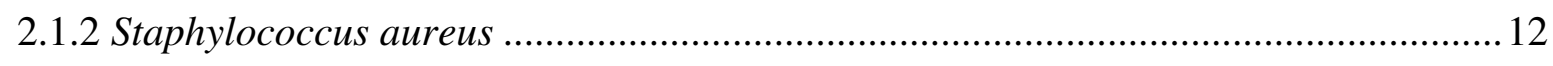

2.1.3 O sistema de condicionamento de ar como fonte de contaminação ........................... 14

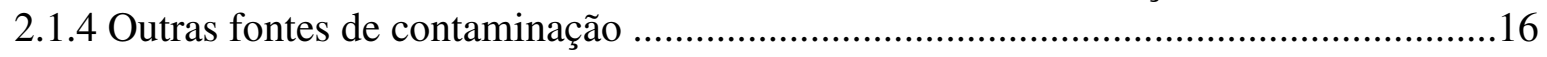

2.2 CONTROLE DA CONTAMINAÇÃO AÉREA EM SALAS CIRÚRGICAS ............... 16

2.2.1 Controle do número de pessoas e nível de atividade................................................. 16

2.2.2 Controle pelo sistema de condicionamento de ar .................................................... 17

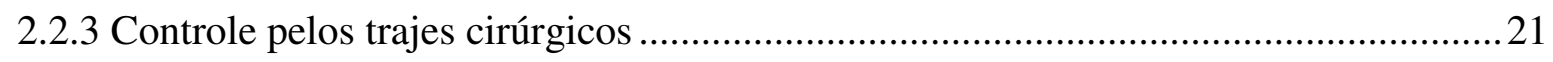

CAPÍTULO 3 - DISTRIBUIÇÃO E MOVIMENTAÇÃO DE AR EM SALAS

CIRÚRGICAS............................................................................24

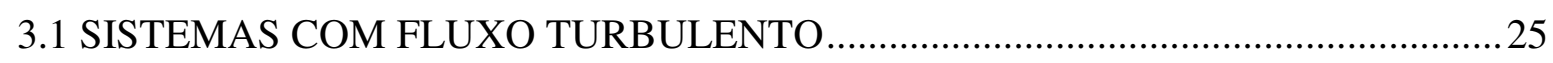

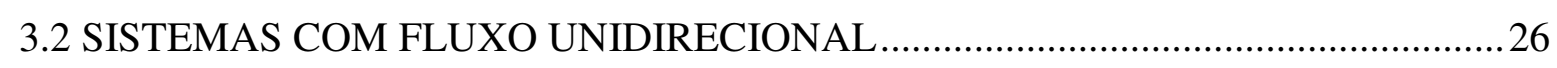

CAPÍTULO 4 - FATORES QUE AFETAM A CONCENTRAÇÃO DE PARTÍCULAS

EM SALAS CIRÚRGICAS .................................................................30

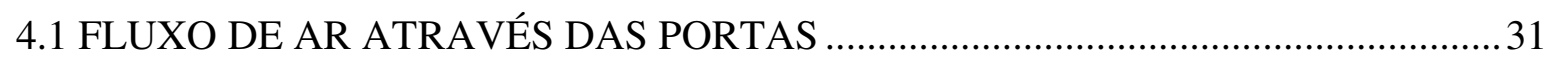

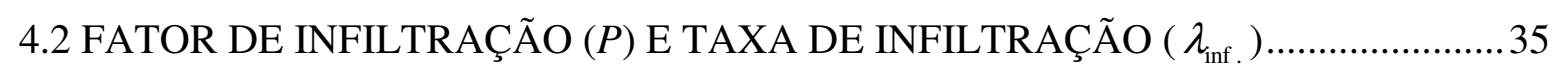

4.3 DEPOSIÇÃO DAS PARTÍCULAS NO INTERIOR DA SALA CIRÚRGICA ............37

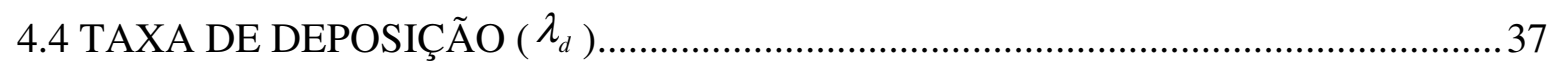

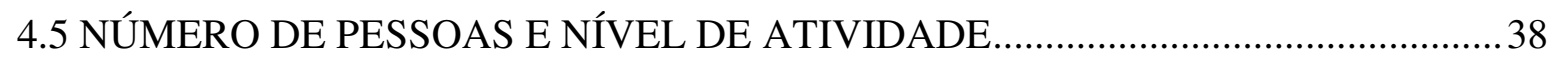

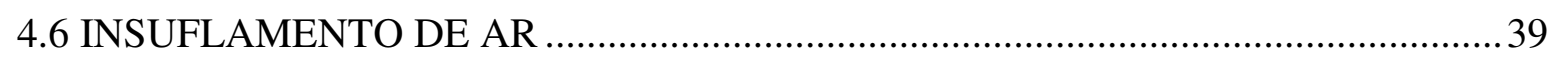

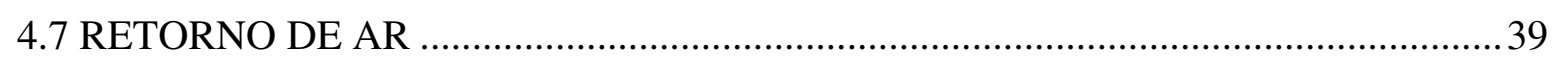




\section{CAPÍTULO 5 - MODELO PARA PREDIÇÃO DA CONCENTRAÇÃO DE}

PARTÍCULAS ..............................................................................................40

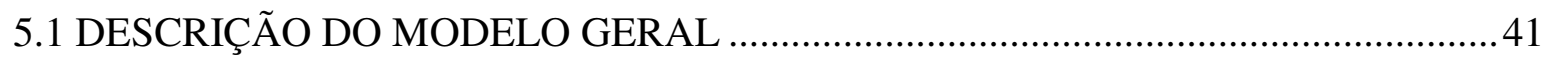

5.2 CONFIGURAÇÕES DE SISTEMAS DE CONDICIONAMENTO E FILTRAGEM DO AR.

5.2.1 Sistemas com recirculação sem renovação de ar.........................................................4

5.2.2 Sistemas sem recirculação e com 100\% de ar externo .................................................. 45

5.2.3 Sistemas com recirculação e renovação de ar ............................................................4

CAPÍTULO 6 - METODOLOGIA EXPERIMENTAL ....................................................49

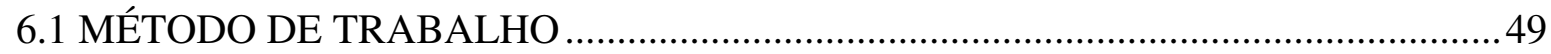

6.2 VALIDAÇÃO DA METODOLOGIA DE MEDIÇÃO ................................................

6.3 APRESENTAÇÃO DOS DADOS EXPERIMENTAIS ……………….......................

6.4 MEDIÇÃO DAS VARIÁVEIS E APARATO EXPERIMENTAL ..................................52

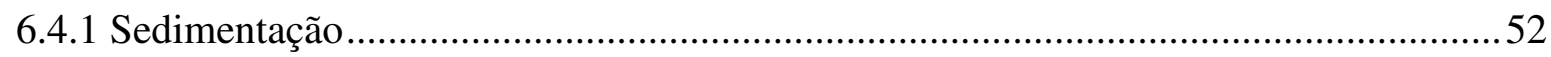

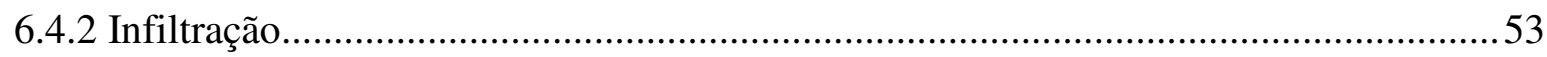

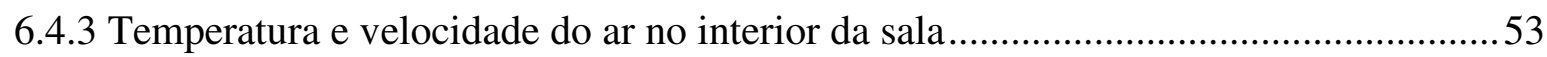

6.4.4 Velocidade e vazão de ar nos difusores e grelhas de insuflamento e retorno ...............55

6.4.5 Medições em sistemas com fluxo não unidirecional ...................................................55

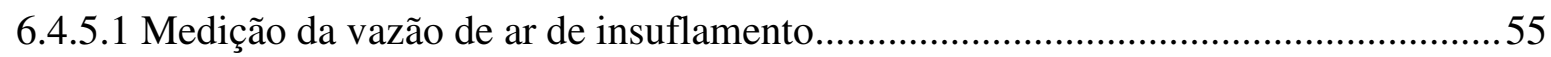

6.4.5.2 Medição da velocidade do ar no insuflamento e no retorno......................................56

6.4.6 Medição da concentração e tamanho das partículas em suspensão................................58

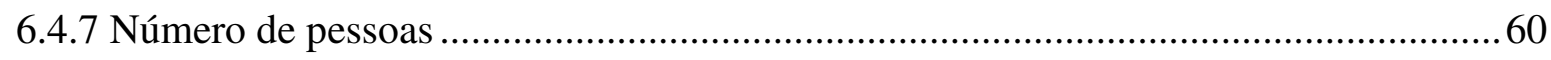

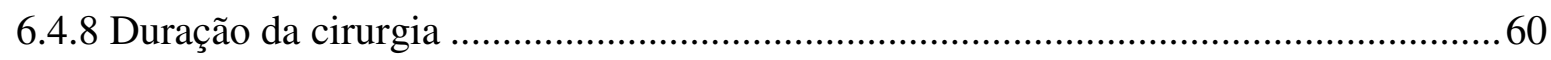

6.4.9 Sistema de aquisição de dados ..............................................................................6

CAPÍTULO 7 - METODOLOGIA DE PREDIÇÃO.........................................................62

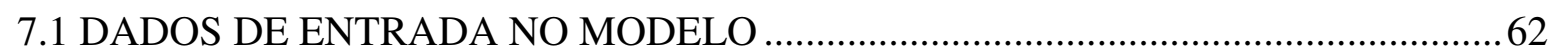

7.2 APRESENTAÇÃO DOS RESULTADOS DE PREDIÇÃO .........................................63

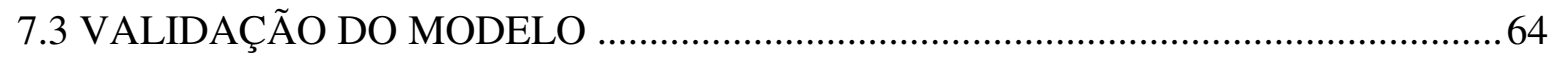

CAPÍTULO 8 - LEVANTAMENTO EXPERIMENTAL_......................................................67

8.1 CARACTERIZAÇÃO DAS SALAS CIRÚRGICAS …………………………........67

8.2 DESCRIÇÃO DOS SISTEMAS DE CONDICIONAMENTO DE AR

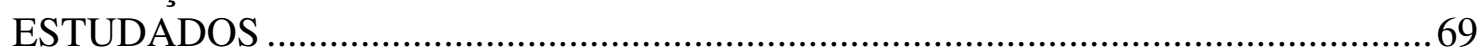

8.2.1 Sistema com insuflamento pela parede e retorno próximo do piso - Sistema A ........69

8.2.2 Sistema com insuflamento e retorno pelo teto - Sistema B ……………………......... 70

8.2.3 Insuflamento pelo teto e retorno próximo ao piso - Sistema C ………………….......71 
8.2.4 Ar condicionado de janela - Sistema D .73

8.3 CARACTERIZAÇÃO DOS PROCEDIMENTOS CIRÚRGICOS

8.4 DISTRIBUIÇÃO DE TEMPERATUIRAS E VELOCIDADES DO AR NAS

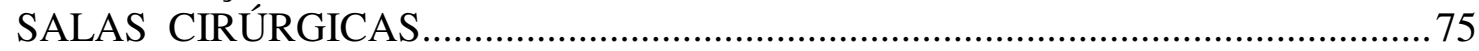

8.5 CONCENTRAÇÃO DE PARTÍCULAS NAS SALAS CIRÚRGICAS .......................76

8.5.1 Sistema A - Condicionamento de ar desligado e portas fechadas ...............................76

8.5.2 Sistema A - Condicionamento de ar desligado e portas abertas ................................. 77

8.5.3 Sistemas A, B, C e D - Condicionamento de ar ligado e portas fechadas ...................78

8.5.4 Sistemas A, B, C e D - Condicionamento de ar ligado e portas abertas ..................... 80

8.6 RELAÇÃO ENTRE A CONCENTRAÇÃO DE PARTÍCULAS E A MÉDIA DAS CONCENTRAÇÕES

8.6.1 Sistema A - Condicionamento de ar desligado e portas fechadas ............................. 82

8.6.2 Sistema A - Condicionamento de ar desligado e portas abertas ................................82

8.6.3 Sistemas A, B, C e D - Condicionamento de ar ligado e portas fechadas .................83

8.6.4 Sistemas A, B, C e D - Condicionamento de ar ligado e portas abertas.....................85

8.7 COMPARAÇÃO ENTRE AS CONCENTRAÇÕES NAS SALAS CIRÚRGICAS E

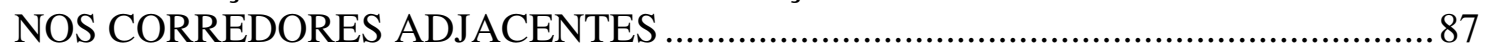

8.7.1 Sistema A - Condicionamento de ar desligado e portas fechadas .............................87

8.7.2 Sistema A - Condicionamento de ar desligado e portas abertas ................................ 88

8.7.3 Sistemas A, B, C e D - Condicionamento de ar ligado e portas fechadas .................88

8.7.4 Sistemas A, B, C e D - Condicionamento de ar ligado e portas abertas .................... 91

CAPÍTULO 9 - PREDIÇÃO DA CONCENTRAÇÃO DE PARTÍCULAS.....................93

9.1 SISTEMA COM INSUFLAMENTO PELA PAREDE E RETORNO PRÓXIMO

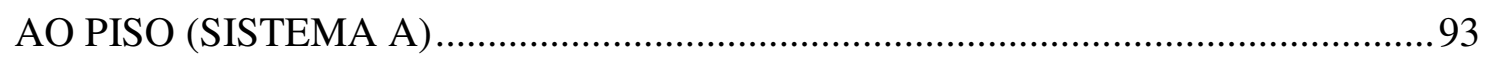

9.1.1 Condicionamento de ar desligado e portas fechadas ...............................................93

9.1.2 Condicionamento de ar desligado e portas abertas.................................................97

9.1.3 Condicionamento de ar ligado e portas fechadas .................................................. 100

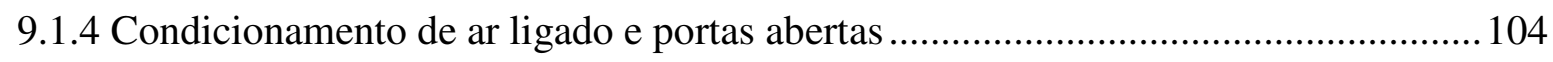

9.2 SISTEMA COM INSUFLAMENTO E RETORNO PELO TETO (SISTEMA B).....107

9.2.1 Condicionamento de ar ligado e portas fechadas .................................................. 107

9.2.2 Condicionamento de ar ligado e portas abertas ..................................................... 111

9.3 SISTEMA COM INSUFLAMENTO PELO TETO E RETORNO PRÓXIMO AO

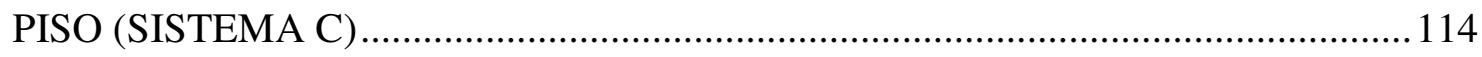

9.3.1 Condicionamento de ar ligado e portas fechadas ................................................ 114

9.3.2 Condicionamento de ar ligado e portas abertas ...................................................... 118

9.4 AR CONDICIONADO DE JANELA (SISTEMA D) ......................................... 121 
9.4.1 Condicionamento de ar ligado e portas fechadas 121

9.4.2 Condicionamento de ar ligado e portas abertas 125

CAPÍTULO 10 - ANÁLISE DOS RESULTADOS EXPERIMENTAIS 128

10.1 DISTRIBUIÇÃO DA TEMPERATURA E VELOCIDADE DO AR NAS SALAS CIRÙRGICAS 128

10.2 CARACTERIZAÇÃO DA CONCENTRAÇÃO DAS PARTÍCULAS NO INTERIOR DAS SALAS CIRÚRGICAS 129

10.3 INFLUÊNCIA DA CONCENTRAÇÃO INICIAL 129

10.4 INFLUÊNCIA DA ATIVIDADE HUMANA NA CONCENTRAÇÃO DE PARTÍCULAS

10.5 INFLUÊNCIAS DO DIÂMETRO DAS PARTÍCULAS SOBRE A CONCENTRAÇÃO

10.6 INFLUÊNCIA DA ABERTURA DAS PORTAS NA CONCENTRAÇÃO DE PARTÍCULAS

10.7 INFLUÊNCIA DO SISTEMA DE CONDICIONAMENTO DE AR SOBRE A CONCENTRAÇÃO DE PARTÍCULAS .

10.8 INFLUÊNCIA DAS VAZÕES DE INSUFLAMENTO E RETORNO NA CONCENTRAÇÃO DE PARTÍCULAS

10.9 INFLUÊNCIA DO TIPO DE SISTEMA DE CONDICIONAMENTO DE AR NA CONCENTRAÇÃO DE PARTÍCULAS .

CAPÍTULO 11 - ANÁLISE DOS RESULTADOS DE PREDIÇÃO DE

PARTÍCULAS 141

11.1 ANÁLISES ESTATÍSTICAS 142

11.2 ANÁLISES GRÁFICAS 143

11.3 ANÁLISE DA CONTRIBUIÇÃO DOS FATORES NA GERAÇÃO E REMOÇÃO DE PARTÍCULAS. 144

11.4 ANÁLISE DAS CONCENTRAÇÕES EM FUNÇÃO DO DIÂMETRO 146

CAPÍTULO 12 - CONCLUSÕES 148

12.1 O MODELO MATEMÁTICO PROPOSTO. 148

12.2 ALGUMAS CONSTATAÇÕES E RESPECTIVAS IMPLICAÇÕES . 150

12.3 RELEVÂNCIA DO ESTUDO 153

12.4 LIMITAÇÕES DO ESTUDO .... 154

12.5 SUGESTÕES PARA A CONTINUIDADE DO PRESENTE TRABALHO 154 


\section{LISTA DE FIGURAS}

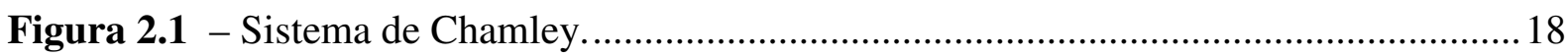

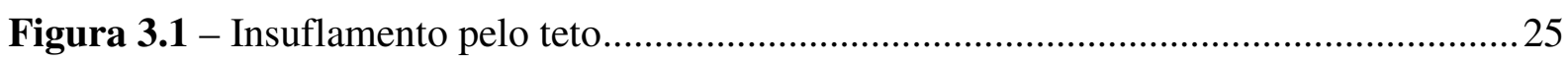

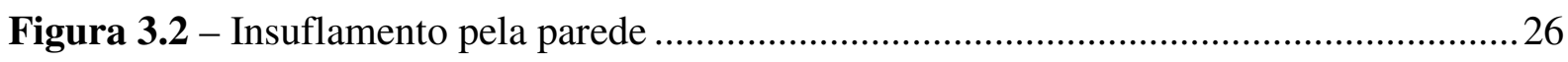

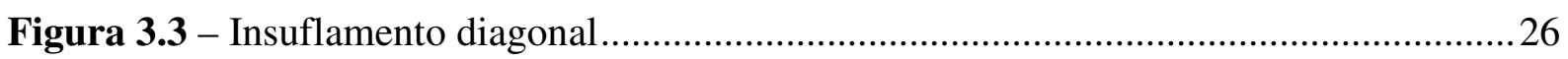

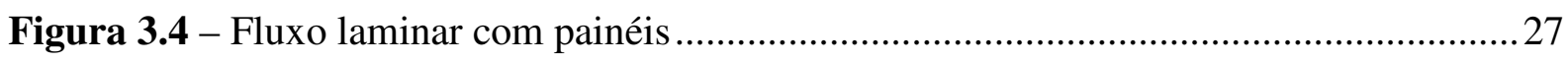

Figura 3.5 - Painéis de proteção localizadas a $2 \mathrm{~m}$ do piso …............................................28

Figura 3.6 - Fluxo de ar com cortina de ar....................................................................... 28

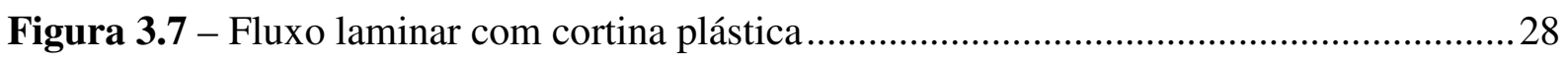

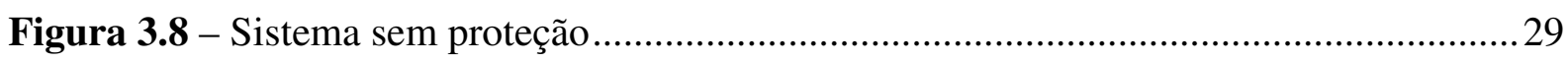

Figura 4.1 - Fatores que influenciam a geração/remoção de partículas em uma

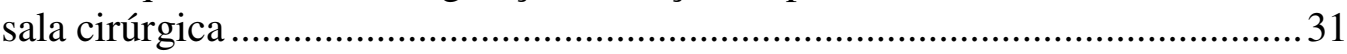

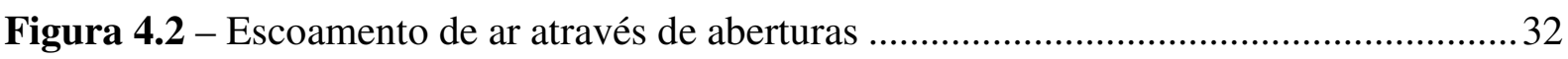

Figura 4.3 - Principais configurações de fluxo de ar através de aberturas ............................. 34

Figura 4.4 - Distribuição de pressão ao longo do eixo vertical de uma porta ........................ 35

Figura 4.5 - Taxa de deposição em função do diâmetro das partículas. .................................. 38

Figura 5.1 - Diagrama de balanço de massa ..................................................................... 41

Figura 5.2 - Fatores que afetam na variação da concentração de partículas...........................42

Figura 5.3 - Sistema sem renovação e sem recirculação de ar ..............................................4

Figura 5.4 - Sistema sem recirculação de ar (100\% ar externo) .......................................... 45

Figura 5.5 - Sistema com recirculação de ar...................................................................47

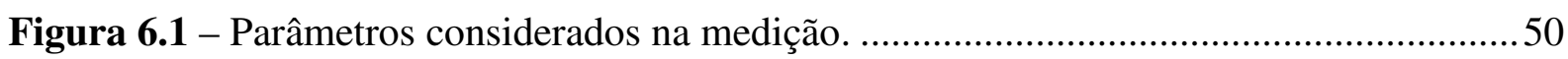

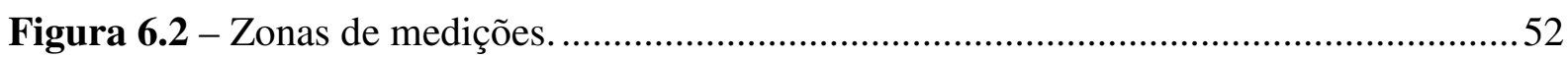

Figura 6.3 - Sensores de temperatura e velocidade do ar. ....................................................53

Figura 6.4 - Distribuição dos pontos de medição de temperaturas e velocidades. .................54

Figura 6.5 - Suportes para medição da velocidade e temperatura do ar .................................54

Figura 6.6 - Foto do suporte para medição da velocidade e temperatura do ar......................55

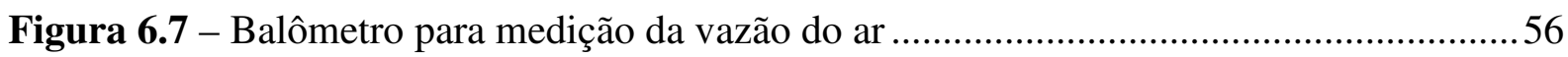

Figura 6.8 - Anemômetro para a medição da velocidade do ar ..............................................57

Figura 6.9 - Pontos de medição de velocidades.................................................................57

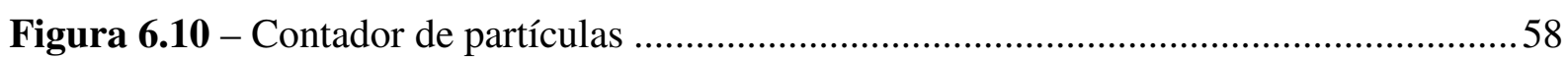

Figura 6.11 - Contador de partículas colocado próximo à área cirúrgica..............................59 
Figura 6.12 - Contador de partículas colocado junto ao insuflamento 59

Figura 6.13 - Contador colocado no corredor. .59

Figura 6.14 - Sistema de aquisição de dados

Figura 7.1 - Variáveis consideradas na medição. 63

Figura 8.1 A - Insuflamento pela parede e retorno próximo ao piso (Sala cirúrgica A)

Figura 8.1 B - Vista geral da sala, mostrando a grelha de insuflamento (Sala cirúrgica A)...70

Figura 8.2 - Vista inferior do sistema com insuflamento e retorno pelo teto (Sala Cirúrgica B) 70

Figura 8.3 A - Vista superior do sistema com insuflamento e retorno pelo teto (Sala Cirúrgica B).

Figura 8.3 B - Vista do insuflamento e do retorno (Sala Cirúrgica B) .................................71

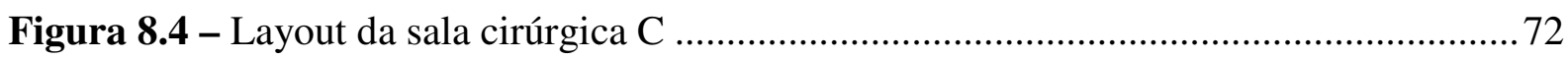

Figura 8.5 A - Vista do insuflamento e retorno (Sala Cirúrgica C) ...................................... 72

Figura 8.5 B - Vista do insuflamento (Sala Cirúrgica C) ................................................... 73

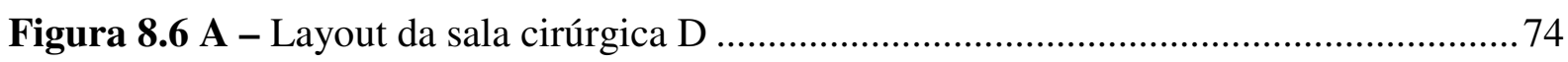

Figura 8.6 B - Vista da sala e do sistema de condicionamento de ar (sala Cirúrgica D)........74

Figura 8.7 - Variação da concentração das partículas de 5 a $10 \mu \mathrm{m}$ ao longo do tempo, para o sistema A, com condicionamento de ar desligado e portas fechadas......77

Figura 8.8 - Variação da concentração das partículas de 5 a $10 \mu \mathrm{m}$ ao longo do tempo, para o sistema A, com condicionamento de ar desligado e portas abertas. ....... 77

Figura 8.9 - Variação da concentração das partículas de 5 a $10 \mu \mathrm{m}$ ao longo do tempo, para o sistema A, com condicionamento de ar ligado e portas fechadas. .78

Figura 8.10 - Variação da concentração das partículas de 5 a $10 \mu \mathrm{m}$ ao longo do tempo, para o sistema B com condicionamento de ar ligado e portas fechadas..... .78

Figura 8.11 - Variação da concentração das partículas de 5 a $10 \mu \mathrm{m}$ ao longo do tempo, para o sistema $\mathrm{C}$, com condicionamento de ar ligado e portas fechadas.

Figura 8.12 - Variação da concentração das partículas de 5 a $10 \mu \mathrm{m}$ ao longo do tempo, para o sistema D, com condicionamento de ar ligado e portas fechadas.

Figura 8.13- Variação da concentração das partículas de 5 a $10 \mu \mathrm{m}$ ao longo do tempo, para o sistema A, com condicionamento de ar ligado e portas abertas.

Figura 8.14 - Variação da concentração das partículas de 5 a $10 \mu \mathrm{m}$ ao longo do tempo, para o sistema B, com condicionamento de ar ligado e portas abertas.

Figura 8.15 - Variação da concentração das partículas de 5 a $10 \mu \mathrm{m}$ ao longo do tempo, para o sistema $\mathrm{C}$, com condicionamento de ar ligado e portas abertas.

Figura 8.16 - Variação da concentração das partículas de 5 a $10 \mu \mathrm{m}$ ao longo do tempo, para o sistema D, com condicionamento de ar ligado e portas abertas.

Figura 8.17 - Razão entre a concentração interna e a média ao longo do tempo para vários diâmetros de partículas, para o sistema A, com condicionamento de ar desligado e portas fechadas 
Figura 8.18 - Razão entre a concentração interna e a média ao longo do tempo para vários diâmetros de partículas, para o sistema A condicionamento de ar desligado e portas abertas.

Figura 8.19 - Razão entre a concentração interna e a média ao longo do tempo para vários diâmetros de partículas, para o sistema A com condicionamento de ar ligado e portas fechadas.

Figura 8.20 - Razão entre a concentração interna e a média ao longo do tempo para vários diâmetros de partículas, para o sistema $\mathrm{B}$, com condicionamento de ar ligado e portas fechadas.

Figura 8.21 - Razão entre a concentração interna e a média ao longo do tempo para vários diâmetros de partículas, para o sistema $\mathrm{C}$, com condicionamento de ar ligado e portas fechadas.

Figura 8.22 - Razão entre a concentração interna e a média ao longo do tempo para vários diâmetros de partículas, para o sistema $\mathrm{D}$, com condicionamento de ar ligado e portas fechadas.

Figura 8.23 - Razão entre a concentração interna e a média ao longo do tempo para vários diâmetros de partículas, para o sistema A, com condicionamento de ar ligado e portas abertas.

Figura 8.24 - Razão entre a concentração interna e a média ao longo do tempo para vários diâmetros de partículas, para o sistema B, com condicionamento de ar ligado e portas abertas.

Figura 8.25 - Razão entre a concentração interna e a média ao longo do tempo para vários diâmetros de partículas, para o sistema $\mathrm{C}$, com condicionamento de ar ligado e portas abertas.

Figura 8.26 - Razão entre a concentração interna e a média ao longo do tempo para vários diâmetros de partículas, para o sistema $\mathrm{D}$, com condicionamento de ar ligado e portas abertas.

Figura 8.27- Concentração de partículas ao longo do tempo no interior da sala e corredor, para o sistema A, com condicionamento de ar desligado e portas fechadas.....88

Figura 8.28 - Concentração de partículas ao longo do tempo no interior da sala e corredor, para o sistema A, com condicionamento de ar desligado e portas abertas. ......88

Figura 8.29- Concentração de partículas ao longo do tempo no interior da sala e corredor, para o sistema A com condicionamento de ar ligado e portas fechadas.

Figura 8.30 - Concentração de partículas ao longo do tempo no interior da sala e corredor, para o sistema B, com condicionamento de ar ligado e portas fechadas.

Figura 8.31 - Concentração de partículas ao longo do tempo no interior da sala e corredor, para o sistema $\mathrm{C}$, com condicionamento de ar ligado e portas fechadas.

Figura 8.32 - Concentração de partículas ao longo do tempo no interior da sala e corredor, para o sistema D, com condicionamento de ar ligado e portas fechadas.

Figura 8.33 - Concentração de partículas ao longo do tempo no interior da sala e corredor, para o sistema A, com condicionamento de ar ligado e portas abertas.

Figura 8.34 - Concentração de partículas ao longo do tempo no interior da sala e corredor, para o sistema B, com condicionamento de ar ligado e portas abertas. 
Figura 8.35 - Concentração de partículas ao longo do tempo no interior da sala e corredor, para o sistema $\mathrm{C}$, com condicionamento de ar ligado e portas abertas.

Figura 8.36 - Concentração de partículas ao longo do tempo no interior da sala e corredor, para o sistema $\mathrm{D}$, com condicionamento de ar ligado e portas abertas.

Figura 9.1 - Comparação entre os dados de campo e de predição, para o sistema A com condicionamento de ar desligado e portas fechadas.

Figura 9.2 - Comparação entre os dados de campo e os resultados de predição, sem considerar o efeito dos campos cirúrgicos, para o sistema A, com condicionamento de ar desligado e portas fechadas.

Figura 9.3 - Comparação entre os dados de campo e os resultados de predição, considerando um fator para os campos cirúrgicos, para o sistema A, com condicionamento de ar desligado e portas fechadas.

Figura 9.4 - Concentração de partículas em função do diâmetro, para o sistema A, com condicionamento de ar desligado e portas fechadas.

Figura 9.5 - Fatores que contribuem na geração total de partículas, para o sistema A, com condicionamento de ar desligado e portas fechadas.

Figura 9.6 - Fatores que contribuem na remoção das partículas do ar da sala, para o sistema A, com condicionamento de ar desligado e portas fechadas.

Figura 9.7 - Comparação entre os dados de campo e o modelo, para o sistema A, com condicionamento de ar desligado e portas abertas.

Figura 9.8 - Comparação entre os dados de campo e os resultados de predição, sem considerar os efeitos dos campos cirúrgicos, para o sistema $\mathrm{A}$, com condicionamento de ar desligado e portas abertas.

Figura 9.9 - Comparação entre os dados de campo e os resultados de predição, considerando um fator para os campos cirúrgicos, para o sistema $\mathrm{A}$, com condicionamento de ar desligado e portas abertas.

Figura 9.10 - Fatores que contribuem para a geração de partículas, para o sistema A, com condicionamento de ar desligado e portas abertas.

Figura 9.11 - Fatores que contribuem para a eliminação de partículas, para o sistema A, com condicionamento de ar desligado e portas abertas.

Figura 9.12 - Comparação das concentrações de partículas medidas no interior da sala com as concentrações preditas pelo modelo, para diferentes diâmetros, para o sistema A, com condicionamento de ar desligado e portas abertas. .... 100

Figura 9.13 - Comparação entre os dados de campo e o modelo, para o sistema A, com condicionamento de ar ligado e portas fechadas.

Figura 9.14 - Comparação entre os dados de campo e os resultados de predição, sem considerar os efeitos dos campos cirúrgicos, para o sistema $\mathrm{A}$, com condicionamento de ar ligado e portas fechadas.

Figura 9.15 - Comparação entre os dados de campo e os resultados de predição, considerando um fator para os campos cirúrgicos, para o sistema $\mathrm{A}$, com condicionamento de ar ligado e portas fechadas.

Figura 9.16 - Concentração de partículas em função do diâmetro, para o sistema A, com condicionamento de ar ligado e portas fechadas. 
Figura 9.17 - Contribuição de diferentes fatores na geração de partículas, para o A, com condicionamento de ar ligado e portas fechadas.

Figura 9.18 - Contribuição de diferentes fatores na remoção de partículas, para o sistema A, com condicionamento de ar ligado e portas fechadas.

Figura 9.19 - Comparação entre os dados de campo e o modelo, para o sistema A, com condicionamento de ar ligado e portas abertas.

Figura 9.20 - Comparação entre os dados de campo e os resultados de predição, sem considerar o efeito dos campos cirúrgicos, para o sistema $\mathrm{A}$, com condicionamento de ar ligado e portas abertas.

Figura 9.21 - Comparação entre os dados de campo e os resultados de predição, considerando um fator para dos campos cirúrgicos, para o sistema A, com condicionamento de ar ligado e portas abertas.

Figura 9.22 - Concentração de partículas em função do diâmetro, para o sistema A, com condicionamento de ar ligado e portas abertas.

Figura 9.23 - Contribuição de diferentes fatores na geração de partículas, para o sistema A, com condicionamento de ar ligado e portas abertas.

Figura 9.24 - Contribuição de diferentes fatores na remoção de partículas, para o sistema A, com condicionamento de ar ligado e portas abertas.

Figura 9.25 - Comparação entre os dados de campo e de predição, para o sistema B, com condicionamento de ar ligado e portas fechadas.

Figura 9.26 - Comparação entre os dados de campo e os resultados de predição, sem considerar o efeito dos campos cirúrgicos, para o sistema $\mathrm{B}$, com condicionamento de ar ligado e portas fechadas.

Figura 9.27 - Comparação entre os dados de campo e os resultados de predição, considerando um fator para os campos cirúrgicos, para o sistema $\mathrm{B}$, com condicionamento de ar ligado e portas fechadas.

Figura 9.28 - Concentração de partículas em função do diâmetro, para o sistema B, com condicionamento de ar ligado e portas fechadas.

Figura 9.29 - Contribuição de diferentes fatores na geração de partículas, para o sistema B, com condicionamento de ar ligado e portas fechadas.

Figura 9.30 - Contribuição de diferentes fatores na remoção de partículas, para o sistema B, com condicionamento de ar ligado e portas fechadas.

Figura 9.31 - Comparação entre os dados de campo e o modelo, para o sistema B, com condicionamento de ar ligado e portas abertas.

Figura 9.32 - Comparação entre os dados de campo e os resultados de predição, sem considerar os efeitos dos campos cirúrgicos, para o sistema $\mathrm{B}$, com condicionamento de ar ligado e portas abertas.

Figura 9.33 - Comparação entre os dados de campo e os resultados de predição, considerando um fator para os campos cirúrgicos, para o sistema $\mathrm{B}$, com condicionamento de ar ligado e portas abertas.

Figura 9.34 - Concentração de partículas em função do diâmetro, para o sistema B, com condicionamento de ar ligado e portas abertas 
Figura 9.35 - Contribuição de diferentes fatores na geração de partículas, para o sistema B, com condicionamento de ar ligado e portas abertas.

Figura 9.36 - Contribuição de diferentes fatores na remoção de partículas, para o sistema B, com condicionamento de ar ligado e portas abertas.

Figura 9.37 - Comparação entre os dados de campo e de predição, para o sistema C, com condicionamento de ar ligado e portas fechadas.

Figura 9.38 - Comparação entre os dados de campo e os resultados de predição, sem considerar os efeitos dos campos cirúrgicos, para o sistema com insuflamento $\mathrm{C}$, com condicionamento de ar ligado e portas fechadas.

Figura 9.39 - Comparação entre os dados de campo e os resultados de predição, considerando um fator para o gesso e os campos cirúrgicos, para o sistema $\mathrm{C}$, com condicionamento de ar ligado e portas fechadas.

Figura 9.40 - Concentração de partículas em função do diâmetro, para o sistema C, com condicionamento de ar ligado e portas fechadas.

Figura 9.41 - Contribuição de diferentes fatores na geração de partículas, para o sistema C, com condicionamento de ar ligado e portas fechadas

Figura 9.42 - Contribuição de diferentes fatores na remoção de partículas, para o sistema C, com condicionamento de ar ligado e portas fechadas.

Figura 9.43 - Comparação entre os dados de campo e de predição, para o sistema C, com condicionamento de ar ligado e portas abertas.

Figura 9.44 - Comparação entre os dados de campo e os resultados de predição, sem considerar o efeito dos campos cirúrgicos, para o sistema $\mathrm{C}$, com condicionamento de ar ligado e portas abertas.

Figura 9.45 - Comparação entre os dados de campo e os resultados de predição, considerando um fator para os campos cirúrgicos, para o sistema $\mathrm{C}$, com condicionamento de ar ligado e portas abertas.

Figura 9.46 - Concentração de partículas em função do diâmetro, para o sistema C, com condicionamento de ar ligado e portas fechadas.

Figura 9.47 - Contribuição de diferentes fatores na geração de partículas, para o C, com condicionamento de ar ligado e portas abertas.

Figura 9.48 - Contribuição de diferentes fatores na remoção de partículas, para o sistema $\mathrm{C}$, com condicionamento de ar ligado e portas abertas.

Figura 9.49 - Comparação entre os dados de campo e de predição, para o sistema D, com condicionamento de ar ligado e portas fechadas

Figura 9.50 - Comparação entre os dados de campo e os resultados de predição, sem considerar os efeitos dos campos cirúrgicos, para o sistema $\mathrm{D}$, com condicionamento de ar ligado e portas fechadas.

Figura 9.51 - Comparação entre os dados de campo e os resultados de predição, considerando um fator para os campos cirúrgicos, para o sistema $\mathrm{D}$, com condicionamento de ar ligado e portas fechadas.

Figura 9.52 - Concentração de partículas em função do diâmetro, para o sistema D, com condicionamento de ar ligado e portas fechadas. 
Figura 9.53 - Contribuição de diferentes fatores na geração de partículas, para o sistema D, com condicionamento de ar ligado e portas fechadas.

Figura 9.54 - Comparação entre os dados de campo e o modelo, para o sistema D, com condicionamento de ar ligado e portas abertas.

Figura 9.55 - Comparação entre os dados de campo e os resultados de predição, sem considerar os efeitos dos campos cirúrgicos, para o sistema $\mathrm{D}$, com condicionamento de ar ligado e portas abertas.

Figura 9.56 - Comparação entre os dados de campo e os resultados de predição, considerando um fator para os campos cirúrgicos, para o sistema $\mathrm{D}$, com condicionamento de ar ligado e portas abertas.

Figura 9.57 - Concentração de partículas em função do diâmetro, para o sistema D, com condicionamento de ar ligado e portas abertas.

Figura 9.58 - Contribuição de diferentes fatores na geração de partículas, para o sistema D, com condicionamento de ar ligado e portas abertas.

Figura 9.59 - Contribuição de diferentes fatores na remoção de partículas, para o sistema D, com condicionamento de ar ligado e portas abertas.

Figura 10.1 - Influência da atividade humana sobre a concentração de partículas no interior da sala cirúrgica, com sistema de condicionamento de ar ligado; Sistema B.

Figura 10.2 - Correlação entre o número de pessoas e a concentração de partículas na sala cirúrgica, com o sistema de condicionamento de ar ligado; Sistema B

Figura 10.3 - Impacto do sistema de condicionamento de ar sobre a concentração de partículas; sistema com insuflamento pela parede e retorno próximo ao piso

Figura 10.4 - Impacto do sistema de condicionamento de ar sobre a concentração de partículas no interior da sala cirúrgica, com as portas fechadas; sistema A ... 136

Figura 10.5 - Impacto do sistema de condicionamento de ar sobre a concentração de partículas no interior da sala cirúrgica, com as portas abertas; sistema A...... 136

Figura 10.6 - Variação da concentração de partículas em função da vazão de insuflamento; Sistema A.

Figura 10.7 - Variação da concentração de partículas com a vazão de retorno; sistema com insuflamento pela parede e retorno próximo ao piso.

Figura 10.8 - Comparação entre as concentrações de partículas para um sistema convencional (Sistema A) e sistema de ar condicionado de janela (Sistema D); portas fechadas.

Figura 10.9 - Comparação entre as concentrações de partículas para um sistema convencional (Sistema A) e sistema de ar condicionado de janela (Sistema D); portas abertas. 


\section{LISTA DE TABELAS}

Tabela 4.1 - Partículas maiores que 0,3 $\mu$ m geradas em função do tipo de atividade. 39

Tabela 8.1 - Parâmetros relativos ao ambiente físico das salas cirúrgicas. .67

Tabela 8.2 - Parâmetros relativos aos sistemas de condicionamento de ar. 68

Tabela 8.3 - Parâmetros calculados 68

Tabela 8.4 - Caracterização dos procedimentos cirúrgicos 75

Tabela 8.5 - Concentração média das partículas de 5 a $10 \mu \mathrm{m}$ para os diferentes sistemas e situações estudadas.

Tabela 11.1 - Comparações estatísticas entre os valores preditos pelo modelo e os valores obtidos em campo, para os diferentes procedimentos de análise adotados.... 142 


\section{LISTA DE SÍMBOLOS}

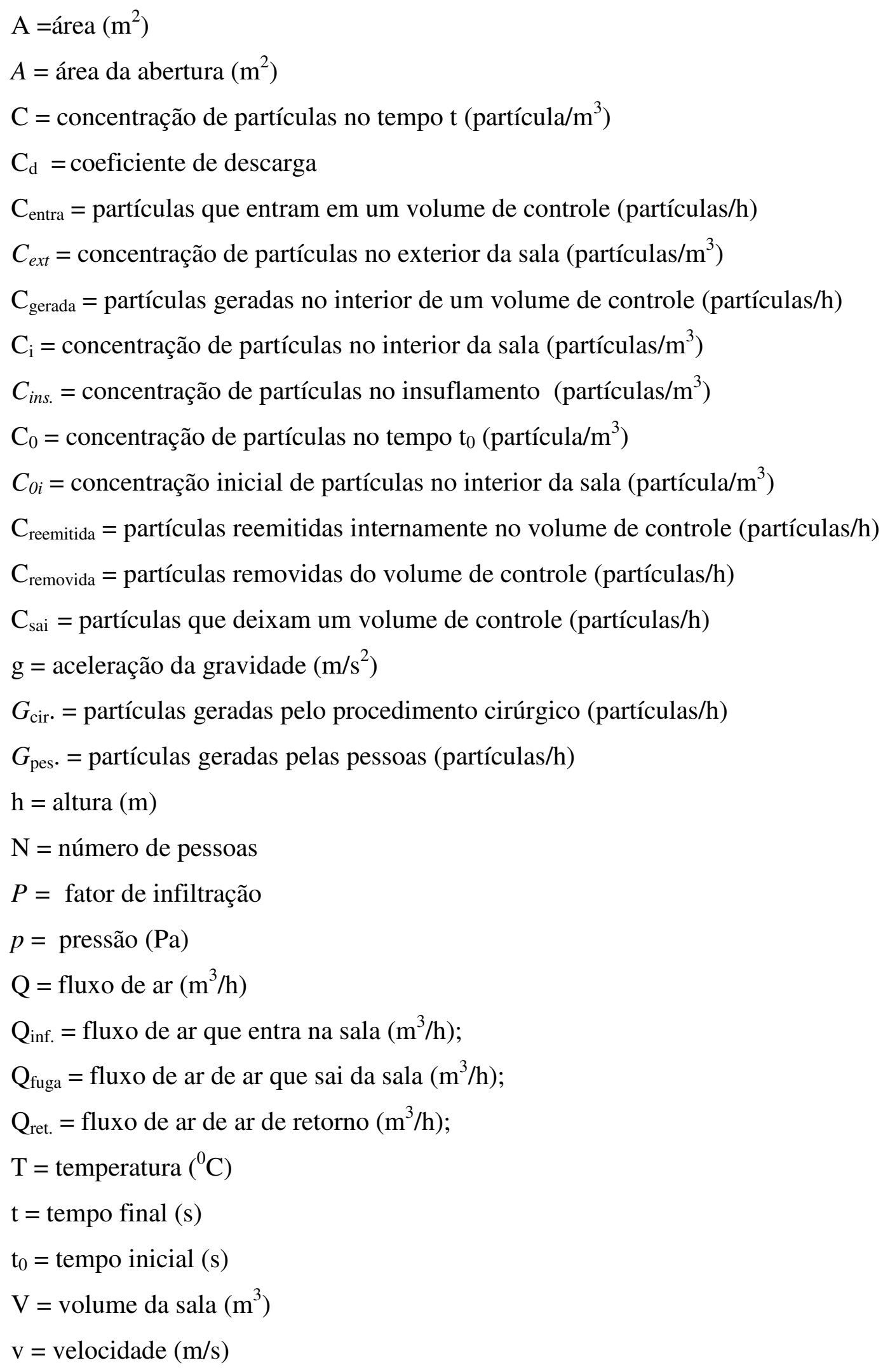


$\Delta p=$ diferença de pressão entre dois lados $(\mathrm{Pa})$

$\lambda_{d}=$ Taxa de deposição $\left(\mathrm{h}^{-1}\right)$

$\lambda_{\text {inf } .}=$ Taxa de infiltração $\left(\mathrm{h}^{-1}\right)$

$\lambda_{r}=$ fator de ressuspensão $\left(\mathrm{h}^{-1}\right)$

$\rho=$ massa específica do ar $\left(\mathrm{kg} / \mathrm{m}^{3}\right)$ 


\section{RESUMO}

Os sistemas de condicionamento de ar exercem função importante em uma sala cirúrgica, que é proteger a ferida cirúrgica e os equipamentos estéreis dos microrganismos carreados pelo ar. Essa proteção é feita pelo controle simultâneo da movimentação e distribuição do ar, da temperatura, da umidade, da filtragem, das infiltrações de ar de outros setores, entre outros. Esses são fatores que afetam diretamente a quantidade de partículas aéreas presentes em uma sala cirúrgica. Dentro deste contexto, no presente trabalho foi desenvolvido um modelo matemático para predição da concentração de partículas em salas cirúrgicas e para determinação da importância relativa dos fatores que interferem na geração e remoção dessas partículas. O modelo proposto baseia-se no balanço de massa para o cálculo da concentração de partículas, que foi aplicado e validado com os dados obtidos em salas cirúrgicas com diferentes tipos de sistemas de condicionamento de ar. Nessas salas cirúrgicas foram realizadas medições de variáveis ambientais considerando diferentes situações que normalmente ocorrem na rotina de salas cirúrgicas. Para cada uma das condições analisadas, é proposto um determinado conjunto de parâmetros relativos ao ambiente, ao sistema de condicionamento de ar e às concentrações de partículas provenientes das diversas fontes, que são utilizados como dados de entrada no modelo. O modelo que está sendo proposto também pode ser utilizado como uma importante ferramenta para auxiliar na análise específica dos fatores que afetam tanto a geração como a remoção de partículas. 


\begin{abstract}
Air conditioning systems exert an important function in surgical rooms, to protect the surgical wound and the sterile equipments from airborne infected particles. This protection is achieved by means of a simultaneous control of the movement and distribution of the air, of the temperature, of the humidity, of the filtering, of air infiltrations from other sections etc. Those factors directly affect the amount of airborne particles present in a surgical room. Within this context, the present work aimed to develop a mathematical model for the prediction of particle concentrations in surgical rooms and for the determination of the relative importance of the factors that interfere in the generation and removal of those particles. The proposed model, based on mass balance for the calculation of the particle concentrations, has been applied and validated with the data obtained from different types of air conditioning systems in which the measurements were carried out, as well as with different conditions that commonly occur in the routine of surgical rooms. For each one of these conditions, a certain group of relative parameters is proposed to the environment, to the air conditioning system, and to the concentrations of particles originated from the different sources, which are used as input data to the model. The proposed model can also be used as an important tool to aid in the specific analysis of the factors that affect both particle generation and removal.
\end{abstract}




\section{CAPÍTULO 1}

\section{INTRODUÇÃO}

As infecções hospitalares representam um importante problema de saúde pública, por causarem incremento na taxa de mortalidade e no tempo médio de internação. Segundo Lacerda (1995), essas infecções são a sexta causa de mortalidade nos Estados Unidos, depois das doenças cardiovasculares, cânceres, pneumonia, gripes e acidentes. Ainda segundo este autor, na Europa e nos EUA, cerca de 5 a $10 \%$ dos pacientes hospitalizados são vítimas de infecções após intervenções cirúrgicas.

No Brasil, segundo a Agência Nacional de Vigilância Sanitária - ANVISA, as infecções hospitalares causam 50 mil mortes por ano e são a terceira causa de mortalidade, após os acidentes de trânsito e as doenças cardiovasculares (ANVISA, 2000). Uma pesquisa realizada pelo Ministério da Saúde em 99 hospitais das capitais brasileiras, totalizando 8.624 pacientes com mais de 24 horas de internação, revelou que a taxa de pacientes com infecção hospitalar era de $13,1 \%$. O levantamento mostrou também que os hospitais públicos eram os campeões em registro de infecção, com índice de 18,4\% no universo estudado, seguidos dos hospitais mistos $(15,0 \%)$, das instituições de ensino $(11,8 \%)$, dos hospitais privados com fins lucrativos $(10,2 \%)$, dos filantrópicos $(10,1 \%)$ e dos privados sem fins lucrativos (10\%). Entre as infecções hospitalares mais prevalentes estão a respiratória $(28,9 \%)$, a cirúrgica $(15,6 \%)$, a de pele $(15,5 \%)$ e a urinária $(11,0 \%)$ (ANVISA, 2000).

Ainda que o percentual relativo às infecções cirúrgicas não seja tão alto quanto o de infecções respiratórias, destaque-se que sua importância não pode ser menosprezada. Em primeiro lugar, deve-se levar em conta que, enquanto a totalidade dos pacientes de um hospital está sujeita a infecções respiratórias ou de pele, somente uma minoria é submetida a cirurgias. Portanto, se considerado apenas o universo dos pacientes cirúrgicos, o índice de contaminação pode ser bem maior que $15,6 \%$. Em segundo lugar, a infecção da ferida cirúrgica é especialmente importante porque pode levar a quadros infecciosos graves, uma vez 
que as estruturas internas do organismo do paciente encontram-se expostas a contaminações, sem a proteção natural dos tecidos de revestimento, pele e mucosa. Daí podem advir consequiências sérias, como septicemias ou infecções localizadas em áreas pouco irrigadas, como articulações e ossos. Em terceiro lugar, é preciso considerar que pacientes submetidos a cirurgias de grande porte, como próteses de quadril, cirurgias cardíacas ou transplantes de órgãos, tendem a ter a imunidade extremamente comprometida. Assim, um quadro de infecção cirúrgica nesses pacientes pode implicar graves efeitos deletérios.

As infecções adquiridas nos hospitais também provocam aumento nos custos médicos. Nos EUA, essas infecções causam um prolongamento médio de 5 a 10 dias no tempo de internação, o que representaria uma despesa adicional de 5 a 10 bilhões de dólares anuais para o sistema de saúde (Lacerda, 1995). Portanto, investimentos na contenção das infecções hospitalares propiciam retornos consideráveis em termos de redução de gastos. O Centro para Controle de Doenças, nos EUA, constatou que hospitais que desenvolvem programas efetivos de controle de infecções hospitalares conseguem reduzir em até um terço sua incidência; sendo que uma redução de 5\% nas infecções já produz retornos suficientes para manutenção de um bom programa de prevenção, inclusive com profissionais qualificados (Mangram, 1999). No Brasil, dados apresentados no II Congresso Brasileiro sobre Controle de Infecção Hospitalar, mostram que cada US\$ 1 investido em treinamento para prevenção de infecções hospitalares oferecia um retorno de US\$ 6 (Lacerda, 1995).

\subsection{MOTIVAÇÃO DO TRABALHO}

Como já mencionado, o paciente pode contrair infecções em ambientes hospitalares mesmo quando não submetido a procedimentos invasivos como as cirurgias. Entretanto, na sala cirúrgica, a possibilidade de infecções graves se acentua. Portanto, o controle das infecções, de grande relevância em todo o ambiente hospitalar, na sala cirúrgica é crucial.

Embora a infecção por contato seja o principal meio de contaminação da ferida cirúrgica, a contaminação aérea é um importante mecanismo de infecção, pois o ar está em contato com todas as superfícies e pode conter partículas portadoras de microorganismos patogênicos.

Daí a necessidade de controle intenso dos contaminantes na atmosfera desse local. Assim, os sistemas de condicionamento de ar exercem uma função importante em uma sala cirúrgica, que é proteger a ferida cirúrgica e os equipamentos estéreis dos microrganismos transportados por partículas carreadas pelo ar. Essa proteção é feita pelo controle simultâneo 
de movimentação e distribuição do ar; temperatura; umidade; filtragem; infiltrações de ar de outros setores etc. Estes são fatores que afetam diretamente a quantidade de partículas presentes em uma sala cirúrgica.

Dada a multiplicidade de fatores que interferem na geração e remoção de partículas em salas cirúrgicas, há necessidade de estudos específicos que abordem esse tema. A grande maioria dos estudos hoje existentes trabalha essencialmente com simulação numérica (CFD) (Chen et al, 1992; Hartung et al, 1998; Memarzadeh e Jiang, 2000; Chow e Yang, 2003; Kameel, 2003). Nesses trabalhos, muitas das simplificações assumidas acabam por afastar os modelos das situações reais (Milner et al., 2004). Da mesma forma, situações de laboratório, ainda que matematicamente mais precisas, podem também afastar-se consideravelmente das situações cotidianas, devido à eliminação de fatores importantes (Chow e Yang, 2003; Pereira e Tribess, 2005). Também falta ainda um melhor entendimento dos fatores que contribuem no processo de geração e remoção de partículas, assim como uma compreensão mais detalhada de como esses fatores afetam a contaminação da ferida cirúrgica.

Dentro deste contexto, é de grande relevância o desenvolvimento de um modelo matemático para predição da concentração de partículas em salas cirúrgicas e de determinação da importância relativa dos vários fatores que interferem na geração e remoção dessas partículas. Esse modelo pode ser obtido por balanço de massa e se basear em dados, coletados em salas cirúrgicas, durante procedimentos cirúrgicos reais, buscando incorporar as variadas situações e fatores que interferem na concentração de partículas no ar em salas cirúrgicas.

Este trabalho visa ainda contribuir para o desenvolvimento de uma infra-estrutura multidisciplinar, com diferentes áreas de conhecimento, fornecendo uma ferramenta de predição e análise da concentração de partículas em salas cirúrgicas. Assim, com a utilização dessa ferramenta, os profissionais poderão envidar esforços na tentativa de reduzir a taxa de infecção hospitalar. Visa-se também, com este trabalho, gerar informações para oportunizar novos trabalhos sobre o tema em estudo ou temas correlatos.

Outrossim, é importante salientar que este trabalho não se limita às particularidades da saúde pública. Sua abrangência tem também uma dimensão social, pois atinge diretamente a vida de todos os que necessitam se submeter a intervenções cirúrgicas sujeitas à infecção hospitalar. Com um controle maior da qualidade do ar em ambientes cirúrgicos, a possibilidade de um paciente adquirir infecção é menor e, conseqüentemente, a dinâmica de sua vida e de sua família sofrerá modificações somente no período destinado à cirurgia e à recuperação normal. 
Outro aspecto de grande relevância deste trabalho é a economia que pode ser proporcionada pela diminuição de infecções hospitalares. Os recursos poupados com a redução da freqüência e gravidade das infecções podem ser destinados à construção de novos hospitais, à manutenção dos que já estão em funcionamento, à contratação de mais funcionários, enfim, à melhoria dos serviços de saúde.

\subsection{OBJETIVOS}

O presente trabalho visa desenvolver um modelo matemático para predição da concentração de partículas em salas cirúrgicas e de determinação da importância relativa dos fatores que interferem na geração e remoção dessas partículas.

Para consecução dos objetivos foram desenvolvidas as seguintes etapas:

a) Caracterização das salas cirúrgicas, onde foram levantados dados das dimensões das salas, dos equipamentos instalados, do número e posicionamento das portas e do sistema de condicionamento de ar adotado

b) Caracterização dos procedimentos cirúrgicos quanto ao tipo de cirurgia, tempo de duração, número de presentes na sala, abertura de portas etc.

c) Realização de medições de velocidade e temperatura do ar e de concentrações de partículas nas salas cirúrgicas e nos corredores adjacentes, durante os procedimentos cirúrgicos

d) Desenvolvimento de um modelo matemático para predição da concentração de partículas no interior das salas cirúrgicas e para determinação da importância relativa dos fatores que afetam a geração e remoção dessas partículas

e) Validação do modelo proposto mediante comparações entre os dados de campo e os dados obtidos com o modelo.

\subsection{ESTRUTURA DO TRABALHO}

A apresentação deste trabalho segue conforme a ordem da sequiência de realização da pesquisa. Inicialmente, no Capítulo 2, é apresentada uma revisão da literatura referente à contaminação aérea em salas cirúrgicas. 
No capítulo 3 é feita uma descrição detalhada sobre os principais sistemas de condicionamento de ar utilizados em salas cirúrgicas, contemplando suas principais características, componentes e as condições de funcionamento.

No capítulo 4 é realizada uma discussão sobre os fatores que afetam na concentração de partículas no interior de uma sala cirúrgica. No capítulo 5 é apresentado o modelo para predição da concentração de partículas.

Os Capítulos 6 e 7 apresentam os procedimentos adotados no desenvolvimento deste estudo. No Capítulo 6, descreve-se a metodologia para coleta dos dados experimentais, especificando-se as variáveis medidas e descrevendo-se o aparato para coleta de dados. No Capítulo 7, descreve-se o procedimento de predição, ajuste e validação.

Os Capítulos 8 e 9 apresentam os resultados experimentais e de predição, respectivamente, enquanto os Capítulos 10 e 11 são analisados e discutidos os resultados experimentais e de predição, respectivamente.

E, finalmente, no Capítulo 12 são apresentadas as principais conclusões da pesquisa e sugestões de continuidade do trabalho. 


\section{CAPÍTULO 2}

\section{CONTAMINAÇÃO AÉREA EM SALAS CIRÚRGICAS}

Em virtude de seu reduzido tamanho, microrganismos tendem a se agregar, por atração eletrostática, a partículas, como descamações da pele das pessoas, fios de cabelo, partículas provenientes dos sistemas de condicionamento de ar etc. Essas partículas, devido à sua grande razão área/volume, são facilmente dispersadas por correntes de ar - mesmo aquelas de baixíssima velocidade, como as que resultam da convecção provocada pela troca de calor do corpo humano -, aparelhos aquecidos e gradientes térmicos no interior da sala cirúrgica. Outros fatores de dispersão importantes são as perturbações provocadas pela movimentação de pessoas, as correntes de ar originadas pelos sistemas de condicionamento de ar, e as infiltrações sob portas (ASHRAE, 2005).

As partículas contendo microrganismos, capazes de produzir colônias em um meio de cultura, são denominadas partículas viáveis. Partículas viáveis, ou não, têm, basicamente, três origens: 1) aquelas geradas no interior da sala de cirurgia; 2) as provindas de áreas adjacentes; 3) as introduzidas na sala cirúrgica pelo sistema de condicionamento de ar. Essas partículas, quando dispersas no ar, tendem a se depositar com variada velocidade sobre as superfícies, por efeito da gravidade e/ou por atração eletrostática. As partículas menores podem permanecer em suspensão durante várias horas (Hinds, 1982). Qualquer movimentação do ar junto às superfícies de deposição (piso, equipamentos, paredes) pode provocar sua ressuspensão.

Os microrganismos aderidos às partículas dispersadas pelo ar podem contaminar a ferida cirúrgica, depois de se precipitarem diretamente sobre ela, ou pela contaminação dos instrumentos, outros materiais cirúrgicos (luvas, gaze, campos cirúrgicos etc) e as roupas da equipe cirúrgica. Por isso, uma variedade de trabalhos estudam a relação entre contaminação do ar e contaminação da ferida e/ou infecção no pós-operatório (Beggs, 2003; Whyte e Hambraeus, 1992; Howorth, 1985; White, 1982). 
Ainda não há consenso com relação à contribuição da contaminação do ar nos processos de infecção pós-cirúrgica, mas há vários trabalhos que indicam haver uma relação forte entre a contaminação do ar e a contaminação da ferida cirúrgica, com conseqüente infecção. Por exemplo, estudo desenvolvido por Whyte e Hambraeus (1992) investigou a influência das bactérias presentes no ar na contaminação de cirurgias biliares. Em tal situação, foi demonstrado que uma redução nas bactérias no ar na sala cirúrgica em cerca de 13 vezes reduziria a contaminação da ferida em aproximadamente $50 \%$. Também foi examinada a contaminação dos campos cirúrgicos por várias fontes e a sua relação com a contaminação da ferida cirúrgica. Foi demonstrado que, em áreas afastadas da ferida, a concentração bacteriana na superfície dos campos cirúrgicos foi afetada apenas pelas bactérias provenientes do ar. Segundo os autores, na região próxima à ferida, as bactérias presentes no ar também afetaram significativamente a contaminação. Porém, foi demonstrado que uma quantidade maior de bactérias se transferiu para a ferida através da superfície dos campos cirúrgicos e vice-versa. Luvas perfuradas, vestimentas impermeáveis e o número de bactérias na pele do paciente não afetaram significativamente a contagem de partículas nas superfícies dos campos cirúrgicos.

Apesar de alguns trabalhos sugerirem que as infecções hospitalares são endógenas, isto é, provenientes da flora do paciente (Foster, 2004; Fluckiger, 1999; Kalmeijer, 2002), Beggs (2003) mostra que a rota de transmissão através do ar pode estar sendo subestimada. Segundo o autor, essa rota pode ser responsável por 10 a $20 \%$ de todas as infecções nosocomiais. Já White (1982) demonstrou que essa porcentagem pode ser ainda maior no caso de cirurgias ortopédicas que utilizam sistema convencional de distribuição de ar (insuflamento pelo teto e retorno próximo ao piso). Nesse caso, foi estimado que $98 \%$ das bactérias isoladas nas feridas cirúrgicas foram aerotransportadas. Dessas, $30 \%$ foram depositadas diretamente sobre a ferida cirúrgica e o restante foi depositado em outros locais e transportado até a ferida por outras rotas.

A importância da contaminação pelo ar também é confirmada por Howorth (1985), segundo o qual estudos clínicos realizados na Inglaterra, Europa e Estados Unidos confirmaram que entre 80 e $90 \%$ dos contaminantes bacterianos que formam unidades de colônia coletados na ferida cirúrgica são provenientes do ar da sala cirúrgica. De acordo com o autor, "quando o número de unidades formadoras de colônia é reduzido em uma sala cirúrgica, há uma correspondente redução na incidência da sepsia da ferida cirúrgica".

E quanto maior a cirurgia, maior o risco de infecção, porque maior a área e o tempo de exposição e também mais graves os efeitos deletérios do ato cirúrgico sobre o sistema imunológico do paciente (Lidwell et al., 1987, 1993). Por exemplo, em algumas intervenções 
ortopédicas as taxas de infecção são relativamente maiores, em virtude das grandes dimensões da ferida cirúrgica e dos materiais estranhos instalados no organismo do paciente. Além da precipitação direta de partículas sobre a ferida, tais contaminantes podem se depositar sobre os materiais de prótese e instrumentos cirúrgicos e contaminá-los.

Ainda no caso das cirurgias ortopédicas, os índices de infecção tendem a ser mais elevados, também porque bastam doses infectantes menores, em virtude da insuficiente irrigação sangüínea dos tecidos envolvidos (Lidwell et al., 1987, 1993; Salvati et al., 1982).

Observa-se na literatura, que a maior parte dos estudos que envolvem o ar como trajetória de infecção são relativos a cirurgias ortopédicas de substituição de articulações. Isto, segundo alguns autores (Whyte, 1988; Gosdena et al., 1998; Lidwell et al., 1987, 1993), é porque a infecção permanece sendo a complicação mais temida, neste tipo de procedimento. Objetos implantados, incluindo plástico, cimentos, suturas e outros corpos estranhos, têm sido apontados por aumentar as taxas de infecção em pelo menos 3 ou 4 vezes, segundo trabalho desenvolvido por Whyte (1988).

Extensivo estudo do Conselho de Pesquisas Médicas (CPM) da Inglaterra, que monitorou 8.000 cirurgias de substituição de joelho e cabeça de fêmur em 19 hospitais e outros estudos relacionados, reportados por Lidwell et al. (1982, 1983, 1987), Lidwell (1988), Whyte (1988) confirmaram a eficácia relativa dos antibióticos, vestimentas especiais, sistemas de ar ultra limpo e outras práticas inerentes ao controle de infecções hospitalares.

Estudo desenvolvido por Lidwell et al. (1983), em salas cirúrgicas de 15 hospitais que realizaram cirurgias ortopédicas de colocação de prótese de joelho e quadril, obteve uma boa correlação entre o nível de contaminação do ar e a taxa de sepsia. Da mesma forma, também houve uma correlação entre os valores médios de contaminação do ar e os números de bactérias isoladas na ferida. Assim, verificou-se que uma proporção maior de bactérias alcançou a ferida pela rota aérea depois que a prótese foi inserida.

Resultados similares foram obtidos por Gosdena et al. (1998), que mostraram a existência de uma forte correlação entre as taxas de infecção em cirurgias ortopédicas e o número de bactérias no ar medidas a $30 \mathrm{~cm}$ da ferida cirúrgica. Segundo os autores, o nível de contaminação é influenciado por fatores como o número de pessoas na sala cirúrgica, tipos de vestimentas e o tipo de sistema de condicionamento de ar.

Alguns estudos indicam que a trajetória do ar durante a cirurgia é uma fonte significativa de infecção pós-operatória apenas em alguns tipos de cirurgia, quando a resistência de um paciente está evidentemente diminuída pela doença ou por drogas, ou quando um amplo corpo estranho é implantado (Whyte, 1998). Whyte (1988) conclui que a 
dispersão de bactérias nos fluidos corpóreos é claramente um fator importante de contaminação. Porém, quando a área da ferida e o tempo de exposição são pequenos, a contaminação do ar parece ser menos importante.

Embora haja muitas evidências da importância das partículas aerotransportadas como fonte de infecção em pacientes cirúrgicos, não há pleno consenso quanto a isso. Segundo Humphreys (2002), não existem evidências conclusivas que sustentem a afirmação de que uma redução na contaminação aérea resulte em menor taxa de infecção.

Entretanto, como destaca o autor, vários cirurgiões ortopédicos afirmam que cirurgias que envolvem a colocação de próteses devem ser realizadas em salas cirúrgicas com sistemas de condicionamento de ar ultra-limpos. Além disso, destaca Humphreys (2002), alguns cirurgiões acreditam que os mesmos benefícios podem ser obtidos para outros tipos de cirurgias ortopédicas, como cirurgias de colocação de parafusos ou fixadores, para as quais existem poucas evidências de que a contaminação aérea resulte em maior taxa de infecção. $O$ autor cita estudos que relacionam baixas contagens de microrganismos a taxas de infecção reduzidas em cirurgias que não envolvem implantes. Contudo, ressalta que esses dados se limitam a estudos de observação, sem grande rigor científico.

Como visto, são muitas as evidências de que partículas aerotransportadas podem provocar infecção em pacientes cirúrgicos. Por outro lado, há vários trabalhos que questionam a importância da contaminação aérea na etiologia de infecções pós-operatórias (Foster, 2004; Fluckiger, 1999; Kalmeijer, 2002). Em vista disso, especialistas de diferentes áreas de três instituições européias - DGKH (Sociedade Alemã de Higiene Hospitalar), SGSH (Sociedade Suíça de Higiene Hospitalar) e ÖGHMP (Sociedade Austríaca para Higiene, Microbiologia e Medicina Preventiva) - desenvolveram um trabalho de pesquisa (DGKH, 2002) que teve como objetivo elucidar a real importância do ar no processo de infecção cirúrgica e estabelecer diretrizes para o projeto de sistemas de condicionamento de ar em hospitais. Entre as várias conclusões e recomendações, destacam que:

- Existem muitas informações de que a contaminação do ar próximo à mesa cirúrgica e instrumentos resulta na contaminação direta e indireta do corte cirúrgico.

- Existem dados que indicam que o ar é um importante meio de transmissão de microrganismos durante a cirurgia, podendo provocar infecção.

- Existem dados suficientes que mostram que em cirurgias que requeiram a implantação de grandes corpos (por exemplo, cirurgias de colocação de próteses), o ar é uma importante variável nos casos de infecção. 
- Não existem estudos clínicos ou microbiológicos que mostram que o ar é um relevante reservatório, que provoque infecções em cirurgias que não requeiram a implantação de grandes corpos.

Contrariamente ao que se afirma no último item, há vários estudos (Beggs, 2003; Whyte e Hambraeus, 1992; Howorth, 1985; White, 1982) associando contaminação aérea da ferida cirúrgica e infecção subseqüente, mesmo em cirurgias nas quais não ocorre a inserção de grandes corpos. Por exemplo, Verkkala et al. (1998), reconhecendo a importância da contaminação aérea recomendam salas cirúrgicas com ar limpo e pacientes com coberturas impermeáveis para a redução da contaminação bacteriológica e da infecção cirúrgica em cirurgias cardíacas. Já Lidwell (1988), sustenta que a contaminação bacteriana da ferida cirúrgica pode ser substancialmente reduzida limitando a dispersão de microrganismos pelo pessoal na sala cirúrgica, com o uso de vestimentas especiais e empregando sistemas com fluxo de ar unidirecional (fluxo "laminar").

\subsection{MICROBIOLOGIA DAS SALAS CIRÚRGICAS}

\subsubsection{A pele como fonte de microrganismos}

O fornecimento de ar limpo para a sala cirúrgica é um fator de suma importância para se obter uma atmosfera limpa, porém não é suficiente, pois a maior fonte de contaminação está no interior da própria sala. No caso das partículas originadas no interior da sala cirúrgica, as fontes de infecção mais importantes são os próprios membros da equipe cirúrgica (Whyte, 1988). A pele humana, por exemplo, libera cerca de 1 bilhão de microfragmentos diariamente (Lewis, 1993). Essas partículas de pele, devido a seu reduzido peso e tamanho podem permanecer longo tempo em suspensão e se dispersar com facilidade. Servem, portanto, como importante veículo de propagação de microrganismos. Mesmo trajando roupas esterilizadas, cada membro da equipe cirúrgica representa uma fonte potencial de contaminação, emitindo entre 1.500 e 50.000 bactérias por minuto (ASHRAE, 2005).

Além de partículas de pele, os seres humanos, durante a conversação e a respiração normal, bem como em espirros e tosses, emitem gotículas que não são retidas pelas máscaras cirúrgicas, em função de seu reduzido tamanho ou por escaparem pelos lados da máscara. $\mathrm{O}$ aerossol formado contém partículas que podem permanecer por até 16 horas em suspensão, caindo lentamente e misturando-se à poeira do chão, podendo ser novamente reerguidas pelas correntes de ar ou pelo movimento das pessoas. 
Um indivíduo médio possui em torno de $1,75 \mathrm{~m}^{2}$ de área de pele, distribuída aproximadamente: $18 \%$ em cada perna, $37 \%$ no tronco, $9 \%$ em cada braço e $9 \%$ na cabeça; áreas como o períneo e as axilas participam em menos de $2 \%$ da área total de pele (Settles e Mcgann, 2001).

A pele humana, com uma temperatura tipicamente em torno de $33^{\circ} \mathrm{C}$ em atividades normais, é aproximadamente $9^{\circ} \mathrm{C}$ maior que o ar em um ambiente com temperatura de $24^{\circ} \mathrm{C}$. Essa diferença de temperatura causa um processo de transmissão de calor do corpo para a atmosfera circunvizinha, ajudando assim a manter um equilíbrio térmico saudável. A perda de calor por convecção e radiação do corpo humano nessas condições é na ordem de 80 a 100W, para uma pessoa descansada. $\mathrm{O}$ ar aquecido tende a subir em função das correntes de convecção. Isso faz com que se forme uma pluma térmica ao longo do corpo humano (Settles e Mcgann, 2001).

Esta pluma térmica começa próxima ao tornozelo, elevando-se acima da cabeça. Ocorre um aumento em sua espessura e velocidade de escoamento à medida que vai subindo ao longo do corpo. Para um homem nu com uma altura de aproximadamente 1,70 m, esta pluma apresenta escoamento laminar a um nível de $1 \mathrm{~m}$ do piso e completamente turbulento a uma altura de 1,5m (Cox e Clark, 1974). Esta camada térmica possui uma espessura em torno de 15 a $20 \mathrm{~cm}$ em torno da cabeça, onde também atinge a maior velocidade, que é de aproximadamente $0,25 \mathrm{~m} / \mathrm{s}$. A taxa global de fluxo de ar que sobe continuamente ao longo do corpo assume um valor na ordem de 50 a 80 litros por segundo (Settles e Mcgann, 2001).

Desta forma, o ar em contato com o corpo humano nunca estará estagnado, mas sim em constante movimento. Esse movimento produz o arrasto de centenas de tipos de biofluentes e milhões de flocos de pele (Settles e Mcgann, 2001).

Segundo Schlierien apud Woods (1986) a camada de ar envoltória de um homem nu, em pé, contém de $30 \%$ a $400 \%$ mais microrganismos que o ar no ambiente, e as concentrações são inversamente proporcionais a uma função da velocidade da camada envoltória. Woods (1986) relata que a vestimenta reduz o desenvolvimento da camada envoltória, devido à redução da diferença de temperatura entre a roupa e o ambiente. Entretanto, postula o autor que a camada envoltória é restabelecida no lado externo da roupa. A partir desses dados, as taxas de geração típica de flocos de pele com diâmetro principal de 7,5 $\mu \mathrm{m}$ foram estimadas em 6,0 $\mu \mathrm{g} / \min$ (Woods, 1986).

Conforme Noble (1975), as escamas de pele que compõem a superfície medem em

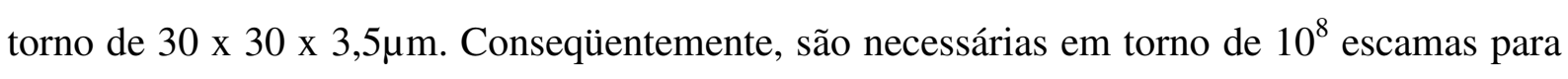
completar a área total de superfície de pele $\left(1,75 \mathrm{~m}^{2}\right)$. As mulheres possuem em média 
escamas maiores que os homens (Plewig, 1970). Uma camada completa de células é perdida e substituída a cada 4 dias, em média (Noble, 1975). Portanto, todas as pessoas adultas disseminam mais de $10^{7}$ partículas de pele a cada dia. Embora o banho remova mecanicamente muito mais escamas, Scriple, Riemensnider e Schleyer (1967) descobriram que os movimentos naturais de locomoção liberam em torno de $10^{4}$ escamas por minuto. As escamas também são liberadas mesmo quando se está parado e nu, provavelmente porque os flocos tendem a se enrolar e se destacar quando ressecados. Estes flocos são então transportados pelas correntes de ar, conforme demonstrado por Lewis et al. (1969). Ainda em outro estudo, Noble (1975) cita que em torno de $10 \mathrm{mg}$ de pele são depositados nas vestimentas de um único membro da equipe cirúrgica em 2 horas.

Os colonizadores microbianos da pele são mais numerosos em algumas áreas que em outras. Por exemplo, a cabeça e o tórax carregam mais microorganismos que os membros. Os homens são mais densamente colonizados por aeróbios que as mulheres, embora os anaeróbios pareçam distribuídos igualmente entre os sexos. Os microrganismos não estão espalhados uniformemente em seu habitat, mas vivem em microcolônias definidas que podem ser menores, na ordem de $10^{2}$ células, ou maiores, na ordem de $10^{5}$ células viáveis. Estas colônias podem estar relativamente distantes da superfície, justificando assim o fato de que apenas 10\% das escamas carreguem microrganismos viáveis (Noble e Davies, 1965; Noble, 1975).

\subsubsection{Staphylococcus aureus}

A maioria das bactérias presentes no ar de uma sala cirúrgica é da espécie Staphylococcus de coagulase-negativa (Roy, 1997). Perl (1995) destaca que esse microrganismo causa entre 15 a 20\% dos casos de infecção nos Estados Unidos. Estudos de Softah et al. (2002), sobre os principais fatores de risco de infecção em cirurgias cardíacas, relatam que o Staphylococcus aureus foi o patógeno mais isolado nas cirurgias. Os autores ainda comentam que esta é a espécie mais comum, segundo os casos reportados na literatura.

A contaminação ambiental aérea por Staphylococcus é particularmente importante, porque esse microrganismo coloniza freqüentemente as vias aéreas superiores. Aproximadamente $1 \%$ das partículas aéreas portadoras de bactérias na sala cirúrgica são Staphylococcus aureus, embora o número possa mudar consideravelmente dependendo do estado do portador da equipe cirúrgica (Roy, 1997). Assim, os membros da equipe cirúrgica, 
ao respirar em ambientes contaminados podem adquirir o microrganismo e facilmente disseminá-lo no ar do interior da sala cirúrgica.

Aproximadamente $40 \%$ da população em geral carregam o Staphylococcus aureus no nariz e $12 \%$ da população são portadores perianais. É estimado que em torno de $30 \%$ do pessoal da sala cirúrgica são portadores do Staphylococcus aureus. Walter e Kundsin (1973) mostraram que entre 379 membros saudáveis de um centro cirúrgico, 17\% eram portadores persistentes e 37\% eram portadores intermitentes de Staphylococcus aureus. Portanto, em qualquer momento pode-se afirmar que há grande probabilidade de existir portador desse patógeno em cada sala cirúrgica (Roy, 1997).

Se um portador do Staphylococcus aureus possui uma doença de pele tal como dermatite nas mãos, ele também pode estar dispersando um grande número desses microrganismos no ar da sala cirúrgica. Surtos de infecção por Staphylococcus aureus em cirurgias cardiotorácicas, com casos devastadores de mediastinite e endocardite, têm sido associados a tais propagadores na equipe cirúrgica. Propagadores de Staphylococcus aureus associados aos surtos devem ser excluídos da sala cirúrgica e tratados adequadamente antes que possam retomar suas atividades. De forma geral, portadores de quaisquer tipos de lesões de pele não devem permanecer trabalhando em uma sala cirúrgica, pois estes indivíduos propagam uma quantidade muito grande de microrganismos no ar.

Estudos realizados por Roy (1997), mostram que na Suécia 57\% das infecções do sítio cirúrgico causadas por Staphylococcus aureus eram de origem exógena; isto é, as cepas foram encontradas no nariz e garganta dos membros da equipe cirúrgica.

Hambraeus et al. (1978) estudaram a presença de propagadores de Staphylococcus aureus em salas de cirurgias torácicas e ortopédicas por meio da exposição de placas de deposição durante 5 dias por semana, a cada 6 semanas. Durante um ano de pesquisa, os autores obtiveram uma contagem total de mais de 100 ufc/placa em $40 \%$ dos centros cirúrgicos de cirurgia torácica e em $12 \%$ dos centros cirúrgicos ortopédicos. Mais de 10 colônias de Staphylococcus aureus foram encontradas em 16\% dos centros cirúrgicos de cirurgia torácica e em $5 \%$ dos centros cirúrgicos de cirurgia ortopédica.

Esses estudos, confirmam a importância do ar da sala cirúrgica como meio de propagação desse microrganismo.

O paciente também pode ser um portador do Staphylococcus aureus e estar abrigando muitos microrganismos na sala cirúrgica. Kluytmans et al. (1995), em um estudo de caso controlado, demonstraram que a presença pré-operatória de Staphylococcus aureus é um fator de risco significativo para infecções do sítio cirúrgico após cirurgia cardíaca. 


\subsubsection{O sistema de condicionamento de ar como fonte de contaminação}

Estudos apresentados na literatura sustentam a necessidade de um cuidadoso planejamento e uso de sistemas de condicionamento de ar que propiciem controle da dispersão de microorganismos (ASHRAE, 2005; Beck e Frank, 1973; Howorth, 1993; Pereira, 2002; Pereira e Tribess, 2005). No projeto desses sistemas, um dos primeiros pontos a ser considerado é o controle da movimentação do ar no interior da sala de cirurgia. É preciso que o ar se movimente das zonas limpas para as contaminadas, e não o contrário (ASHRAE, 2005). O controle desse tipo de movimentação é mais eficientemente feito quando se cria pressão positiva para a sala cirúrgica com relação às áreas adjacentes. Isso também ajuda a compensar uma localização pouco estratégica do centro cirúrgico.

Em segundo lugar, é preciso que o sistema de condicionamento de ar controle a temperatura do ar, de forma a evitar a formação de gradientes excessivos, pois estes provocam movimentos de convecção que, por sua vez, causarão o alçamento de partículas depositadas (Beck e Frank, 1973).

Os sistemas convencionais de condicionamento de ar promovem um suprimento de ar limpo sobre o campo cirúrgico, utilizando um sistema de insuflamento de ar com os difusores no teto (ou na parede, em alguns casos). Porém, segundo Lewis (1993), esse sistema cria zonas de baixa pressão próximas ao perímetro de insuflamento do ar, para onde se dirigirá o ar do interior da sala cirúrgica, contaminando o ar limpo. Se isso não for evitado, compromete-se a qualidade do ar filtrado.

Quando se usa ar condicionado de janela ou splits, esse problema é ainda mais grave, porque não há qualquer controle sobre a movimentação do ar. Alie-se a isso ainda o fato de que o fluxo turbulento criado por esses equipamentos contribui para a dispersão das partículas de outros pontos da sala, podendo projetá-las sobre o campo cirúrgico, contaminando-o. (Pereira, 2002).

De acordo com Josephe (1981) e Friberg et. al. (1998) haveria a necessidade do estabelecimento de fluxos laminares, não turbulentos, para reduzir a suspensão de partículas depositadas no chão e sobre outras superfícies da sala cirúrgica. Entretanto, segundo Howorth (1993), os sistemas de fluxo laminar apresentam limitações. Argumenta-se, por exemplo, que os sistemas de fluxo "laminar" não podem fornecer um fluxo unidirecional em uma sala de cirurgia em que o pessoal, ou os pacientes, estejam se movimentando, ou quando existam focos luminosos suspensos móveis, aparelhos de sucção, fontes de calor (por exemplo, pessoas, unidades de eletrocoagulação e luzes). Qualquer desses fatores pode produzir 
turbulência. Também se ressalta que, quando a equipe cirúrgica está inclinada sobre o paciente, um fluxo laminar descendente conduz para o sítio cirúrgico os microorganismos liberados pelos membros da equipe. Como outra limitação importante dos sistemas de fluxo laminar descendente, destaca-se seu alto custo de operação.

Além de controlar a dispersão de microrganismos por meio de planejamento e uso racional do sistema de condicionamento de ar, é preciso reduzir as chances de contaminantes provenientes de outros meios invadirem a sala cirúrgica (Hays et al., 1995). A operação e manutenção dos sistemas de condicionamento de ar, também são fatores que afetam diretamente a qualidade do ar em uma sala cirúrgica.

Segundo Pereira (2002), os sistemas de condicionamento de ar em centros cirúrgicos, de forma geral, mostram-se ineficientes. No Brasil muitos dos centros cirúrgicos são antigos, não oferecendo condições de garantia quanto à qualidade do ar para a realização de cirurgias que exijam largo tempo de realização e grande equipe cirúrgica, como é o caso dos transplantes de órgãos, das cirurgias cardíacas e de grandes cirurgias ortopédicas. Também não são garantidas boas condições de conforto térmico para a equipe cirúrgica e o paciente (Felix, 2008).

Na mesma linha, Hays et al. (1995) destaca que, entre os problemas existentes nos sistemas de condicionamento de ar em centros cirúrgicos, muitos decorrem de projetos inadequados. As tomadas de ar, muitas vezes, são feitas em localizações impróprias, normalmente impostas por limitações arquitetônicas, que fazem com que o ar seja captado em locais contaminados. Tem-se também dimensionamento inadequado da taxa de renovação de ar e, em casos extremos, ausência total de renovação, como no caso do uso de ar condicionado de janela ou do tipo split sem renovação. O fluxo de ar normalmente é turbulento e mal dirigido, favorecendo a dispersão de contaminantes sobre o sítio cirúrgico. Os dutos, filtros e difusores em geral não são posicionados de forma a facilitar a limpeza, essencial para evitar o acúmulo de poeira e a proliferação de fungos, bactérias e protozoários. Os sistemas de filtragem, muitas vezes, também são inadequados e não conseguem remover eficientemente o material particulado. Muitos dos sistemas existentes também não conseguem estabelecer pressão positiva na sala cirúrgica, para evitar a infiltração de contaminantes dos espaços adjacentes.

Outros problemas são oriundos de manutenção inadequada. Os filtros, muitas vezes, não são substituídos com a freqüência necessária. A falta de substituição faz com que o sistema opere com filtros saturados, diminuindo a vazão do ar insuflado no ambiente. Isso pode fazer com que não se garanta a pressão positiva e a renovação de ar nos níveis 
desejáveis. Além disso, o acúmulo de substâncias sobre os elementos filtrantes e a formação de condensado em sua superfície tornam o filtro um potencial contribuidor de problemas de qualidade do ar, pois, nesse meio úmido, torna-se possível a multiplicação de microorganismos e o crescimento de colônias de fungos que podem atingir até o lado limpo do filtro (Hays et al., 1995).

A falta de limpeza dos dutos e bandejas de condensação também constitui sério problema. A manutenção ineficiente nesses casos pode transformar dutos e acessórios nos maiores disseminadores de microorganismos nocivos à saúde, pois o acúmulo de poeiras e condensados provê meio excelente para sua proliferação (Pereira , 2002; Hays et al., 1995).

\subsubsection{Outras fontes de contaminação}

Outra fonte importante que provoca a formação de fumaça e aerossóis que podem permanecer suspensos no ar durante muito tempo é o próprio procedimento cirúrgico. A concentração e distribuição de tamanho dessas partículas dependem do tipo de procedimento que foi executado. Por exemplo, em procedimentos cirúrgicos ortopédicos, são comumente usadas ferramentas cirúrgicas como eletro-cauterizadores, serras de osso, mandris e brocas. A fumaça e aerossóis produzidos por esses dispositivos, ao entrar em contato com pisos e outras superfícies, também podem ser contaminados e vir a servir como veículos de infecção. Em condições experimentais, foi demonstrado que o uso dessas ferramentas também pode produzir aerossóis que permanecem um longo tempo no ar e que são inaláveis (Jones, 1995). Estas partículas devem ser removidas da sala cirúrgica para diminuir os riscos de inalação pelos ocupantes, evitar contaminação do próprio paciente e também para prevenir a contaminação do procedimento cirúrgico posterior, pois podem permanecer bastante tempo suspensas no ar. Desta forma, o mero controle da qualidade do ar fornecido à sala cirúrgica não evitaria a presença de partículas em suspensão potencialmente perigosas ao paciente.

\subsection{CONTROLE DA CONTAMINAÇÃO AÉREA EM SALAS CIRÚRGICAS}

\subsubsection{Controle do número de pessoas e nível de atividade}

Vários estudos indicam que a principal fonte de infecção por partículas aéreas são as pessoas presentes no interior da sala cirúrgica, ou seja, a equipe cirúrgica e o paciente (Fitzgerald, 1979; Roy, 1997; Blakemore et al., 1979; Ritter, 1999). 
A distribuição e a quantidade desses microrganismos variam muito, dependendo do número de pessoas presentes na sala cirúrgica, como também do grau de atividade (Fitzgerald, 1979; Roy, 1997; Blakemore et al., 1979; Ritter, 1999). Roy (1997) cita que uma sala cirúrgica sem desenvolvimento de atividades é virtualmente livre de bactérias ou partículas maiores que $0,5 \mu \mathrm{m}$.

Segundo Fitzgerald (1979), o nível de contaminação bacteriana aerotransportada em uma sala cirúrgica pode ser reduzido limitando o tráfego e controlando as atividades e o número de pessoas na sala. Blakemore et al. (1979), monitoraram os níveis trans-operatórios de bactérias aéreas próximo à ferida cirúrgica e verificaram uma relação direta entre o número de unidades de formação de colônias (ufc) e o número de pessoas presentes na sala cirúrgica.

Segundo Ritter (1999), a sepsia em procedimentos cirúrgicos ortopédicos de substituição total está diretamente relacionada à contaminação ambiental. Desta forma, segundo o autor, é importante controlar as fontes de contaminação ambiental e, conseqüentemente, a sepsia.

Ritter (1999) diz que, nos procedimentos cirúrgicos atuais, percebe-se que o número de ufc's cresce de 13, em uma sala cirúrgica sem pessoas, para mais de 400 durante a ocupação. $\mathrm{O}$ autor complementa que para se reduzir a contaminação ambiental por bactérias é importante a redução do número de pessoas na sala cirúrgica e do tempo de cirurgia (Ritter, 1999). Tais recomendações também são sugeridas por especialistas do Centro de Controle e Prevenção de Doenças dos EUA, além da manutenção das portas da sala cirúrgica fechadas, com a garantia de que todos os equipamentos necessários para o procedimento estejam na sala cirúrgica no início da cirurgia (Roy, 1997).

\subsubsection{Controle pelo sistema de condicionamento de ar}

Embora ainda haja controvérsia quanto à importância relativa da contaminação aérea sobre as taxas de infecção pós-cirúrgica, muitos são os trabalhos que assumem ser o ar um importante veículo para dispersão de contaminantes e muitos indicam que essa contaminação pode ser controlada pelo tipo de sistema de condicionamento de ar utilizado.

Enquanto alguns trabalhos enfocam somente a relação entre ventilação e contaminação, outros associam diretamente ventilação e infecção, ressaltando que alguns métodos de distribuição de ar da sala cirúrgica podem reduzir os índices de infecção pós-operatória (Josephe, 1981; Friberg et al., 1998; Ayliffe, 1991). De fato, em procedimentos cirúrgicos de porte, como a substituição de articulação, precauções assépticas excepcionais 
devem prevalecer para compensar os riscos de contaminação da ferida pela grande exposição e pelo implante massivo, principalmente quando cimentado.

Whitfield, em 1960, foi o primeiro a criar um sistema com fluxo laminar (Howorth, 1993). Para procedimentos ortopédicos esse é o sistema de fluxo mais utilizado (Roy, 1997), porque tende a evitar que contaminações geradas no interior da sala depositem-se sobre o campo cirúrgico. Os sistemas de fluxo laminar também se têm mostrado promissores em salas usadas no tratamento de pacientes altamente suscetíveis à infecção, como os pacientes com queimaduras, os pacientes de radioterapia e quimioterapia, os transplantados, os amputados e os de cirurgias ortopédicas (ASHRAE, 2005).

Em 1964, Chamley desenvolveu um protótipo de um encapsulamento contendo ar filtrado, construído para conter três cirurgiões e a parte inferior do corpo do paciente. $\mathrm{O}$ objetivo de tal sistema era eliminar as contaminações emitidas pelos cirurgiões e outras fontes de bactérias aéreas da sala cirúrgica. Neste sistema o ar filtrado era forçado para dentro do compartimento pela parte de cima e os cirurgiões dentro do compartimento vestiam trajes especiais com respiradores, pelos quais o ar exalado era extraído para evitar a mistura com o ar filtrado do compartimento. Por meio deste procedimento, conseguiram-se reduzir as taxas de infecção após cirurgia de substituição de coxa de 9,5\%, com o uso do sistema convencional de condicionamento de ar, para $1,1 \%$, quando o sistema de compartimento foi usado (Chamley, 1964). Entretanto, como se pode ver na Figura 2.1 (A) e (B), o conforto da equipe cirúrgica era comprometido.

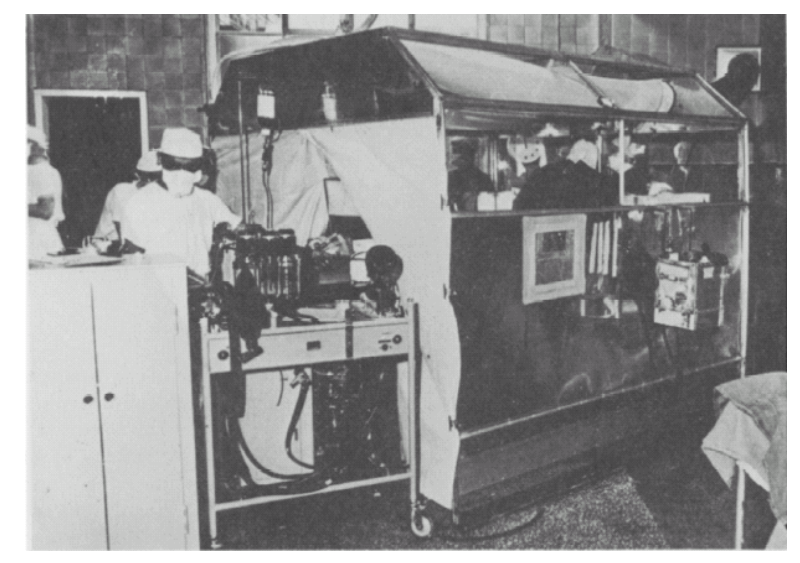

(A)

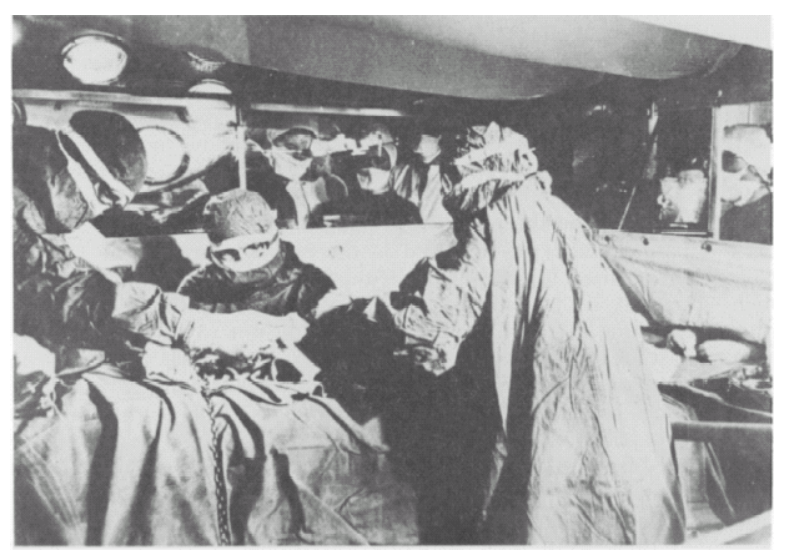

(B)

Figura 2.1 - Sistema de Chamley.

Ritter (1999) diz que o uso de sistemas de condicionamento de ar com fluxo laminar produz uma redução de $90 \%$ do número de bactérias na ferida cirúrgica e $60 \%$ no ar da sala 
cirúrgica (Ritter, 1999). Salvati et al. (1982), determinaram o efeito do sistema de condicionamento de ar sobre a taxa de infecção depois da realização de cirurgias de artroplastia total de quadril e de joelho. As cirurgias foram feitas em salas cirúrgicas com fluxo de ar filtrado unidirecional (laminar) horizontal e com sistemas convencionais, utilizando condições anti-sépticas modernas e profilaxia antibiótica. Comparativamente a procedimentos similares realizados em salas cirúrgicas com sistemas de condicionamento de ar convencionais (insuflamento pelo teto), quando os pacientes foram operados com o sistema com fluxo de ar laminar filtrado, foi observada uma redução na taxa de infecção depois da substituição total de quadril (de 1,4 a $0,9 \%$ ) e um aumento na taxa de infecção depois da substituição total de joelho (de 1,4 a 3,9 por cento). Segundo os autores essas diferenças podem ter ocorrido devido às posições da equipe cirúrgica e da ferida com relação ao fluxo de ar.

Scott et al. (1971) compararam a contagem de bactérias e partículas maiores que 0,5 $\mu \mathrm{m}$ em diâmetro em salas cirúrgicas ventiladas com sistemas com fluxo turbulento e com fluxo laminar vertical e horizontal. Segundo os autores, as contagens de partículas bacterianas foram mais baixas nas salas com fluxo laminar, tanto para a contagem geral do ar como para a contagem nos locais de trabalho críticos. Obtiveram-se os melhores resultados nas salas cirúrgicas que utilizaram sistemas com fluxo laminar vertical. Friberg et al. (1998) desenvolveram um estudo comparativo entre três tipos de sistemas de fluxo de ar laminar: sistema vertical protegido com paredes laterais, sistema vertical sem proteção e sistema horizontal com paredes laterais. Segundo os autores, embora tenham encontrado uma pequena diferença na eficiência no controle da contaminação sobre o campo cirúrgico entre os três sistemas, é recomendável uma utilização dos sistemas sem proteção lateral, em função de sua maior versatilidade.

Pittet (1994) apresenta o sistema de condicionamento de ar como sendo um dos fatores de risco relacionados às salas cirúrgicas. Entre os outros fatores relacionados pelo autor estão os riscos associados ao paciente (idade, estado imunológico etc), o ambiente da sala cirúrgica, a limpeza e esterilização e o número e nível de atividade das pessoas na sala cirúrgica.

Da mesma forma que há muitos trabalhos relacionando os tipos de sistemas de condicionamento de ar existentes com as taxas de contaminação/infecção, também há grande variedade de estudos que descrevem os efeitos das mudanças do sistema de condicionamento de ar em uma sala cirúrgica sobre as taxas de infecção. Por exemplo, Ferrazi et al. (1986) investigaram, durante mais de 9 anos, a influência do controle ambiental sobre as taxas de 
infecção em 3275 pacientes submetidos a cirurgias cardíacas. Na primeira fase do estudo, as cirurgias foram realizadas em uma sala cirúrgica onde nenhum método padrão de anti-sepsia e assepsia era empregado. A segunda fase foi realizada em salas cirúrgicas com sistema com fluxo de ar laminar e melhores protocolos de controle de infecção. Na terceira fase novos protocolos de controle de infecção foram implementados. Durante a primeira fase de observação, 7,3 \% dos pacientes tiveram problemas de infecção. Na segunda fase, esse índice foi reduzido para $2,7 \%$. E na terceira fase, para $0,8 \%$. Os autores concluem que mudanças no controle ambiental, mudanças nos protocolos e uma maior atenção aos riscos de infecção associados às pessoas podem reduzir drasticamente a incidência de infecção após cirurgias cardíacas.

Everett e Kipp (1991) relatam caso de um centro cirúrgico onde ocorreu um aumento na taxa de infecção em um período quando o sistema de condicionamento de ar estava operando fora dos padrões e em condições de temperaturas elevadas no interior das salas cirúrgicas. Com a substituição do sistema, não ocorreram infecções durante os meses quentes do ano subseqüente à instalação do novo sistema, e a incidência de infecção durante os meses quentes e frios foi semelhante. Diante dessas observações, os autores concluem que condições de má operação do sistema de condicionamento de ar em uma sala cirúrgica podem ter efeito potencializador sobre as taxas de infecção.

Em contrapartida, existem trabalhos que questionam a real eficácia do controle do ar sobre as taxas de contaminação e/ou infecção pós-cirúrgica. Por exemplo, Ayliffe (1991) relata caso em que as taxas de infecção foram mais elevadas durante o período em que uma sala cirúrgica estudada possuía um sistema de condicionamento de ar convencional, em comparação com anos anteriores em que esta mesma sala operava sem sistema de condicionamento de ar (12,6\% contra 8,8\%). Segundo esses dados, em cirurgias convencionais, a adoção de ventilação pelo teto não se mostrou superior, na prevenção de infecções, em relação à ausência de ventilação. Já no caso das cirurgias ortopédicas, segundo o autor, pelo fato de o ar ser uma rota importante na expansão de infecção, é recomendável o uso rotineiro de um sistema de ar ultra-limpo e vestimentas com exaustão corporal. A importância de tais sistemas em outros tipos de cirurgia limpa seria duvidosa. De acordo com Ayliffe (1991), outras medidas podem fornecer resultados semelhantes com menores custos: redução do número de pessoas na sala cirúrgica; adoção de uma política de não abrir portas durante cirurgias; o uso de roupa confortável, lavável, bacteriologicamente impermeável; concentração da corrente de ar no campo cirúrgico em vez de em toda sala etc. 
As recomendações de Ayliffe (1991) parecem apontar para a não adoção de sistemas de condicionamento de ar para outras cirurgias que não as ortopédicas. Entretanto, examinando-se com atenção as recomendações oferecidas pelo autor, pode-se perceber claramente que a adoção de um sistema de condicionamento de ar adequado pode tornar mais eficientes algumas dessas medidas, como o direcionamento da corrente de ar, que só é possível mediante a utilização de um sistema de condicionamento de ar.

\subsubsection{Controle pelos trajes cirúrgicos}

Uma outra forma importante de controlar a dispersão de contaminantes particulados é o uso de trajes cirúrgicos adequados. O traje ideal deve prevenir a dispersão aérea bacteriana, funcionando como barreira. Mas, ao mesmo tempo, deve permitir a passagem de ar e vapor d'água para o conforto do usuário.

Segundo Whyte (1991) as ações desejáveis das vestimentas em uma sala cirúrgica são: minimizar a dispersão de bactérias dentro da sala; dificultar o lançamento de bactérias no ar através ou pelas aberturas da vestimenta; e quando a roupa estiver molhada, evitar que a bactéria seja liberada do traje por ação capilar (Whyte, 1991).

Roy (1997) descreve que o tecido de algodão usado normalmente nos hospitais possui tamanho de poros entre $80 \mu \mathrm{m}$ e $100 \mu \mathrm{m}$, enquanto as células da superfície da pele se fragmentam em partículas de tamanho médio de $20 \mu \mathrm{m}$. Portanto, pode-se facilmente perceber que as roupas comuns não conseguem reter eficientemente as partículas de pele.

Aproximadamente $70 \%$ das bactérias são dispersas da cintura para baixo, principalmente Staphylococcus aureus. Se a pessoa adiciona uma túnica à sua vestimenta, esta taxa de dispersão será reduzida a apenas $30 \%$, pois a bactéria será filtrada pela roupa ou sairá pelas frestas (Whyte, 1991). Em mulheres, a dispersão de microrganismos é mais facilmente controlada com o uso de calça comprida do que de saia. Para garantir a mínima dispersão bacteriana, a equipe cirúrgica deve usar calças compridas de material oclusivo. Segundo Whyte (1991), também é recomendável uso de uma camisa e capuz com alças que se prendem por debaixo da túnica, prevenindo desta forma a dispersão de bactérias pela abertura do colarinho.

Roy (1997) mostra que o tecido de algodão molhado permitia a passagem fácil de bactérias pela vestimenta pela ação da capilaridade. De fato, muitas bactérias podem ser transferidas da pele do cirurgião para fora da roupa se esta for molhada pelo suor do cirurgião 
ou por outros fluidos como o sangue. Este tipo de barreira vulnerável é proporcional à duração da cirurgia, à intensidade de trabalho e ao nível de umidade (Roy, 1997).

Uma alternativa ao algodão comum são os materiais descartáveis não trançados. Estes materiais são feitos de fibras e sua eficácia está no fato das partículas carreadoras de bactérias, para atravessar o material, terem que se desviar em um emaranhado de fibras. Por isso são retidas com muito mais eficiência (Roy, 1997).

Os tecidos com trama fechada, incluindo o poli-algodão e poliéster, são eficazes na redução da dispersão bacteriana, porque possuem uma capacidade maior de filtragem das partículas carreadoras de bactéria. Além do mais, estes tecidos são eficazes contra a permeabilidade se forem substituídos a intervalos regulares.

Numerosos experimentos têm sido realizados para se verificar a real eficiência de alguns tipos de roupas cirúrgicas no controle da dispersão de bactérias, para garantir barreiras efetivas tanto para o cirurgião como para o paciente. Em estudo realizado com 90 pacientes submetidos a cirurgias de artroplastia total de quadril ou joelho, Ahl et al. (1995) utilizaram três regimes diferentes para verificar a eficiência de diferentes sistemas de condicionamento de ar combinados com diferentes tipos de vestimenta: (1) sistema de ventilação laminar horizontal e roupas convencionais (camisas de algodão e calças compridas) para todos os membros da sala, (2) sistema de ventilação laminar horizontal e artigos de vestuário com tramas fechadas (Klinidress) e (3) ventilação convencional e artigos de vestuário fechados. Segundo os autores, a ventilação laminar, com ou sem artigos oclusivos, registrou um menor nível de contaminação do ar comparada à ventilação convencional. O sistema convencional combinado com a vestimenta fechada, porém, também provocou uma baixa contagem de contaminação. Os autores concluíram que cirurgias de artroplastia de joelho e quadril podem ser executados em salas cirúrgicas com condicionamento de ar convencional, quando vestimentas oclusivas forem utilizadas.

Whyte et al. (1976) estudaram o efeito da roupa na dispersão de partículas bacterianas em uma câmara de dispersão. Foi feita uma comparação entre seis tipos de trajes e quatro tipos de calças compridas. Os trajes utilizados foram de três tipos básicos: tecido de algodão convencional; tecido sem trama e vestimenta com exaustão corporal (sistema Charnley). Os resultados obtidos mostraram que as vestimentas sem trama reduziram a taxa de dispersão em aproximadamente $30 \%$ no sistema convencional e aproximadamente $65 \%$ no sistema de fluxo de laminar. A vestimenta com exaustão corporal reduziu a contagem de partículas a cerca de $10 \%$ no sistema ventilado convencional e $66 \%$ no sistema de fluxo laminar. Segundo os 
autores, o baixo desempenho das vestimentas nos sistemas convencionais foi causado pela dispersão de partículas bacterianas na parte inferior da vestimenta (aproximadamente 80\%).

Dankert et al. (1979) analisaram a dispersão de bactérias viáveis em 20 testes com pessoas que usaram um traje cirúrgico composto por $65 \%$ de poliéster e $35 \%$ de algodão (Diolen). Os estudos foram realizados em uma câmara de teste e também em sala cirúrgica e comparados com situações quando roupas convencionais eram usadas. O uso dos trajes cirúrgicos experimentais resultou em uma redução significante (50-75\%) no número de partículas transportadoras de bactérias no ar, tanto nos testes realizados na câmara como na sala cirúrgica quando todos os presentes usaram este traje. Uma combinação do traje com botas altas até o joelho mostrou uma redução adicional na dispersão das unidades formadoras de colônia. 


\section{CAPÍTULO 3}

\section{DISTRIBUIÇÃO E MOVIMENTAÇÃO DE AR EM SALAS CIRÚRGICAS}

As intervenções cirúrgicas complexas e demoradas, que se fazem hoje, exigem atividades intensas, uma grande equipe de pessoas e o uso de muitos tipos de equipamentos. Esta situação torna importante o controle eficaz das variáveis que interferem na saúde, conforto e bem-estar do paciente e da equipe cirúrgica (Dharan, 2002).

Para se conseguir um desempenho aceitável, as salas cirúrgicas devem cumprir um dos mais complexos conjuntos de exigências de controle, tendo como critério de desempenho a proteção e o conforto para os pacientes e equipe médica.

Na proteção dos ocupantes de uma sala cirúrgica, o controle de partículas viáveis, odor, vírus e microorganismos carreados pelo ar, substâncias químicas perigosas e substâncias radioativas é considerado essencial (Lidwell et al., 1987, Belkin, 1998, Friberg et al., 1998).

Desta forma, para o controle preciso das condições ambientais e a diluição e remoção desses agentes, alguns requisitos devem ser considerados, tais como: restrição do movimento do ar internamente e entre vários setores, necessidades específicas de ventilação e filtragem, necessidade de controle de temperatura e umidade etc. (ASHRAE, 2005).

Os sistemas de condicionamento de ar desempenham uma tarefa fundamental no cumprimento destes requisitos para a garantia da segurança e conforto térmico ao paciente, cirurgiões e equipe na sala cirúrgica.

Em sistemas de condicionamento de ar inadequados, além de comprometer a saúde e o bem estar dos ocupantes de uma sala cirúrgica, os microrganismos carreados pelas gotículas ou pelas partículas de poeira podem se depositar sobre feridas cirúrgicas, instrumentos, superfícies, etc. Também podem ser inalados por indivíduos e causar ou agravar doenças. 


\subsection{SISTEMAS COM FLUXO TURBULENTO}

Em salas cirúrgicas que utilizam sistemas com fluxo turbulento, o ar tratado, isto é, o ar que passou pelos processos de filtragem e de resfriamento e desumidificação, é insuflado através de difusores instalados no teto ou na parede. $\mathrm{O}$ ar insuflado mistura-se rapidamente e uniformemente com o ar do ambiente provocando uma diluição do teor de contaminantes. Desta forma, a contaminação originada de uma certa fonte é distribuída de maneira uniforme ao longo de toda a sala, assim como a uniformidade da temperatura é atingida rapidamente (Howorth, 1993, Woods, 1986).

Esta concepção de insuflamento de ar é uma das mais utilizadas na maioria dos centros cirúrgicos. A distribuição turbulenta diminui a formação de ilhas estáticas de ar, ao longo da sala. O projeto desses sistemas tem uma boa flexibilidade e os filtros e o sistema de distribuição de ar são menos complexos e de fácil manutenção. Porém, a sua grande desvantagem é que, quando a troca de ar é pequena, a recuperação do ambiente a partir de uma condição contaminada é lenta (Lewis, 1993).

A Figura 3.1 mostra um esquema de uma sala cirúrgica com um sistema de fluxo turbulento com vários difusores localizados no teto.

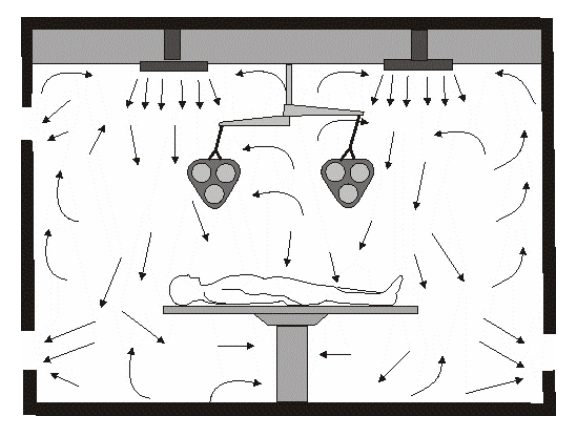

Figura 3.1 - Insuflamento pelo teto (Schmidt 1987)

A Figura 3.2 mostra um sistema com fluxo turbulento com a grelha de insuflamento de ar localizada em uma das paredes da sala. Após o ar passar pelo equipamento de condicionamento de ar é conduzido pelos dutos e insuflado para o interior do ambiente através dos difusores (Lewis, 1993, Howorth, 1993). A Figura 3.3 mostra um esquema de uma sala cirúrgica com um sistema com fluxo turbulento com insuflamento em diagonal 


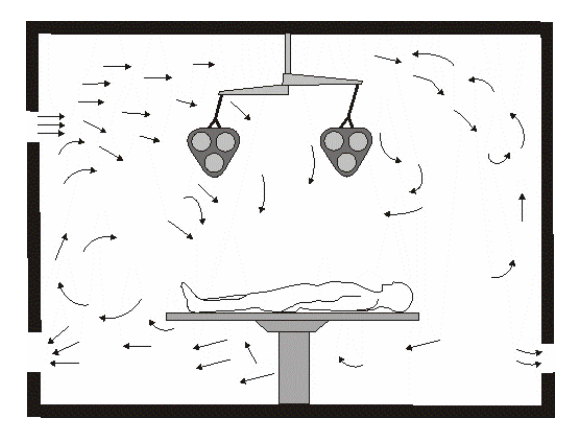

Figura 3.2 - Insuflamento pela parede (Schmidt 1987)

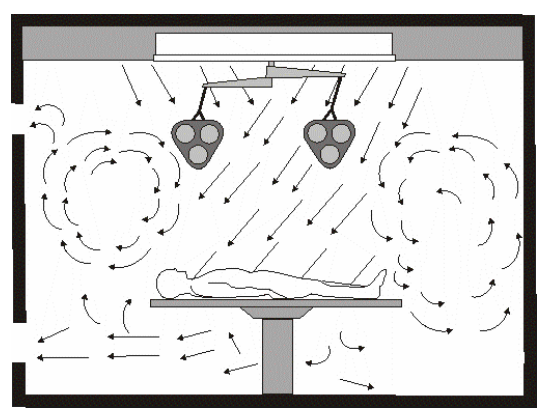

Figura 3.3 - Insuflamento diagonal (Schmidt, 1987)

\subsection{SISTEMAS COM FLUXO UNIDIRECIONAL}

Os sistemas cirúrgicos com fluxo de ar unidirecional também chamados de fluxo "laminar", têm sido muito estudados e utilizados em cirurgias ortopédicas. Segundo alguns autores (Lidwell, 1988; Lidwell et al., 1987, 1993; Tat, 1997), em procedimentos ortopédicos, como por exemplo em substituição de articulação, precauções assépticas devem prevalecer para compensar os riscos de contaminação da ferida devido à grande exposição e pelo implante massivo, principalmente quando cimentado.

Nos sistemas que fornecem fluxo de ar unidirecional, o ar se movimenta uniformemente e é insuflado no ambiente com uma velocidade de aproximadamente $0,45 \mathrm{~m} / \mathrm{s}$, em linhas de fluxo paralelas (ASHRAE, 2005).

Algumas concepções de movimentação unidirecional permitem que toda a contaminação gerada dentro do ambiente seja levada para fora o mais rápido possível. Neste tipo de sistema o equipamento pode insuflar o ar na direção horizontal ou vertical. Quando o insuflamento é horizontal, o ar normalmente é insuflado por toda a parede ou em alguns casos a partir de todo o forro, quando vertical.

A disposição vertical tem a vantagem de ter a ação da gravidade na precipitação e eliminação das partículas maiores, obtendo-se, portanto, um sistema de elevada eficiência (Turpin, 1998). 
A maioria dos sistemas de fluxo laminar é equipado com filtros HEPA, garantindo ar livre de partículas acima de 0,3 $\mu \mathrm{m}$ (remoção de 99,97\%); removendo assim grande parte das bactérias, fungos e até alguns vírus maiores (Tat, 1997). Esta filtração assegura ar essencialmente estéril, que é renovado constantemente.

Como forma de se garantir a movimentação uniforme da corrente de ar em um sistema com fluxo unidirecional, são propostos vários tipos de proteções para estes sistemas, como painéis laterais e cortinas de ar. Nos sistemas de fluxo unidirecional protegidos com painéis, a corrente de ar se movimenta paralelamente varrendo todo o campo asséptico. O ar é estratificado de forma que não existe praticamente contaminação cruzada. As partículas eventualmente em suspensão em uma linha de fluxo tendem a permanecer nesta linha até serem captadas na parte inferior das paredes.

Para garantir um movimento de ar uniforme com pouca mistura, a velocidade do ar deve ser suficientemente elevada para vencer as correntes de ar térmicas originadas das fontes de calor internas (Woods, 1986). A figura 4 mostra um sistema com fluxo laminar com insuflamento pelo teto protegido com painéis laterais.

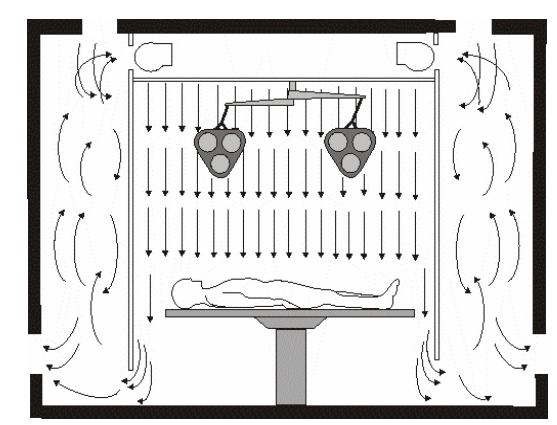

Figura 3.4 - Fluxo laminar com painéis (Schmidt, 1987)

Embora os sistemas com painéis tenham sido bem sucedidos com relação ao controle microbiológico do ar (Friberg et al., 1998, Howort, 1993), eles provocam uma considerável restrição à movimentação dos cirurgiões, aos outros membros da equipe cirúrgica e ao posicionamento dos instrumentos e de todos os itens que estão no interior da sala cirúrgica. Desta forma, para evitar estes tipos de problemas são propostos os sistemas com os painéis de proteção localizados aproximadamente a $2 \mathrm{~m}$ do piso. A Figura 3.5, mostra um sistema com fluxo laminar com insuflamento pelo teto com este tipo de proteção (Lewis, 1993, Howorth, 1993). 


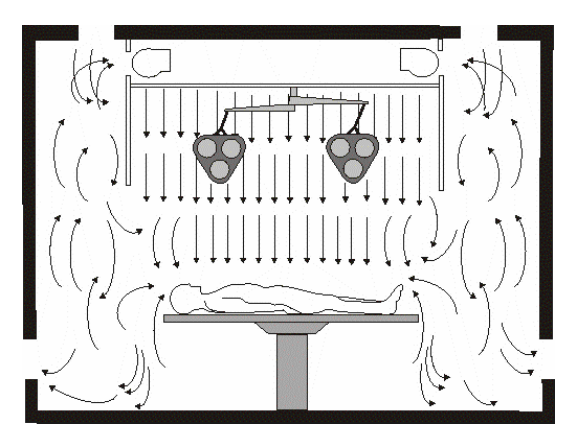

Figura 3.5 - Painéis de proteção localizadas a 2 m do piso (Schmidt, 1987)

Uma outra concepção de proteção da uniformidade do fluxo são os difusores de fluxo laminar protegido com cortina de ar. $\mathrm{O}$ ar é insuflado nos quatros lados da mesa cirúrgica, criando uma cortina de ar em torno desta área em função do ar ser insuflado em alta velocidade e inclinado em relação à vertical. (Lewis, 1993). A Figura 3.6 mostra um exemplo deste tipo de sistema (Lewis, 1993, Howorth, 1993).

A cortina de ar torna-se uma barreira física entre o ar filtrado do difusor unidirecional e o ar contaminado do ambiente, inclusive ao nível do teto, onde o ar do difusor unidirecional é mais sujeito a ser misturado com o ar ambiente. A cortina de ar também induz a saída do ar. Um outro tipo de sistema com proteção lateral do fluxo laminar são as cortinas plásticas. A Figura 3.7 mostra um sistema com este tipo de proteção (Lewis, 1993, Howorth, 1993).

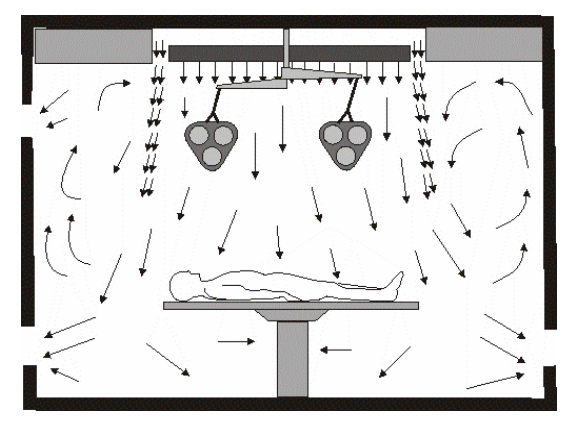

Figura 3.6 - Fluxo de ar com cortina de ar (Schmidt, 1987)

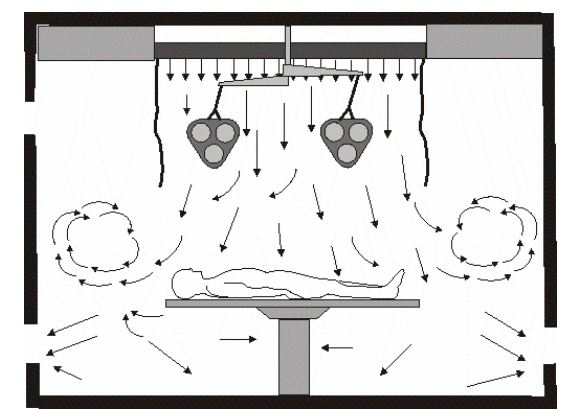

Figura 3.7 - Fluxo laminar com cortina plástica (Schmidt 1987) 
Finalmente um outro tipo de sistema com fluxo unidirecional são sistemas sem proteção lateral. Estes tipos de dispositivos possuem pouca utilização em salas cirúrgicas em função de sua baixa eficiência no combate de partículas infecciosas. A Figura 3.8 mostra um exemplo deste tipo de sistema. A limitação deste sistema está associada à facilidade de contaminação do ar insuflado. $\mathrm{O}$ ar insuflado pelo difusor pode se misturar facilmente com o ar do ambiente por indução (Lewis, 1993; Howorth, 1993).

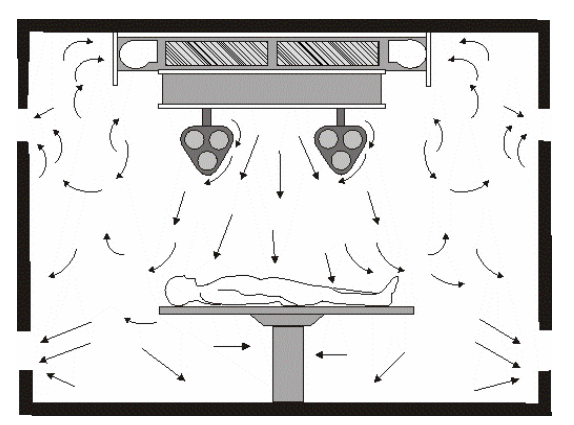

Figura 3.8 - Sistema sem proteção (Schmidt, 1987) 


\section{CAPÍTULO 4}

\section{FATORES QUE AFETAM A CONCENTRAÇÃO DE PARTÍCULAS EM SALAS CIRÚRGICAS}

A concentração de partículas no interior de uma sala cirúrgica pode variar amplamente. Os níveis de contaminação dependem das fontes geradoras de partículas e dos processos de remoção.

As fontes geradoras de contaminação podem ser externas ou internas. As partículas provenientes das fontes externas podem penetrar na sala através de infiltrações de áreas adjacentes e/ou pelo sistema de condicionamento de ar. A contaminação proveniente das áreas adjacentes pode ser combatida por meio da manutenção de um gradiente de pressão positivo no interior da sala. Já a contaminação proveniente do sistema de condicionamento de ar é função da eficiência do sistema de filtragem.

As fontes internas contribuem com a maior parcela da contaminação gerada no interior da sala. As pessoas representam uma fonte muito importante de partículas, cuja taxa de geração depende do número de pessoas presentes na sala, do grau de atividade destas pessoas e da eficiência da vestimenta no controle dessas partículas. O procedimento cirúrgico também é um fator que pode contribuir com a geração de partículas no interior da sala. Por exemplo, alguns tipos de cirurgias ortopédicas geram grande quantidade de partículas.

Ainda com relação às fontes internas, tem-se a ressuspensão de partículas, que tem uma grande influência na concentração de partículas no ar do interior da sala cirúrgica. (Thatcher e Layton, 1995). A ressuspensão pode ser definida como o destacamento de uma partícula de uma superfície e o seu transporte para longe da superfície. Vários fatores podem provocar a ressuspensão de uma partícula: jatos de ar, forças mecânicas, forças eletrostáticas, movimentação dos ocupantes etc.

Também é fator de relevância na ressuspensão a formação de gradientes de temperatura, os quais podem provocar movimentos de convecção que, por sua vez, causarão o 
alçamento de partículas depositadas. Os fluxos turbulentos, criados por correntes de ar também contribuem para a ressuspensão de partículas.

A remoção das partículas dispersas no ar do interior da sala ocorre pela ação do sistema de condicionamento de ar, pela deposição nas superfícies e pela fuga através das aberturas (portas). O sistema de condicionamento de ar remove as partículas através de três mecanismos: pelas trocas de ar, pela renovação e pelo processo de filtragem.

A deposição é um importante mecanismo de perda de partículas do ar do interior de uma sala cirúrgica. A taxa de deposição é influenciada pelo tamanho das partículas, que, por sua vez, influencia a velocidade de deposição.

A perda por fuga para áreas adjacentes pode ocorrer quando a sala está ou não operando com gradientes de pressão. Mas é mais intensa quando a sala está com pressão positiva em relação aos ambientes adjacentes.

A Figura 4.1 mostra os fatores que influenciam na concentração de partículas aéreas no interior de uma sala cirúrgica.

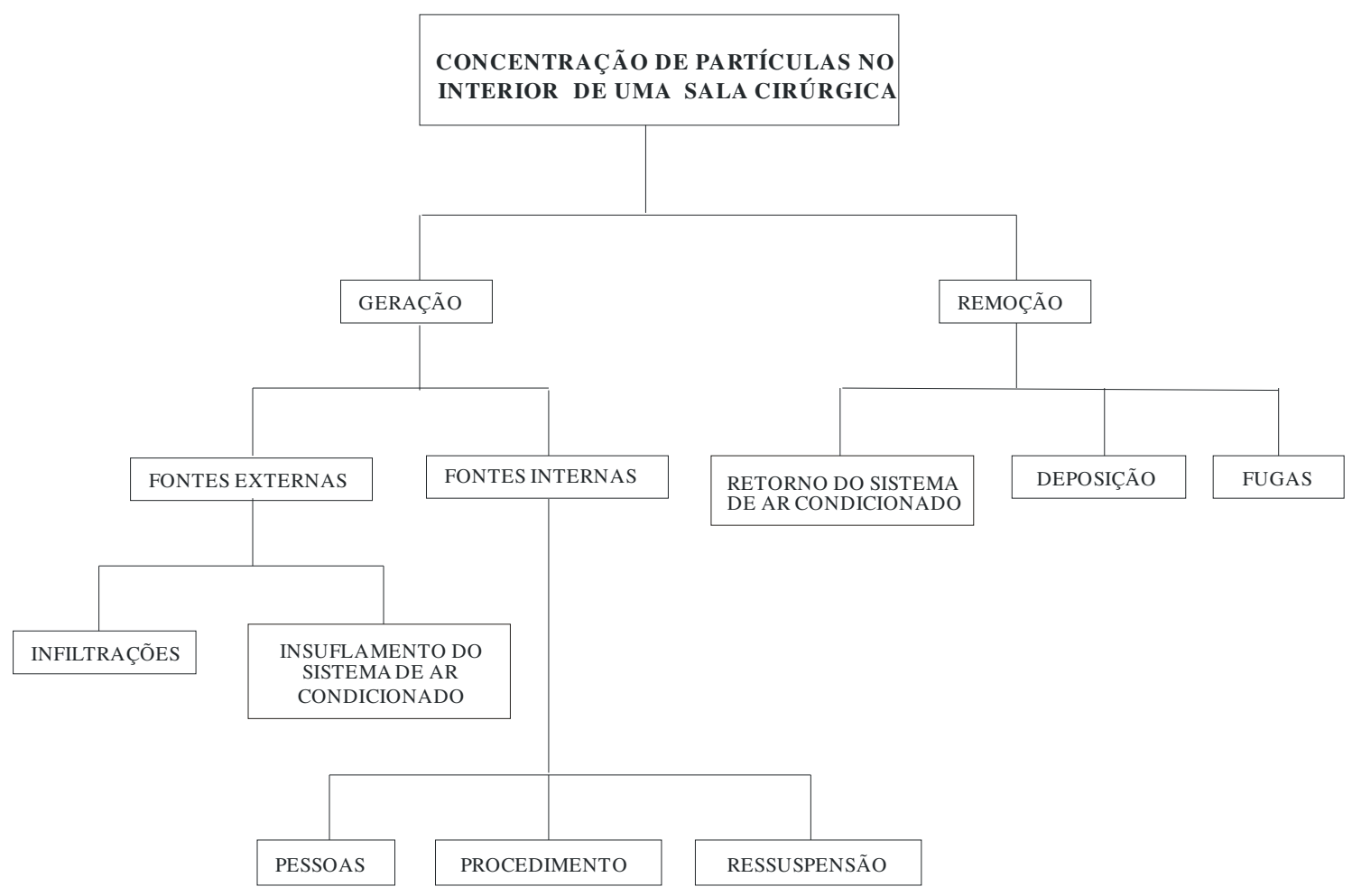

Figura 4.1 - Fatores que influenciam a geração/remoção de partículas em uma sala cirúrgica

\subsection{FLUXO DE AR ATRAVÉS DAS PORTAS}

O conhecimento do fluxo de ar que passa através de uma abertura é uma importante aplicação no controle do transporte poluente, que pode penetrar para o interior de uma sala 
cirúrgica através das portas. O mecanismo de escoamento do ar é geralmente influenciado pela diferença de densidade, pelo sistema de condicionamento de ar e pelos efeitos cinemáticos, tais como o movimento de pessoas através da abertura ou o movimento da própria porta (Favarolo e Manz, 2005; Beck e Frank, 1973; Lidwell, 1977; Woloszyn e Rusaouën, 2004).

Os modelos mais difundidos que representam o fluxo de massa e calor através de uma porta aberta são baseados na equação de Bernoulli. A equação de Bernoulli estabelece uma relação entre as variáveis velocidade $v$, pressão $p$ e altura $h$ para um determinado escoamento (Equação 4.1). Essa equação é muito utilizada em aplicações de escoamento de fluidos, porém é muito importante entender suas limitações, que resultam de várias suposições formuladas em sua dedução: escoamento não viscoso; escoamento permanente; escoamento incompressível.

$$
\frac{v_{1}^{2}}{2}+\frac{p_{1}}{\rho}+g h_{1}=\frac{v_{2}^{2}}{2}+\frac{p_{2}}{\rho}+g h_{2}
$$

Uma das aplicações importantes da equação de Bernoulli é no escoamento de ar através de aberturas entre dois ambientes, resultado de uma diferença de temperatura e pressão estática entre os ambientes. Isto gera um fluxo de ar entre o espaço interior e o ambiente externo, como é mostrado na figura 4.2.

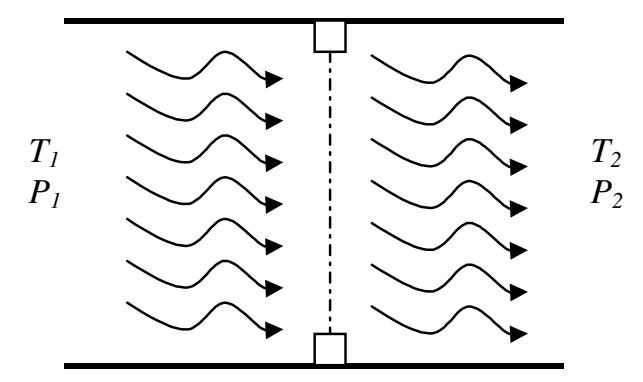

Figura 4.2 - Escoamento de ar através de aberturas

Considerando as suposições estabelecidas para a obtenção da equação de Bernoulli, a taxa de fluxo de ar (Q) que atravessa a abertura é obtida com a seguinte expressão:

$$
Q=A \sqrt{\frac{2 \Delta p}{\rho}}
$$

onde

$\Delta p=p_{2}-p_{1}=$ diferença de pressão entre os dois lados; 


$$
\begin{aligned}
& \rho=\text { massa específica do ar; } \\
& A=\text { área da abertura. }
\end{aligned}
$$

Quando existe uma diferença de temperatura entre os dois ambientes, a Equação 4.2 também pode ser expressa em termos de:

$$
Q=A \sqrt{\frac{2\left(T_{1}-T_{2}\right)}{T_{1}}}
$$

onde

$\mathrm{T}_{1}=$ temperatura do lado 1 ;

$\mathrm{T}_{2}=$ temperatura do lado 2 .

É importante lembrar que tanto a equação (4.2) como a equação (4.3) são obtidas por aproximações, que muitas vezes não descrevem a realidade de um escoamento através de uma abertura. É importante considerar os efeitos da viscosidade do fluido, das contrações, da turbulência e dos efeitos térmicos, que são fenômenos que ocorrem na prática.

Uma das simplificações que se faz é considerar constante a temperatura do ar em cada um dos dois lados da porta. Isto é, o ar é considerado totalmente misturado em ambos os lados da porta. Segundo Lidwell (1977), esta consideração é dificilmente obtida na prática, pois normalmente existem variações de temperatura ao longo da altura da porta.

Desta forma, com o objetivo de obter resultados que descrevam melhor as situações, a equação de Bernoulli é modificada com a introdução de uma constante empírica $\mathrm{C}_{\mathrm{d}}$, chamada de coeficiente de descarga, onde são considerados todos estes fatores:

$$
Q=C_{d} A \sqrt{\frac{2 \Delta p}{\rho}}
$$

$\mathrm{O}$ coeficiente de descarga, $\mathrm{C}_{\mathrm{d}}$, é um parâmetro adimensional, com valor variando de 0 a 1 . Heiselberg et al (2005), encontraram valores entre 0,4 e 0,8 para o coefiente de descarga em portas.

O diferencial de pressão pode, freqüentemente, parecer ser o mecanismo dominante no escoamento do ar através de aberturas. Mas, em muitas circunstâncias, variações de temperatura têm uma grande influência nos padrões de movimentação do ar dentro do espaço e na natureza de troca com o espaço exterior. A diferença de temperatura entre o interior e as áreas adjacentes dentro de um edifício produz uma flutuabilidade das forças que dirigem o fluxo. A tendência natural é que o ar quente suba e o ar frio desça. Esta estratificação pode 
conduzir a configurações bastante diferentes de fluxo de ar através das portas. Segundo Woloszyn e Rusaouën (2004) existem vários tipos de configurações de fluxo de ar através de aberturas. A Figura 4.3 mostra os três tipos principais de configurações.

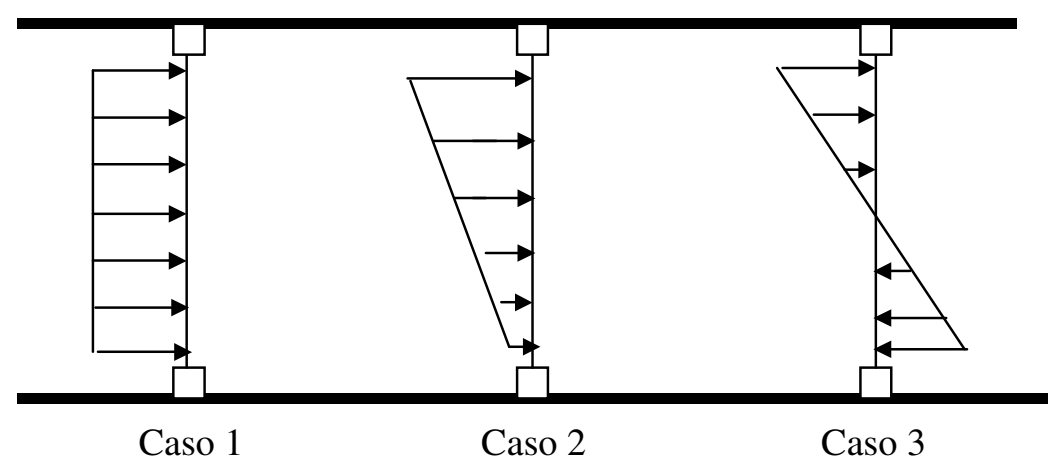

Figura 4.3 - Principais configurações de fluxo de ar através de aberturas

O escoamento esquematizado no caso 1 é uma situação onde o fluido escoa uniformemente ao longo da abertura. No caso 2, tem-se a influência da viscosidade do fluido, da turbulência e dos efeitos térmicos. $\mathrm{O}$ caso 3 é uma situação que normalmente acontece na prática. A viscosidade do fluido, a turbulência e os efeitos térmicos produzem uma descontinuidade no escoamento do fluido, ou seja, o escoamento não tem um comportamento uniforme ao longo do plano vertical (Woloszyn e Rusaouën, 2004; Favarolo e Manz, 2005).

Segundo alguns autores (Beck e Frank, 1973; Lidwell, 1977; Woloszyn e Rusaouën, 2004) em um ambiente que opera com um gradiente de pressão e temperatura, o fluxo de ar através das portas não possui um comportamento uniforme ao longo do plano vertical das portas. Devido à diferença de temperatura existente entre o interior da sala cirúrgica e as áreas adjacentes, um fluxo de ar frio é induzido para o interior da sala pela parte inferior, enquanto um fluxo com temperatura mais elevada tende a ser exaurido pela porta, na porção superior. A divisão das correntes de ar ocorre aproximadamente na metade da porta, tendo-se neste ponto um gradiente de pressão igual a zero. A Figura 4.4 mostra a distribuição de pressão ao longo da altura da porta. 


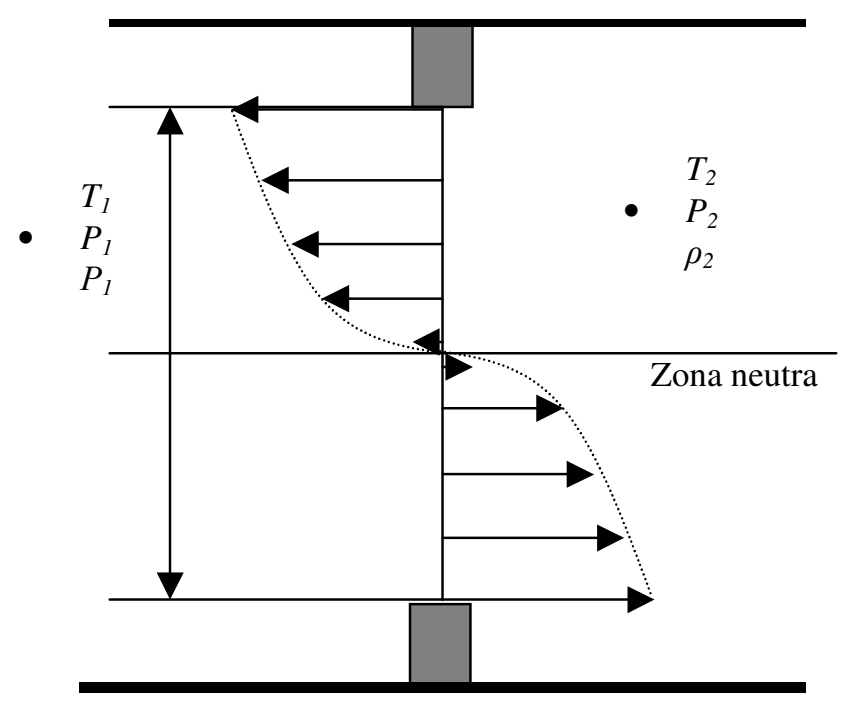

Figura 4.4 - Distribuição de pressão ao longo do eixo vertical de uma porta

Assumindo-se que o nível de pressão neutra esteja localizado no meio da abertura, onde $\Delta p(\mathrm{y}=\mathrm{h} / 2)=0$, assumindo temperatura constante em ambos os lados, perfis de pressão lineares e aplicando a lei dos gás ideal, uma integração na direção vertical conduz à seguinte equação (Favarolo e Manz, 2005):

$$
Q=C_{d} W \int_{y=0}^{y=h / 2} \sqrt{\frac{2 \Delta p(y)}{\rho} d y}
$$

Se o fluxo de ar através da abertura é causado devido a uma diferença de temperatura entre o lado interno e externo, a taxa de fluxo de ar $\mathrm{Q}\left(\mathrm{m}^{3} / \mathrm{s}\right)$ pode ser obtida pela seguinte expressão (Favarolo e Manz, 2005):

$$
\begin{aligned}
& Q=\frac{1}{3} C_{d} A \sqrt{g h \frac{T_{1}-T_{2}}{T_{1}}}, \text { se } T_{1}>\mathrm{T}_{2} \\
& Q=\frac{1}{3} C_{d} A \sqrt{g h \frac{T_{2}-T_{1}}{T_{2}}}, \text { se } T_{2}>\mathrm{T}_{1}
\end{aligned}
$$

\subsection{FATOR DE INFILTRAÇÃO (P) E TAXA DE INFILTRAÇÃO $\left(\lambda_{\text {inf. }}\right)$}

O fator de infiltração $(P)$ é um parâmetro adimensional que denota a fração de partículas que penetra para o interior de um ambiente, associada ao fluxo de infiltração de ar (Nazaroff, 2004). Esse fator descreve a quantidade de partículas que são filtradas pelas barreiras quando um determinado fluxo de ar penetra para o interior da sala através das portas 
(Chao et al., 2003). No caso de uma sala cirúrgica, as portas de acesso para o interior da sala são as fontes de infiltração de partículas provenientes de áreas adjacentes. Sendo assim, essas partículas podem ficar depositadas nas molduras das portas quando ocorre uma troca de ar com o ambiente interno.

O valor do coeficiente de infiltração varia de 0 a 1 e tende a ser unitário quando toda a porta é aberta. Assim, elevados coeficientes de infiltração indicam que uma elevada quantidade de partículas conseguiu passar através das portas. Quando a quantidade de partículas nas áreas adjacentes é elevada, a medição deste fator é uma informação importante para a proteção do ambiente interno contra a infiltração de partículas (Chao et al., 2003).

Grande parte dos estudos existentes na literatura é focada na infiltração de partículas do meio externo para o interior de edifícios e residências (Mosley et al., 2001; Thornburg, 2001; Thatcher e Layton, 1995; Wallace, 1996; Chao et al., 2003; Nazaroff, 2004; Vette et al., 2001).

Dois estudos importantes, Thatcher e Layton (1995) e Ozkaynak et al. (1996), concluíram que o fator de infiltração para partículas com diâmetro menor que $10 \mu \mathrm{m}$ possui valor unitário. Thatcher e Layton (1995) estudaram experimentalmente várias faixas de partículas: 1 a $3 \mu \mathrm{m}, 3$ a $6 \mu \mathrm{m}, 1$ a $5 \mu \mathrm{m}, 5$ a $10 \mu \mathrm{m}$ e 10 a $25 \mu \mathrm{m}$. Segundo esse estudo, se não há geração ou ressuspensão de partículas, o fator de infiltração é expresso em termos do nível de concentração de partículas do ambiente externo (áreas adjacentes), da concentração de partículas do ambiente interno e da relação entre a taxa de troca de ar e a taxa de deposição. Assim, este fator pode ser determinado pela seguinte equação:

$$
P=\left(\frac{C_{\text {int. }}}{C_{\text {ext. }}}\right) \frac{\lambda_{d}+\lambda_{\text {inf }}}{\lambda_{\text {inf }} .}
$$

onde

$C_{\text {int. }}=$ Concentração interna de partículas $\left(\right.$ partícula $\left./ \mathrm{cm}^{3}\right)$;

$C_{\text {ext. }}=$ Concentração externa (corredor) de partículas (partícula $\left./ \mathrm{cm}^{3}\right)$;

$\lambda_{d}=$ Taxa de deposição $\left(\mathrm{h}^{-1}\right)$;

$\lambda_{\text {inf } .}=$ Taxa de infiltração $\left(\mathrm{h}^{-1}\right)$.

A taxa de infiltração é obtida pela seguinte equação (Thatcher \& Layton, 1995):

$$
\lambda_{\mathrm{inf} .}=\frac{1}{t-t_{0}} \ln \left(\frac{C}{C_{0 .}}\right)
$$


onde

$$
\begin{aligned}
& \mathrm{t}_{0}=\text { tempo inicial } \\
& \mathrm{t}=\text { tempo final } \\
& \mathrm{C}=\text { concentração de partículas no tempo } \mathrm{t} \\
& \mathrm{C}_{0}=\text { concentração de partículas no tempo } \mathrm{t}_{0}
\end{aligned}
$$

A equação 4.8 se reduz à simples relação entre a concentração de partículas internas e externas quando a taxa de deposição é muito menor que a taxa de infiltração (Thatcher \& Layton, 1995).

\subsection{DEPOSIÇÃO DAS PARTÍCULAS NO INTERIOR DA SALA CIRÚRGICA}

O conhecimento da taxa de deposição é uma informação muito importante sobre as diferentes perdas de partículas que podem ocorrer em um ambiente interno (Chao et al., 2003). A maior parte dos estudos, que descrevem a deposição num determinado ambiente também foram realizados em edifícios e residências (Xu et al., 1994; Thatcher e Layton, 1995; Fogh et al., 1997; Vette et al., 2001; Mosley et al., 2001).

\subsection{TAXA DE DEPOSIÇÃO $\left(\lambda_{d}\right)$}

A taxa de deposição descreve a quantidade de partículas que se depositam sobre as superfícies por unidade de tempo. Segundo He et al. (2005), a taxa de deposição tem sido investigada por meio de modelos teóricos e estudos experimentais. Os estudos experimentais incluem investigações em câmaras de teste e residências. Em função da complexidade do fenômeno da deposição de partículas e da influência de vários fatores, é muito complicado medir a taxa de deposição diretamente em um determinado ambiente. Em função disso, os dados experimentais existentes são muito limitados (Howard-Reed et al., 2003).

Estudos mostram que não existe grande variabilidade dos valores das taxas de deposição obtidas em função do tamanho das partículas e também que não existe uma base de entendimento dos vários fatores que afetam a taxa de deposição em um determinado ambiente (Thatcher and Layton, 1995).

Alguns dos fatores que afetam a taxa de deposição em um ambiente são: tamanho das partículas, área e volume da sala, velocidade e movimentação do ar, número de trocas de ar (Wallace, 1996). Segundo Thatcher e Layton (1995), os efeitos da perda de partículas por deposição em um ambiente interno têm a mesma magnitude que a remoção de partículas 
obtida pela taxa de renovação de ar. Elevadas taxas de deposição ocorrem com partículas de tamanho grande. Num determinado estudo, para partículas com tamanhos acima de $25 \mu \mathrm{m}$, a perda de partículas por deposição foi 29 vezes maior que a remoção pela taxa de renovação (Thatcher e Layton, 1995).

A taxa de deposição pode ser calculada pela seguinte expressão proposta por Thatcher e Layton (1995):

$$
\lambda_{d}=\frac{1}{(t)} \ln \left(\frac{C_{i}}{C}\right)-\lambda_{\text {inf }}
$$

Embora esta equação não forneça informações sobre onde as partículas se depositam, ela é uma boa estimativa da taxa de deposição global para diferentes faixas de tamanho de partículas (Thatcher e Layton, 1995).

A figura 4.5 representa uma síntese do modelo e dos resultados experimentais obtidos por Riley et al. (2002) quanto à variação da taxa de deposição em função do diâmetro das partículas.

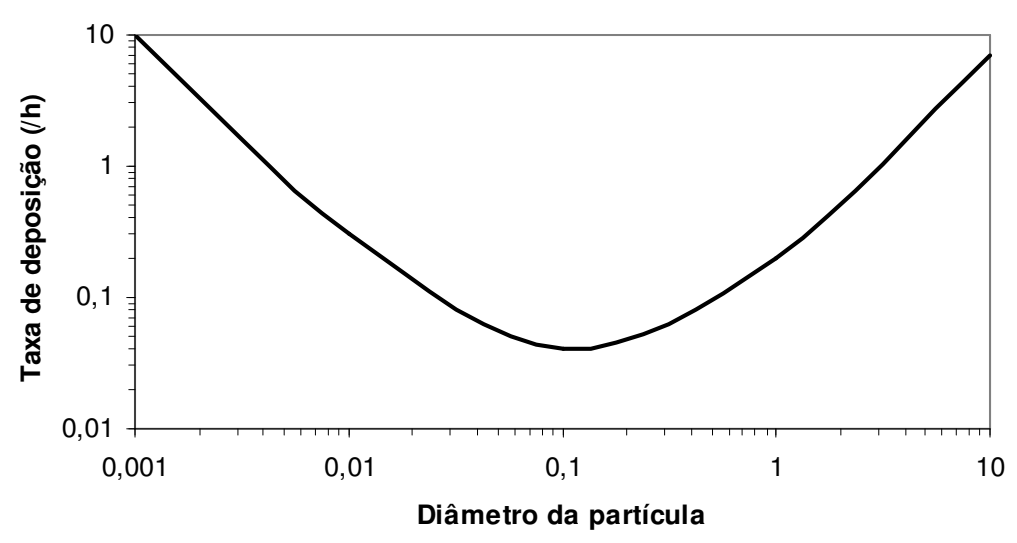

Figura 4.5 - Taxa de deposição em função do diâmetro das partículas (Riley et al., 2002).

\subsection{NÚMERO DE PESSOAS E NÍVEL DE ATIVIDADE}

A quantidade de partículas é diretamente proporcional ao número de pessoas e ao nível de atividade desenvolvido por essas pessoas na sala cirúrgica (Fitzgerald, 1979; Blakemore et al., 1979; Roy, 1997; Ritter, 1999; Quraishi et al., 1983; Wiley, 2001). Ao longo de um procedimento cirúrgico o número e o nível de atividade desenvolvida pelas pessoas presentes na sala variam. Por exemplo, no processo de preparação do campo cirúrgico e da indução anestésica, normalmente o número de pessoas é maior e o nível de atividade é mais intenso. Diferente do momento do ato cirúrgico, no qual a quantidade de pessoas é menor e o nível de atividades é menos intenso. A Tabela 4.1 mostra a quantidade de partículas 
maiores que $0,3 \mu \mathrm{m}$ que são geradas por um indivíduo realizando diferentes tipos de atividades (Torreira, 1985).

Tabela 4.1 - Partículas maiores que 0,3 $\mu$ m geradas em função do tipo de atividade (Torreira, 1985, adaptado).

\begin{tabular}{lc}
\hline Tipo de atividade & Partículas geradas por minuto \\
\hline Sentado ou em pé (sem movimento) & 100.000 \\
Sentado (ligeiro movimento de cabeça e braços) & 500.000 \\
Sentado (ligeiro movimento do corpo e pernas) & 1.000 .000 \\
Levantando-se a partir da posição sentada & 2.500 .000 \\
Caminhando a aproximadamente $1 \mathrm{~m} / \mathrm{s}$ & 5.000 .000 \\
Caminhando a aproximadamente $2 \mathrm{~m} / \mathrm{s}$ & 7.500 .000 \\
Caminhando depressa & 10.000 .000 \\
Subindo escada & 10.000 .000 \\
Exercício de ginástica & 15.000 .000 a 30.000 .000 \\
\hline
\end{tabular}

\subsection{INSUFLAMENTO DE AR}

Uma parcela da concentração de partículas existente no interior de uma sala cirúrgica é proveniente do sistema de condicionamento do ar. Porém, o insuflamento dessas partículas, pode ser controlado pelo sistema de filtragem. O sistema de filtragem desenvolve um papel fundamental no sentido de manter uma atmosfera controlada no espaço condicionado. $\mathrm{O}$ ar externo contém contaminantes, como bactérias, pólen, insetos, fuligens, cinzas, poeiras, etc. Da mesma forma o ar de retorno pode conter uma série de contaminantes. Desta forma, o sistema de filtragem torna-se a medida decisiva que define a qualidade do ar (Morawska et al., 1998).

\subsection{RETORNO DE AR}

O retorno de ar também exerce uma função importante na eliminação dos contaminantes gerados no interior de uma sala cirúrgica. Para se manter uma pressão positiva no interior da sala a quantidade de ar que é insuflado deve ser maior que a quantidade que retorna. Nos sistemas que não operam dessa forma ocorre um déficit e o ambiente não está mais em suprimento proporcional aos corredores; o que pode acarretar a entrada de ar contaminado de outros ambientes. 


\section{CAPÍTULO 5}

\section{MODELO PARA PREDIÇÃO DA CONCENTRAÇÃO DE PARTÍCULAS}

Modelos matemáticos podem ser usados para prever a média das concentrações de poluente do ar em recintos fechados, em função das fontes externas e internas, características do ambiente e dos poluentes. A grande maioria desses modelos é baseada no balanço de massa das partículas (Spaarks, 1996; Law e Owen, 1994; Jamriska et al., 2000, 2001; Nazarrof , 2004; Nazarrof e Cass, 1989, 1986; Chao et al., 2003; Thatcher e Layton, 1995). Conhecidos como modelos de equilíbrio de massa ou modelos de balanço de massa, esses modelos apresentam uma visão macroscópica do problema, calculando a média das concentrações em diferentes zonas de um ambiente. Esta técnica de modelação é bastante utilizada na predição da concentração de poluentes, devido à simplicidade da matemática envolvida.

Contudo, ainda são poucos os trabalhos que utilizam a modelação por balanço de massa para a predição da concentração de partículas em ambientes cirúrgicos (Jamariska et al, 2000; Salvigni et al, 1996). É mais freqüente a utilização de CFD com esse fim (Chen et al, 1992; Chow and Yang, 2003; Hartung et al, 1998; Kameel, 2003; Memarzadeh and Jiang, 2000).

Para a utilização desta técnica de modelação algumas hipóteses devem ser satisfeitas, e a principal delas é que a concentração dos contaminantes seja uniforme no ambiente. É importante observar que a concentração em um edifício pode ser extremamente variável, principalmente quando as fontes de contaminação estão próximas ao edifício. Devido a isto, a utilização de um valor médio que representa a concentração no ambiente externo pode conduzir a uma série de inexatidões nos resultados produzidos pelos modelos de balanço de massa. Porém, em salas cirúrgicas o impacto do ambiente externo é bastante pequeno, devido à localização do centro cirúrgico no edifício e ao sistema de condicionamento de ar. 
Segundo Milner et al. (2004), em ambientes de tamanho médio, pode-se considerar na modelagem por balanço de massa a existência de zonas bem-misturadas internamente, desde que a mistura entre os ambientes seja mais rápida que as trocas que ocorrem entre os ambientes e as paredes, que agem como partições de cada zona. Já em ambientes muito grandes, com ventilação e/ou fontes de contaminação localizadas, podem produzir gradientes de concentração significativos no espaço. Assim, pode ser impróprio considerar-se um ambiente desse tipo como um único compartimento bem-misturado, pois este tipo de configuração tende a subestimar as concentrações próximas às fontes (Sohn et al., 1999; Milner et al., 2004). Além disso, em alguns casos, particularmente em grandes ambientes, o ar pode não ser bem misturado ao longo do tempo (Kulkarni e Patil, 2002; Gadgil et al., 2003).

Para resolver o problema da falta de uniformidade da mistura do ar em algumas situações, alguns autores (Esmen, 1978; Feigley et al., 2002; Milner et al., 2004) sugerem a introdução, nas equações de balanço de massa, de um "fator de mistura", que é definido como a fração do ar de ventilação completamente misturado em um ambiente (Milner et al., 2004).

\subsection{DESCRIÇÃO DO MODELO GERAL}

A equação de balanço de massa para um volume de controle (Figura 5.1) estabelece que a concentração em massa de partículas que entram em um volume de controle, mais a concentração gerada no interior de um volume de controle, menos a concentração que deixa um volume de controle e a quantidade removida internamente, deve ser igual à concentração que permanece no interior do volume do controle:

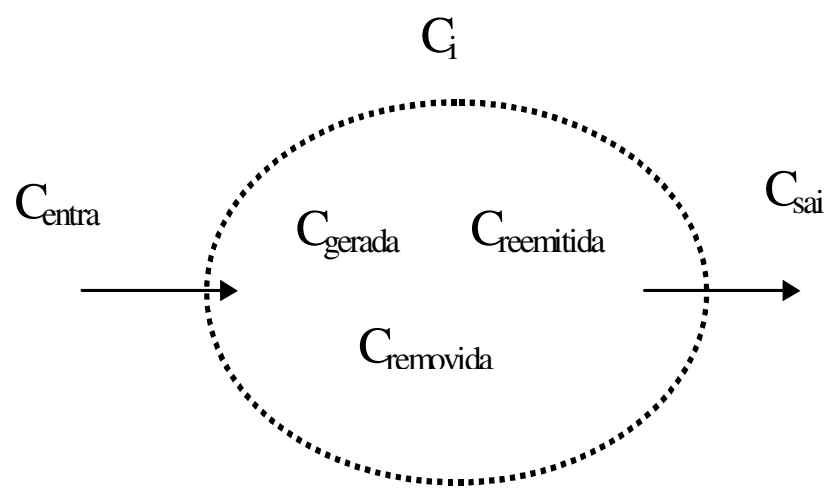

Figura 5.1 - Diagrama de balanço de massa

Em geral, a equação de balanço de massa representa a variação da concentração interna, $\mathrm{C}_{\mathrm{i}}$, com volume, $\mathrm{V}$, ao longo do tempo, $\mathrm{t}$, podendo ser escrita da seguinte forma: 
$V \frac{d C_{i}}{d t}=$ [concentração de partículas que entram] + [concentração gerada internamente: $V \frac{d c_{i}}{d t}=$ pessoas, procedimento] + [concentração reemitida internamente: ressuspensão] - [massa removida internamente: deposição] - [concentração de partículas que saem: filtragem, fugas]

Na Figura 5.2, são representados os fatores que afetam na variação da concentração de partículas no interior de uma sala cirúrgica.

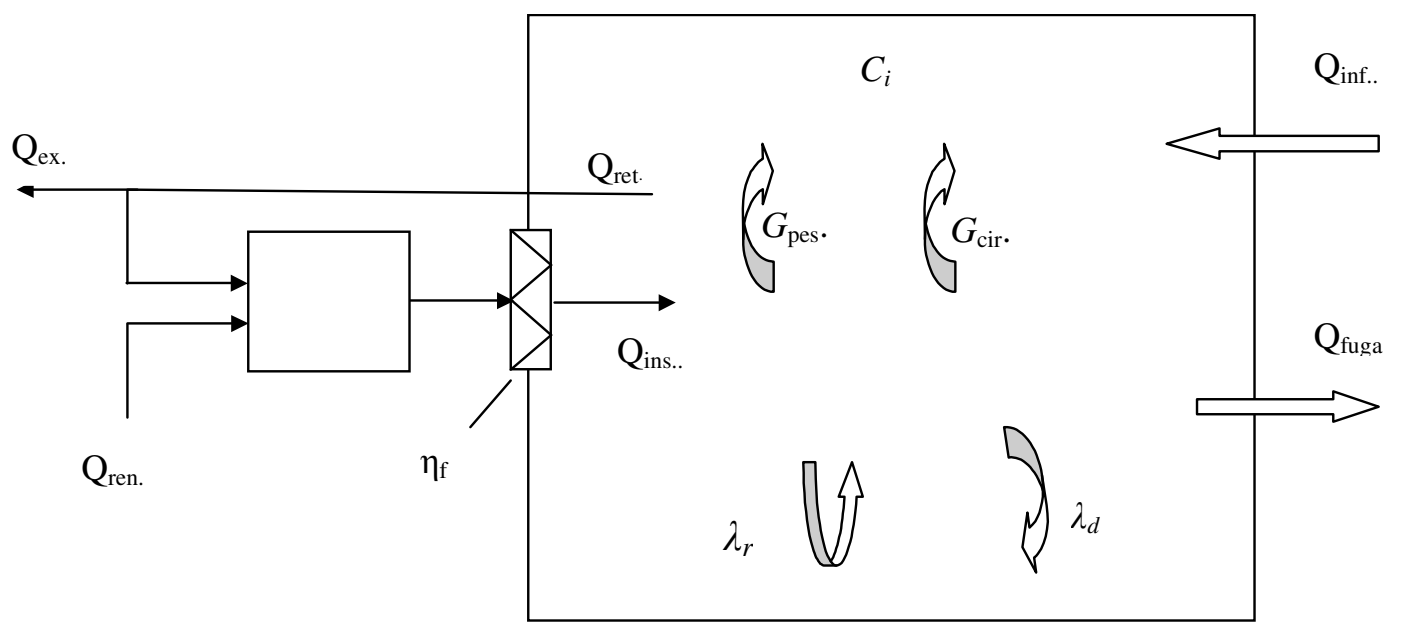

Figura 5.2- Fatores que afetam na variação da concentração de partículas

Analisando a Figura 5.2, cada termo da equação 5.1 pode ser expresso da seguinte forma:

$$
V \frac{d C_{i}}{d t}=\left[P Q_{\text {inf. }} C_{e x t .}+Q_{\text {ins. }} C_{\text {ins. }}+N G_{\text {pes. }}+G_{\text {cir. }}+\lambda_{r} V C_{r}\right]-\left[Q_{\text {ret. }} C_{i}+Q_{\text {fuga }} C_{i}+\lambda_{d} V C_{i}\right]
$$

onde:

$C_{i}=$ concentração de partículas no interior da sala $\left(\right.$ partículas $\left./ \mathrm{m}^{3}\right)$;

$C_{e x t}=$ concentração de partículas no exterior da sala - áreas adjacentes (partículas $/ \mathrm{m}^{3}$ );

$C_{\text {ins. }}=$ concentração de partículas no insuflamento de $\operatorname{ar}\left(\right.$ partículas $/ \mathrm{m}^{3}$ );

$\mathrm{C}_{\mathrm{r}}=$ concentração de partículas ressuspensas (partículas $/ \mathrm{m}^{3}$ )

$V=$ volume da sala $\left(\mathrm{m}^{3}\right)$;

$G_{\text {pes. }}=$ partículas geradas pelas pessoas (partículas/h);

$N=$ número de pessoas;

$G_{\text {cir. }}=$ partículas geradas pelo procedimento cirúrgico (partículas $\left./ \mathrm{h}\right) ;$

$\mathrm{Q}_{\text {inf. }}=$ vazão volumétrica de ar que entra na sala $\left(\mathrm{m}^{3} / \mathrm{h}\right)$;

$\mathrm{Q}_{\text {fuga }}=$ vazão volumétrica de ar que sai da sala $\left(\mathrm{m}^{3} / \mathrm{h}\right)$; 
$Q_{\text {ret. }}=$ vazão volumétrica de ar de retorno $\left(\mathrm{m}^{3} / \mathrm{h}\right)$;

$P=$ fator de infiltração

$\lambda_{d}=$ taxa de deposição $\left(\mathrm{h}^{-1}\right)$;

$\lambda_{r}=$ fator de ressuspensão $\left(\mathrm{h}^{-1}\right)$;

Os termos positivos do lado direito da equação representam as fontes de geração de partículas, e os termos negativos representam as perdas e remoções. Assume-se que as partículas estão perfeitamente misturadas por todo o espaço do ambiente interno, isto é, a concentração de partículas é uniforme ao longo do volume (Nazarrof, 2004; Nazarrof e Cass, 1989).

Para cada faixa de tamanho de partículas, a solução da Equação 5.2 fica escrita da seguinte forma:

$$
\begin{aligned}
& C_{i}=\frac{P Q_{\text {inf. }} C_{\text {ext. }}+Q_{\text {ins. }} C_{\text {ins. }}+N G_{\text {pes. }}+G_{\text {cir. }}+\lambda_{r} V C_{r}}{Q_{\text {ret. }}+Q_{\text {fuga }}+\lambda_{d} V}\left[1-\exp \left(-\frac{Q_{\text {ret. }}+Q_{\text {fuga }}+\lambda_{d} V}{V} t\right)\right]+ \\
& +C_{0_{i}}\left[1-\exp \left(-\frac{Q_{\text {ret. }}+Q_{\text {fuga }}+\lambda_{d} V}{V} t\right)\right]
\end{aligned}
$$

onde $C_{0 i}$ é a concentração inicial no interior da sala.

Como se observa, a equação 5.3 é dividida em duas partes: uma onde os termos estão em regime permanente e a outra em regime transiente.

Desta forma, se a concentração interna das partículas consideradas estiver em regime permanente, a equação pode ser escrita da seguinte forma:

$$
C_{i}=\frac{P Q_{\text {inf. }} C_{\text {ext. }}+Q_{\text {ins. }} C_{\text {ins. }}+N G_{\text {pes. }}+G_{\text {cir. }}+\lambda_{r} V C_{r}}{Q_{\text {ret. }}+Q_{\text {fuga }}+\lambda_{d} V}+C_{o i}
$$

\subsection{CONFIGURAÇÕES DE SISTEMAS DE CONDICIONAMENTO E FILTRAGEM DO AR}

Na obtenção dos modelos que descrevem a concentração de partículas no interior da sala cirúrgica, o tipo e a localização do sistema de filtragem e a existência ou não de renovação de ar são informações importantes na definição do volume de controle, a partir do qual será feito o balanço de massa para a obtenção do modelo. Estes parâmetros exercem grande influência no processo de remoção das partículas do interior do ambiente e também na 
quantidade de partículas que podem penetrar para o ambiente através do ar de renovação (ar externo) e do ar de recirculação. A seguir, apresentam-se três configurações básicas de sistemas existentes na grande maioria das salas cirúrgicas estudadas.

\subsubsection{Sistemas com recirculação sem renovação de ar}

Nesses sistemas, o ar do interior do ambiente apenas recircula no ambiente, não existindo mecanismos de filtragem e renovação do ar. Os únicos processos de perdas de partículas do interior da sala são os processos de deposição e fugas pelas portas. Com esse tipo de configuração, estudou-se um sistema de ar condicionado de janela.

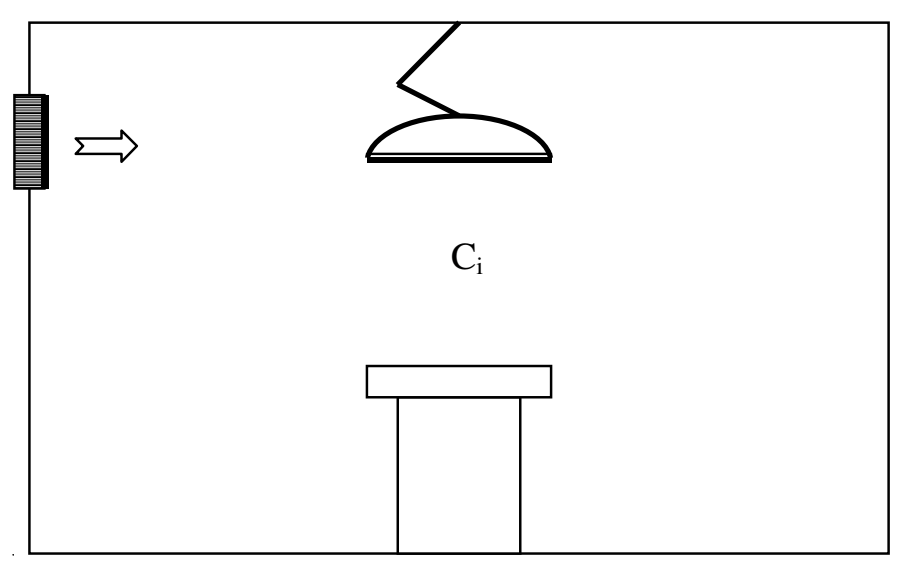

Figura 5.3 - Sistema sem renovação e sem recirculação de ar

Assim, para este tipo de sistema o equacionamento é dado em função dos parâmetros associados à geração interna e às perdas internas e para o exterior, fincando da seguinte forma:

$$
V \frac{d C_{i}}{d t}=\left[P Q_{\text {inf. }} C_{e x t .}+N G_{p e s .}+G_{c i r .}+\lambda_{r} V C_{r}\right]-\left[Q_{f u g a} C_{i}+\lambda_{d} V C_{i}\right]
$$

Da mesma forma, para cada faixa de tamanho de partículas a solução da equação 5.5 fica escrita da seguinte forma: 


$$
\begin{aligned}
& C_{i}=\frac{P Q_{\text {inf. }} C_{\text {ext. }}+\mathrm{N} G_{\text {pes. }}+G_{\text {cir. }}+\lambda_{r} V C_{r}}{+Q_{\text {fuga }}+\lambda_{d} V}+\left[1-\exp \left(-\frac{Q_{\text {fuga }}+\lambda_{d} V}{V} t\right)\right]+ \\
& +C_{0_{i}}\left[1-\exp \left(-\frac{Q_{\text {fuga }}+\lambda_{d} V}{V} t\right)\right]
\end{aligned}
$$

Em regime permanente, a equação (5.6) pode ser escrita da seguinte forma:

$$
C_{i}=\frac{P Q_{\text {inf. }} C_{e x t .}+\mathrm{N} G_{\text {pes. }}+G_{\text {cir. }}+\lambda_{r} V C_{r}}{+Q_{\text {fuga }}+\lambda_{d} V}+C_{o i}
$$

\subsubsection{Sistemas sem recirculação e com $100 \%$ de ar externo}

Na Figura 5.4, tem-se um exemplo de sistema sem recirculação de ar. O ar que é insuflado para o interior do ambiente, $Q_{\text {inf. }}$, é constituido exclusivamente por ar externo. Toda a contaminação por partículas que é removida pelo retorno de ar é exaurida para o meio externo. Desta forma, neste caso, os filtros têm a função de remover apenas as partículas provenientes do ar externo. A maioria dos sistemas constantes deste estudo (insuflamento pela parede e retorno próximo ao piso, insuflamento e retorno pelo teto, insuflamento pelo teto e retorno próximo ao piso) apresentam essa configuração.

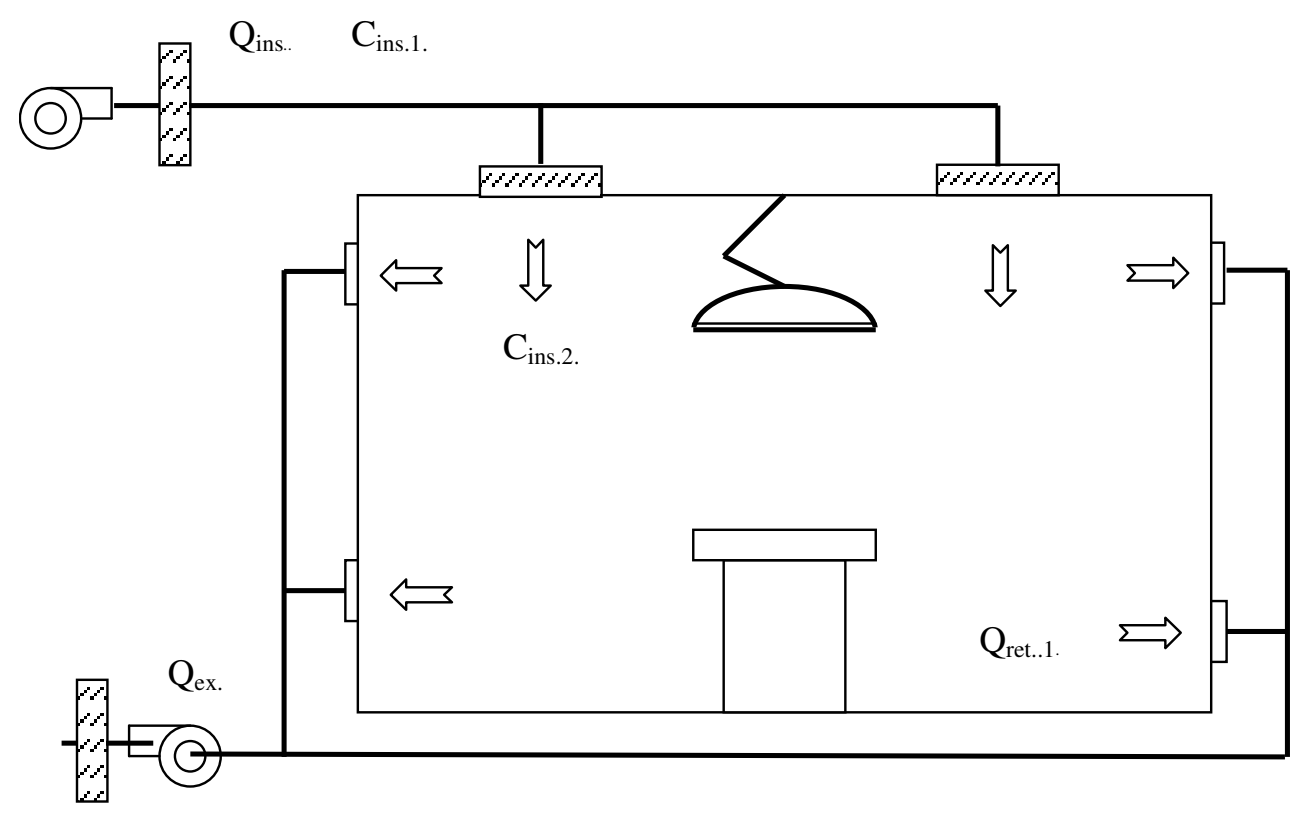

Figura 5.4 - Sistema sem recirculação de ar (100\% ar externo) 
Levando-se em consideração o insuflamento de $100 \%$ de ar externo e a localização do sistema de filtragem, o equacionamento deste sistema é dado da seguinte forma:

$$
V \frac{d C_{i}}{d t}=\left[P Q_{\text {inf. }} C_{e x t .}+\eta_{f} Q_{i n s .1} C_{i n s .1}+\mathrm{N} G_{p e s .}+G_{\text {cir. } .}+\lambda_{r} V C_{r}\right]-\left[Q_{\text {ret. } 1 .} C_{i}+Q_{\text {fuga }} C_{i}+\lambda_{d} V C_{i}\right]
$$

ou

$$
V \frac{d C_{i}}{d t}=\left[P Q_{\text {inf. }} C_{e x t .}+Q_{i n s .1} C_{i n s .2}+\mathrm{N} G_{p e s .}+G_{c i r .}+\lambda_{r} V C_{r}\right]-\left[Q_{r e t .1 .} C_{i}+Q_{\text {fuga }} C_{i}+\lambda_{d} V C_{i}\right]
$$

Para cada faixa de tamanho de partículas a solução das equações 5.8 e 5.9 fica da seguinte forma:

$$
\begin{aligned}
& C_{i}=\frac{P Q_{\text {inf. }} C_{\text {ext. }}+\eta_{f} Q_{\text {ins. }} C_{\text {ins. } 1}+\mathrm{NA} G_{\text {pes. }}+G_{\text {cir. }}+\lambda_{r} V C_{r}}{Q_{\text {ret. }}+Q_{\text {fuga }}+\lambda_{d} V} \\
& {\left[1-\exp \left(-\frac{Q_{\text {ret. } 1}+Q_{\text {fuga }}+\lambda_{d} V}{V} t\right)\right]+C_{0_{i}}\left[1-\exp \left(-\frac{Q_{\text {ret. } 1}+Q_{\text {fuga }}+\lambda_{d} V}{V} t\right)\right]}
\end{aligned}
$$

ou

$$
\begin{aligned}
& C_{i}=\frac{P Q_{\text {inf. }} C_{\text {ext. }}+Q_{\text {ins. }} C_{\text {ins. } 2}+\mathrm{NA} G_{\text {pes. }}+G_{\text {cir. }}+\lambda_{r} C_{r}}{Q_{\text {ret. }}+Q_{\text {fuga }}+\lambda_{d} V} \\
& {\left[1-\exp \left(-\frac{Q_{\text {ret. } 1}+Q_{\text {fuga }}+\lambda_{d} V}{V} t\right)\right]+C_{0_{i}}\left[1-\exp \left(-\frac{Q_{\text {ret. } 1}+Q_{\text {fuga }}+\lambda_{d} V}{V} t\right)\right]}
\end{aligned}
$$

Em regime permanente, as equações (5.10) e (5.11) podem ser escritas da seguinte forma:

$$
\begin{gathered}
C_{i}=\frac{P Q_{\text {inf. }} C_{e x t .}+\eta_{f} Q_{\text {ins. }} C_{\text {ins. } 1}+\mathrm{NA} G_{\text {pes. }}+G_{\text {cir. }}+\lambda_{r} V C_{r}}{Q_{\text {ret. }}+Q_{\text {fuga }}+\lambda_{d} V}+C_{o i} \\
C_{i}=\frac{P Q_{\text {inf. }} C_{\text {ext. }}+Q_{\text {ins. }} C_{\text {ins. } 2}+\mathrm{NA} G_{\text {pes. }}+G_{\text {cir. }}+\lambda_{r} C_{r}}{Q_{\text {ret. }}+Q_{\text {fuga }}+\lambda_{d} V}+C_{o i}
\end{gathered}
$$




\subsubsection{Sistemas com recirculação e renovação de ar}

$\mathrm{Na}$ Figura 5.5, tem-se um exemplo de sistema de condicionamento de ar com recirculação de ar. O ar que é insuflado para o interior do ambiente, Qinf., é constituido por uma mistura do ar de retorno, $\mathrm{Q}_{\text {ret. }}$ e de ar externo, $\mathrm{Q}_{\text {ren. }} \mathrm{O}$ ar, antes de ser insuflado para o ambiente, passa através de um filtro com eficiência $\eta_{\mathrm{f}}$. Grande parte da contaminação de partículas existentes no interior do ambiente é removida pelo sistema de condicionamento de ar, através da linha de retorno $\mathrm{Q}_{\text {ret. }}$.

Por meio do processo de renovação de ar, consegue-se uma eliminação significativa dos poluentes gerados internamente, ou uma redução da concentração a níveis mais aceitáveis. E os filtros têm a função de remover as partículas provenientes do ar que retorna do ambiente e do meio externo.

Destaca-se que, esse tipo de configuração não aparece entre os casos selecionados para o desenvolvimento deste estudo. Porém, como se visa fornecer uma ferramenta de predição abrangente, incluem-se também as equações relativas a essa configuração.

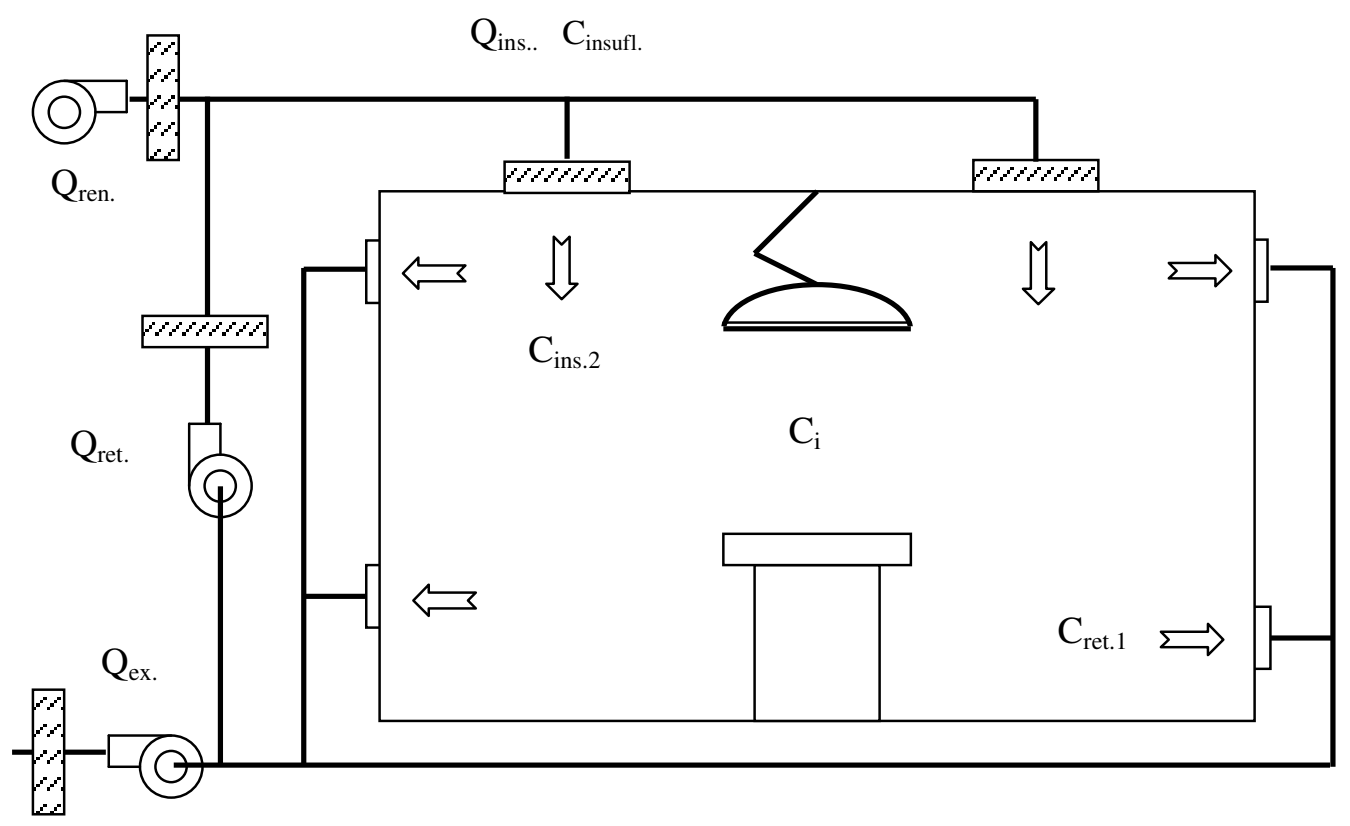

Figura 5.5 - Sistema com recirculação de ar

Da mesma forma que no item anterior, levando-se em consideração a recirculação do ar e o posicionamento do sistema de filtragem, juntamente com os demais parâmetros que influenciam na concentração de partículas no interior da sala, o equacionamento deste sistema fica da seguinte forma: 
$V \frac{d C_{i}}{d t}=\left[P Q_{\text {inf. }} C_{\text {ext. }}+\eta_{f} Q_{\text {ins. }}\left(C_{\text {ins. } 1}\right)+N G_{\text {pes. }}+G_{\text {cir. }}+\lambda_{r} V C_{r}\right]-\left[Q_{\text {ret. } 1} C_{i}+Q_{\text {fuga } a} C_{i}+\lambda_{d} V C_{i}\right](5$

A equação 5.14 também pode ser escrita em função da concentração de insuflamento obtida após o filtro (interior da sala).

$$
V \frac{d C_{i}}{d t}=\left[P Q_{\text {inf. }} C_{\text {ext. }}+Q_{i n s .}\left(C_{i n s .2}\right)+N G_{p e s .}+G_{\text {cir. }}+\lambda_{r} V C_{r}\right]-\left[Q_{r 1} C_{i}+Q_{\text {fuga }} C_{i}+\lambda_{d} V C_{i}\right](5.1
$$

Para cada faixa de tamanho de partículas, a solução das equações 5.14 e 5.15 fica da seguinte forma:

$$
\begin{aligned}
& C_{i}=\frac{P Q_{\text {inf. }} C_{\text {ext. }}+\eta_{f} Q_{\text {ins. }} C_{\text {ins. } 1}+N G_{\text {pes. }}+G_{\text {cir. }}+\lambda_{r} V C_{r}}{Q_{\text {ret. } 1}+Q_{\text {fuga }}+\lambda_{d} V} \\
& {\left[1-\exp \left(-\frac{Q_{\text {ret.1 }}+Q_{\text {fuga }}+\lambda_{d} V}{V} t\right)\right]+C_{0_{i}}\left[1-\exp \left(-\frac{Q_{\text {ret. } 1}+Q_{\text {fuga }}+\lambda_{d} V}{V} t\right)\right]} \\
& \mathrm{Ou} \\
& C_{i}=\frac{P Q_{\text {inf. }} C_{\text {ext. }}+Q_{\text {ins. }} C_{\text {ins. } .2}+N G_{\text {pes. }}+G_{\text {cir. }}+\lambda_{r} V C_{r}}{Q_{\text {ret. } 1}+Q_{\text {fuga }}+\lambda_{d} V} \\
& {\left[1-\exp \left(-\frac{Q_{\text {ret. } 1}+Q_{\text {fuga }}+\lambda_{d} V}{V} t\right)\right]+C_{0_{i}}\left[1-\exp \left(-\frac{Q_{\text {ret. .1 }}+Q_{\text {fuga }}+\lambda_{d} V}{V} t\right)\right]}
\end{aligned}
$$

Em regime permanente, as equações (5.16) e (5.17) podem ser escritas da seguinte forma:

$$
\begin{gathered}
C_{i}=\frac{P Q_{\text {inf. }} C_{\text {ext. }}+\eta_{f} Q_{\text {ins. }} C_{\text {ins. } 1}+N G_{\text {pes. }}+G_{\text {cir. }}+\lambda_{r} V C_{r}}{Q_{\text {ret. } 1}+Q_{\text {fuga }}+\lambda_{d} V}+C_{o i} \\
C_{i}=\frac{P Q_{\text {inf. }} C_{\text {ext. }}+Q_{\text {ins. }} C_{\text {ins. } 2}+N G_{\text {pes. }}+G_{\text {cir. }}+\lambda_{r} V C_{r}}{Q_{\text {ret. } .1}+Q_{\text {fuga }}+\lambda_{d} V}+C_{o i}
\end{gathered}
$$




\section{CAPÍTULO 6}

\section{METODOLOGIA EXPERIMENTAL}

Neste capítulo será descrita a metodologia experimental utilizada para a obtenção dos dados experimentais, para os diferentes sistemas de condicionamento de ar estudados e para as condições específicas: portas fechadas e sistema de condicionamento de ar desligado, portas abertas e sistema de condicionamento de ar desligado, portas fechadas e sistema de condicionamento de ar ligado e portas abertas e sistema de condicionamento de ar ligado.

\subsection{MÉTODO DE TRABALHO}

Inicialmente, colheram-se dados no Centro Cirúrgico do Hospital Universitário da Universidade de São Paulo. Estes serviram para o desenvolvimento da metodologia de medição proposta, para melhor compreensão da utilização do modelo e também para definir os procedimentos de análise.

Após selecionados os fatores, identificaram-se as variáveis a eles relacionadas e definiu-se a metodologia para sua medição. Foram definidas quatro condições para estudo, baseadas na rotina de trabalho das salas cirúrgicas:

a) sistema de condicionamento de ar desligado e portas da sala cirúrgica fechadas;

b) sistema de condicionamento de ar desligado e portas da sala cirúrgica abertas;

c) sistema de condicionamento de ar ligado e portas da sala cirúrgica fechadas;

d) sistema de condicionamento de ar ligado e portas da sala cirúrgica abertas.

Mediram-se as variáveis listadas abaixo:

a) relativas à sala cirúrgica: volume da sala, taxa de deposição, taxa de infiltração, fator de infiltração;

b) relativas ao sistema de condicionamento de ar: vazão de insuflamento, vazão de retorno;

c) relativas à cirurgia: número de pessoas, duração; 
d) relativas às partículas: concentração e tamanho de partículas no interior da sala, concentração e tamanho de partículas no corredor, concentração e tamanho de partículas na saída do insuflamento do sistema de condicionamento de ar.

Algumas dessas variáveis foram medidas antes do procedimento cirúrgico ${ }^{1}$ e outras durante o procedimento. Antes do procedimento, com a sala vazia, obtiveram-se as medidas para cálculo do volume da sala e mediram-se os valores de sedimentação, para calcular a taxa de deposição para cada diâmetro de partículas analisado. Da mesma forma, obteve-se a taxa e o fator de infiltração, pela medição da infiltração através da porta. Também foram obtidas as vazões de insuflamento e retorno do sistema de condicionamento de ar. Durante a cirurgia, foi medida a temperatura do ar, sua velocidade nas posições descritas na Figura 6.4 e a concentração e tamanho das partículas no interior da sala próximo à área cirúrgica, próximo ao insuflamento de ar e no corredor.

Para os demais sistemas estudados, foram adotadas apenas a terceira e a quarta das condições citadas, pois nos demais centros cirúrgicos, dada a natureza das cirurgias acompanhadas, não seria recomendável desligar-se o sistema de condicionamento de ar.

Destaca-se que a temperatura e a velocidade do ar no interior da sala cirúrgica foram medidas para verificação da homogeneidade do ar, mas essas grandezas não foram utilizadas no modelo. A Figura 6.1 ilustra o procedimento de medição, especificando os parâmetros considerados.

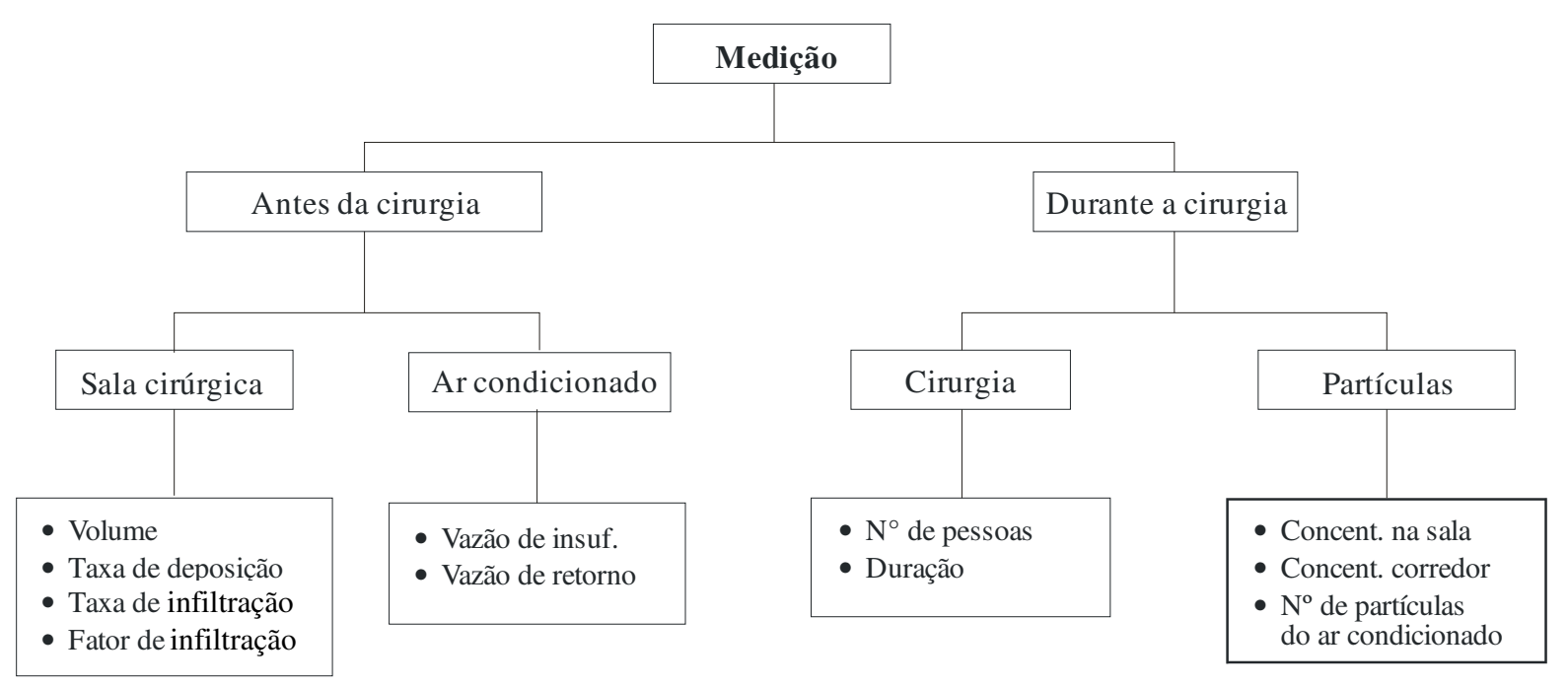

Figura 6.1 - Parâmetros considerados na medição.

\footnotetext{
1 Neste estudo, "procedimento cirúrgico" refere-se a todo o trabalho realizado no interior da sala cirúrgica, desde a entrada do paciente até a sua remoção. Compreende, portanto, a preparação para a cirurgia (indução anestésica, colocação dos campos cirúrgicos etc.), o ato cirúrgico (a cirurgia em si, cujo final corresponde à retirada dos campos cirúrgicos) e a remoção do paciente.
} 
Como forma de tornar o estudo mais abrangente e representativo e também verificar a aplicabilidade do modelo proposto, buscou-se efetuar as medições em diferentes centros cirúrgicos, em salas cirúrgicas com características diversas quanto ao tamanho da sala, ao posicionamento e tamanho das portas, ao tipo de sistema de condicionamento de ar, etc. São os seguintes os sistemas de condicionamento de ar analisados neste estudo:

a) insuflamento pela parede e retorno próximo ao piso (Centro Cirúrgico do Hospital Universitário da Universidade de São Paulo);

b) insuflamento e retorno pelo teto (Setor de Obstetrícia do Hospital Universitário da Universidade de São Paulo);

c) insuflamento pelo teto e retorno próximo ao piso (Centro Cirúrgico do Hospital Geral de Itapecerica da Serra, SP);

d) ar condicionado de janela (Centro Cirúrgico do Hospital Nereu Ramos).

\subsection{VALIDAÇÃO DA METODOLOGIA DE MEDIÇÃO}

A validação da metodologia de medição foi feita por meio da análise da incerteza de medição dos dados medidos. As incertezas de medição são um parâmetro que caracteriza a dispersão dos valores medidos de uma grandeza específica (Scottish Quality Assurance Specialist Interest Group, 2002). Nesse estudo todas as variáveis medidas são independentes, assim as estimativas das incertezas de medição dos dados medidos em campo foram baseadas nas incertezas fornecidas pelos fabricantes dos equipamentos por meio dos respectivos certificados de calibração.

\subsection{APRESENTAÇÃO DOS DADOS EXPERIMENTAIS}

Para organização dos resultados experimentais (Capítulo 8), buscou-se primeiramente tratar dos dados relativos aos ambientes cirúrgicos e aos sistemas de condicionamento de ar utilizados. Assim, inicialmente, caracterizaram-se as salas cirúrgicas quanto a áreas (piso e paredes), volume, dados das portas (número, dimensões), tipo de sistema de condicionamento de ar utilizado e quanto a alguns parâmetros calculados (taxa de deposição, taxa de infiltração e fator de infiltração). A seguir, caracterizaram-se os sistemas de condicionamento de ar quanto à configuração (posição do insuflamento e do retorno, quando há) e quanto às vazões. Em seguida, apresentam-se, mediante gráficos, os dados relativos à concentração de partículas (variação da concentração de partículas ao longo do tempo, relação entre a concentração e a 
média das concentrações, comparação entre as concentrações nas salas cirúrgicas e nos corredores adjacentes).

\subsection{MEDIÇÃO DAS VARIÁVEIS E APARATO EXPERIMENTAL}

Para que todas as medições fossem realizadas em pontos representativos do ambiente - sem interferir nas atividades realizadas na sala, principalmente durante o procedimento cirúrgico - para o posicionamento dos equipamentos, considerou-se a sala dividida em duas zonas de medição: o macro ambiente, que representa a zona periférica da sala, e o micro ambiente, que representa a zona estéril da sala. Este tipo de configuração, mostrado na Figura 6.2, é uma adaptação da proposta de Woods (1986). Assim, no macroambiente, mediu-se o campo de distribuição de temperatura e de velocidade e, no microambiente, mediu-se a concentração de partículas.

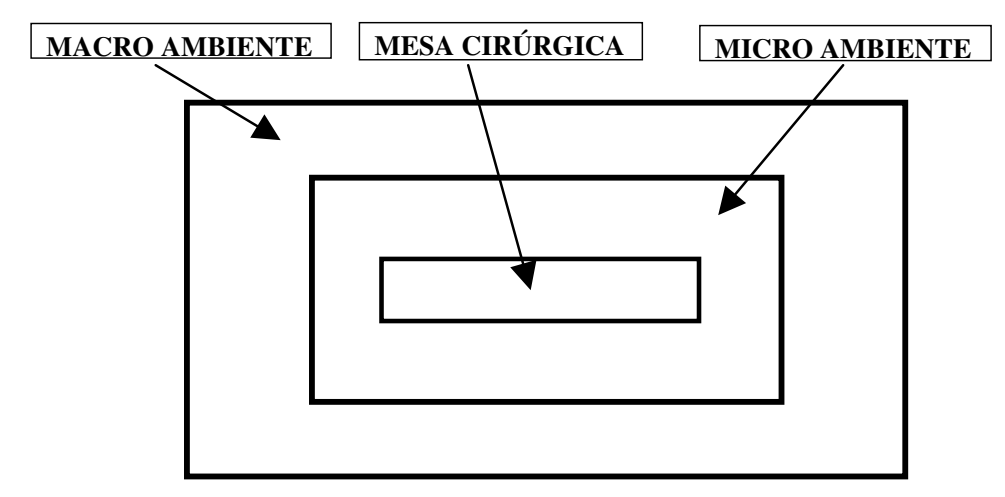

Figura 6.2 - Zonas de medições (Woods, 1986).

O objetivo dessa configuração foi permitir um melhor entendimento da dinâmica da movimentação do ar. O posicionamento dos equipamentos para aquisição de dados foi baseado nas orientações dadas pelos responsáveis do centro cirúrgico, visando não interferir com os procedimentos cirúrgicos.

\subsubsection{Sedimentação}

Para medição da sedimentação, eram geradas partículas no interior da sala, com a porta fechada e sistema de condicionamento de ar desligado. As partículas eram geradas mediante a agitação vigorosa de uma flanela. Após a geração, foram feitas medições com contador de partículas a intervalos de 5 minutos, durante 1 hora. O contador de partículas foi 
posicionado no centro da sala, a uma altura de 1 metro. Com os valores de sedimentação, calculou-se a taxa de deposição para cada diâmetro de partícula analisado.

\subsubsection{Infiltração}

A medição da infiltração era realizada com o ar desligado e a porta aberta. Posicionava-se um contador de partículas no meio do corredor, em frente à porta da sala cirúrgica, e outro no centro da sala cirúrgica, ambos a uma altura de $1 \mathrm{~m}$ do piso. Depois, foram geradas partículas no corredor também mediante a agitação vigorosa de uma flanela. Após a geração, também foram feitas medições com contador de partículas a intervalos de 5 minutos, durante 1 hora. Com esses dados, obteve-se o fator de infiltração.

\subsubsection{Temperatura e velocidade do ar no interior da sala}

A distribuição e a movimentação do ar no ambiente podem ser influenciadas por gradientes térmicos, ilhas estáticas e correntes de convecção. Esses fenômenos caracterizam uma falta de uniformidade nas condições de mistura do ar no interior da sala cirúrgica. Por isso, a temperatura e a velocidade do ar foram medidas em vários pontos da sala para a obtenção do campo de distribuição de temperaturas e velocidades.

$\mathrm{Na}$ medição de temperatura do ar foram utilizados sensores do tipo NTC, com condicionador de sinal 0-5 DCV, incerteza $\pm 0,2{ }^{\circ} \mathrm{C}$. Os sensores de velocidade do ar são do tipo termoanemômetro omnidirecional com faixa de medição de 0,03 a $3 \mathrm{~m} / \mathrm{s}$ e incerteza de $\pm 0,03 \mathrm{~m} / \mathrm{s}$. A Figura 6.3 ilustra os sensores de temperatura e velocidade do ar utilizados.

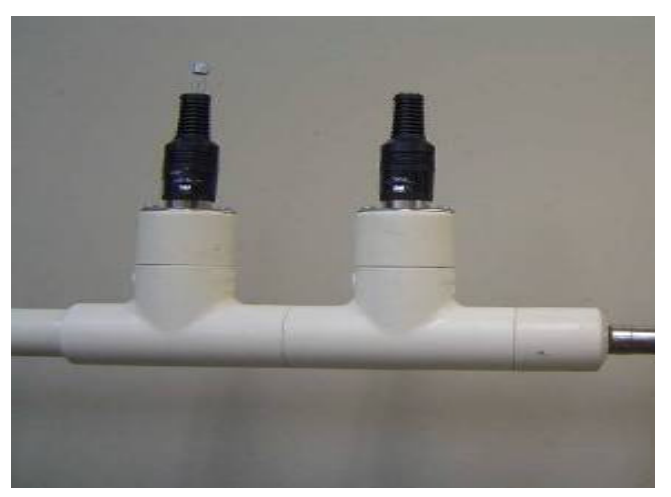

Figura 6.3 - Sensores de temperatura e velocidade do ar.

Os sensores foram fixados em suportes apropriados e foram distribuídos no macro ambiente, cobrindo toda área periférica da sala, como se pode ver na Figura 6.4. 


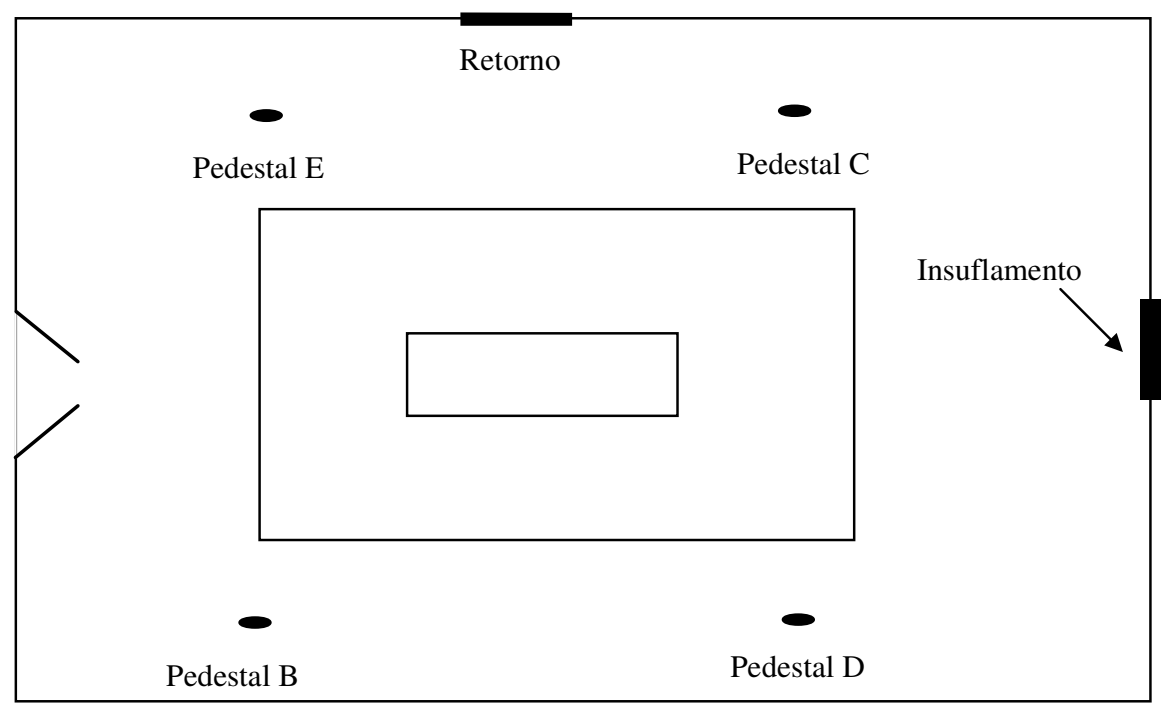

Figura 6.4 - Distribuição dos pontos de medição de temperaturas e velocidades.

Como mostrado na Figura 6.5, foram realizadas medidas em quatro posições e em quatro alturas eqüidistantes, totalizando 16 pontos. Em cada ponto, as variáveis temperatura e velocidade do ar, foram medidas nos níveis de 0,$66 ; 1,24 ; 1,83 ; 2,43 \mathrm{~m}$ do piso. A Figura 6.6 ilustra um exemplo de um suporte para fixação dos sensores de medição da velocidade e temperatura do ar.

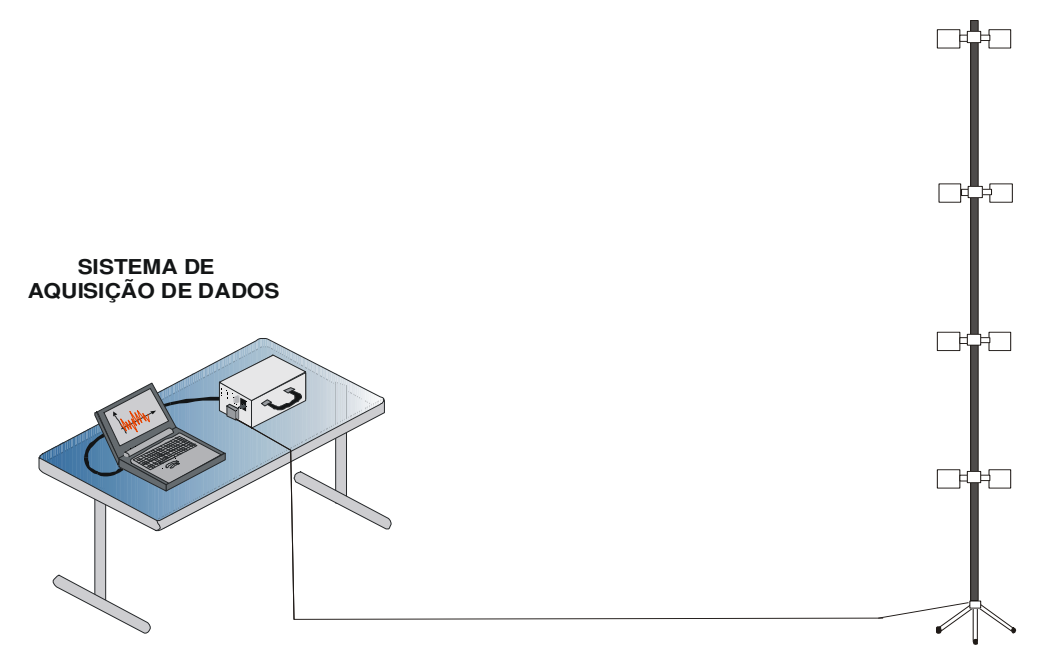

Figura 6.5 - Suportes para medição da velocidade e temperatura do ar

Para a obtenção da velocidade e temperatura do ar, a aquisição dos dados foi feita a cada 0,2 segundos, com médias calculadas e gravadas, a cada 1 minuto, em arquivo de planilha eletrônica. Para cada ponto de medição foram determinadas as médias aritméticas das medidas e os desvios padrão. Essas médias, por ponto e nível medidos, compuseram os perfis relativos a cada grandeza. 


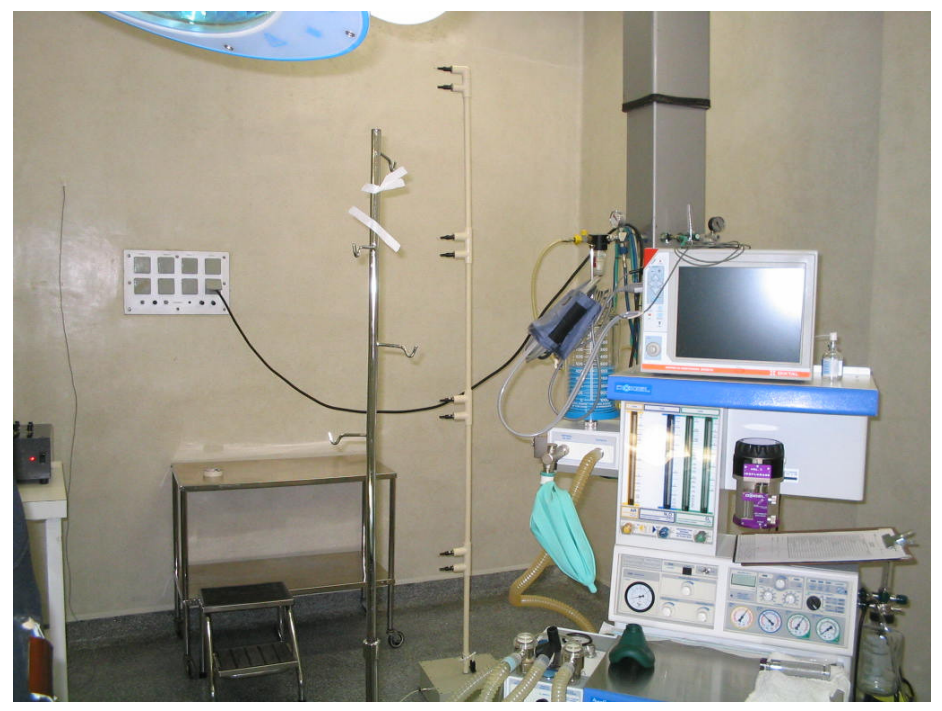

Figura 6.6 - Foto do suporte para medição da velocidade e temperatura do ar.

\subsubsection{Velocidade e vazão de ar nos difusores e grelhas de insuflamento e retorno}

Conforme o tipo de difusores de insuflamento e as grelhas de retorno, foram adotados diferentes procedimentos de medição para a determinação da velocidade média e vazão do fluxo de ar. Nos sistemas com fluxo unidirecional as vazões foram obtidas diretamente por meio de um anemômetro. No caso dos sistemas não unidirecionais (difusores de teto), as medições das velocidades foram feitas utilizando balômetro.

Para cada tipo de sistema de condicionamento de ar foram adotadas metodologias de medição de velocidades recomendadas pelas normas ASHRAE Standard 111 (1998), recomendação normativa da SBCC-RN-005 (SBCC, 1997) e da SHTM 2025 (SHTM, 2001).

\subsubsection{Medições em sistemas com fluxo não unidirecional}

\subsubsection{Medição da vazão de ar de insuflamento}

Nos casos em que foi possível, a vazão de ar insuflado foi medida diretamente com um balômetro, de maneira que o mesmo captasse todo o ar proveniente de cada difusor. $\mathrm{O}$ coletor foi colocado de tal forma que cobria totalmente o difusor, aplicando a moldura do coletor contra uma área plana para evitar fuga de ar e leituras inexatas. A figura 6.7 mostra o balômetro utilizado nas medições, com. faixas de leitura de vazão de 85 a 4078 m³/h, precisão de $+/-3 \%$ de fundo de escala e tempo de resposta de 2 a $43 \mathrm{~s}$, conforme ajuste. 


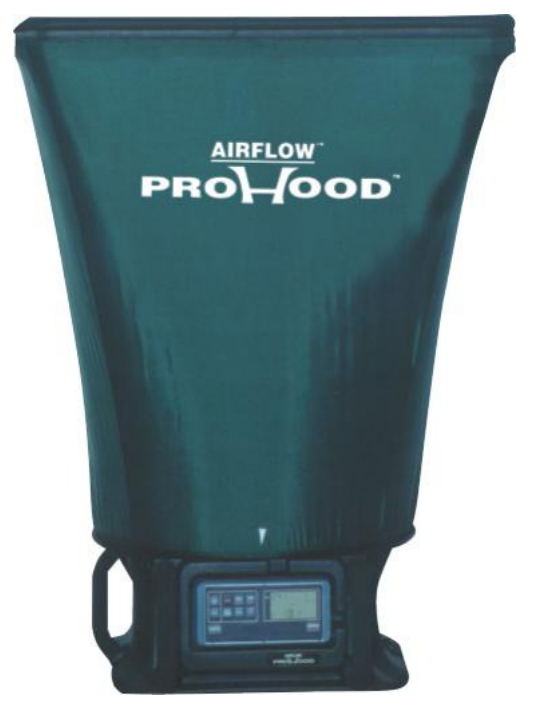

Figura 6.7 - Balômetro para medição da vazão do ar

\subsubsection{Medição da velocidade do ar no insuflamento e no retorno}

Nos locais onde não foi possível a colocação do balômetro para a medição direta da vazão do ar, foi medida a velocidade do ar, tanto no insuflamento quanto no retorno, para a obtenção da vazão do ar.

O anemômetro utilizado nas medições possui as seguintes características: escala de 0,4 a $12,0 \mathrm{~m} / \mathrm{s}$, precisão de $\pm 2 \%$ e resolução de $0,01 \mathrm{~m} / \mathrm{s}$. A Figura 6.8 ilustra o anemômetro utilizado para a medição da velocidade do ar tanto no insuflamento quanto no retorno.

Para as medições das velocidades do ar a sonda do anemômetro foi fixada em um suporte apropriado. O uso do suporte evita erros resultantes da perturbação do fluxo causado pelo corpo ou braço, caso a sonda seja manipulada pelo operador. A sonda foi orientada perpendicularmente à direção do fluxo. As posições da sonda para as medições da velocidade do ar foram determinadas pelo mapeamento, nas alturas estabelecidas pelas normas, com todos os pontos de medição dentro do fluxo de ar.

A metodologia adotada baseou-se na norma ASHRAE Standard 111 (1998) que recomenda a divisão da área de passagem em pequenos quadrados e retângulos. A Figura 6.9 mostra um exemplo das dimensões estabelecidas pela norma, que podem variar conforme o tamanho do dispositivo de passagem de ar. No caso, têm-se 30 pontos de medição. A velocidade foi obtida no centro da cada um destes retângulos. A velocidade total será a média aritmética das velocidades obtidas em cada retângulo. A norma recomenda um tempo de medição de pelo menos 10 segundos. A recomendação normativa da SBCC-RN-005 (1997) estabelece que a sonda deve ficar a mais de $15 \mathrm{~cm}$ da face de cada elemento. 

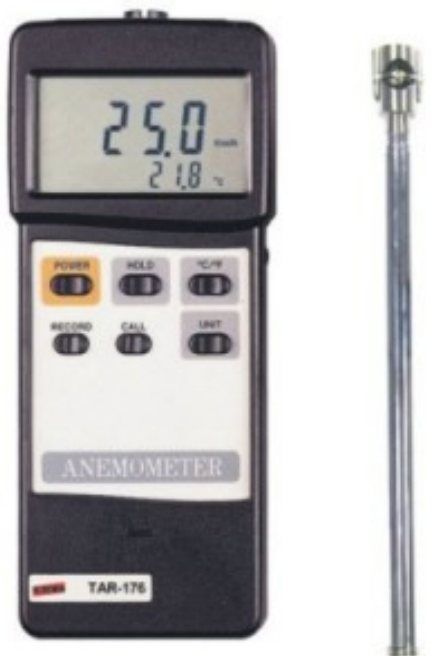

Figura 6.8 - Anemômetro para a medição da velocidade do ar

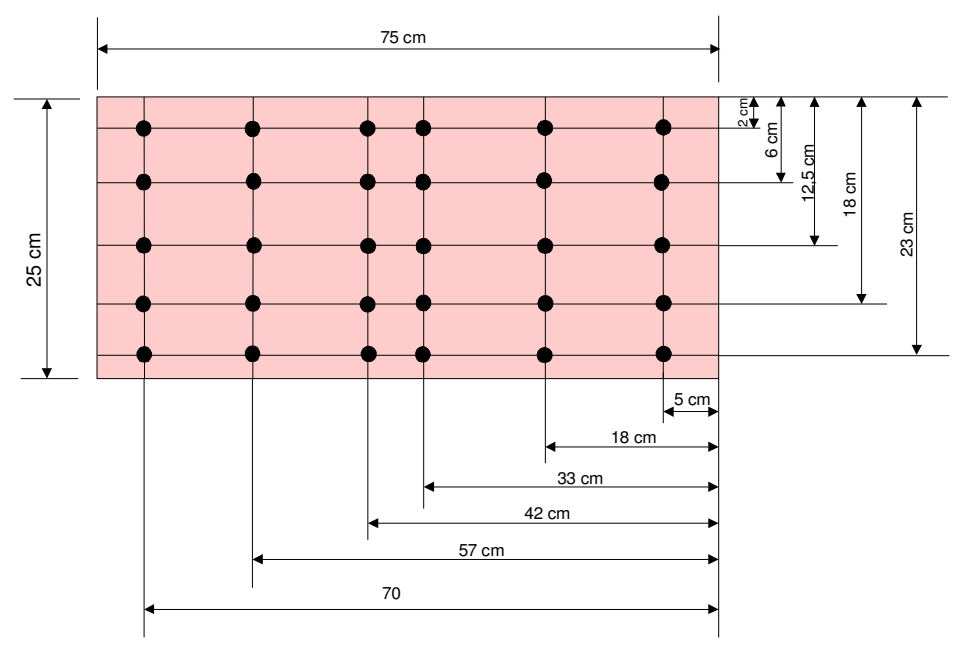

Figura 6.9 - Pontos de medição de velocidades

No caso da determinação da vazão de ar insuflado, por meio da velocidade e da área de passagem, esta deverá ser obtida utilizando a expressão:

$$
Q=v \cdot A,
$$

onde

$$
\begin{aligned}
& \mathrm{A}=\text { área }\left(\mathrm{m}^{2}\right) \\
& v=\operatorname{velocidade}(\mathrm{m} / \mathrm{s})
\end{aligned}
$$




\subsubsection{Medição da concentração e tamanho das partículas em suspensão}

A contagem das partículas em suspensão foi realizada utilizando-se três contadores de partículas da marca Met One, calibrados pelo fabricante. Cada um desses medidores possui 6 canais para medição de partículas na faixa de 0,3 a $10,0 \mu \mathrm{m}(0,3$ a $0,5 \mu \mathrm{m}$, de 0,5 a 1,0 $\mu \mathrm{m}$, de 1,0 a $3,0 \mu \mathrm{m}$, de 3 a $5 \mu \mathrm{m}$ e de 5 a $10 \mu \mathrm{m}$ ) com uma vazão volumétrica de 0,1 cfm $(2,83$ l/min.). Essas, normalmente, são as faixas de tamanhos de partículas carreadoras de agentes microbiológicos e que podem permanecer no ar durante muito tempo. As bactérias, por exemplo, são microorganismos que possuem dimensões que variam de 0,3 a $10 \mu \mathrm{m}$.

Esses equipamentos funcionam pelo principio de dispersão de um feixe luminoso. $\mathrm{Ou}$ seja, um sensor a laser emite um feixe luminoso que é dispersado pela passagem das partículas aspiradas pela bomba do equipamento.

A Figura 6.10 ilustra um dos equipamentos utilizados para medição do número e dimensão das partículas em suspensão.

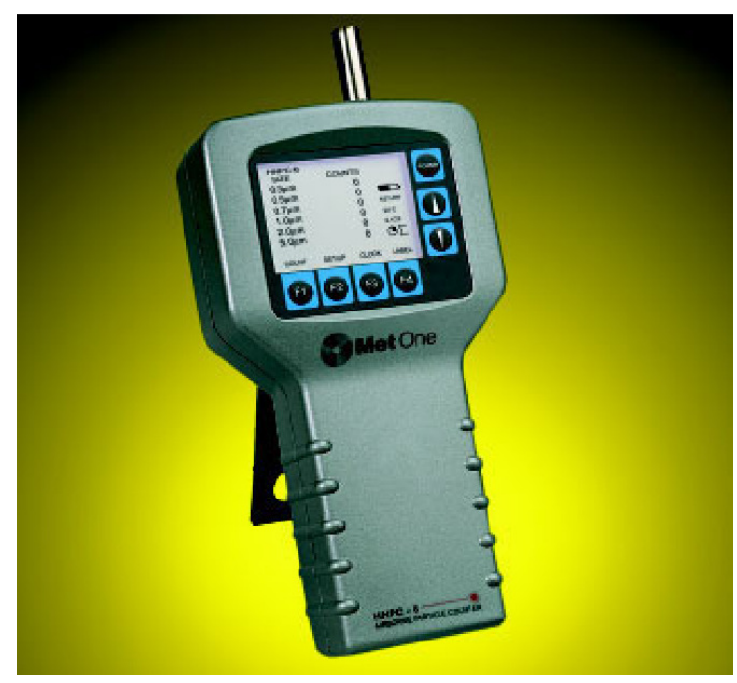

Figura 6.10 - Contador de partículas

Em função das restrições durante a realização do ato cirúrgico, os medidores permaneceram fixos durante todo o processo de medição. Porém, como o objetivo principal foi a medição da concentração de partículas em pontos definidos no micro ambiente, insuflamento do sistema de condicionamento de ar e do lado externo da sala, durante todas as medições os equipamentos permaneceram fixos nessas regiões. As figuras 6.11, 6.12 e 6.13 ilustram os locais de medição no interior e na parte externa da sala cirúrgica. 


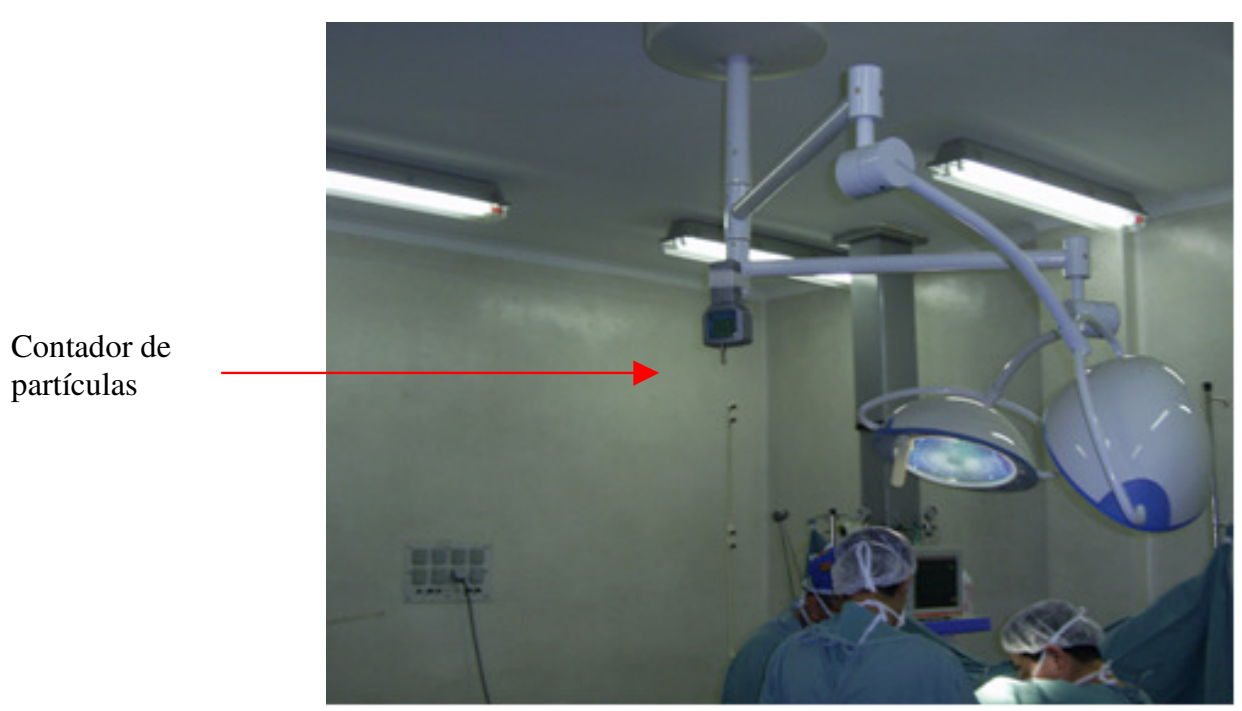

Figura 6.11 - Contador de partículas colocado próximo à área cirúrgica

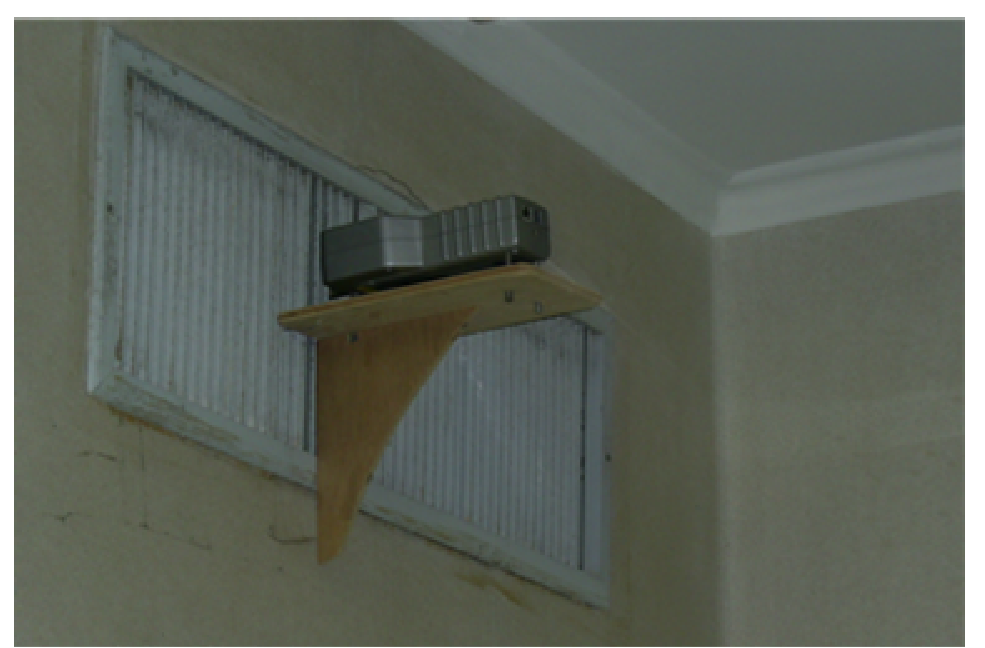

Figura 6.12 - Contador de partículas colocado junto ao insuflamento

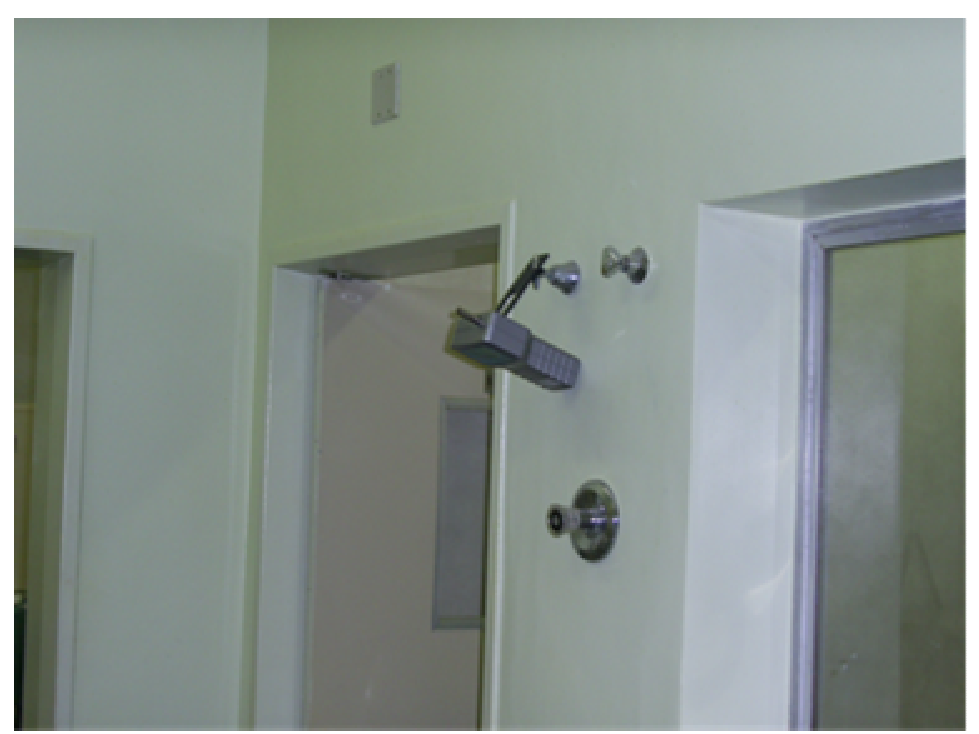

Figura 6.13 - Contador colocado no corredor 
As amostragens foram realizadas durante os mesmos períodos e de forma simultânea em todos os pontos, para evitar leituras incorretas devido a possíveis variações dos níveis de contaminação nos respectivos pontos de medição.

A taxa de volume de ar de amostragem dos medidores é de $0.1 \mathrm{ft}^{3}$ por min e o tempo de amostragem foi de 1 minuto a cada 5 minutos.

\subsubsection{Número de pessoas}

Segundo alguns trabalhos publicados na literatura (Quraishi et al., 1983; Wiley, 2001; Fitzgerald, 1979; Roy, 1997; Blakemore et al., 1979; Ritter, 1999) a quantidade de partículas dispersas no ambiente está diretamente relacionado com o nível de atividade e ao número de pessoas na sala cirúrgica. Ao longo de um procedimento cirúrgico o grau de atividade e o número de pessoas presentes na sala variam. Desta forma, a contagem de pessoas foi feita por meio do processo de observação, com registro a cada 5 minutos do tipo de atividade e do número de pessoas no interior da sala.

\subsubsection{Duração da cirurgia}

A duração de cada tipo de procedimento cirúrgico é padronizada. Mesmo assim, foi registrado o tempo de cada procedimento cirúrgico, pois normalmente ocorrem variações no tempo de um mesmo tipo de cirurgia.

\subsubsection{Sistema de aquisição de dados}

Foi utilizado um sistema de aquisição de dados composto por um sistema de condicionamento de sinais, um microcomputador e um software. O sistema de aquisição de sinais possui 100 canais analógicos e 10 entradas/saídas digitais. Esse equipamento recebe o sinal de dados dos diversos sensores instalados no interior da sala (sensores de temperatura, velocidade). A Figura 6.14 apresenta o sistema de aquisição de dados utilizado nas medições em salas cirúrgicas. 


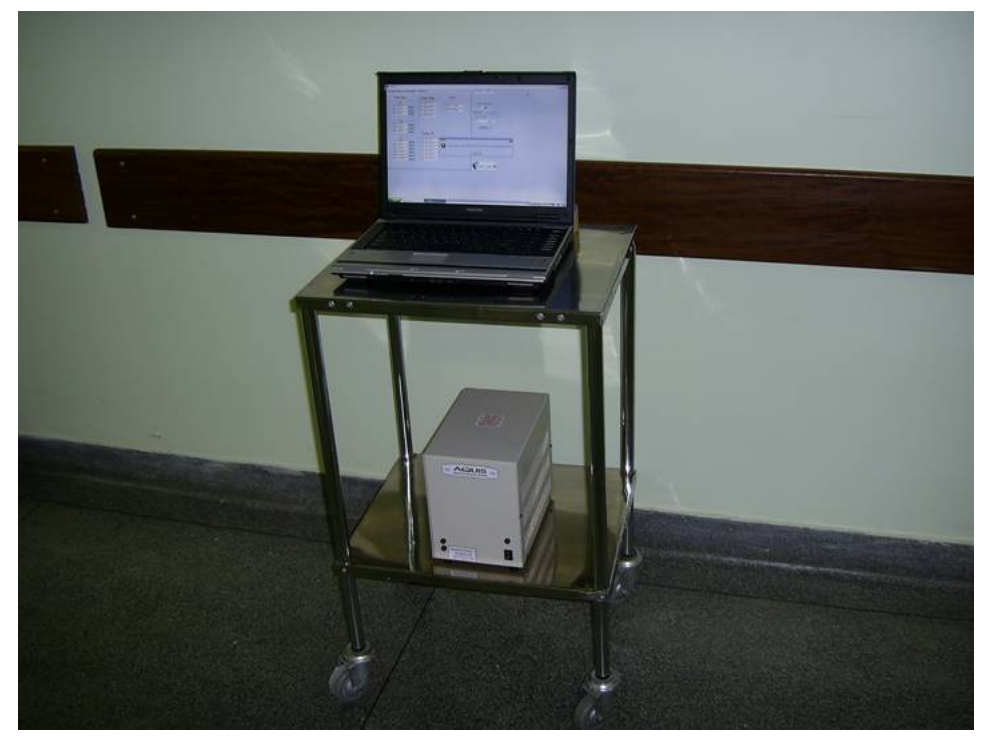

Figura 6.14 - Sistema de aquisição de dados 


\section{CAPÍTULO 7}

\section{METODOLOGIA DE PREDIÇÃO}

Como já mencionado nos capítulos anteriores, existe uma série de fatores que afetam a concentração de partículas no interior de uma sala cirúrgica, que pode variar amplamente. As fontes geradoras e os processos de remoção definem os níveis de contaminação no interior do ambiente. No caso de uma sala cirúrgica os modelos matemáticos podem ser utilizados como uma importante ferramenta para a predição e o entendimento dos mecanismos de transporte, movimentação, recirculação, filtração, geração, ressuspensão e deposição das partículas no interior desses ambientes.

Desta forma, nesse capítulo será apresentada a metodologia utilizada para predizer a média das concentrações de partículas do ar no interior das salas cirúrgicas, para os diferentes sistemas de condicionamento de ar estudados e para as condições específicas: portas fechadas e sistema de condicionamento de ar desligado, portas abertas e sistema de condicionamento de ar desligado, portas fechadas e sistema de condicionamento de ar ligado e portas abertas e sistema de condicionamento de ar ligado.

\subsection{DADOS DE ENTRADA NO MODELO}

Como já mencionado o modelo geral proposto baseia-se no balanço de massa. Assim, para cada condição analisada, o balanço de massa aplicado, resulta em equações especificas aplicáveis àquela condição. A Figura 7.1 mostra as variáveis consideradas na obtenção das equações, para cada condição estudada. 


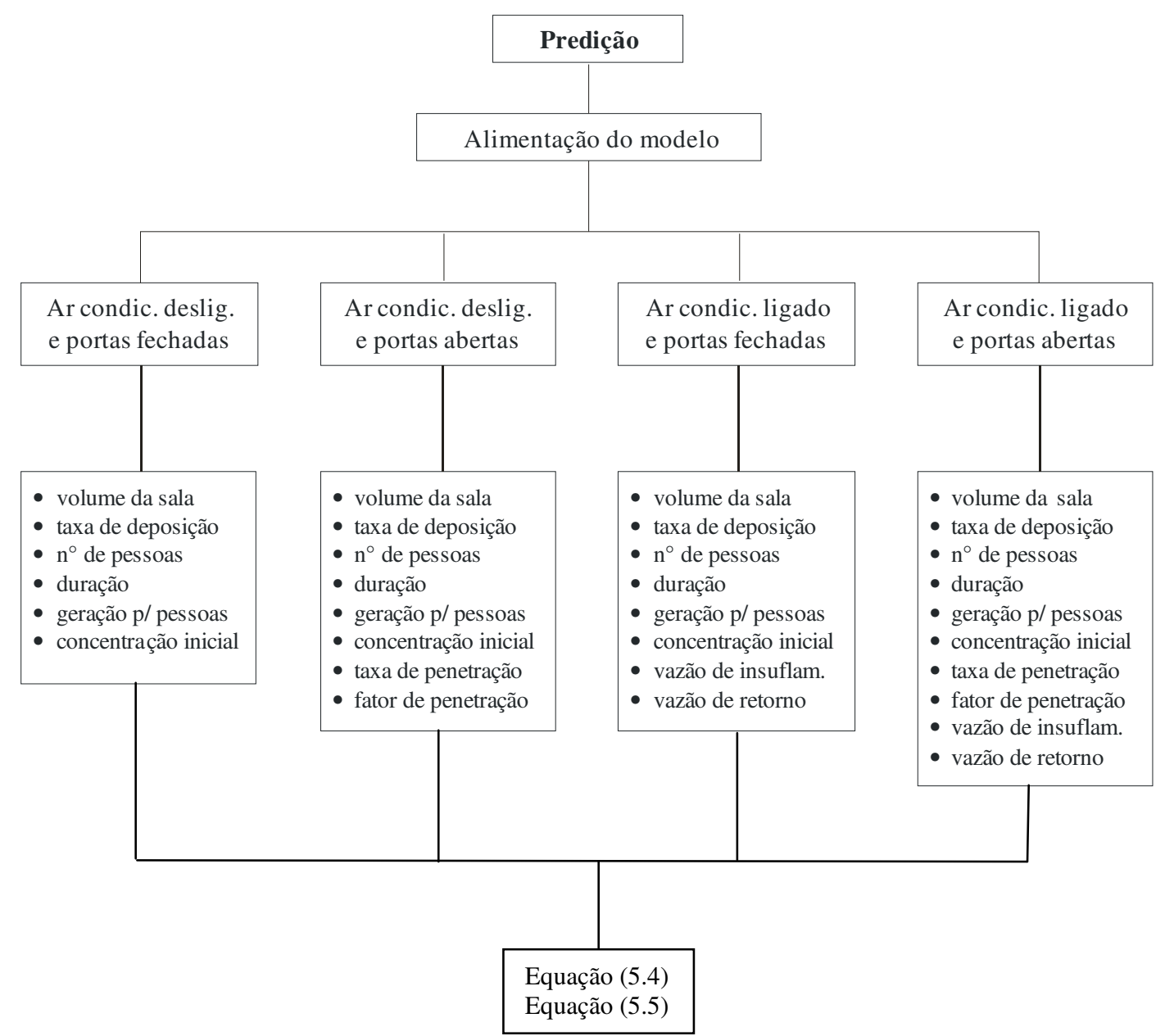

Figura 7.1 - Variáveis consideradas na medição.

\subsection{APRESENTAÇÃO DOS RESULTADOS DE PREDIÇÃO}

Os resultados de predição são comparados com os resultados experimentais, utilizando-se três formas de comparação:

a) Normal: comparam-se os valores preditos pelo modelo com os dados brutos de campo;

b) Com expurgo de dados: comparam-se os valores preditos com os dados de campo, após expurgar os valores de concentração das partículas geradas nos momentos em que são colocados os trajes e campos cirúrgicos; no caso das cirurgias ortopédicas, são expurgados também os valores de concentração das partículas geradas pela remoção da tala;

c) Com fator de correcão: comparam-se os dados brutos de campo com valores preditos pelo modelo, modificados pelo acréscimo de um fator de correção, que leva em conta as partículas geradas pela colocação de trajes e campos cirúrgicos; 
no caso das cirurgias ortopédicas, o fator de correção diz respeito também ao momento de remoção da tala.

Com a comparação (a), visa-se comparar integralmente o modelo proposto com dados de campo, a fim de avaliar sua precisão, sem levar em consideração situações de grande geração de partículas, porque sua ocorrência pode se dar com consideráveis variações. Por exemplo: a quantidade de campos pode variar entre cirurgias; em alguns centros cirúrgicos, utilizam-se campos cirúrgicos descartáveis, com baixa geração de partículas; em cirurgias com grande sangramento, é comum que sejam utilizadas toalhas para secagem, cuja agitação também gera uma grande quantidade de partículas.

Com a comparação (b) visa-se verificar o quanto o modelo aproxima-se dos dados de campo quando são desconsideradas as situações com geração mais intensa de partículas e com grandes variações. Por fim, a comparação (c) representa uma tentativa de aproximar a predição da situação mais corriqueira, que é aquela na qual a maior geração de partículas ocorre quando a equipe cirúrgica veste os trajes e depois coloca os campos cirúrgicos sobre o paciente.

Também são apresentadas, para os diferentes sistemas e casos estudados, a contribuição de cada fator no processo de geração e remoção das partículas no interior da sala cirúrgica. Para isso, nos diferentes casos estudados, retiraram-se das equações de regime permanente os valores totais das concentrações geradas e removidas por cada um dos parâmetros utilizados nas mesmas, relativos aos diversos fatores considerados.

O modelo foi desenvolvido tomando por base as partículas de 5 a $10 \mu \mathrm{m}$. Desejando observar sua precisão para todas as faixas de tamanhos consideradas neste estudo, são apresentadas comparações entre os dados de campo e os valores preditos pelo modelo, para partículas de $0,3 \mu \mathrm{m}, 0,5 \mu \mathrm{m}, 1 \mu \mathrm{m}, 3 \mu \mathrm{m}, 5 \mu \mathrm{m}$ e $10 \mu \mathrm{m}$. Para isso, foi utilizada a média das concentrações.

\subsection{VALIDAÇÃO DO MODELO}

Para validação do modelo proposto, realizaram-se análises estatísticas gráficas e numéricas. Inicialmente, analisaram-se os campos de distribuição de temperatura e velocidade do ar na sala, porque, para utilização do modelo proposto, é necessário que as condições no interior da sala sejam uniformes. Os resultados de medição de temperaturas e velocidades estão no anexo A. 
Depois, compararam-se os valores de concentração medidos e com os previstos pelo modelo, para partículas de $5 \mu \mathrm{m}$. Para verificar a acuidade do modelo e perceber em quais momentos ocorrem as maiores discrepâncias entre os valores medidos e os valores preditos pelo modelo, fez-se uma comparação entre esses valores e os dados brutos, sem exclusão de dados. Percebeu-se que as maiores discrepâncias ocorriam na etapa de preparação para a cirurgia, na colocação de trajes e campos cirúrgicos e, no caso de cirurgias ortopédicas, na remoção da tala de gesso, mediante serragem. Portanto, realizou-se um segundo conjunto de comparações, expurgando esses dados mais discrepantes. Depois, introduziram-se no modelo fatores de correção, variando de 1,5 a 3,0, visando um melhor ajuste do modelo aos padrões observados de variação na concentração de partículas.

Visando verificar a capacidade de predição do modelo proposto para diferentes diâmetros de partículas, efetuou-se uma comparação entre as concentrações médias preditas pelo modelo e os valores médios de concentração medidos no interior da sala cirúrgica para partículas de 0,3 a $0,5 \mu \mathrm{m}$, de 0,5 a $1,0 \mu \mathrm{m}$, de 1,0 a 3,0 $\mu \mathrm{m}$, de 3 a $5 \mu \mathrm{m}$ e de 5 a $10 \mu \mathrm{m}$.

Para verificar a diferença entre as concentrações no interior e no exterior da sala cirúrgica e para avaliar o efeito da infiltração através das portas, realizaram-se comparações entre os valores de concentração no interior da sala e no corredor, para partículas de 5 a $10 \mu \mathrm{m}$.

Por fim, utilizando o próprio modelo proposto, com as equações de regime permanente, avaliou-se a contribuição percentual dos vários fatores (sistema de condicionamento de ar, infiltração pelas portas, atividade das pessoas, deposição, etc.) na total de geração e remoção de partículas da sala cirúrgica.

Para validar estatisticamente o desempenho dos modelos, procedeu-se conforme sugerido pela norma ASTM D5157-97 (ASTM, 1997). Essa norma fornece alguns critérios estatísticos para estimar a precisão de modelos de predição da qualidade do ar de interiores. Da mesma forma são fornecidos valores referenciais para avaliar se o desempenho dos modelos é adequado ou não. Os critérios para se avaliar a concordância entre os dados experimentais e os preditos sugeridos pela norma e utilizado nesse trabalho são:

1) o coeficiente de correlação entre os dados experimentais e os preditos (r), obtido mediante aplicação da equação

$$
r=\frac{\sum_{i=1}^{n}\left[\left(C_{0 i}-\bar{C}_{0}\right)\left(C_{p i}-\bar{C}_{p}\right)\right]}{\sqrt{\sum_{i=1}^{n}\left[\left(C_{0 i}-\bar{C}_{0}\right)^{2}\right]\left[\sum_{i=1}^{n}\left(C_{p i}-\bar{C}_{p}\right)^{2}\right]}}
$$


onde $\mathrm{C}_{0}$ é a concentração medida em campo e $\mathrm{C}_{\mathrm{p}}$ é a concentração predita;

2) o erro médio quadrático normalizado (NMSE) calculado com a seguinte equação

$$
\mathrm{NMSE}=\frac{\overline{\left(\mathrm{C}_{\mathrm{p}}-\mathrm{C}_{0}\right)^{2}}}{\overline{\mathrm{C}}_{0} \cdot \overline{\mathrm{C}}_{\mathrm{p}}}
$$

O coeficiente de correlação de Pearson mede o grau da correlação entre os valores preditos e os valores medidos enquanto que o erro médio quadrático normalizado mede a variação dos valores preditos ao redor dos valores medidos.

Conforme a ASTM D5157, $\mathrm{r}$ deve ser igual ou maior que 0,9, enquanto valores de NMSE menores que 0,25 são bons indicadores de uma performance aceitável do modelo. Entretanto, ressalte-se que a literatura sugere que valores de $\mathrm{r}$ iguais ou superiores a 0,75 indicam uma correlação forte (Costa, 1992). 


\section{CAPÍTULO 8}

\section{LEVANTAMENTO EXPERIMENTAL}

Conforme detalhado no Capítulo 6, as medições foram realizadas com diferentes tipos de sistemas de condicionamento de ar utilizados em diferentes condições específicas. Neste capítulo são apresentados os resultados das medições para estes diferentes sistemas e condições estudadas.

\subsection{CARACTERIZAÇÃO DAS SALAS CIRÚRGICAS}

Nas Tabelas 8.1, 8.2 e 8.3 são apresentados, respectivamente, os parâmetros relativos ao ambiente físico, os parâmetros relativos ao sistema de condicionamento de ar e os parâmetros calculados. Lembrando que os parâmetros calculados, referem-se ao fator de infiltração, a taxa de infiltração e a taxa de deposição, calculados pelas equações 4.8, 4.9 e 4.10 respectivamente.

Tabela 8.1 - Parâmetros relativos ao ambiente físico das salas cirúrgicas.

\begin{tabular}{ccccccc}
\hline $\begin{array}{c}\text { Tipo de } \\
\text { sistema }\end{array}$ & $\begin{array}{c}\text { Área do } \\
\text { piso }\left(\mathbf{m}^{2}\right)\end{array}$ & $\begin{array}{c}\text { Área total } \\
\left(\mathbf{m}^{2}\right)\end{array}$ & $\begin{array}{c}\text { Volume } \\
\left(\mathbf{m}^{\mathbf{3}}\right)\end{array}$ & $\begin{array}{c}\text { Largura da } \\
\text { porta }(\mathbf{m})\end{array}$ & $\begin{array}{c}\text { Altura da } \\
\text { porta }(\mathbf{m})\end{array}$ & $\begin{array}{c}\text { Área da } \\
\text { porta }\left(\mathbf{m}^{2}\right)\end{array}$ \\
\hline A & 36,0 & 147,0 & 113,0 & 1,5 & 2,1 & 3,2 \\
\hline B & 30,8 & 130,4 & 95,4 & 1,62 & 2,1 & 3,4 \\
\hline C & 25,6 & 114,8 & 77,0 & 1,50 & 2,1 & 3,1 \\
\hline D & 24,0 & 103,9 & 79,23 & 1,2 & 2,1 & 2,5 \\
\hline
\end{tabular}

A - Insuflamento pela parede e retorno próximo ao piso;

B - Insuflamento e retorno pelo teto;

C - Insuflamento pelo teto e retorno próximo ao piso;

D - Ar condicionado de janela. 
Tabela 8.2 - Parâmetros relativos aos sistemas de condicionamento de ar.

\begin{tabular}{ccc}
\hline Tipo de sistema & Vazão de insuflamento $\left(\mathbf{m}^{3} / \mathbf{h}\right)$ & Vazão de retorno $\left(\mathbf{m}^{\mathbf{3}} / \mathbf{h}\right)$ \\
\hline A & 1760 & 995 \\
B & 810 & 214 \\
C & 1811 & 1035 \\
D & - & - \\
\hline
\end{tabular}

A - Insuflamento pela parede e retorno próximo ao piso;

B - Insuflamento e retorno pelo teto;

C - Insuflamento pelo teto e retorno próximo ao piso;

D - Ar condicionado de janela.

Tabela 8.3 - Parâmetros calculados

\begin{tabular}{|c|c|c|c|c|c|c|c|}
\hline \multirow{2}{*}{$\begin{array}{l}\text { Tipo de } \\
\text { sistema }\end{array}$} & \multirow{2}{*}{ Parâmetros } & \multicolumn{6}{|c|}{ Diâmetros das partículas $(\mu \mathrm{m})$} \\
\hline & & 0,3 a 0,5 & 0,5 a 1 & 1 a 3 & 3 a 5 & 5 a 10 & $>10$ \\
\hline \multirow{3}{*}{ A } & Taxa de deposição (partículas/h) & 0,29 & 0,75 & 1,05 & 1,08 & 1,32 & 1,45 \\
\hline & Taxa de infiltração (partículas/h) & 0,18 & 0,58 & 1,25 & 1,90 & 1,98 & 2,25 \\
\hline & Fator de infiltração & 1,12 & 0,85 & 0,74 & 0,91 & 0,64 & 3,00 \\
\hline \multirow{3}{*}{ B } & Taxa de deposição (partículas/h) & 0,71 & 1,39 & 2,40 & 4,96 & 5,08 & 4,63 \\
\hline & Taxa de infiltração (partículas/h) & 0,34 & 0,58 & 1,16 & 1,47 & 1,30 & 0,93 \\
\hline & Fator de infiltração & 2,31 & 1,98 & 2,16 & 2,22 & 1,24 & 1,68 \\
\hline \multirow{3}{*}{ C } & Taxa de deposição (partículas/h) & 0,29 & 0,75 & 0,07 & 1,06 & 1,32 & 1,45 \\
\hline & Taxa de infiltração (partículas/h) & 0,21 & 0,72 & 1,16 & 1,47 & 1,30 & 0,93 \\
\hline & Fator de infiltração & 1,45 & 0,91 & 2,06 & 2,32 & 1,31 & 1,38 \\
\hline \multirow{3}{*}{ D } & Taxa de deposição (partículas/h) & 0,30 & 0,47 & 0,62 & 1,07 & 1,35 & 2,05 \\
\hline & Taxa de infiltração (partículas/h) & 0,08 & 0,60 & 1,15 & 1,30 & 1,78 & 2,12 \\
\hline & Fator de infiltração & 1,21 & 1,01 & 0,96 & 1,20 & 0,81 & 2,53 \\
\hline
\end{tabular}

A - Insuflamento pela parede e retorno próximo ao piso;

B - Insuflamento e retorno pelo teto;

C - Insuflamento pelo teto e retorno próximo ao piso;

D - Ar condicionado de janela. 


\subsection{DESCRIÇÃO DOS SISTEMAS DE CONDICIONAMENTO DE AR ESTUDADOS}

\subsubsection{Sistema com insuflamento pela parede e retorno próximo do piso - Sistema A}

Neste sistema o ar proveniente da central de tratamento de ar é insuflado no ambiente por meio de uma grelha de insuflamento, localizada na parte superior de uma das paredes da sala cirúrgica, e retorna também por meio de uma grelha de retorno, localizada na mesma parede na parte inferior. A central de tratamento do ar é do tipo expansão direta com condensação a água e fica localizada na parte externa do prédio. Por meio de dutos o ar tratado é conduzido ao ambiente. A figura 8.1 mostra o layout da sala cirúrgica com a localização das grelhas de insuflamento e retorno.

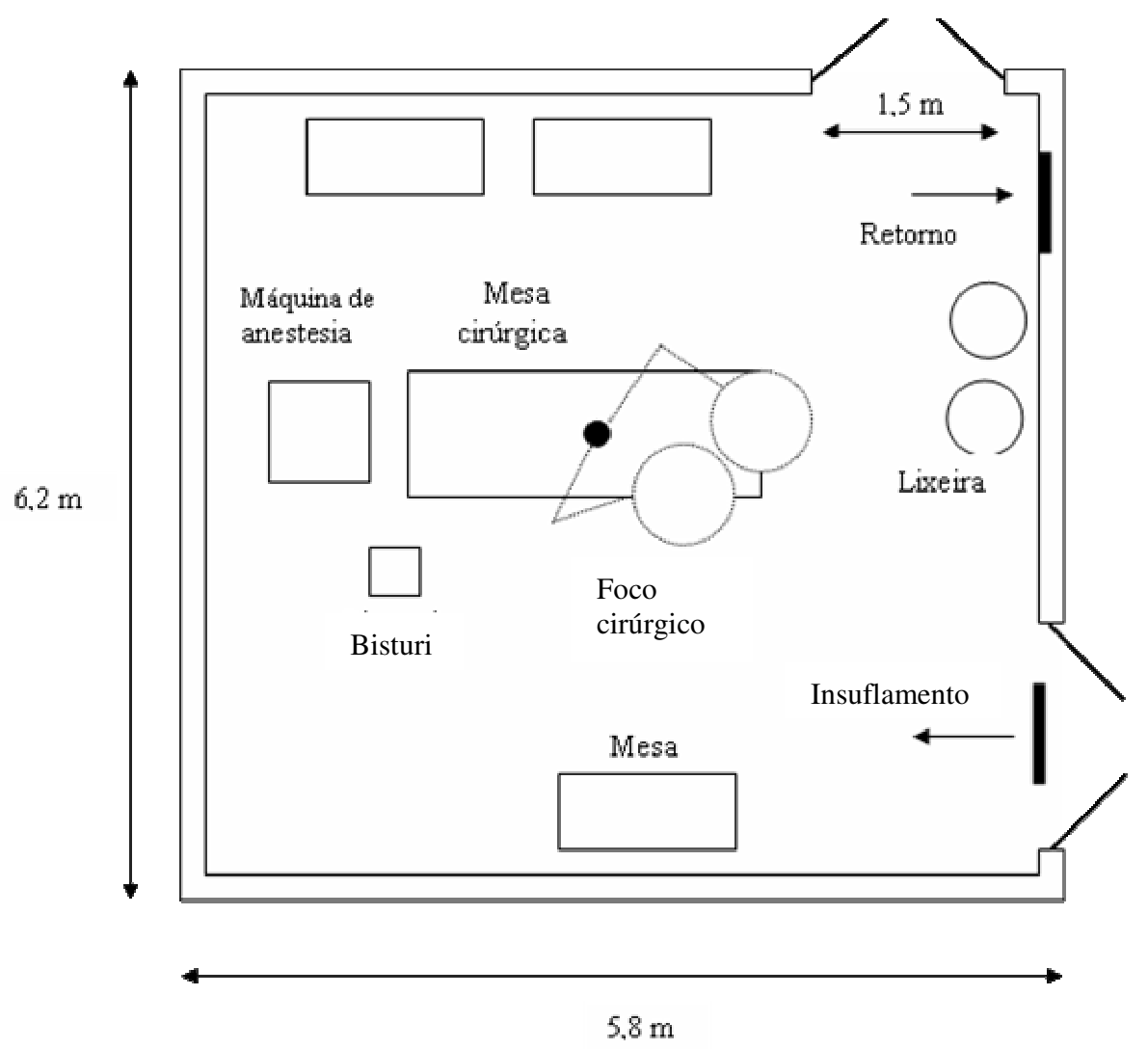

Figura 8.1A - Insuflamento pela parede e retorno próximo ao piso (Sala cirúrgica A) 


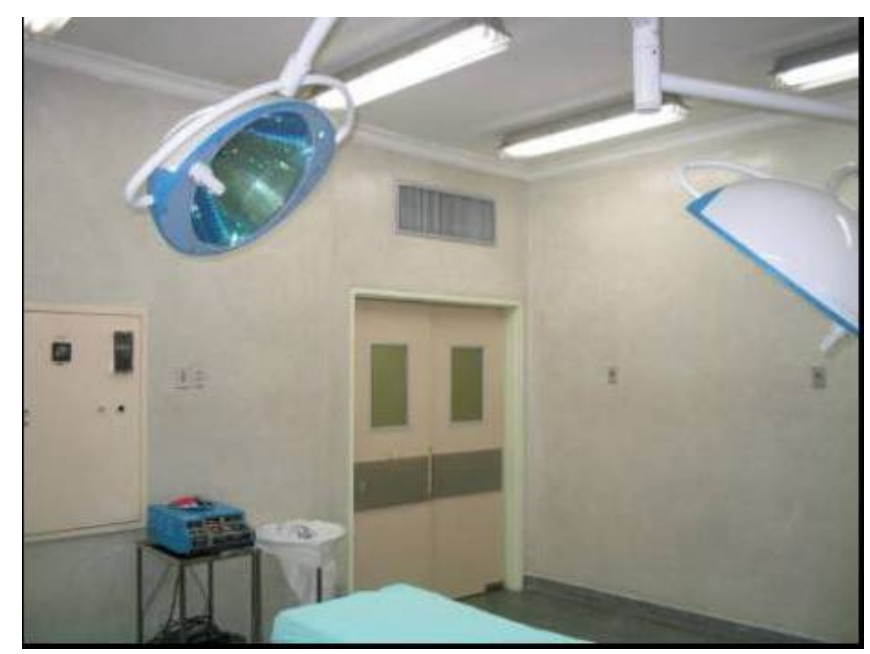

Figura 8.1B - Vista geral da sala, mostrando a grelha de insuflamento (Sala cirúrgica A)

\subsubsection{Sistema com insuflamento e retorno pelo teto - Sistema B}

Também neste sistema o ar que é insuflado no ambiente é proveniente da uma central de tratamento de ar. As grelhas de insuflamento e retorno ficam localizadas no teto, em extremidades opostas. Da mesma forma que no sistema anterior, a central de tratamento do ar é do tipo expansão direta com condensação a água e fica localizada na parte externa do prédio. $\mathrm{O}$ ar tratado é conduzido ao ambiente por meio de dutos, sendo insuflado no ambiente através de três grelhas. As Figuras 8.2 e 8.3 mostram as vistas superior e inferior da sala com o layout da sala e a localização das grelhas de insuflamento e retorno.

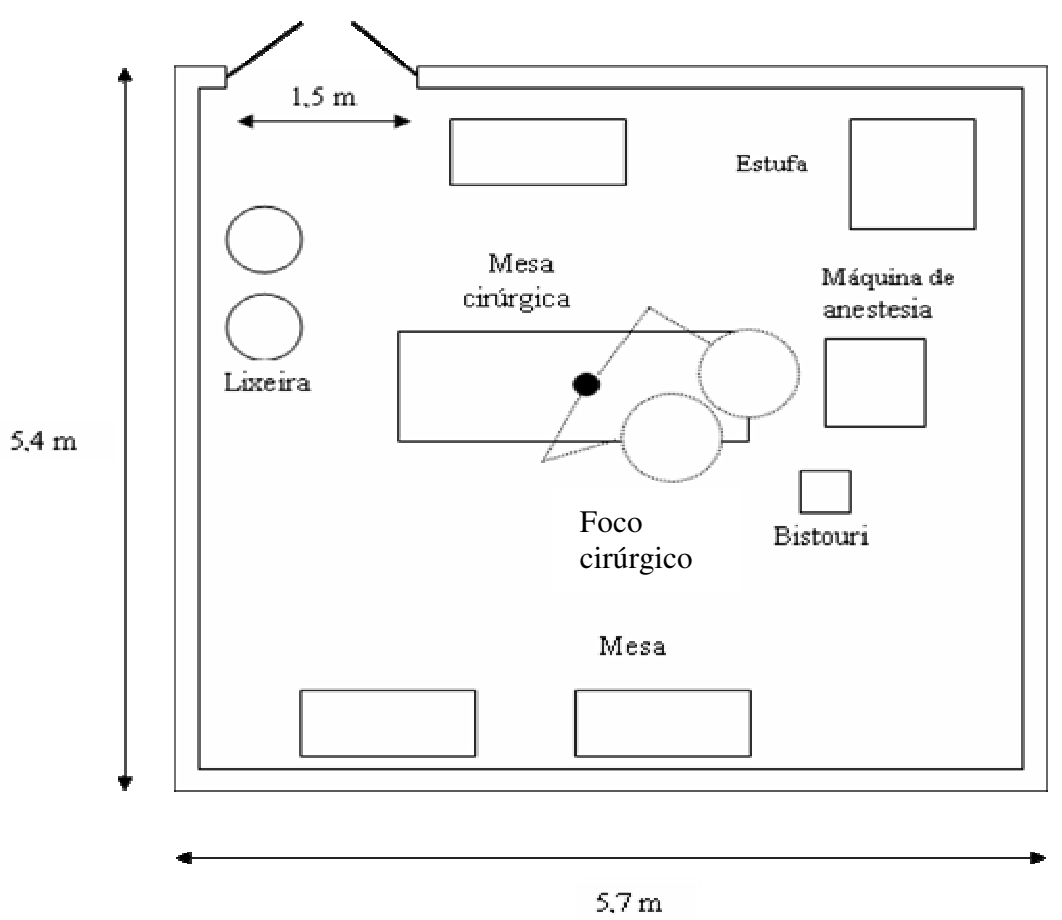

Figura 8.2 - Vista inferior do sistema com insuflamento e retorno pelo teto (Sala Cirúrgica B) 


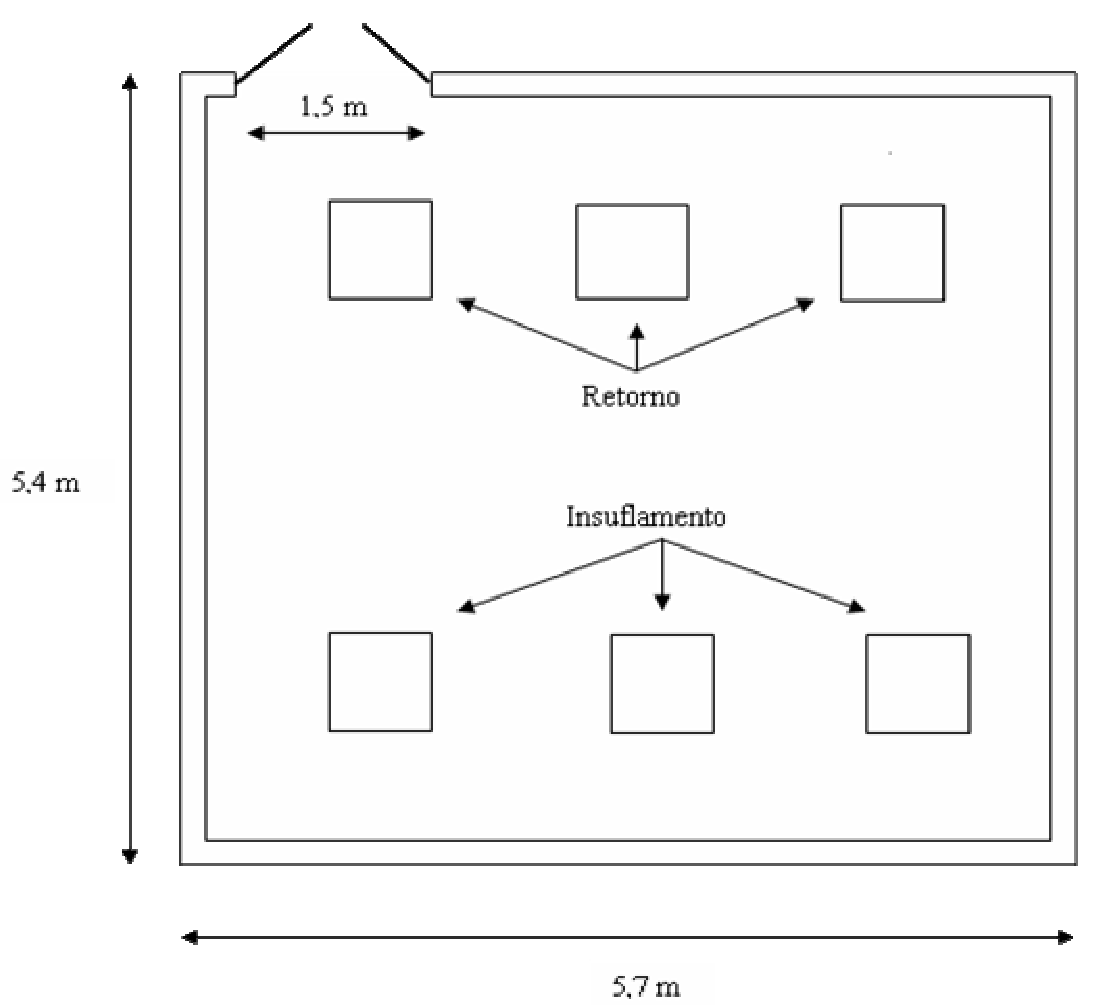

Figura 8.3-A - Vista superior do sistema com insuflamento e retorno pelo teto (Sala Cirúrgica B)

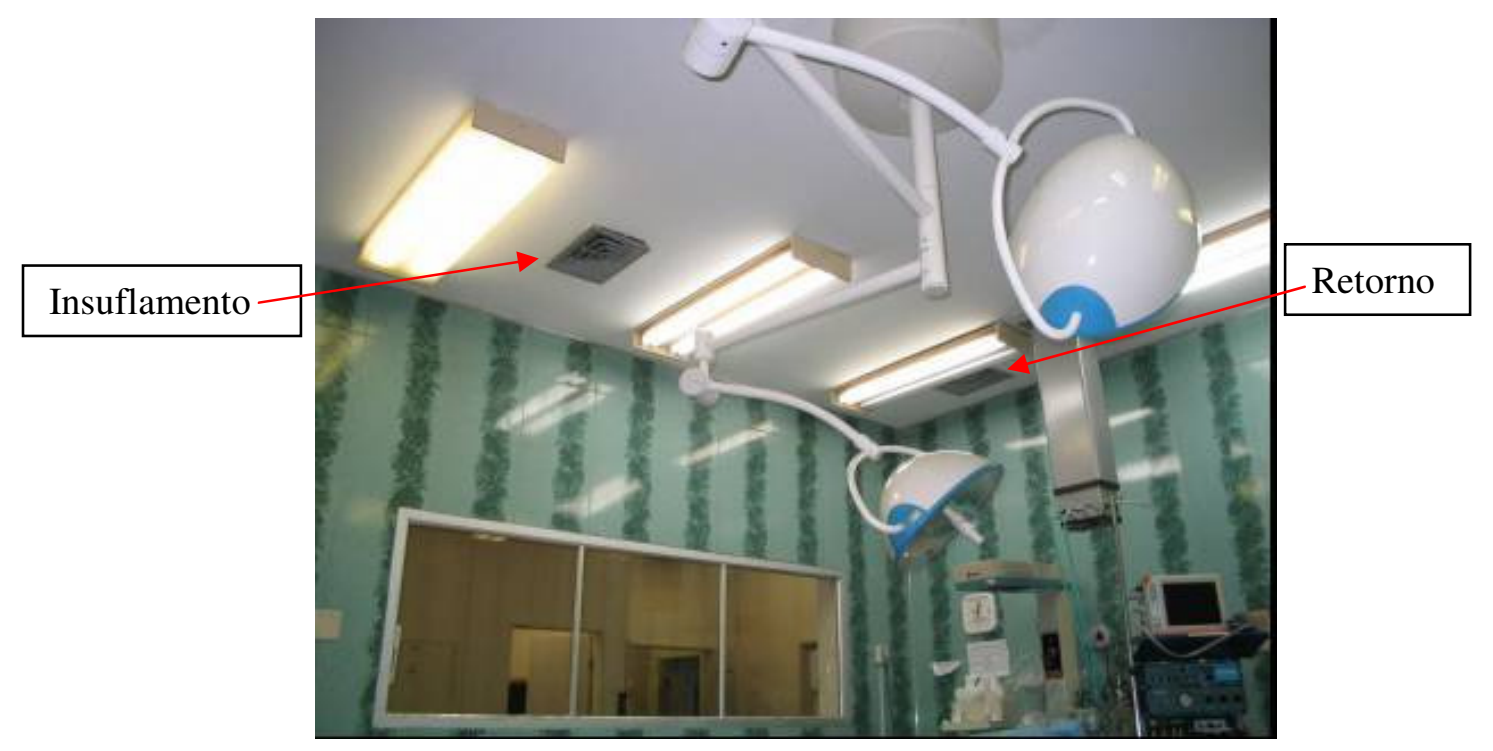

Figura 8.3-B - Vista do insuflamento e do retorno (Sala Cirúrgica B)

\subsubsection{Insuflamento pelo teto e retorno próximo ao piso - Sistema C}

Nesse sistema o ar proveniente da central de tratamento de ar é insuflado no ambiente por meio de dois difusores lineares localizados no teto, e retorna por meio de quatro grelhas localizadas nos quatro cantos da sala na parte inferior (Figuras. 8.4 e $8.5 \mathrm{~A}$ e $8.5 \mathrm{~B}$ ). 


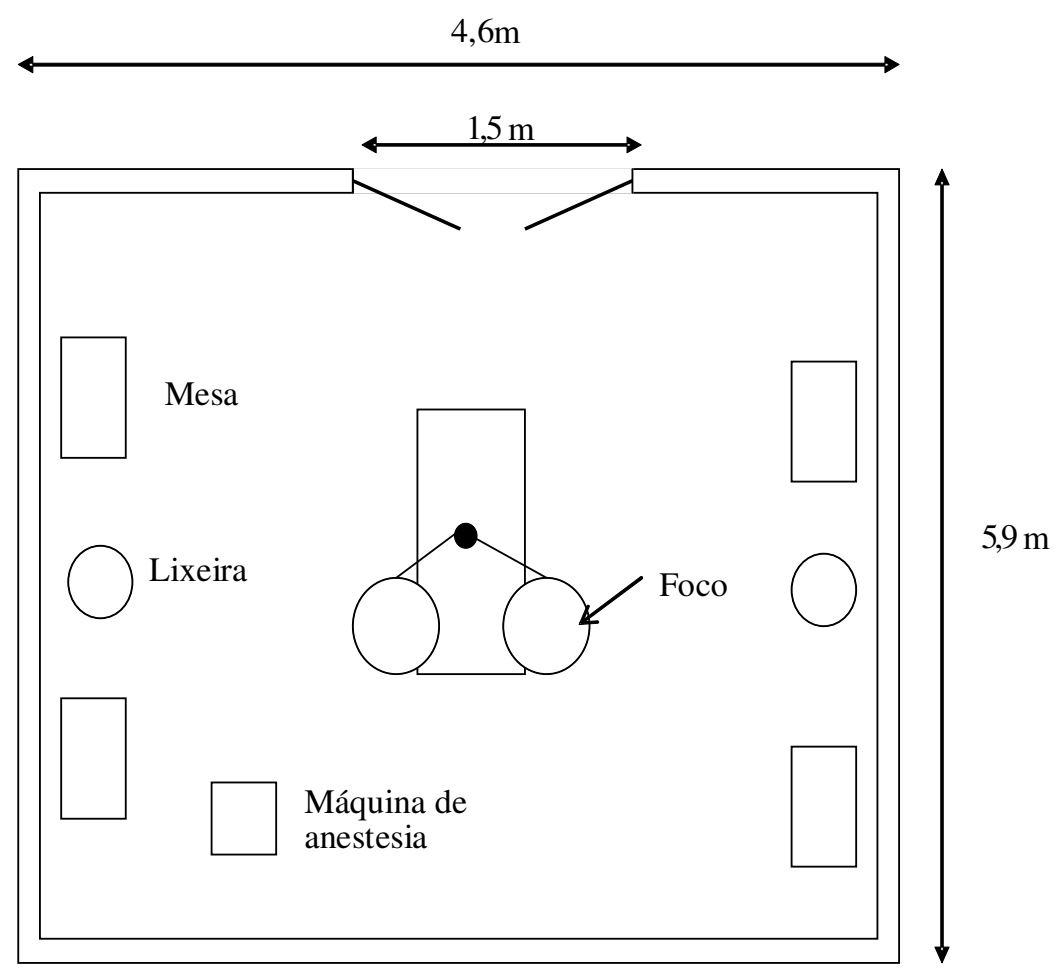

Figura 8.4 - Layout da sala cirúrgica C

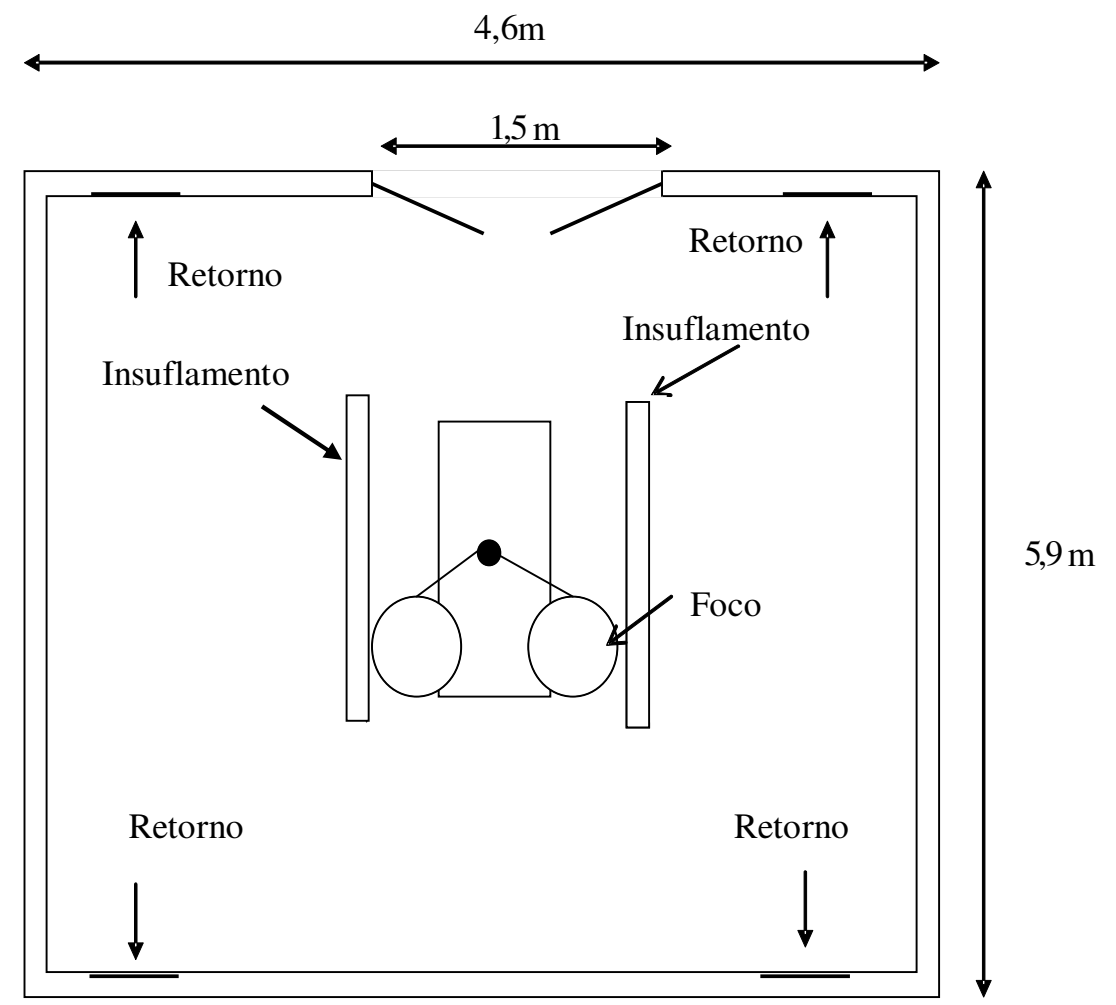

Figura 8.5 A - Vista do insuflamento e retorno (Sala Cirúrgica C) 


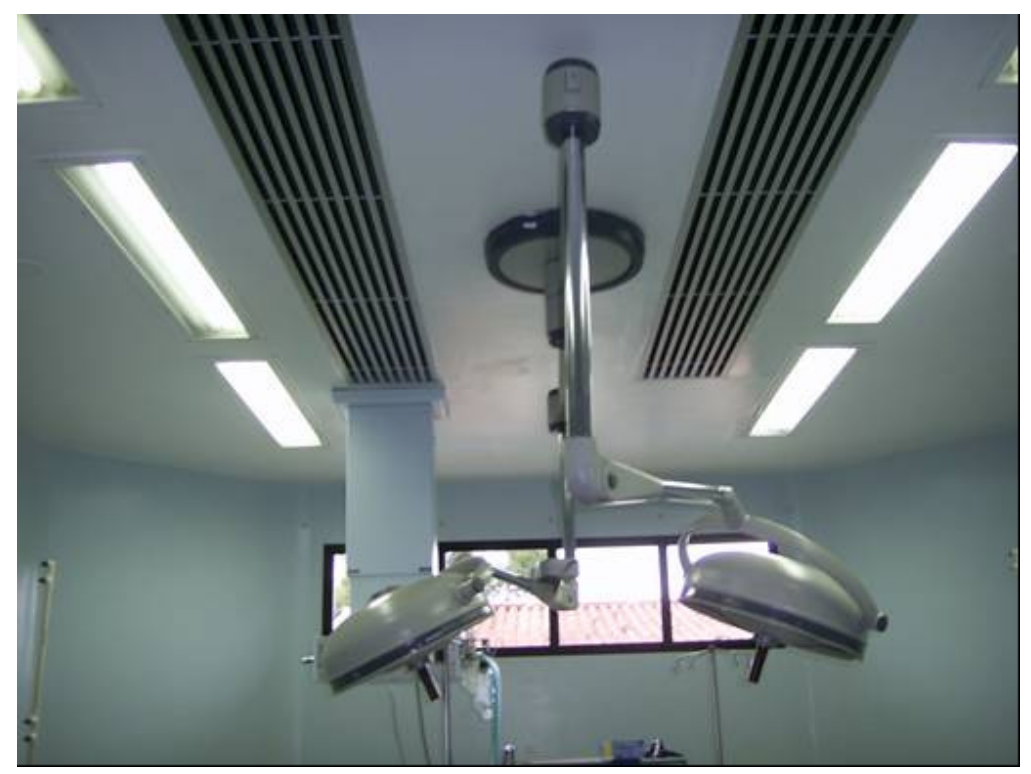

Figura 8.5 B - Vista do insuflamento (Sala Cirúrgica C)

\subsubsection{Ar condicionado de janela - Sistema D}

Outro sistema de condicionamento de ar utilizado nos levantamentos experimentais é do tipo ar condicionado de janela, com capacidade de resfriamento de $18.000 \mathrm{Btu} / \mathrm{h}$. Esse tipo de equipamento apresenta o sistema de tratamento de ar e o ciclo de refrigeração dentro de uma mesma carcaça. Esse equipamento não possui renovação de ar. O ar proveniente do ambiente entra pela parte inferior do equipamento, sendo condicionado até determinada temperatura e umidade, e então é insuflado novamente para o ambiente pela parte superior por meio de um ventilador.

A Figura 8.6 mostra o layout da sala cirúrgica, bem como a localização desse tipo de sistema de condicionamento de ar na sala. 


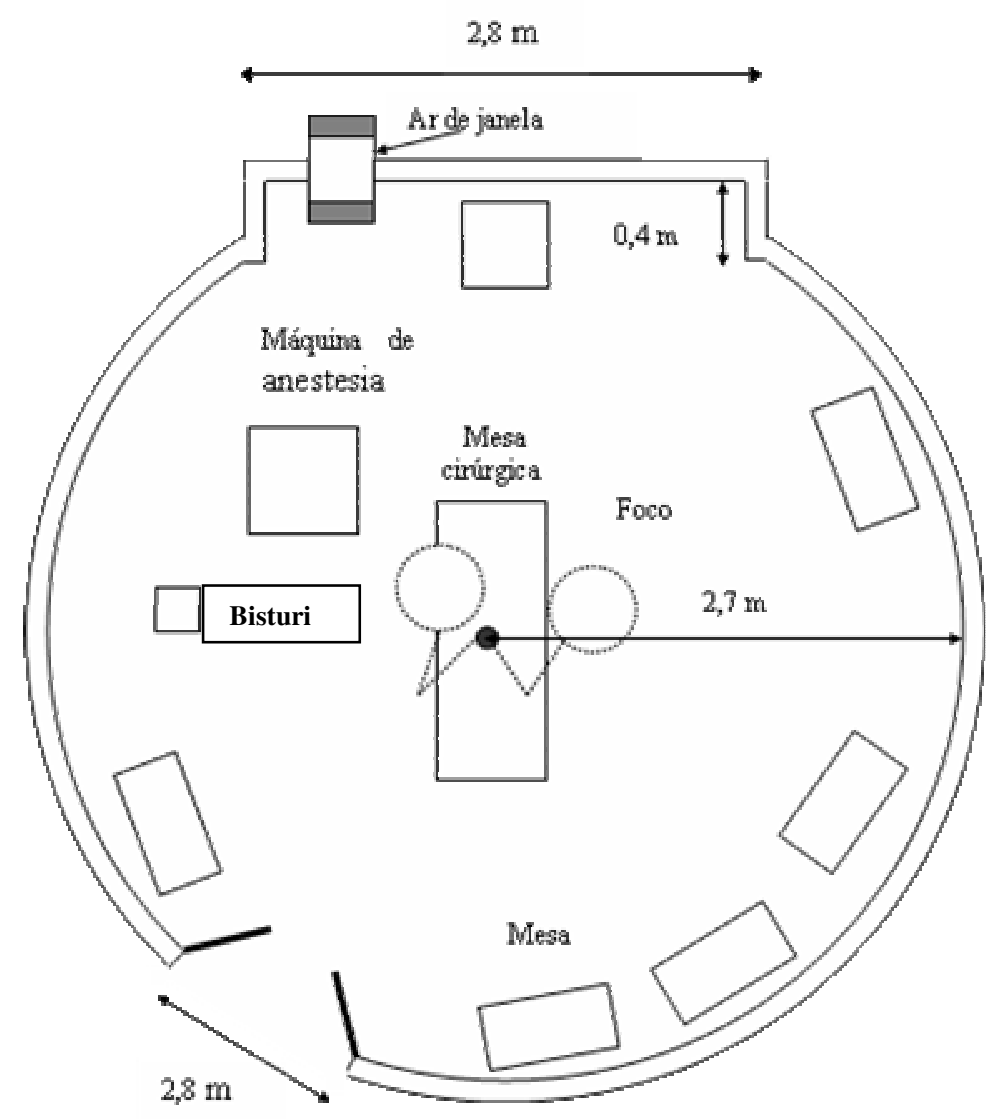

Figura 8.6 A - Layout da sala cirúrgica D

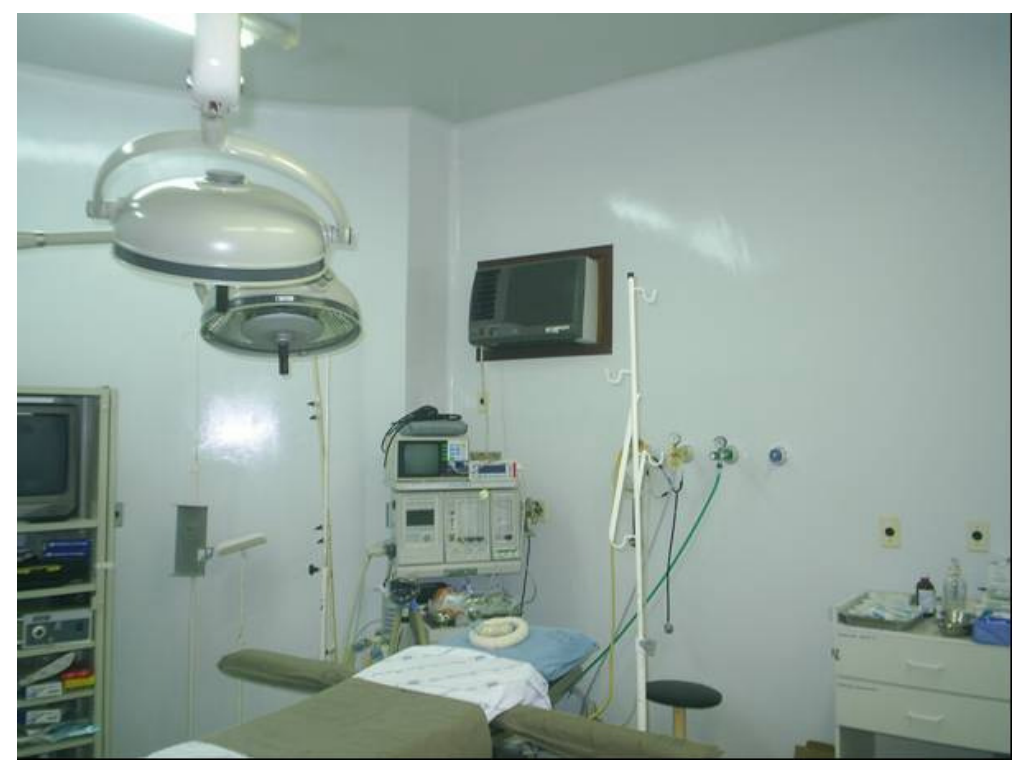

Figura 8.6 B - Vista da sala e do sistema de condicionamento de ar (sala Cirúrgica D) 


\subsection{CARACTERIZAÇÃO DOS PROCEDIMENTOS CIRÚRGICOS}

Na Tabela 8.4, são caracterizados os procedimentos cirúrgicos, a duração e o número de pessoas na sala cirúrgica durante o procedimento, não incluído o paciente.

Tabela 8.4 - Caracterização dos procedimentos cirúrgicos

\begin{tabular}{ccccc}
\hline $\begin{array}{c}\text { Tipo de } \\
\text { sistema }\end{array}$ & Casos & Procedimentos cirúrgicos & $\begin{array}{c}\text { Duração } \\
\text { aproximada (h) }\end{array}$ & $\begin{array}{c}\mathbf{N}^{\circ} \text { médio de } \\
\text { pessoas }\end{array}$ \\
\hline \multirow{2}{*}{ A } & A1 & estética de varizes & $2: 00$ & 5 \\
& A2 & herniorrafia umbilical & $2: 00$ & 4 \\
& A3 & herniorrafia inquinal & $2: 00$ & 4 \\
\hline \multirow{2}{*}{ B } & A4 & herniorrafia inguinal & $2: 00$ & 4 \\
\hline \multirow{2}{*}{ C } & B2 & parto cesário & $2: 00$ & 7 \\
\hline \multirow{2}{*}{ D } & C1 & parto cesário & $1: 15$ & 7 \\
& D1 & fratura de tíbia & $1: 45$ & 4 \\
\hline
\end{tabular}

A1 - sistema de condicionamento de ar desligado e as portas da sala cirúrgica fechadas;

A2 - sistema de condicionamento de ar desligado e as portas da sala cirúrgica abertas;

A3, B1, C1, D1 - sistema de condicionamento de ar ligado e as portas da sala cirúrgica fechadas;

A4, B2, C2, D2 - sistema de condicionamento de ar ligado e as portas da sala cirúrgica abertas.

\subsection{DISTRIBUIÇÃO DE TEMPERATUIRAS E VELOCIDADES DO AR NAS SALAS CIRÚRGICAS}

Em todos os casos analisados, as condições de distribuição de temperatura e velocidade do ar (Anexo A) indicam um comportamento estável no interior das salas cirúrgicas. Analisando, por exemplo, os dados de perfis de temperatura apresentados no Anexo A, verifica-se que as maiores variações de temperatura ocorreram na sala cirúrgica com o sistema de ar condicionado de janela. Neste caso foram verificadas as seguintes diferenças máximas: $0,8{ }^{\circ} \mathrm{C}$ na estratificação de temperatura; $0,3{ }^{\circ} \mathrm{C}$ entre a temperatura média de todos os pedestais e $1,1{ }^{\circ} \mathrm{C}$ entre todos os pontos de medição na sala cirúrgica; o que sugere uma distribuição homogênea de partículas. 


\subsection{CONCENTRAÇÃO DE PARTÍCULAS NAS SALAS CIRÚRGICAS}

A Tabela 8.5 apresenta a concentração média das partículas de 5 a $10 \mu \mathrm{m}$, medida em várias etapas dos procedimentos cirúrgicos. Como já mencionado, escolheu-se este diâmetro de partículas porque essa é a faixa de tamanho em que se encontra a maior concentração de partículas resultantes de descamação de pele e fibras de algodão. Além disso, é nessa faixa de tamanho que se encontram a maioria das partículas com bactérias (partículas viáveis).

Tabela 8.5 - Concentração média das partículas de 5 a $10 \mu \mathrm{m}$ para os diferentes sistemas e situações estudadas.

\begin{tabular}{|c|c|c|c|c|c|c|c|c|c|c|}
\hline \multirow[b]{3}{*}{ Condições } & \multicolumn{10}{|c|}{ Tipos de sistemas e respectivas situações } \\
\hline & \multicolumn{4}{|c|}{ A } & \multicolumn{2}{|c|}{ B } & \multicolumn{2}{|c|}{ C } & \multicolumn{2}{|c|}{ D } \\
\hline & $\mathbf{A 1}$ & A2 & A3 & A4 & B1 & B2 & C1 & $\mathbf{C 2}$ & D1 & D2 \\
\hline sala vazia & 0,09 & 0,23 & 0,04 & 0,05 & 0,01 & 0,05 & 0,01 & 0,02 & 0,25 & 0,06 \\
\hline durante o ato cirúrgico & 0,73 & 0,76 & 0,11 & 0,08 & 0,18 & 0,21 & 0,02 & 0,03 & 0,47 & 0,19 \\
\hline diferença* & 0,65 & 0,53 & 0,07 & 0,03 & 0,18 & 0,16 & 0,01 & 0,02 & 0,22 & 0,12 \\
\hline no corredor & 0,26 & 0,60 & 0,21 & 0,30 & 0,29 & 0,29 & 0,07 & 0,03 & 0,37 & 0,28 \\
\hline
\end{tabular}

São apresentadas, nos itens 8.5.1 a 8.5.4, as variações da concentração de partículas de $5 \mu \mathrm{m}$ ao longo do procedimento cirúrgico, para os vários sistemas e casos analisados. Em alguns casos, foram realizadas medições ainda com a sala vazia. Em outros, as medições foram iniciadas com a entrada do paciente.

\subsubsection{Sistema A - Condicionamento de ar desligado e portas fechadas}

A Figura 8.7 mostra a variação da concentração das partículas de 5 a $10 \mu \mathrm{m}$ ao longo do tempo, para o sistema com insuflamento pela parede e retorno próximo ao piso; condicionamento de ar desligado e portas fechadas. Destaca-se que este foi o único centro cirúrgico em que foi possível fazer este tipo de medição. Dada a natureza dos procedimentos 
realizados nos demais centros cirúrgicos, não seria recomendável desligar o sistema de condicionamento de ar e manter as portas fechadas.

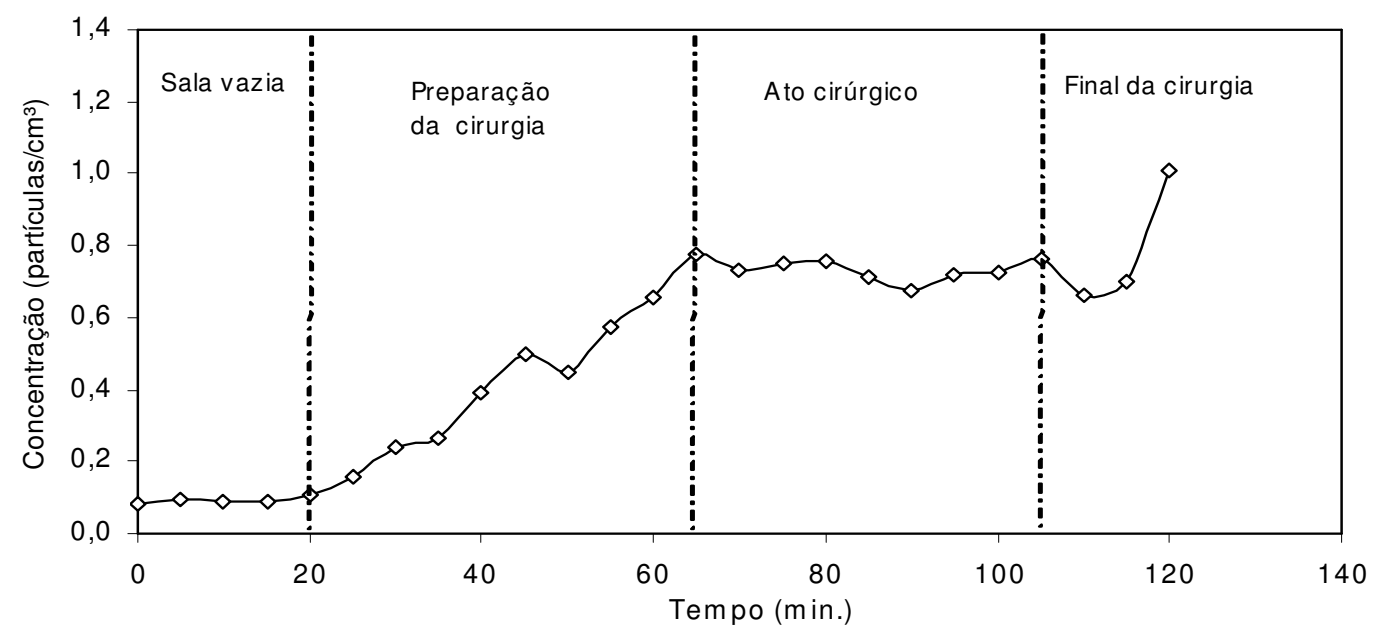

Figura 8.7 - Variação da concentração das partículas de 5 a $10 \mu \mathrm{m}$ ao longo do tempo, para o sistema A, com condicionamento de ar desligado e portas fechadas.

\subsubsection{Sistema A - Condicionamento de ar desligado e portas abertas}

A Figura 8.8 mostra a variação da concentração das partículas de 5 a $10 \mu \mathrm{m}$ ao longo do tempo, para o sistema com insuflamento pela parede e retorno próximo ao piso com o condicionamento de ar desligado e portas abertas. Essas medições foram obtidas no mesmo centro cirúrgico anterior, o qual, levando em consideração a natureza da cirurgia, permitiu que se mantivesse desligado o sistema de condicionamento, mas com as portas da sala cirúrgica abertas.

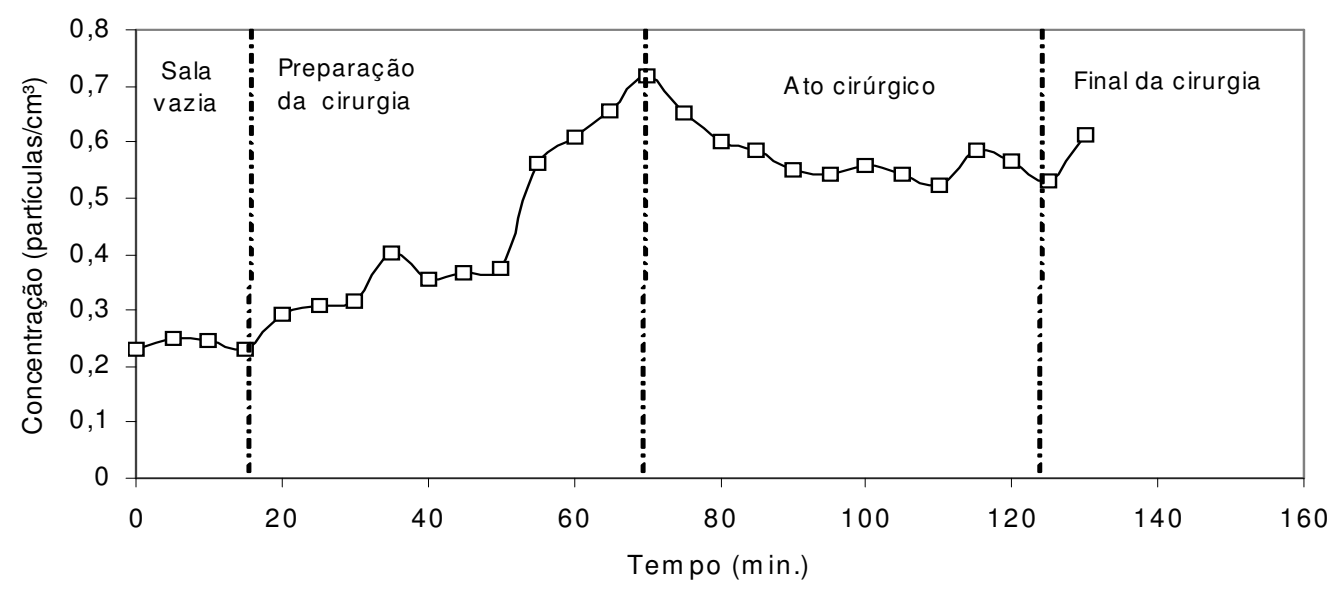

Figura 8.8 - Variação da concentração das partículas de 5 a $10 \mu \mathrm{m}$ ao longo do tempo, para o sistema A, com condicionamento de ar desligado e portas abertas. 


\subsubsection{Sistemas A, B, C e D - Condicionamento de ar ligado e portas fechadas}

As Figuras 8.9 a 8.12 mostram a variação da concentração das partículas de 5 a $10 \mu \mathrm{m}$ ao longo do tempo, para os casos nos quais o condicionamento de ar permaneceu ligado e as portas fechadas, respectivamente, para os sistemas A, B, C e D..

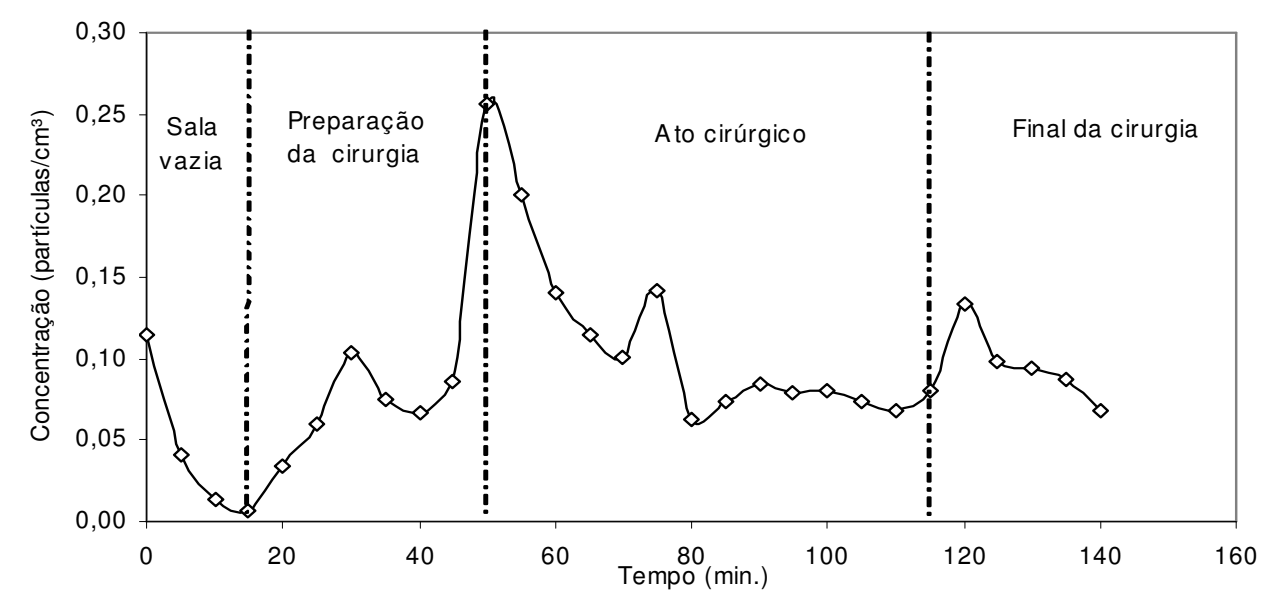

Figura 8.9 - Variação da concentração das partículas de 5 a $10 \mu \mathrm{m}$ ao longo do tempo, para o sistema A, com condicionamento de ar ligado e portas fechadas.

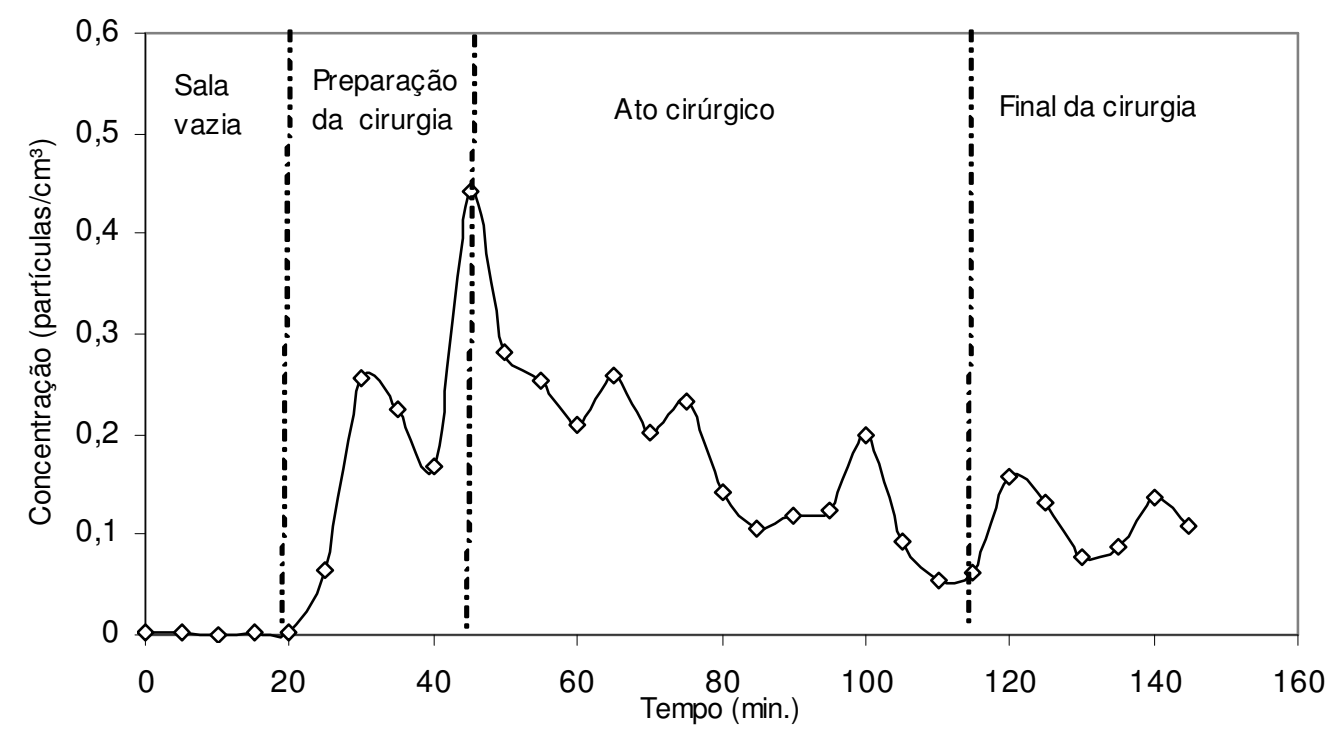

Figura 8.10 - Variação da concentração das partículas de 5 a $10 \mu \mathrm{m}$ ao longo do tempo, para o sistema B com condicionamento de ar ligado e portas fechadas. 


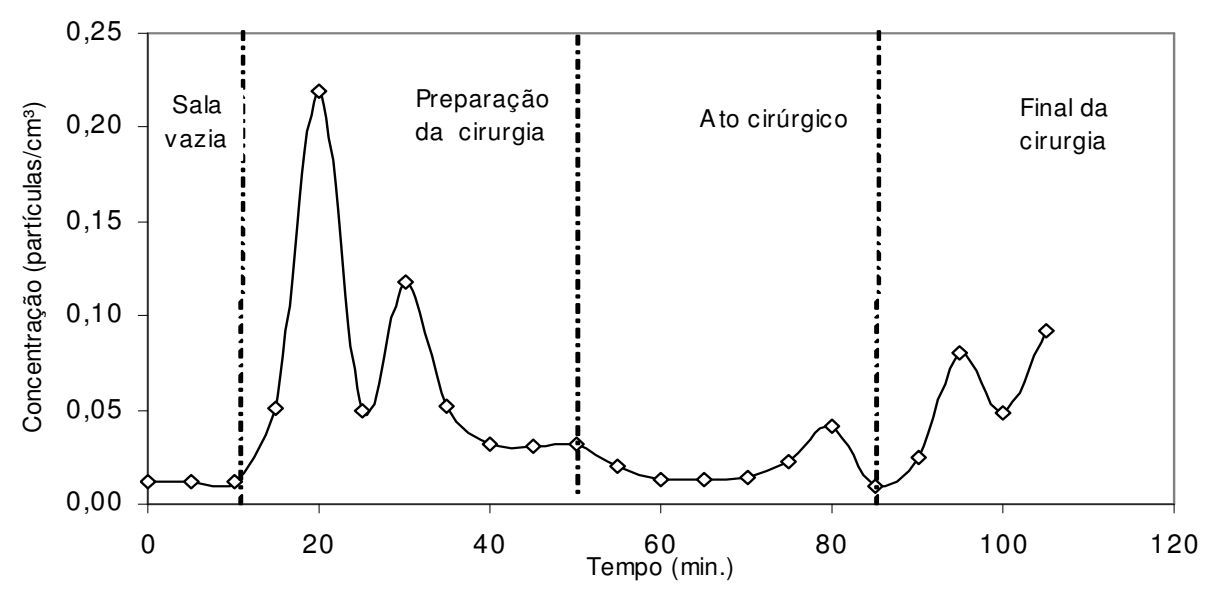

Figura 8.11 - Variação da concentração das partículas de 5 a $10 \mu \mathrm{m}$ ao longo do tempo, para o sistema C, com condicionamento de ar ligado e portas fechadas.

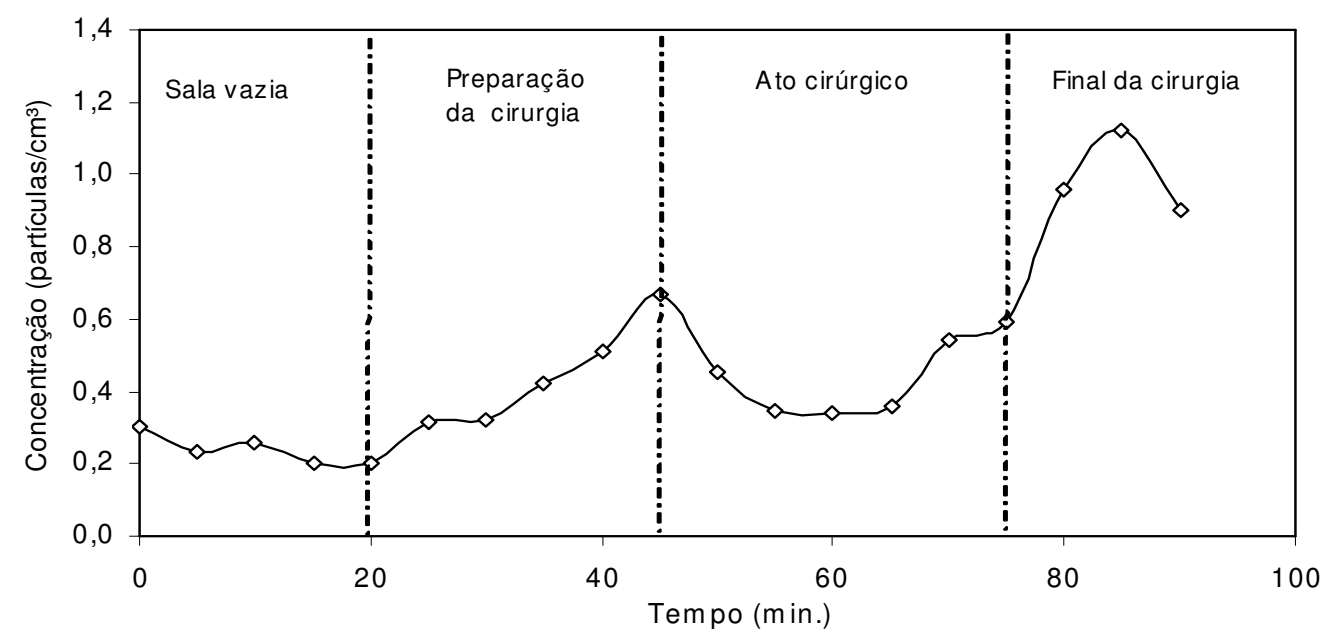

Figura 8.12 - Variação da concentração das partículas de 5 a $10 \mu \mathrm{m}$ ao longo do tempo, para o sistema D, com condicionamento de ar ligado e portas fechadas. 


\subsubsection{Sistemas A, B, C e D -- Condicionamento de ar ligado e portas abertas}

As Figuras 8.13 a 8.16 mostram a variação da concentração das partículas de 5 a 10 $\mu \mathrm{m}$ ao longo do tempo, para os casos em que o condicionamento de ar permaneceu ligado e as portas abertas, respectivamente, para os sistemas A, B, C e D.

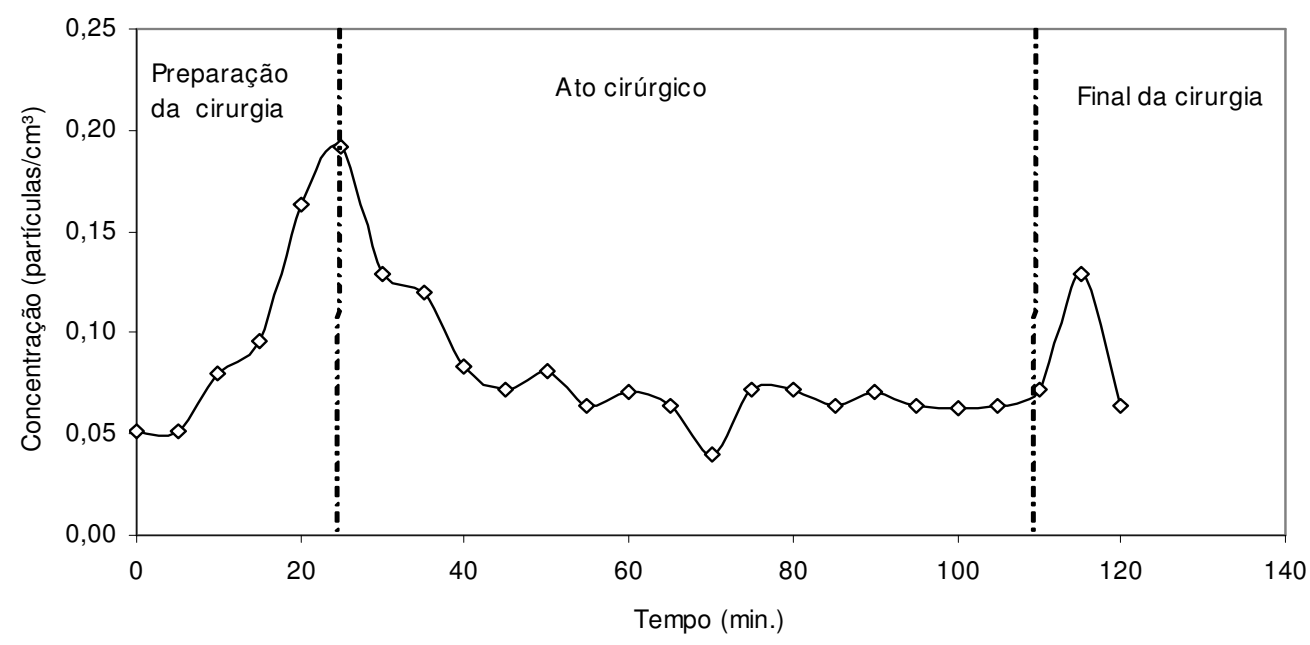

Figura 8.13- Variação da concentração das partículas de 5 a $10 \mu \mathrm{m}$ ao longo do tempo, para o sistema A, com condicionamento de ar ligado e portas abertas.

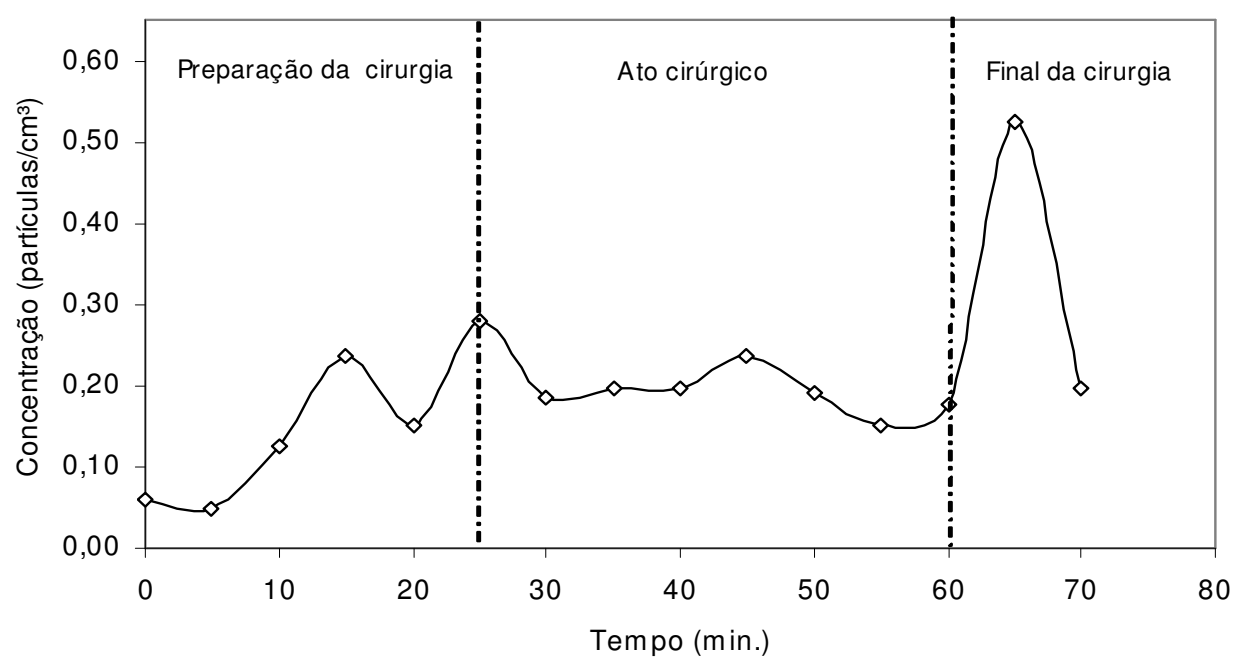

Figura 8.14 - Variação da concentração das partículas de 5 a $10 \mu \mathrm{m}$ ao longo do tempo, para o sistema B, com condicionamento de ar ligado e portas abertas. 


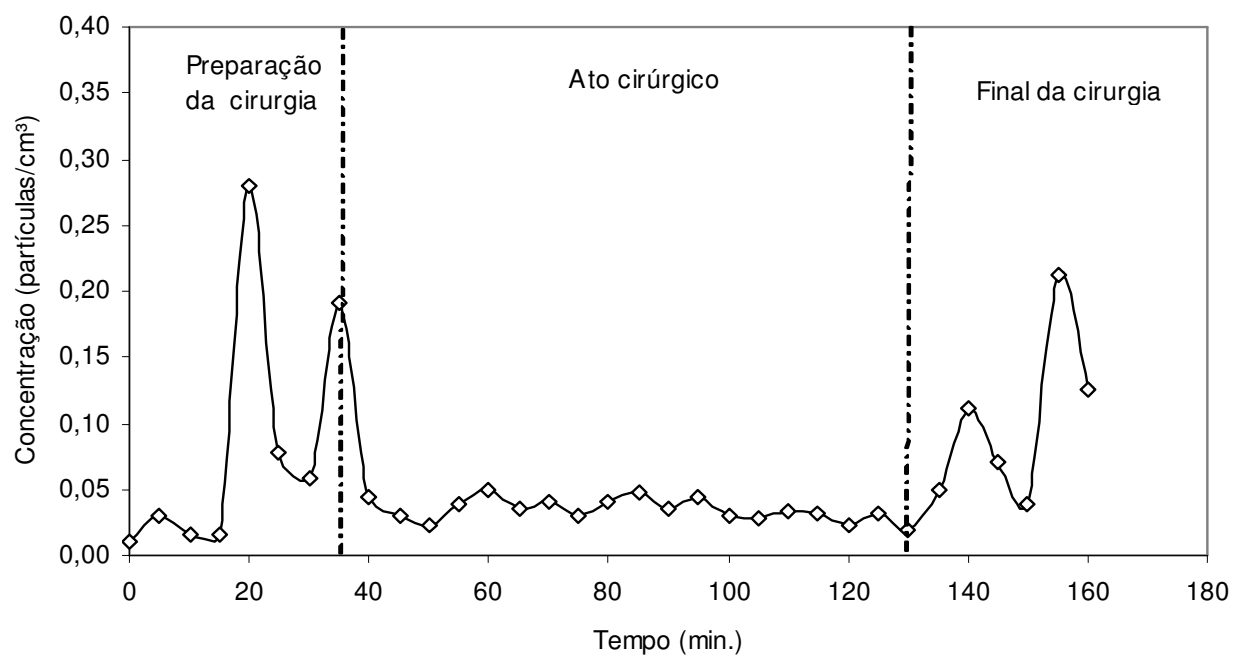

Figura 8.15 - Variação da concentração das partículas de 5 a $10 \mu \mathrm{m}$ ao longo do tempo, para o sistema $\mathrm{C}$, com condicionamento de ar ligado e portas abertas.

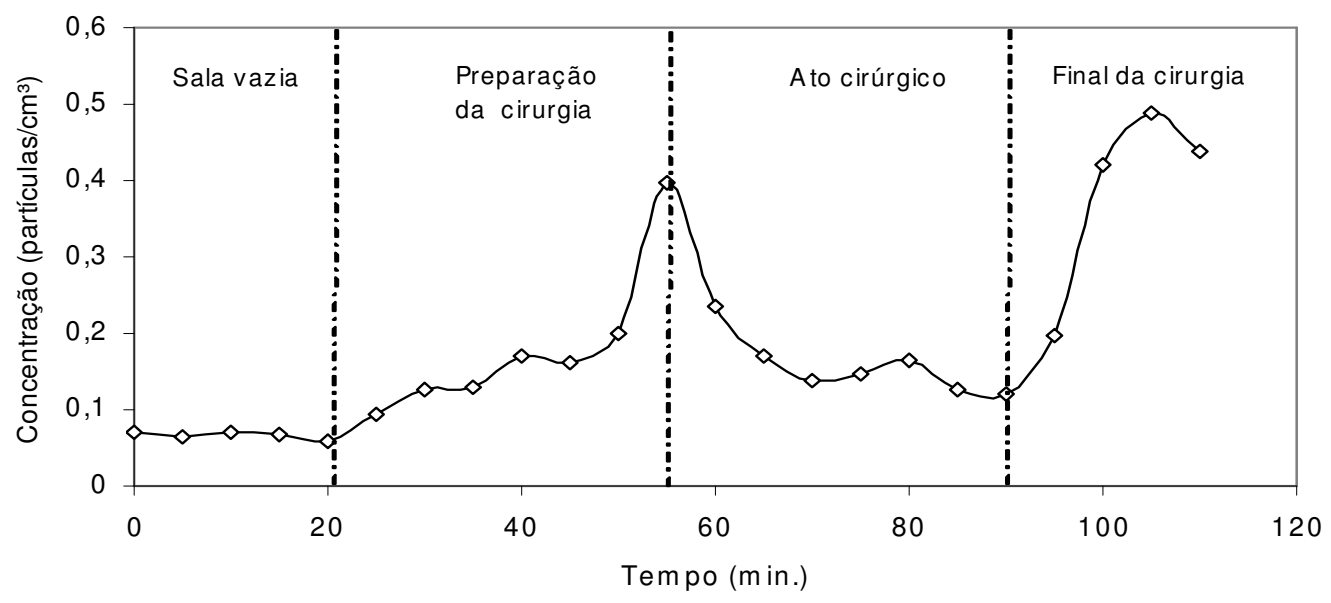

Figura 8.16 - Variação da concentração das partículas de 5 a $10 \mu \mathrm{m}$ ao longo do tempo, para o sistema D, com condicionamento de ar ligado e portas abertas.

\subsection{RELAÇÃO ENTRE A CONCENTRAÇÃO DE PARTíCULAS E A MÉDIA DAS CONCENTRAÇÕES}

Como descrito anteriormente, a fim de melhor evidenciar as variações nas concentrações das partículas nos vários tamanhos estudados, dividiu-se a concentração ao longo do tempo pela concentração média. Isso permitiu que se pudesse comparar graficamente o comportamento das partículas nas várias faixas de tamanho. Nos itens 8.6.1 a 8.6.4, são apresentadas as razões entre as concentrações de partículas e a média das concentrações para cada faixa de diâmetro. 


\subsubsection{Sistema A - Condicionamento de ar desligado e portas fechadas}

A Figura 8.17 mostra a variação da razão entre a concentração interna e a média para vários diâmetros de partículas, para o sistema com insuflamento pela parede e retorno próximo ao piso, com o sistema condicionamento de ar desligado e as portas fechadas.

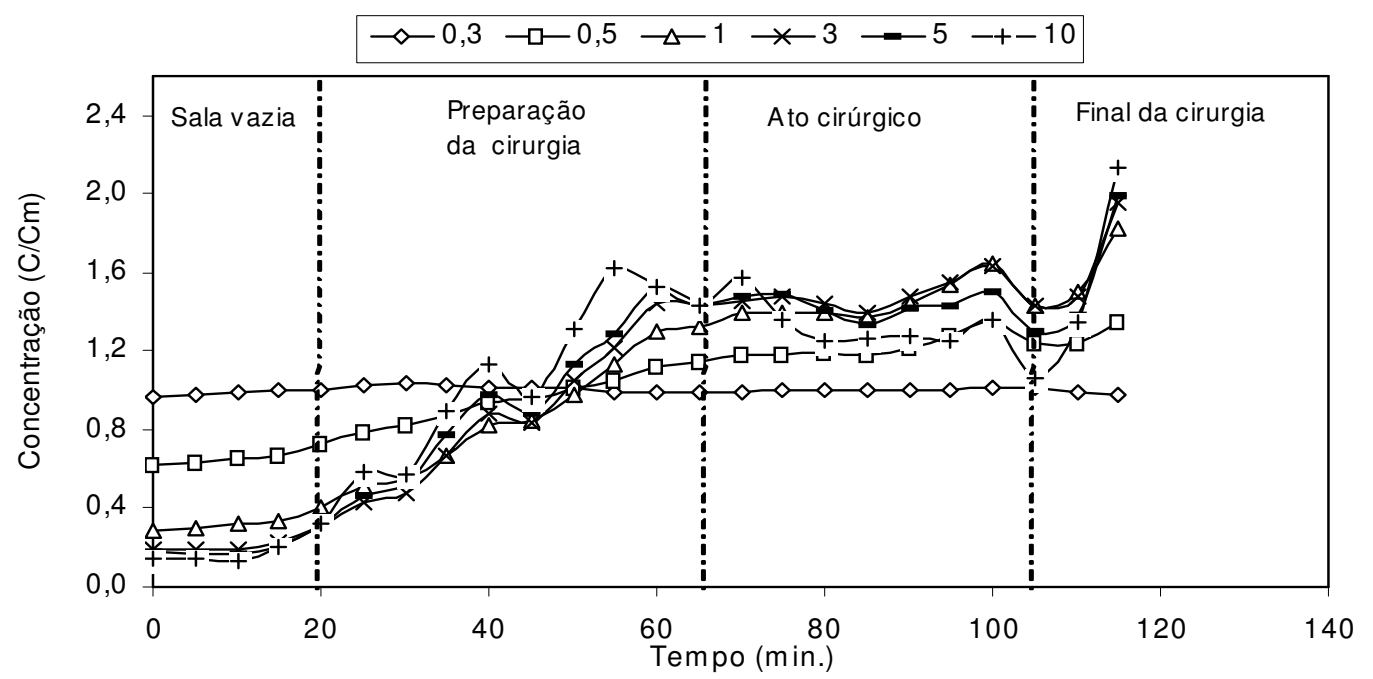

Figura 8.17 - Razão entre a concentração interna e a média ao longo do tempo para vários diâmetros de partículas, para o sistema A, com condicionamento de ar desligado e portas fechadas.

\subsubsection{Sistema A - Condicionamento de ar desligado e portas abertas}

A Figura 8.18 mostra a variação da razão entre a concentração interna e a média para vários diâmetros de partículas, para o sistema com insuflamento pela parede e retorno próximo ao piso, com o sistema condicionamento de ar desligado e as portas abertas. 


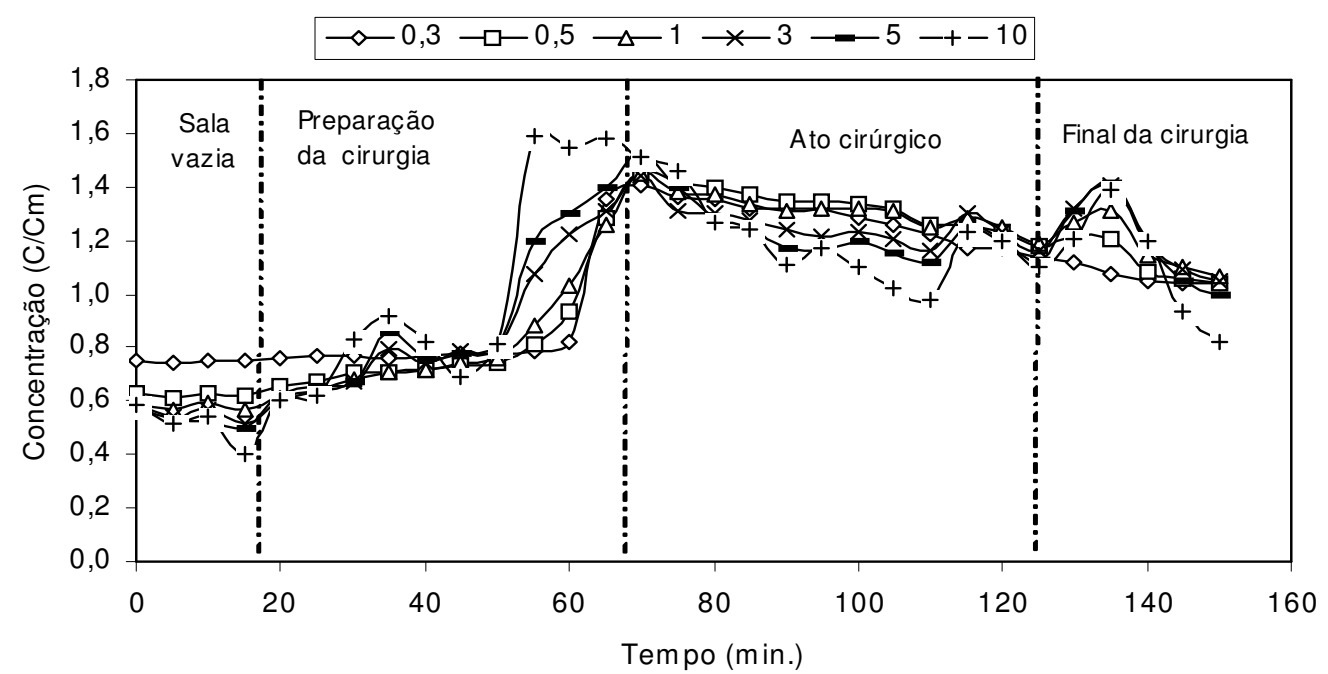

Figura 8.18 - Razão entre a concentração interna e a média ao longo do tempo para vários diâmetros de partículas, para o sistema A condicionamento de ar desligado e portas abertas.

\subsubsection{Sistemas A, B, C e D - Condicionamento de ar ligado e portas fechadas}

As Figuras 8.19 a 8.22 mostram a variação da razão entre a concentração interna e a média para vários diâmetros de partículas, para os vários sistemas de condicionamento de ar, com o sistema ligado e as portas fechadas, respectivamente, para os sistemas A, B, C e D.

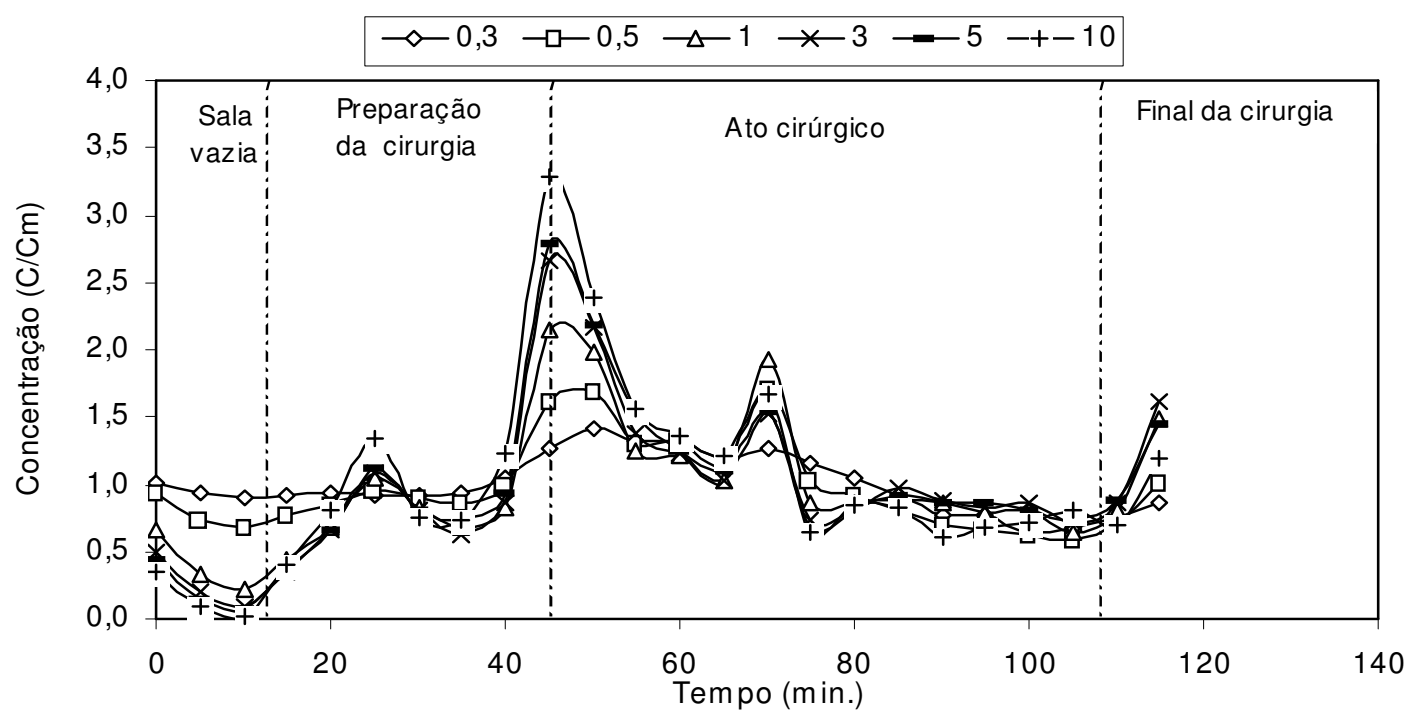

Figura 8.19 - Razão entre a concentração interna e a média ao longo do tempo para vários diâmetros de partículas, para o sistema A com condicionamento de ar ligado e portas fechadas. 


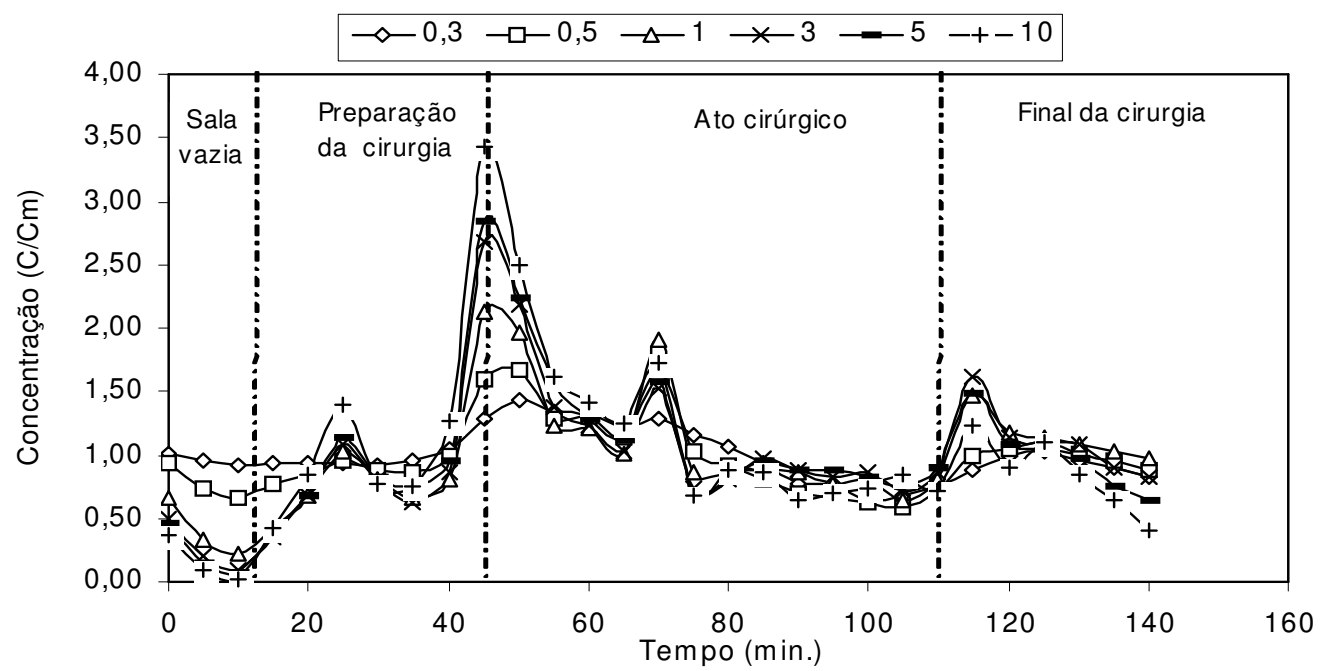

Figura 8.20 - Razão entre a concentração interna e a média ao longo do tempo para vários diâmetros de partículas, para o sistema B, com condicionamento de ar ligado e portas fechadas.

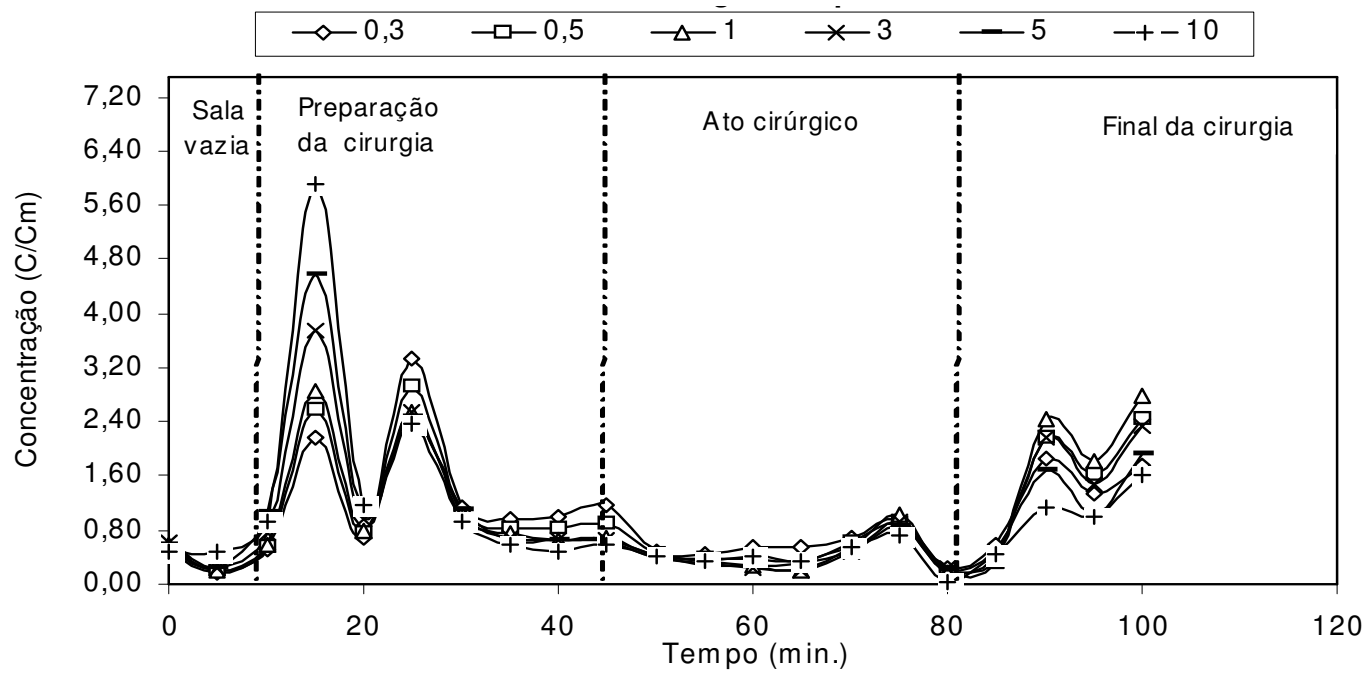

Figura 8.21 - Razão entre a concentração interna e a média ao longo do tempo para vários diâmetros de partículas, para o sistema $\mathrm{C}$, com condicionamento de ar ligado e portas fechadas. 


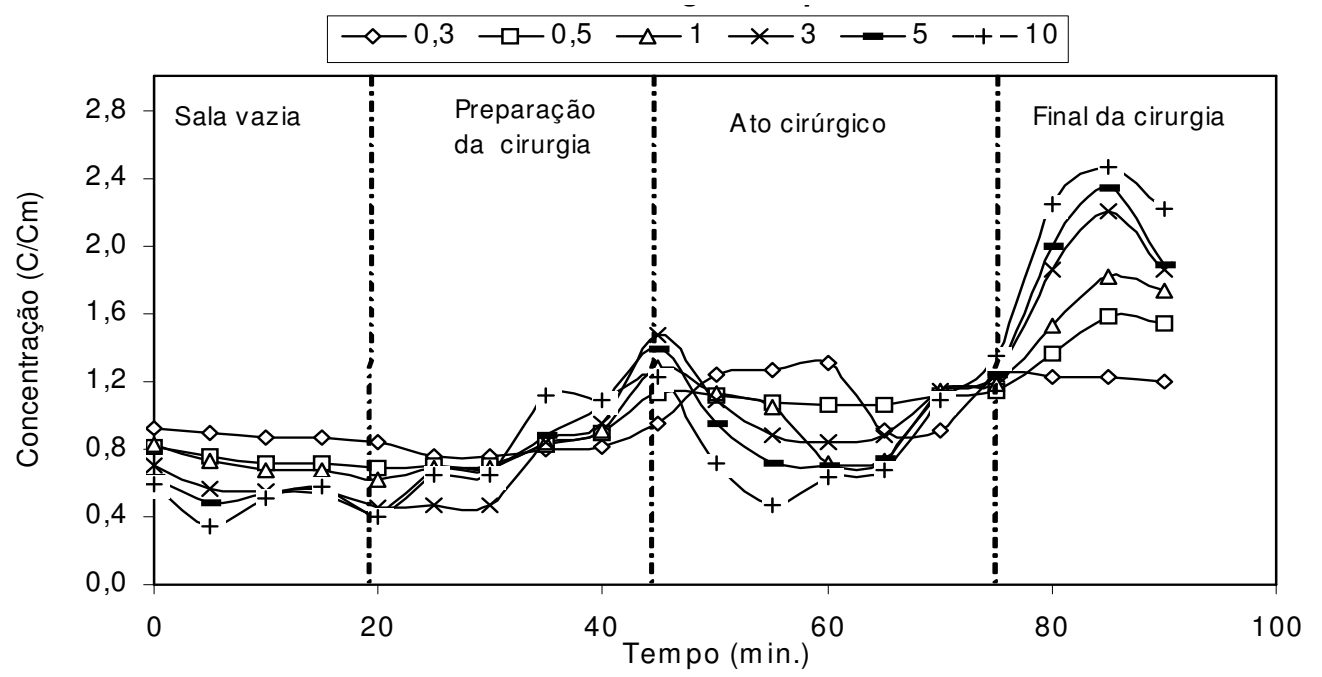

Figura 8.22 - Razão entre a concentração interna e a média ao longo do tempo para vários diâmetros de partículas, para o sistema $\mathrm{D}$, com condicionamento de ar ligado e portas fechadas.

\subsubsection{Sistemas A, B, C e D - Condicionamento de ar ligado e portas abertas}

As Figuras 8.23 a 8.26 mostram a variação da razão entre a concentração interna e a média para vários diâmetros de partículas, para os vários sistemas de condicionamento de ar, com o sistema ligado e as portas abertas, respectivamente, para os sistemas A, B, C e D.

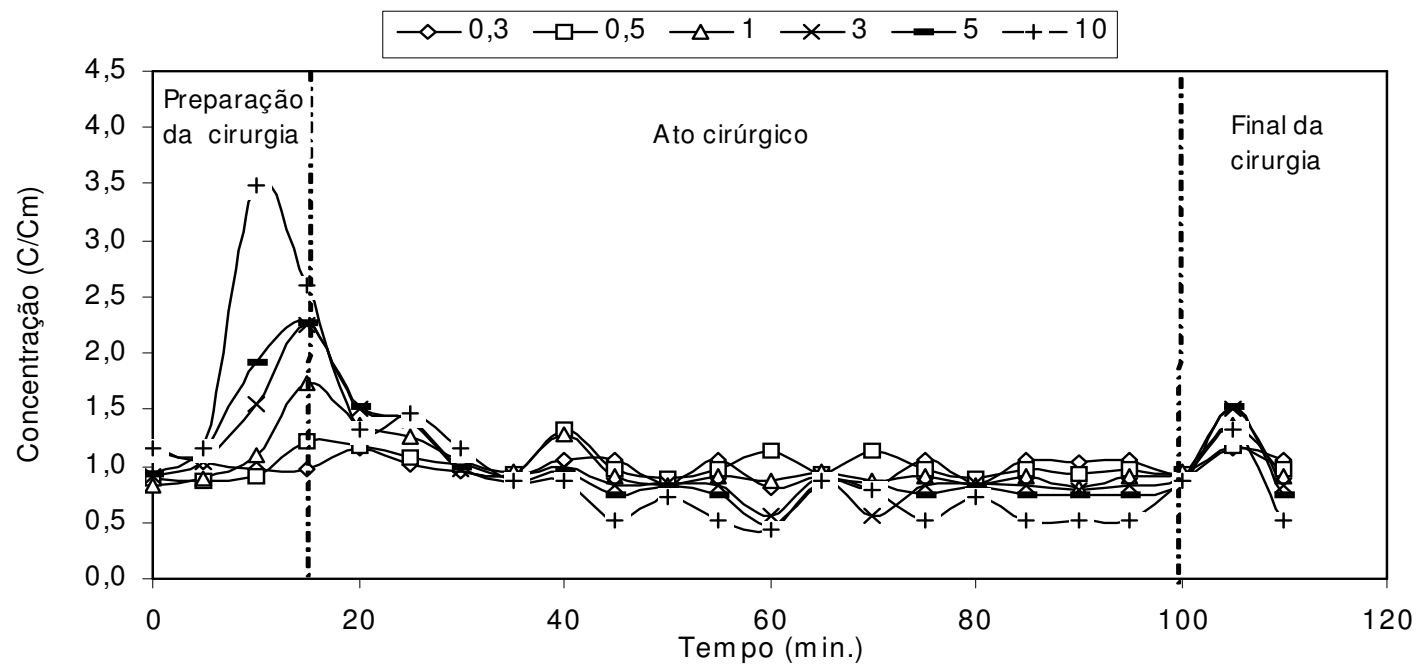

Figura 8.23 - Razão entre a concentração interna e a média ao longo do tempo para vários diâmetros de partículas, para o sistema A, com condicionamento de ar ligado e portas abertas. 


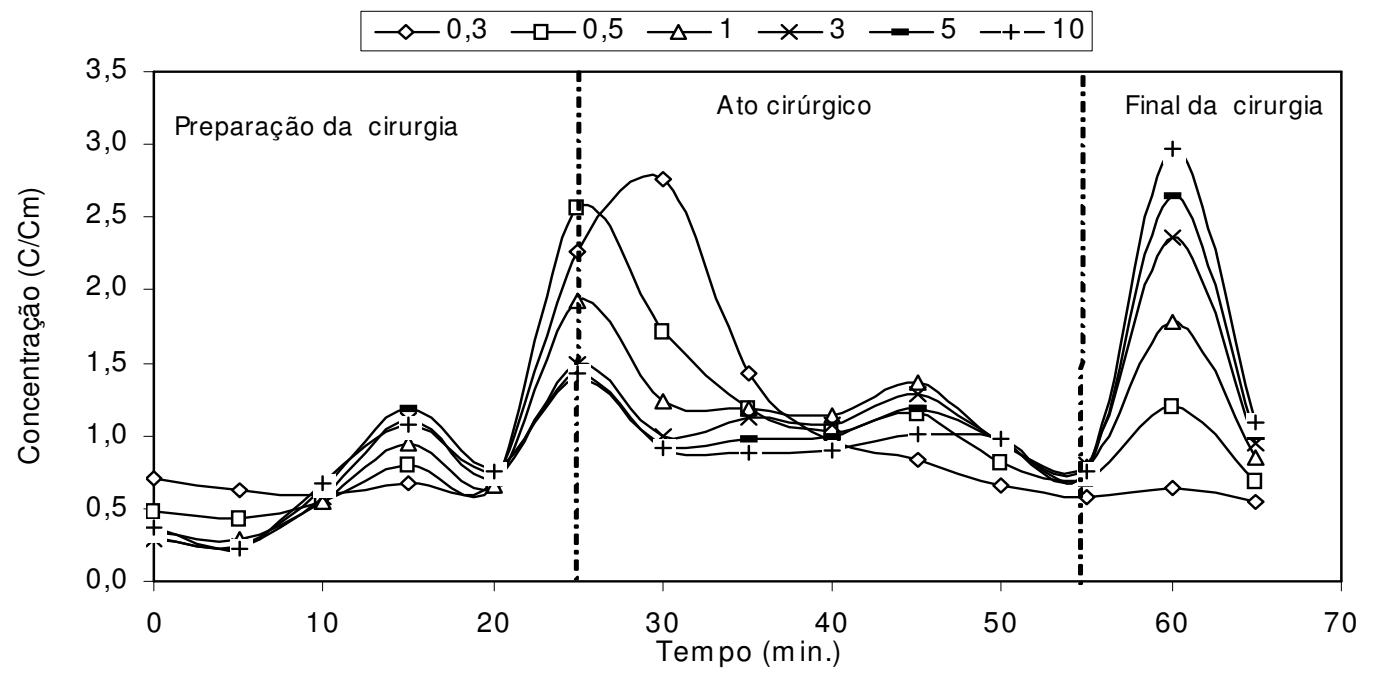

Figura 8.24 - Razão entre a concentração interna e a média ao longo do tempo para vários diâmetros de partículas, para o sistema B, com condicionamento de ar ligado e portas abertas.

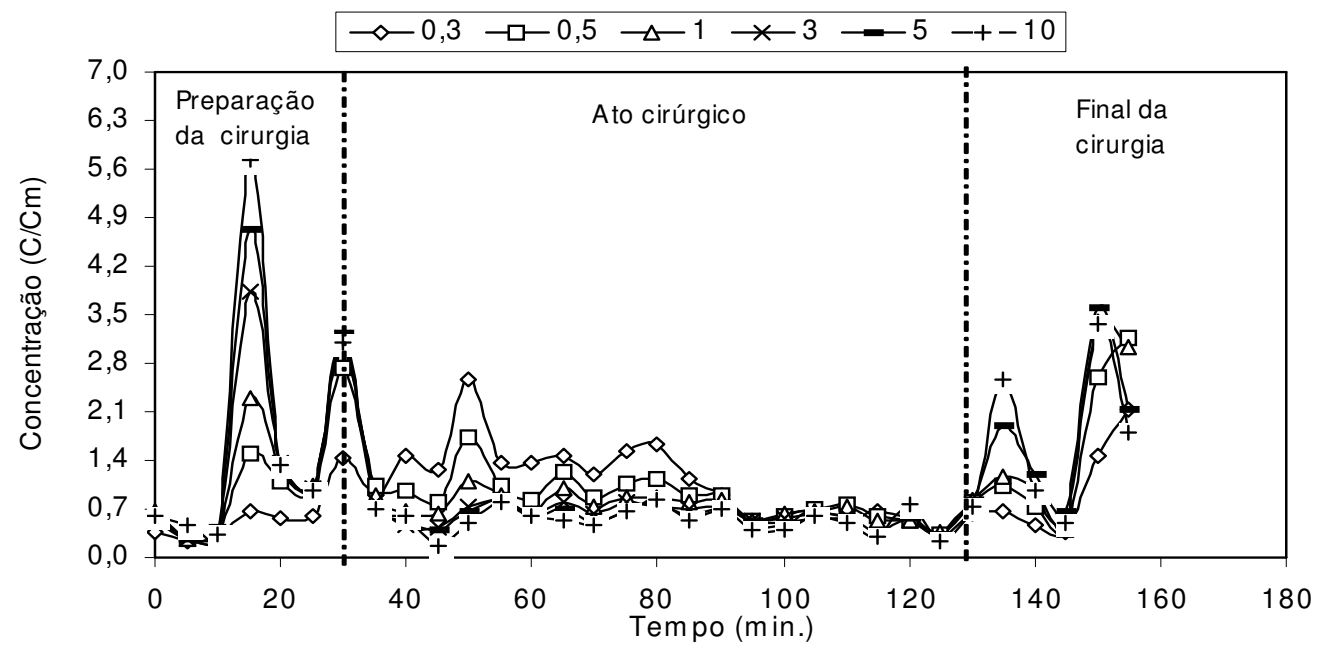

Figura 8.25 - Razão entre a concentração interna e a média ao longo do tempo para vários diâmetros de partículas, para o sistema $\mathrm{C}$, com condicionamento de ar ligado e portas abertas. 


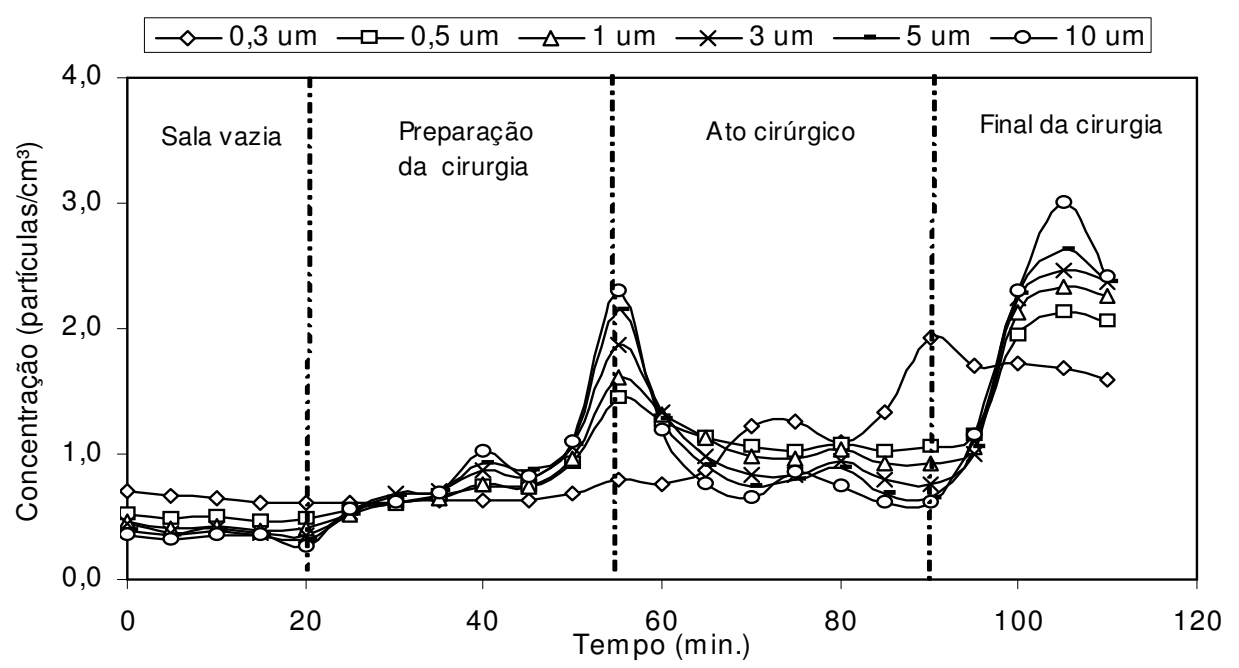

Figura 8.26 - Razão entre a concentração interna e a média ao longo do tempo para vários diâmetros de partículas, para o sistema $\mathrm{D}$, com condicionamento de ar ligado e portas abertas.

\subsection{COMPARAÇÃO ENTRE AS CONCENTRAÇÕES NAS SALAS CIRÚRGICAS E NOS CORREDORES ADJACENTES}

Nos itens 8.7.1 a 8.7.2, mostram-se comparações entre as concentrações de partículas ao longo do tempo, no interior das salas cirúrgicas e nos corredores. O objetivo dessas comparações é observar o efeito da abertura das portas sobre a concentração de partículas no interior da sala cirúrgica. Quando as portas estão fechadas, pode-se utilizar a concentração externa como referência para avaliar os processos de geração e remoção de partículas no interior da sala cirúrgica. Por outro lado, quando as portas estão abertas, é possível avaliar as trocas de partículas entre a sala e o corredor adjacente.

\subsubsection{Sistema A - Condicionamento de ar desligado e portas fechadas}

A Figura 8.27 apresenta uma comparação entre a concentração interna e externa à sala cirúrgica, para o caso em que o condicionamento de ar permanece desligado e as portas fechadas. 


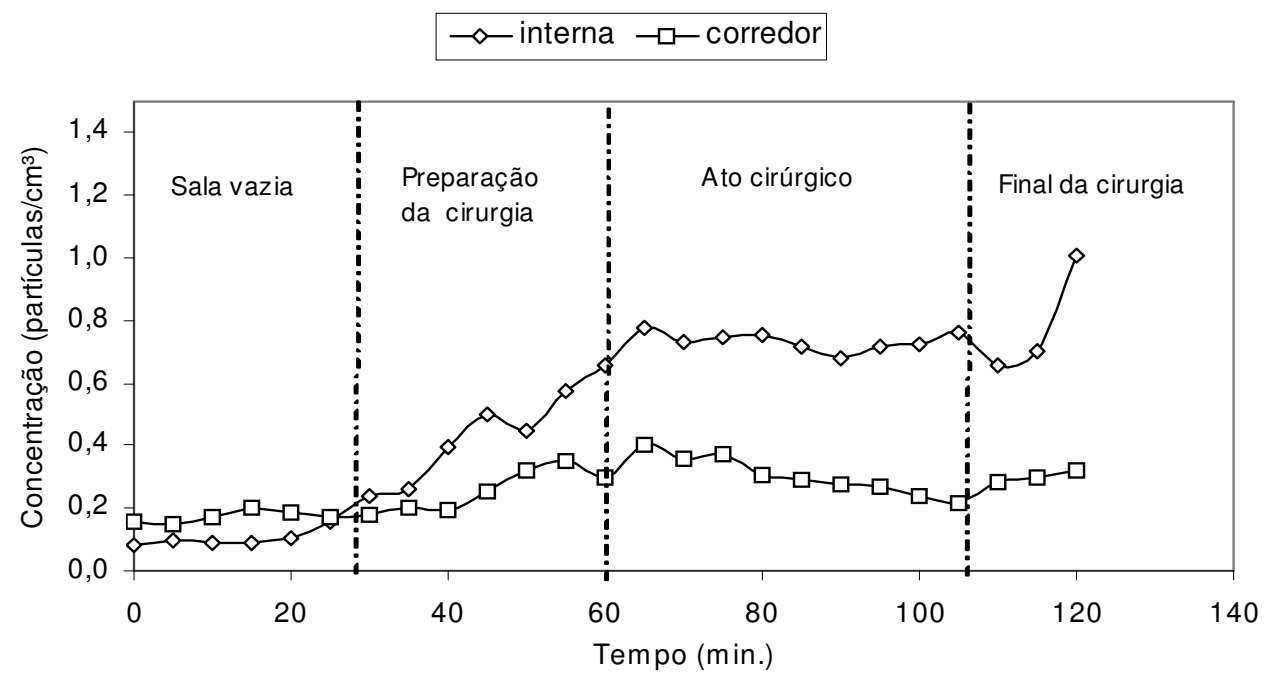

Figura 8.27- Concentração de partículas ao longo do tempo no interior da sala e corredor, para o sistema A, com condicionamento de ar desligado e portas fechadas.

\subsubsection{Sistema A - Condicionamento de ar desligado e portas abertas}

Na Figura 8.28, mostra-se a comparação entre a concentração de partículas no interior da sala cirúrgica e no corredor, para o caso em que o condicionamento de ar permanece desligado e as portas abertas.

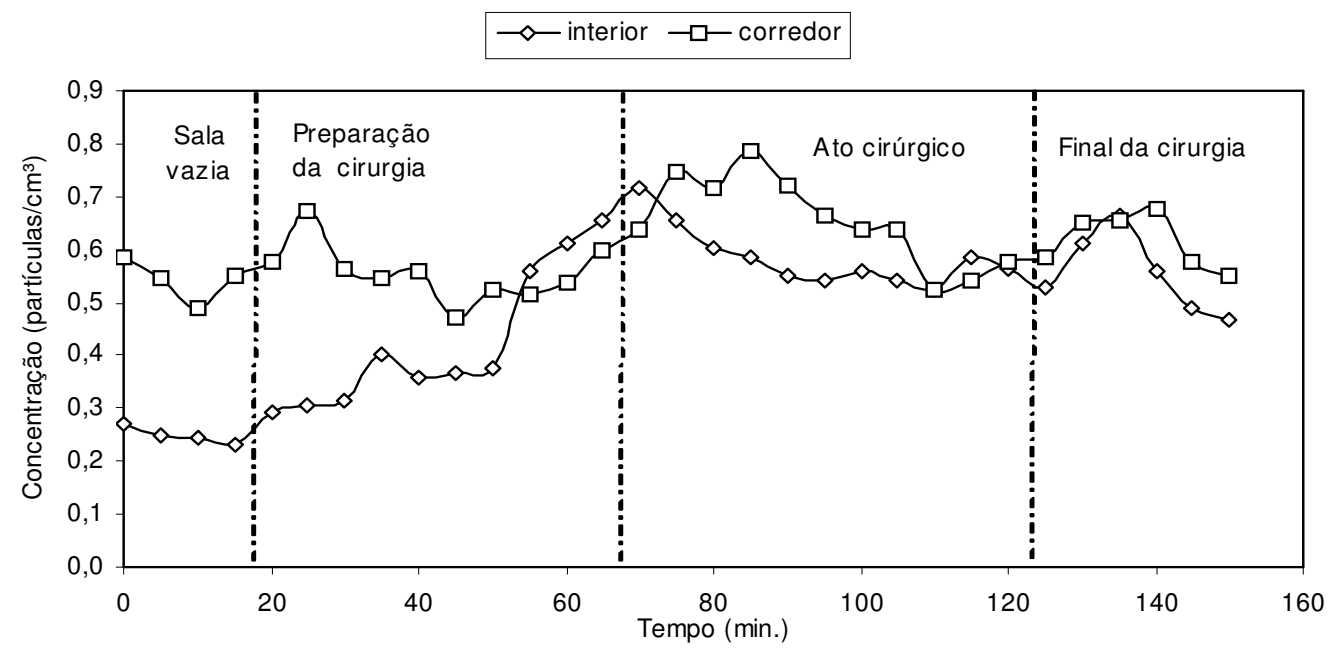

Figura 8.28 - Concentração de partículas ao longo do tempo no interior da sala e corredor, para o sistema A, com condicionamento de ar desligado e portas abertas.

\subsubsection{Sistemas A, B, C e D - Condicionamento de ar ligado e portas fechadas}

Nas Figuras 8.29 a 8.32, apresentam-se comparações entre as concentrações de partículas no interior das salas cirúrgicas e nos corredores adjacentes, para o caso em que o 
condicionamento de ar está ligado e as portas fechadas, respectivamente, para os sistemas A, $\mathrm{B}, \mathrm{C}$ e D.

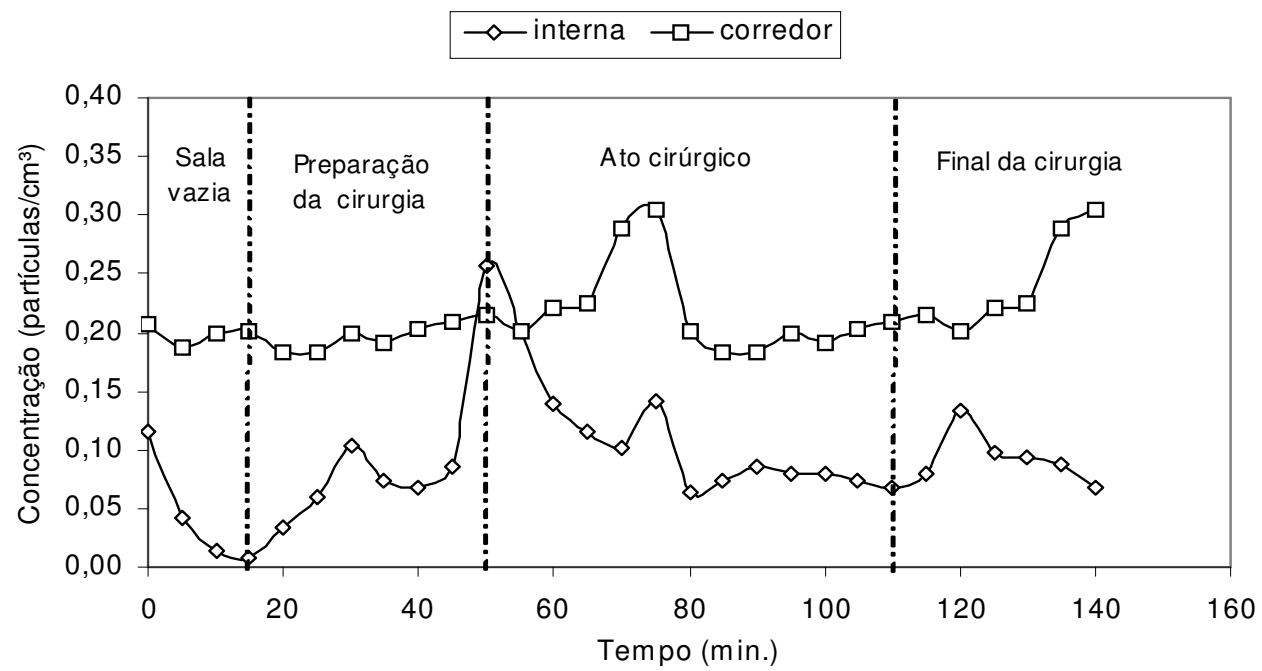

Figura 8.29- Concentração de partículas ao longo do tempo no interior da sala e corredor, para o sistema A com condicionamento de ar ligado e portas fechadas.

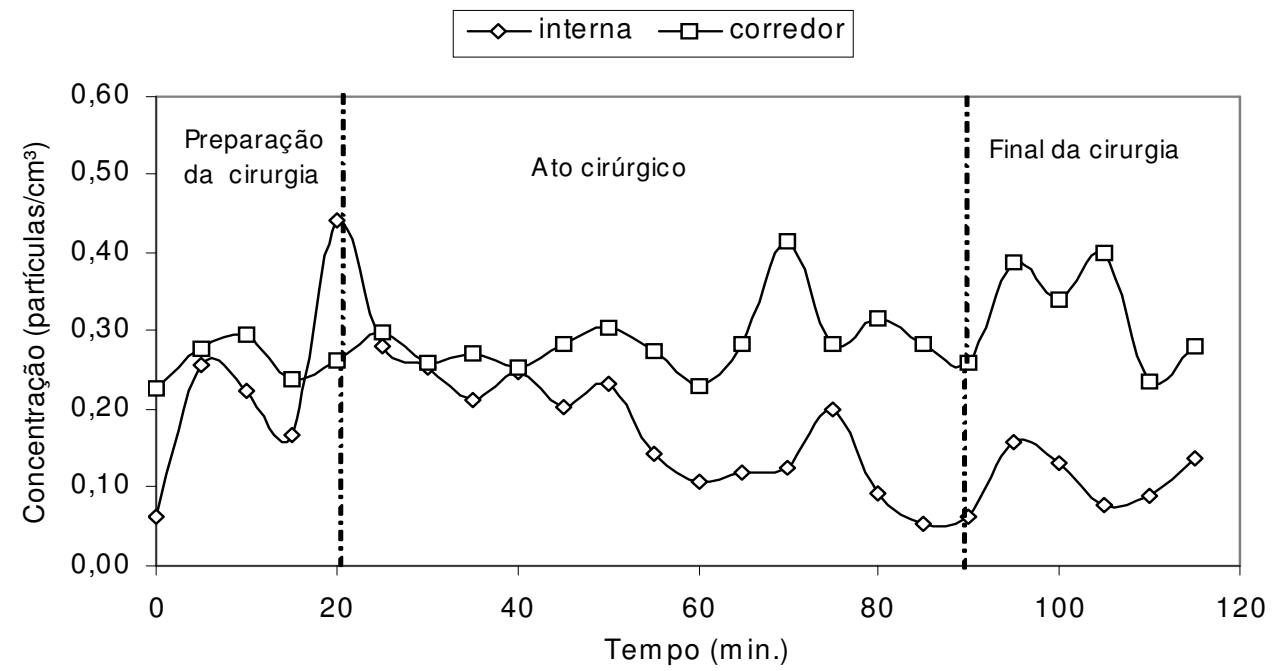

Figura 8.30 - Concentração de partículas ao longo do tempo no interior da sala e corredor, para o sistema B, com condicionamento de ar ligado e portas fechadas. 


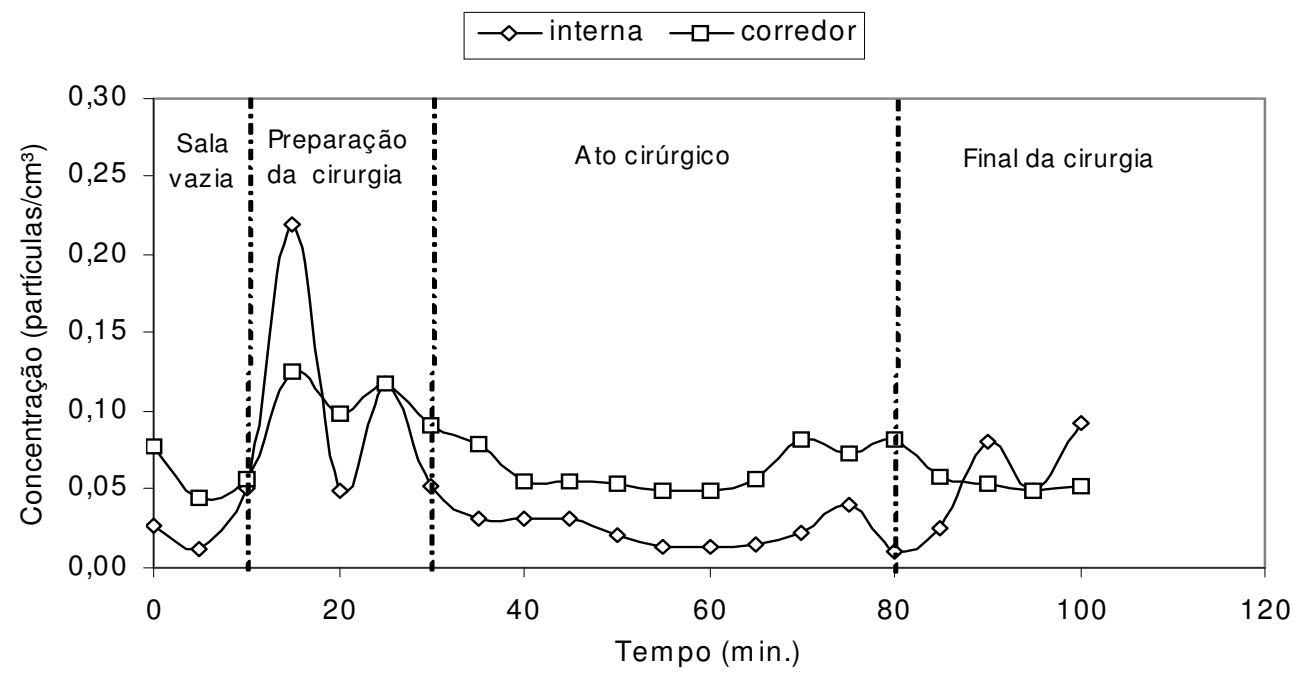

Figura 8.31 - Concentração de partículas ao longo do tempo no interior da sala e corredor, para o sistema $\mathrm{C}$, com condicionamento de ar ligado e portas fechadas.

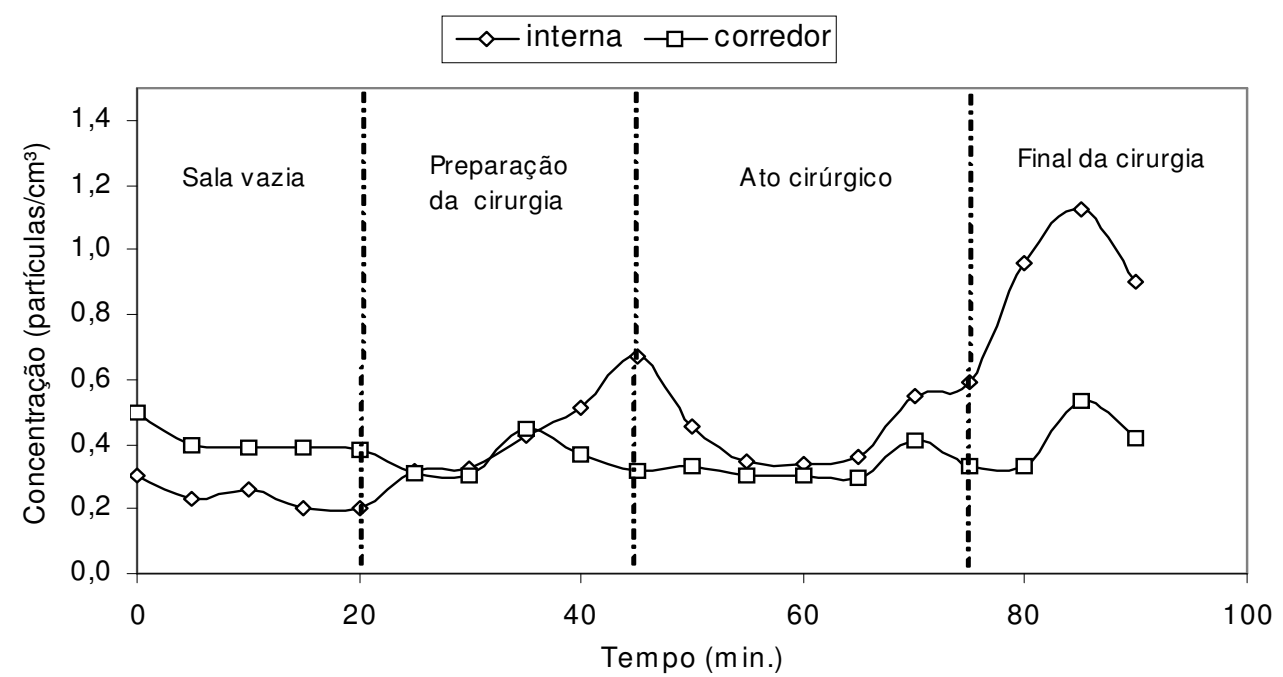

Figura 8.32 - Concentração de partículas ao longo do tempo no interior da sala e corredor, para o sistema D, com condicionamento de ar ligado e portas fechadas. 


\subsubsection{Sistemas A, B, C e D - Condicionamento de ar ligado e portas abertas}

Nas Figuras 8.33 a 8.36, apresentam-se comparações entre as concentrações de partículas no interior das salas cirúrgicas e nos corredores adjacentes, para o caso em que o condicionamento de ar está ligado e as portas fechadas, respectivamente, para os sistemas A, $\mathrm{B}, \mathrm{C}$ e D.

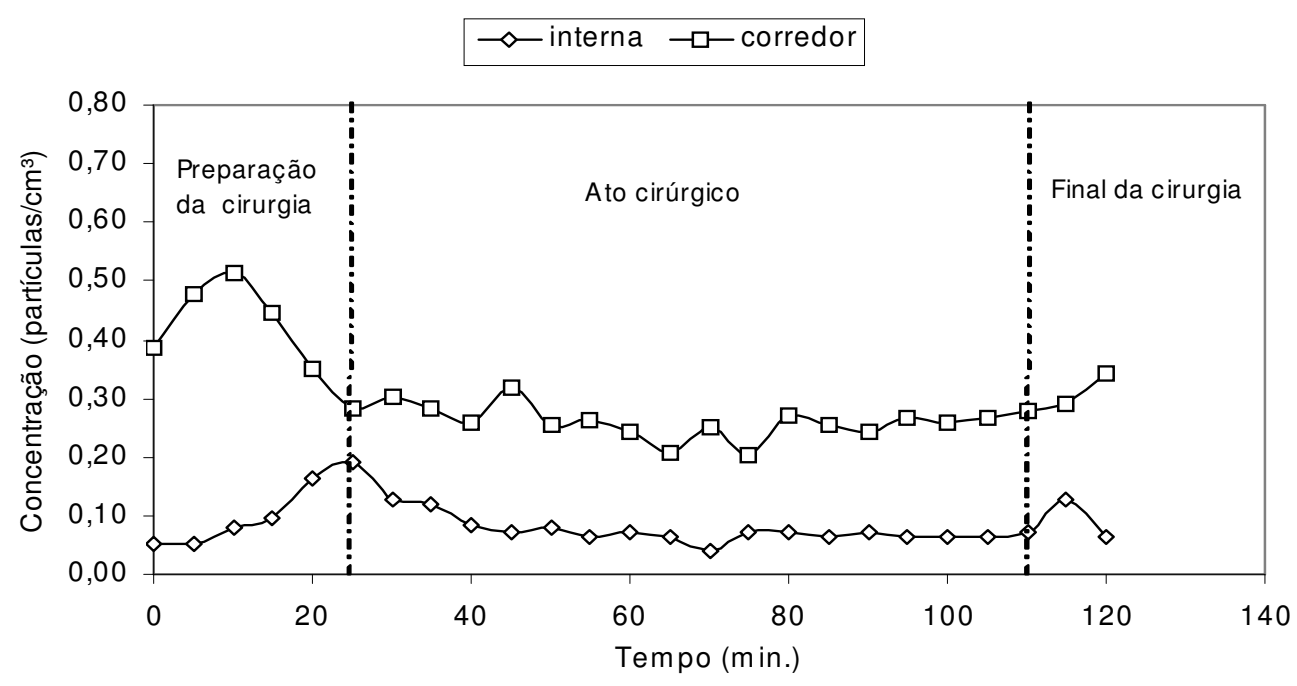

Figura 8.33 - Concentração de partículas ao longo do tempo no interior da sala e corredor, para o sistema A, com condicionamento de ar ligado e portas abertas.

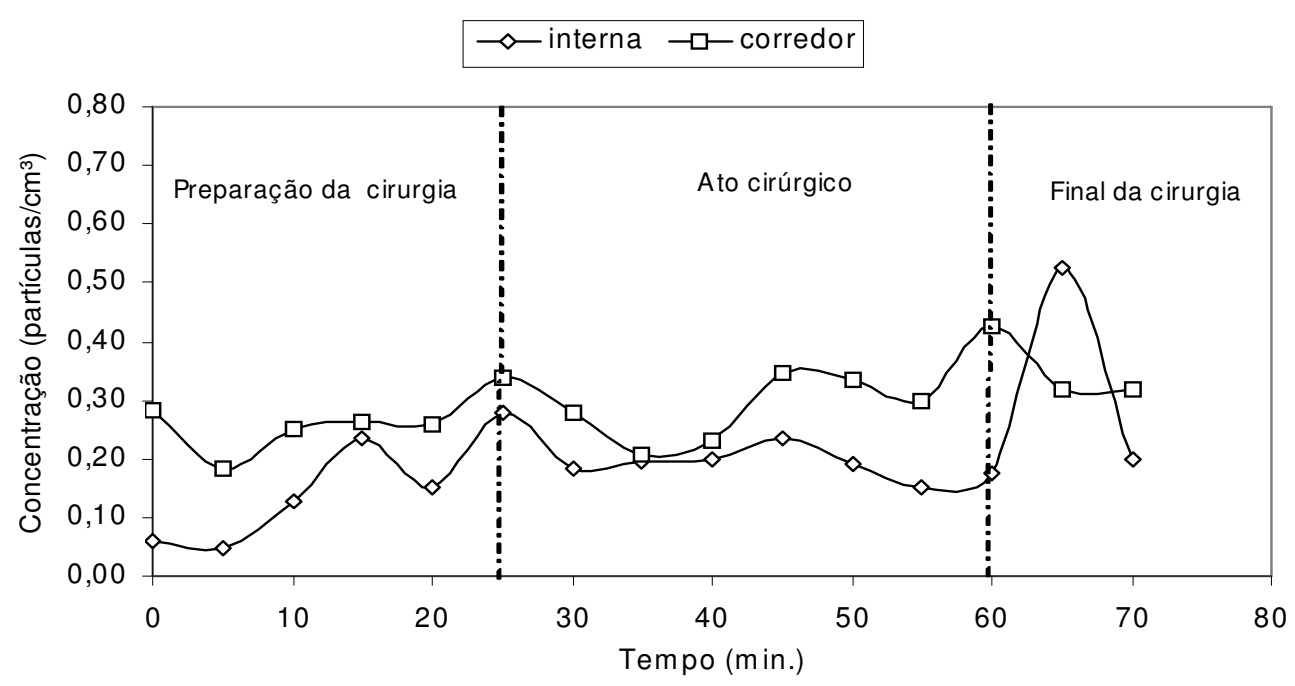

Figura 8.34 - Concentração de partículas ao longo do tempo no interior da sala e corredor, para o sistema B, com condicionamento de ar ligado e portas abertas. 


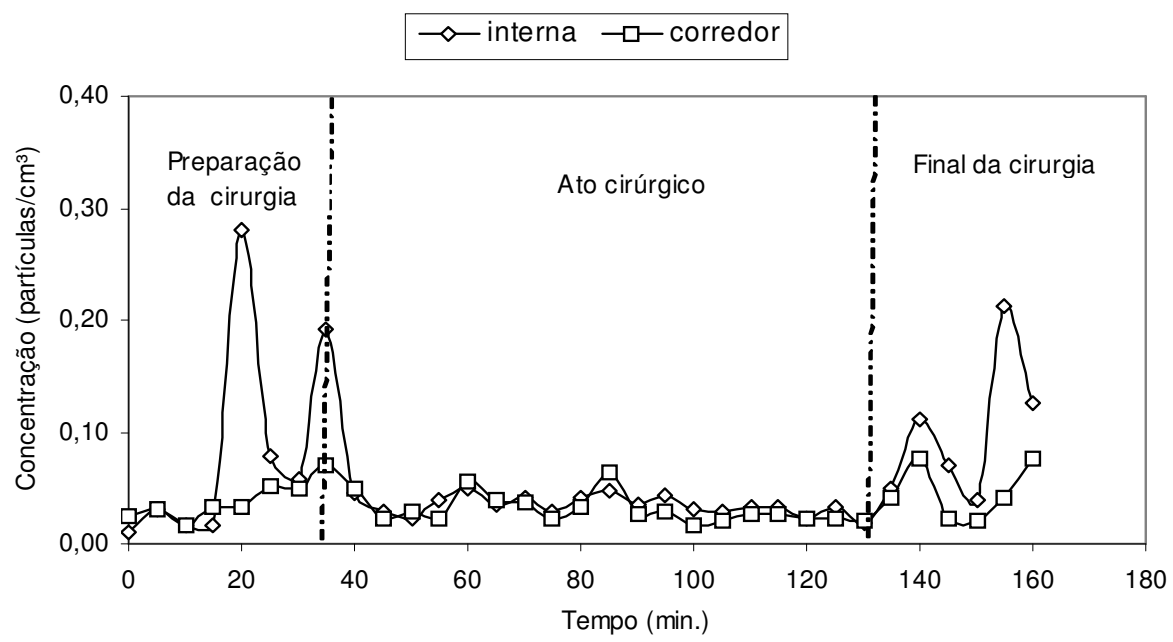

Figura 8.35 - Concentração de partículas ao longo do tempo no interior da sala e corredor, para o sistema $\mathrm{C}$, com condicionamento de ar ligado e portas abertas.

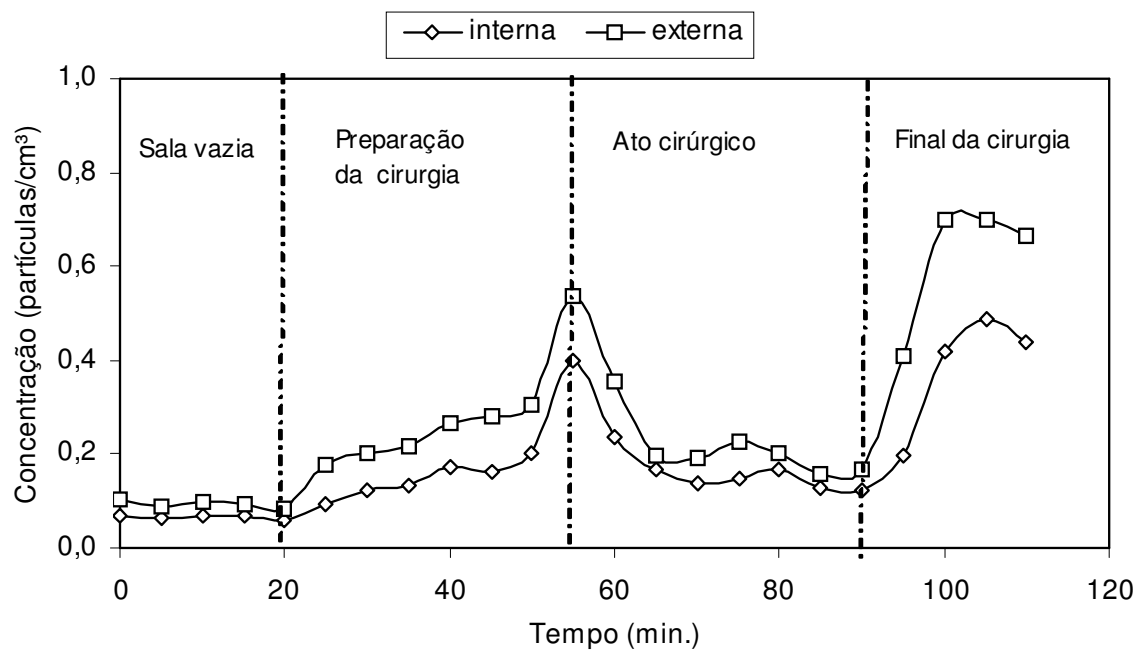

Figura 8.36 - Concentração de partículas ao longo do tempo no interior da sala e corredor, para o sistema $\mathrm{D}$, com condicionamento de ar ligado e portas abertas. 


\section{CAPÍTULO 9}

\section{PREDIÇÃO DA CONCENTRAÇÃO DE PARTÍCULAS}

Neste capítulo são apresentados os resultados das predições das concentrações de partículas para os diferentes sistemas e situações estudadas. Como já mencionado anteriormente, o modelo proposto trabalha a partir de iterações, isto é, utilizam-se os valores finais de concentração para um intervalo como valores iniciais para o intervalo subseqüente. Dessa forma, a variação da concentração com o tempo é determinada por aplicações sucessivas, para cada intervalo de tempo, das equações de balanço de massa obtidas para cada caso analisado.

O valor inicial da concentração de partículas no interior da sala cirúrgica para a primeira iteração deve ser arbitrado. Assim, escolheram-se, para isso, valores médios de concentrações em salas cirúrgicas vazias, antes do início da entrada da equipe cirúrgica e do paciente.

Os demais parâmetros que alimentam o modelo são: volume da sala, vazão de insuflamento e retorno, taxa de deposição, taxa de infiltração e fator de infiltração (no caso das portas abertas) e as partículas geradas pelas pessoas.

\subsection{SISTEMA COM INSUFLAMENTO PELA PAREDE E RETORNO PRÓXIMO AO PISO (SISTEMA A)}

\subsubsection{Condicionamento de ar desligado e portas fechadas}

A Figura 8.1 apresenta uma comparação entre as concentrações de partículas medidas no interior da sala (próximo ao campo cirúrgico) e as concentrações preditas pelo modelo, para o caso onde o sistema de condicionamento de ar permaneceu desligado e as portas fechadas. 


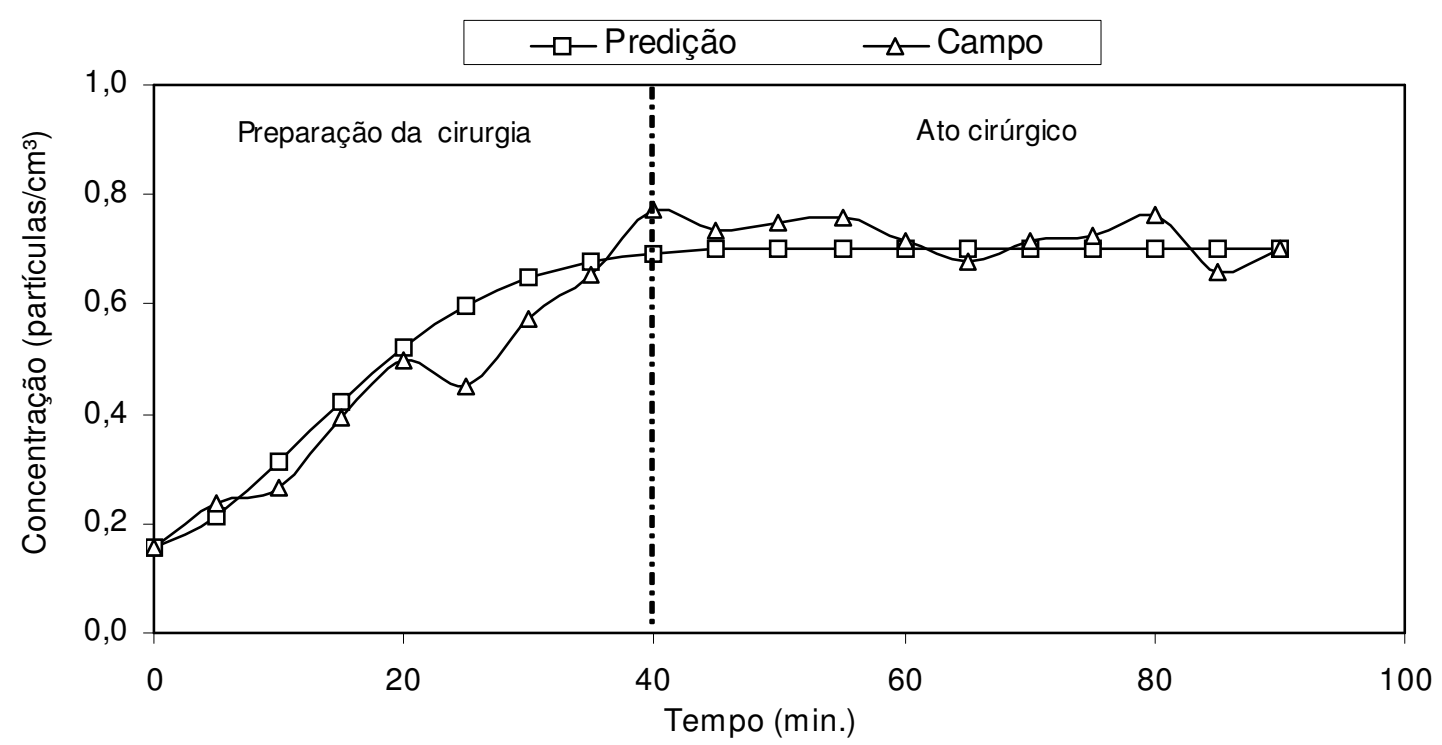

Figura 9.1 - Comparação entre os dados de campo e de predição, para o sistema A com condicionamento de ar desligado e portas fechadas.

A Figura 9.2 apresenta uma comparação entre as concentrações de partículas medidas no interior da sala e as concentrações preditas pelo modelo, sem considerar as partículas geradas na colocação dos campos cirúrgicos.

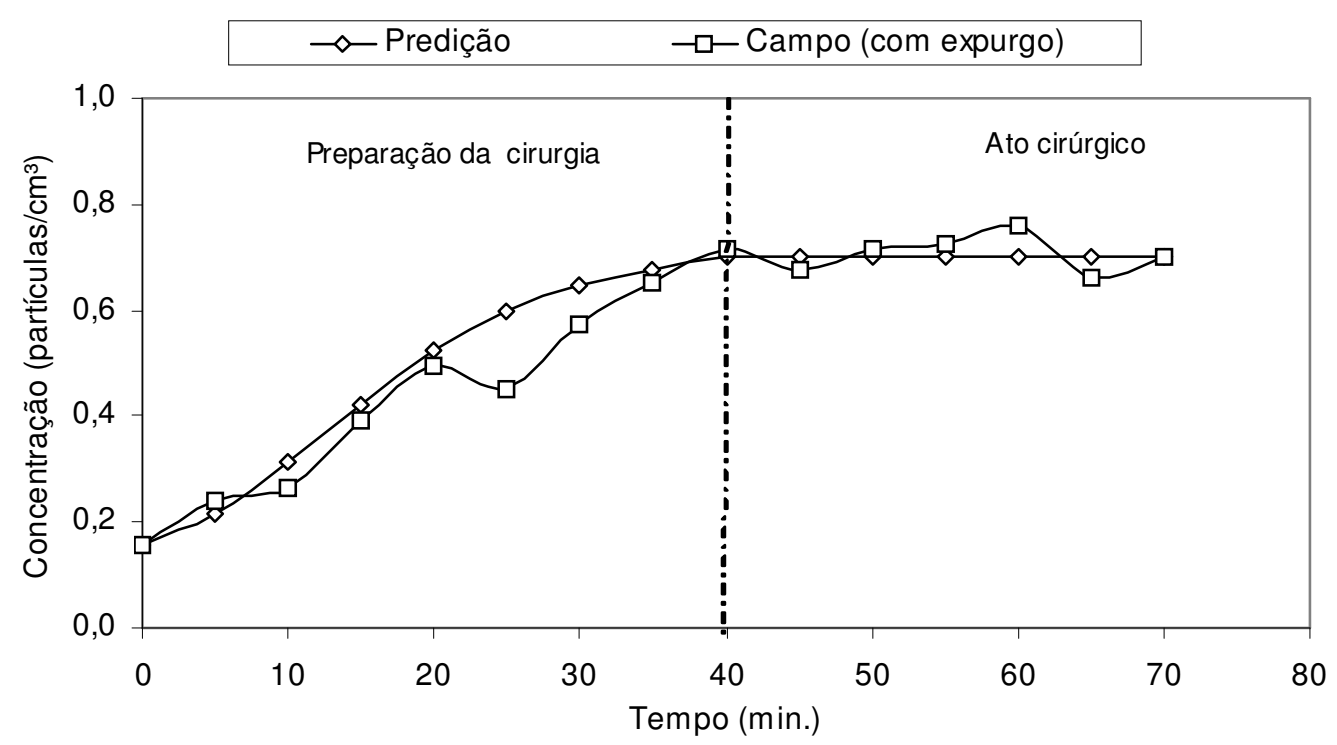

Figura 9.2 - Comparação entre os dados de campo e os resultados de predição, sem considerar o efeito dos campos cirúrgicos, para o sistema $\mathrm{A}$, com condicionamento de ar desligado e portas fechadas.

A Figura 9.3 apresenta uma comparação entre as concentrações de partículas medidas no interior da sala e as concentrações preditas pelo modelo, considerando um fator de 
multiplicação que leva em consideração o efeito das partículas geradas na colocação dos campos cirúrgicos.

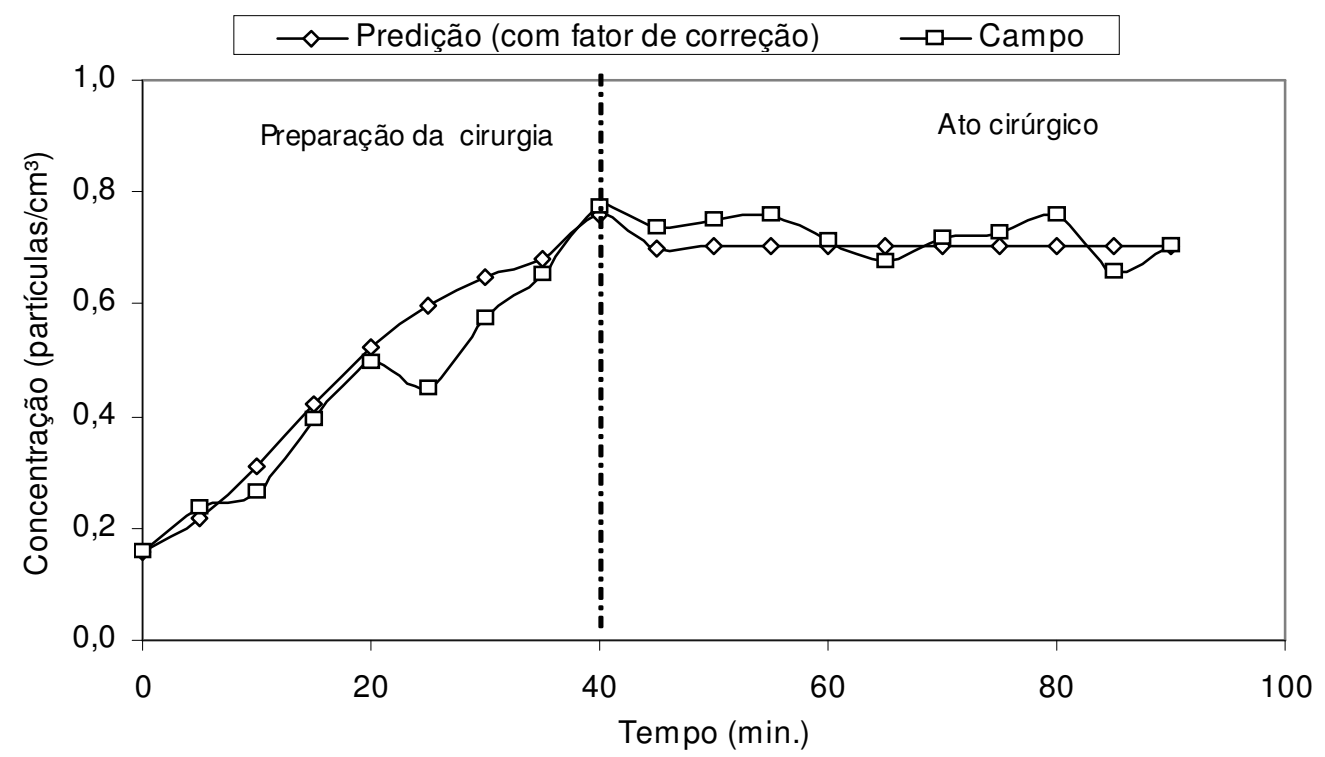

Figura 9.3 - Comparação entre os dados de campo e os resultados de predição, considerando um fator para os campos cirúrgicos, para o sistema A, com condicionamento de ar desligado e portas fechadas.

A Figura 9.4 apresenta uma comparação entre as concentrações medidas das partículas e as concentrações preditas pelo modelo para diferentes tamanhos (diâmetros) de partículas.

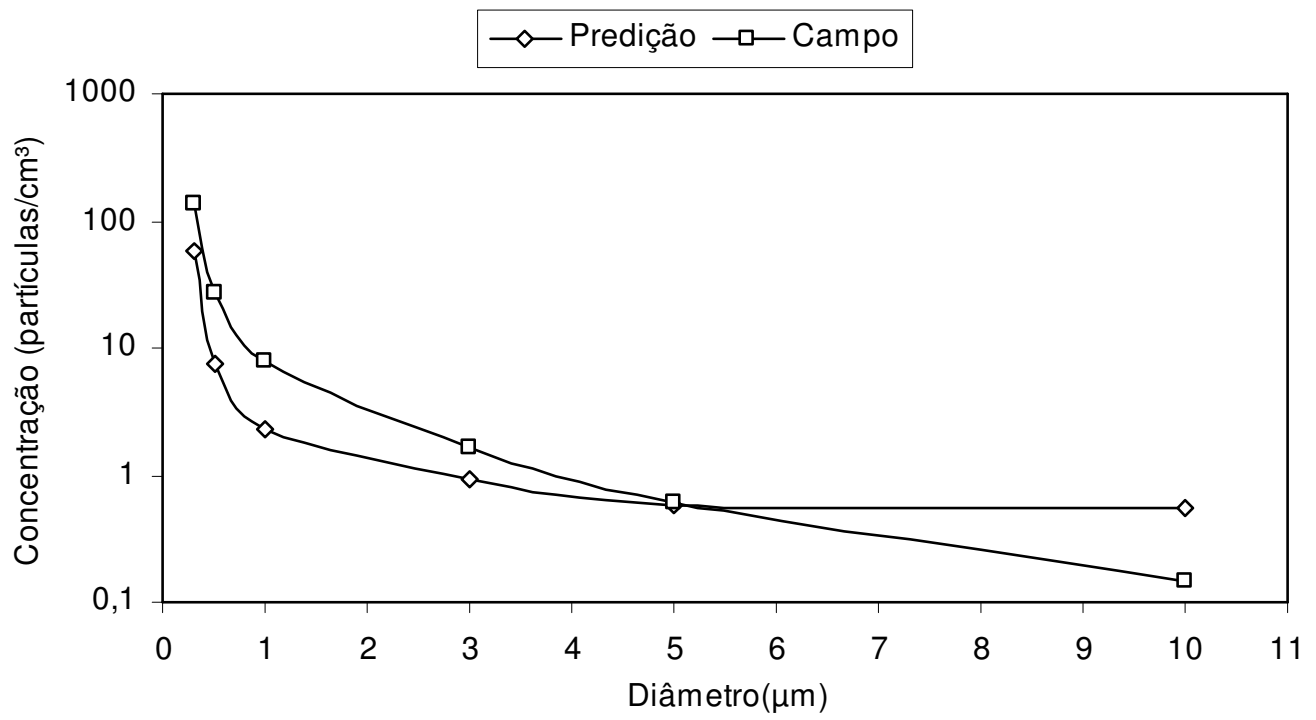

Figura 9.4-Concentração de partículas em função do diâmetro, para o sistema A, com condicionamento de ar desligado e portas fechadas. 
A Figura 9.5 mostra a contribuição de cada fator na geração total das partículas no interior da sala. Como se previa, a maior fonte de geração de partículas para a situação estudada (portas fechadas e condicionamento de ar desligado) são as pessoas. Os processos de colocação e de remoção dos aventais e campos cirúrgicos contribuíram apenas com uma pequena parcela $(0,89 \%)$ do total de partículas geradas na sala.

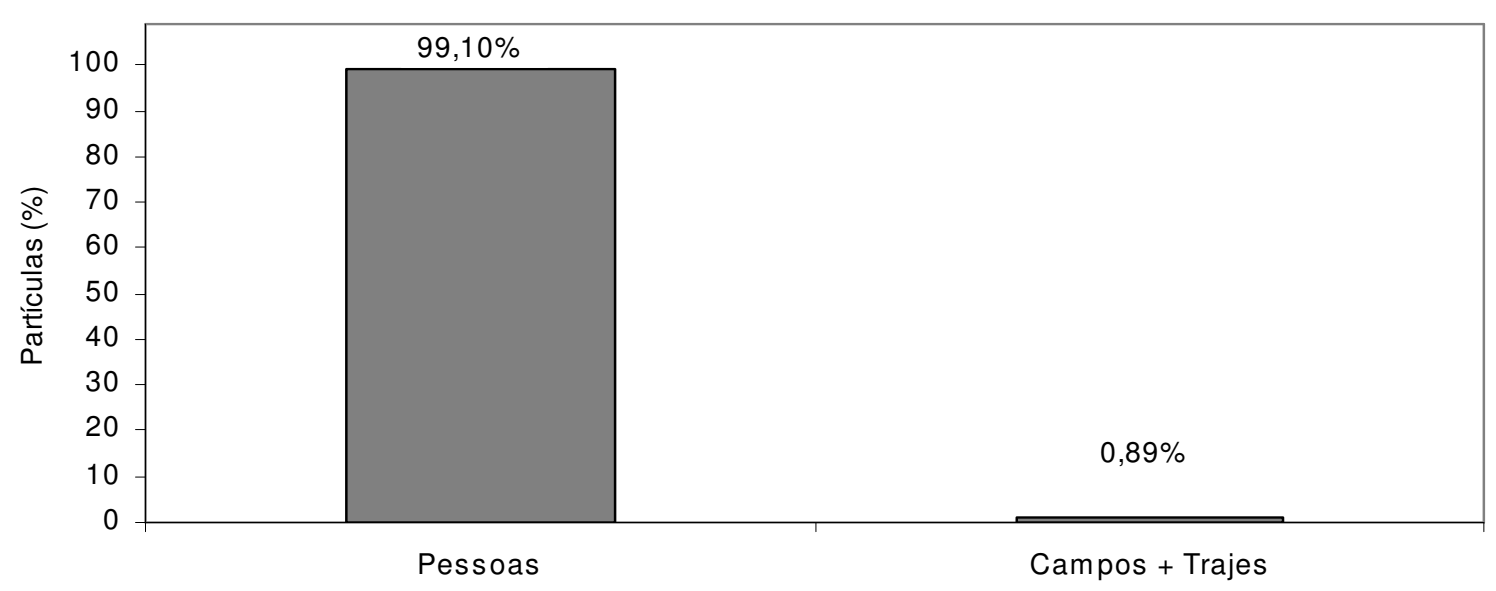

Figura 9.5 - Fatores que contribuem na geração total de partículas, para o sistema A, com condicionamento de ar desligado e portas fechadas.

No caso do processo de remoção, foi considerada no modelo apenas a deposição como mecanismo de perda de partículas. Porém, como mostra a Figura 9.6, outros fatores influenciam na remoção de partículas do interior da sala.

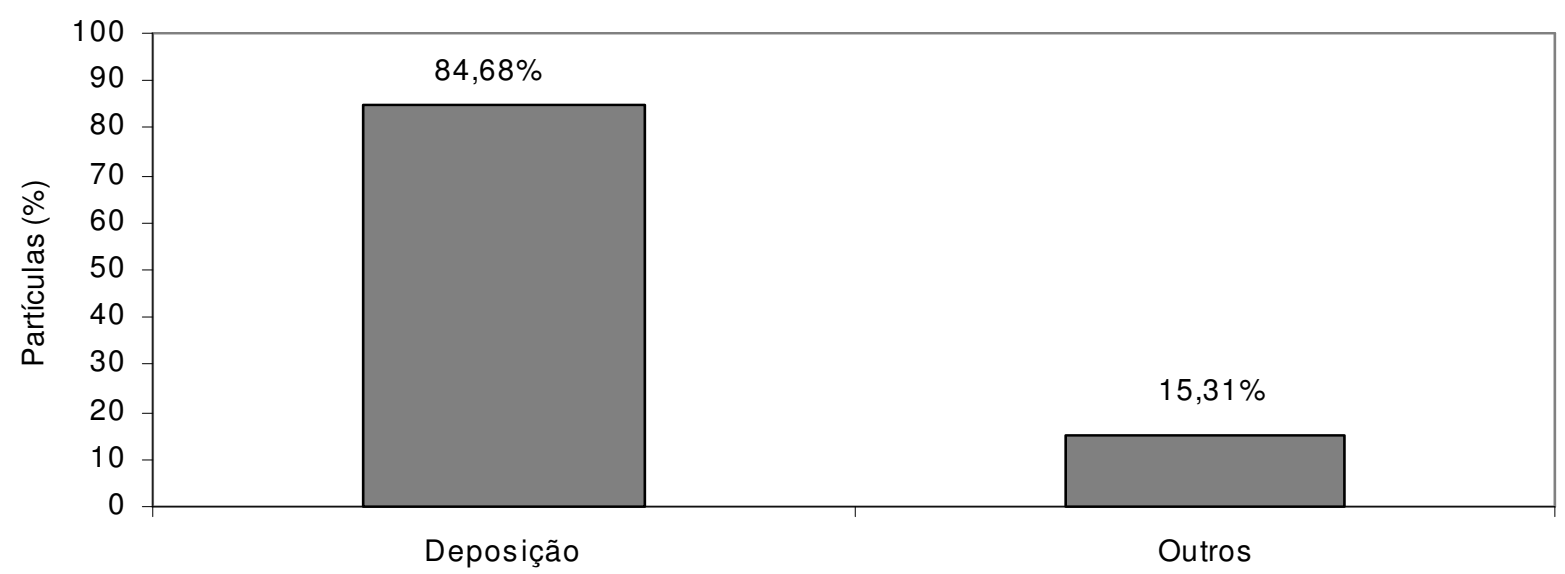

Figura 9.6 - Fatores que contribuem na remoção das partículas do ar da sala, para o sistema A, com condicionamento de ar desligado e portas fechadas. 


\subsubsection{Condicionamento de ar desligado e portas abertas}

A Figura 9.7 apresenta uma comparação entre as concentrações de partículas medidas no interior da sala e as concentrações preditas pelo modelo, para o caso onde o sistema de condicionamento de ar permaneceu desligado e as portas abertas.

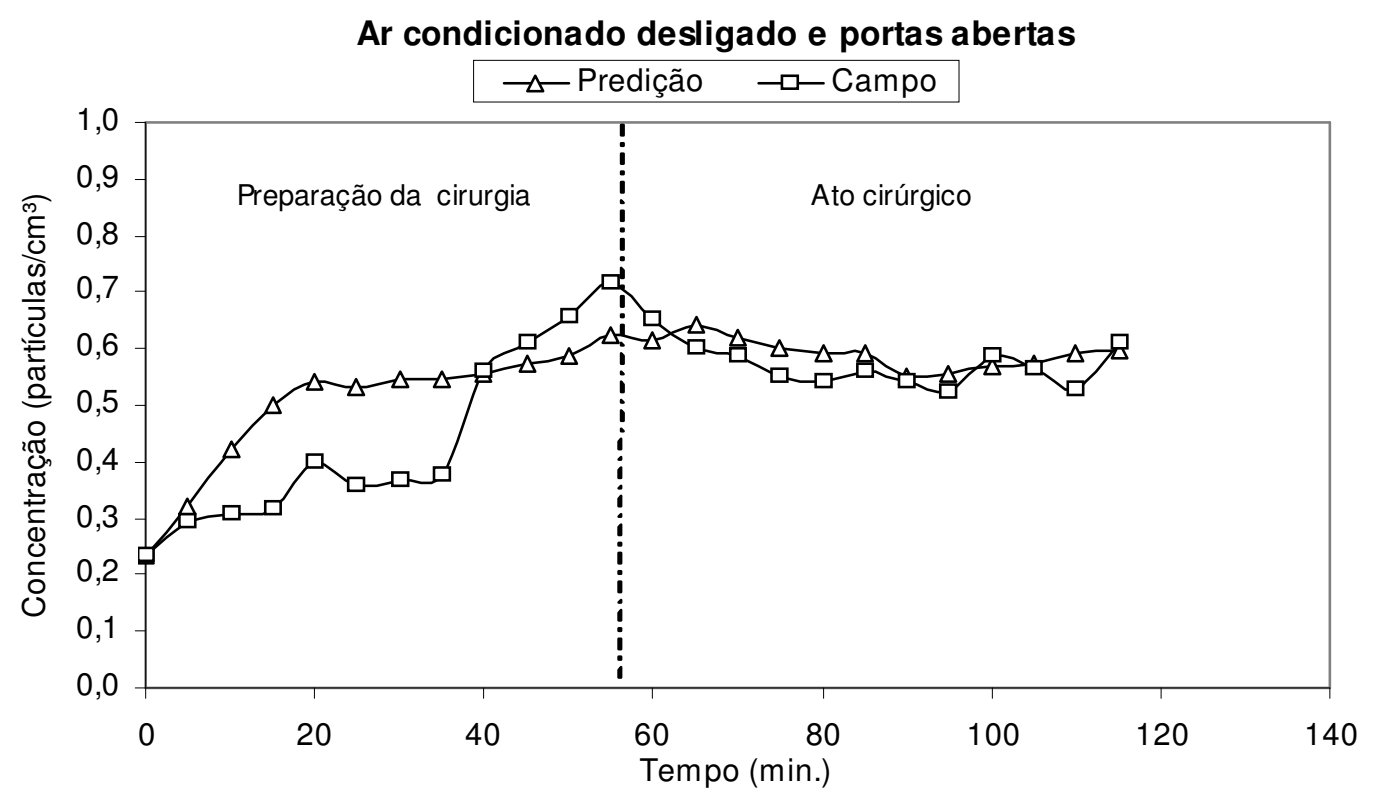

Figura 9.7 - Comparação entre os dados de campo e o modelo, para o sistema A, com condicionamento de ar desligado e portas abertas.

A Figura 9.8 apresenta uma comparação entre as concentrações de partículas medidas no interior da sala e as concentrações preditas pelo modelo, sem considerar as partículas geradas na colocação dos campos cirúrgicos.

A Figura 9.9 apresenta uma comparação entre as concentrações de partículas medidas no interior da sala e as concentrações preditas pelo modelo, considerando um fator de multiplicação que leva em conta as partículas geradas na colocação dos campos cirúrgicos.

A Figura 9.10 mostra que as pessoas e a infiltração pelas portas são os fatores que mais contribuem na geração de partículas no interior da sala, 62,76\% e 36,75\%, respectivamente. Os processos de colocação e remoção dos aventais e campos cirúrgicos contribuíram apenas com uma pequena parcela $(0,48 \%)$ do total de partículas geradas na sala. 


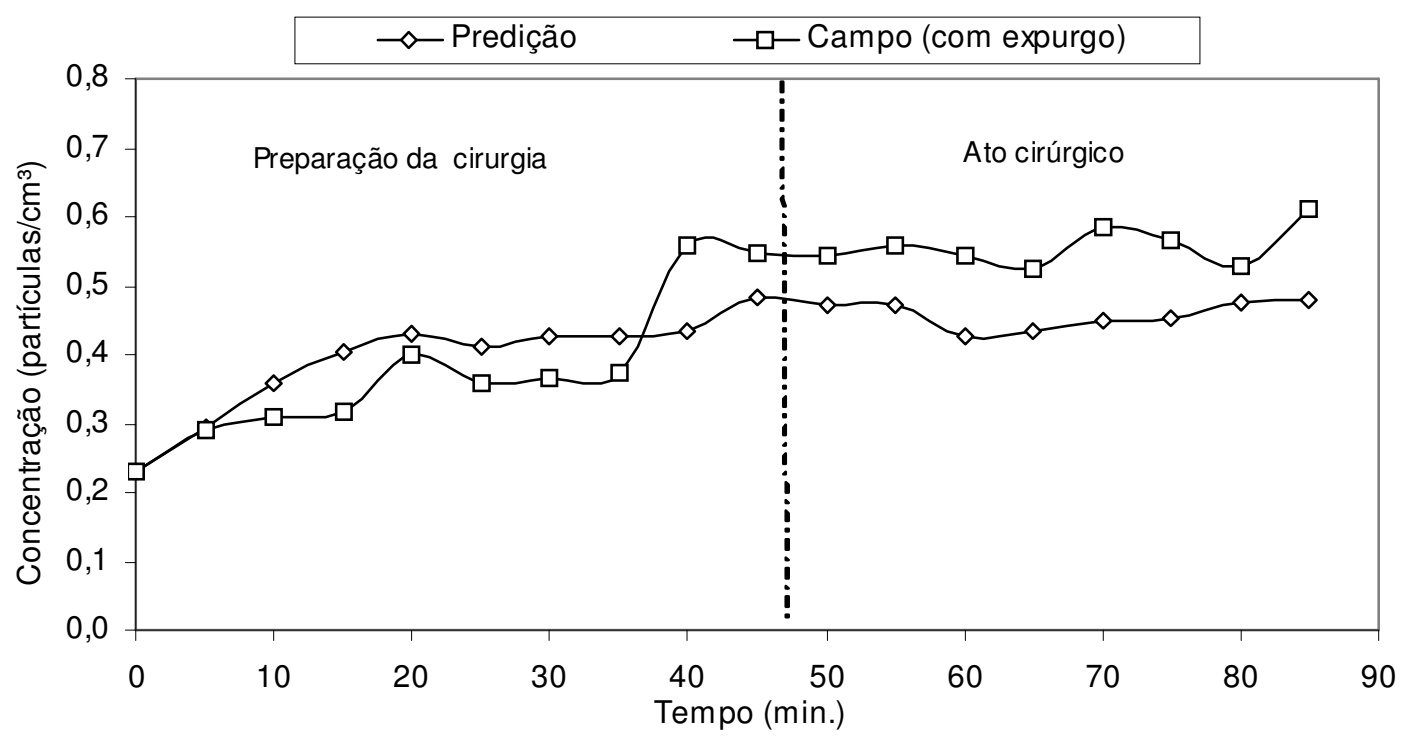

Figura 9.8 - Comparação entre os dados de campo e os resultados de predição, sem considerar os efeitos dos campos cirúrgicos, para o sistema $\mathrm{A}$, com condicionamento de ar desligado e portas abertas.

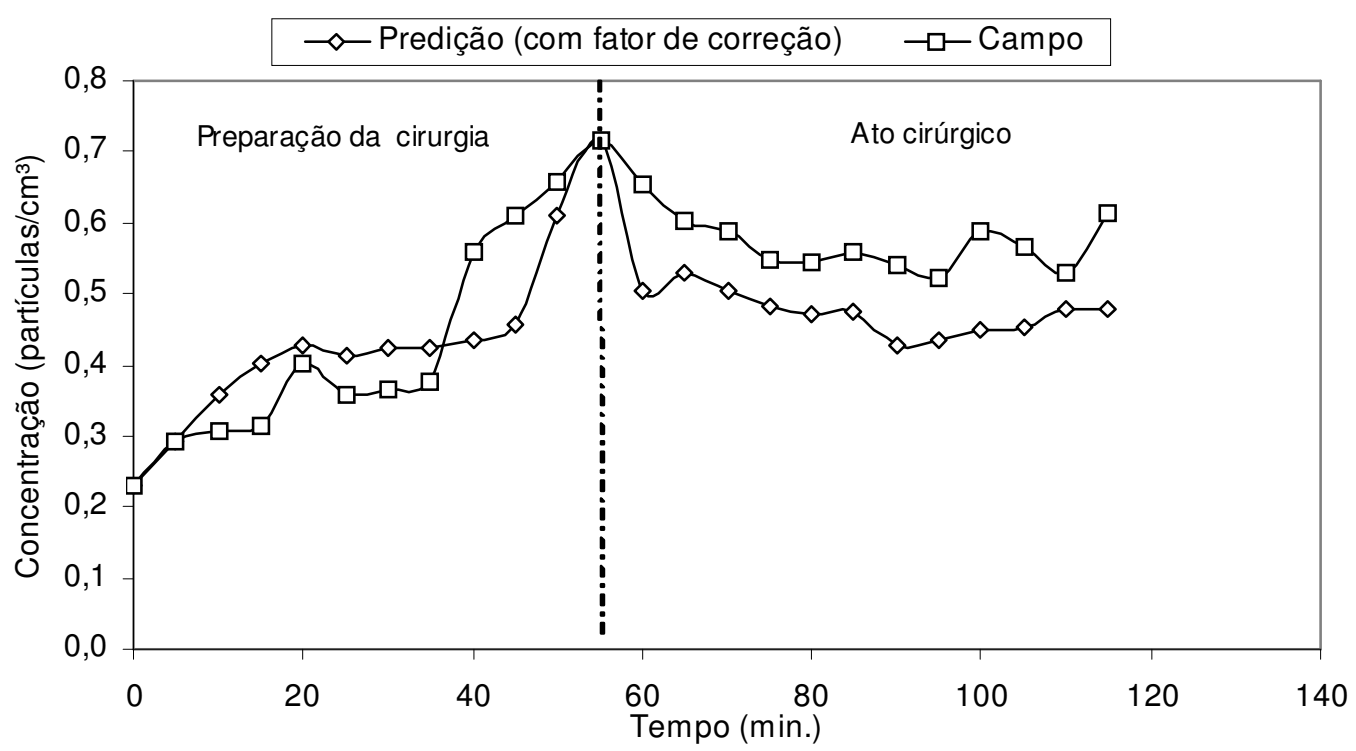

Figura 9.9 - Comparação entre os dados de campo e os resultados de predição, considerando um fator para os campos cirúrgicos, para o sistema $\mathrm{A}$, com condicionamento de ar desligado e portas abertas. 


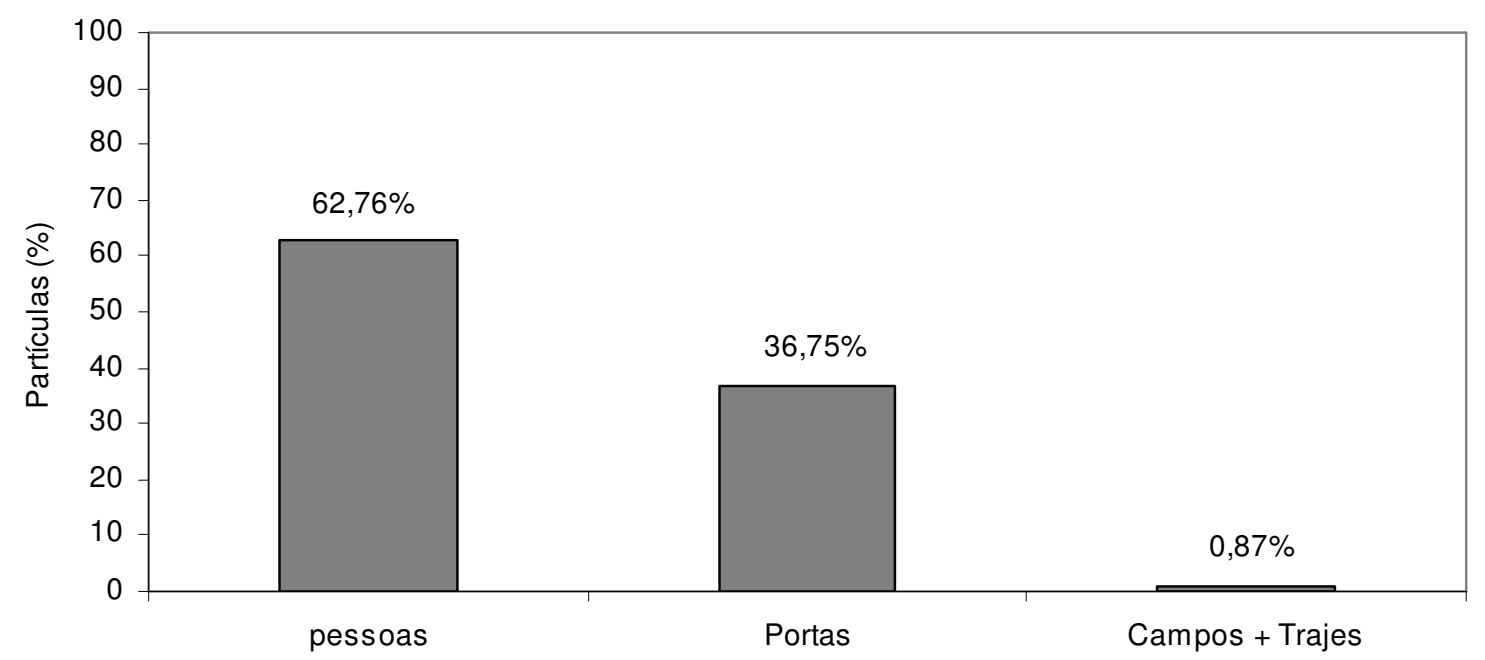

Figura 9.10 - Fatores que contribuem para a geração de partículas, para o sistema A, com condicionamento de ar desligado e portas abertas.

Percebe-se, na Figura 9.11, que a abertura das portas atua como uma importante fonte de eliminação de partículas do interior da sala, contribuindo com 95,03\% da remoção. A deposição sobre as superfícies colabora com $4,96 \%$.

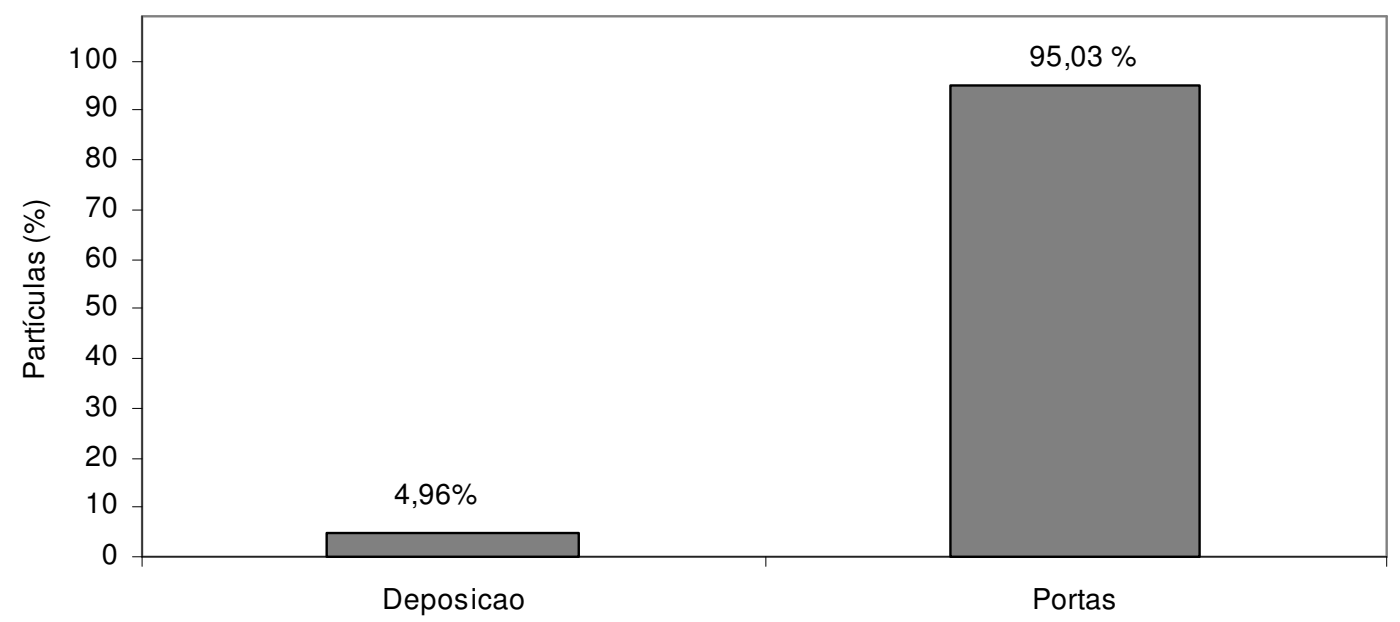

Figura 9.11 - Fatores que contribuem para a eliminação de partículas, para o sistema A, com condicionamento de ar desligado e portas abertas.

Na Figura 9.12, tem-se uma comparação das concentrações de partículas medidas no interior da sala com as concentrações preditas pelo modelo para diferentes diâmetros. 


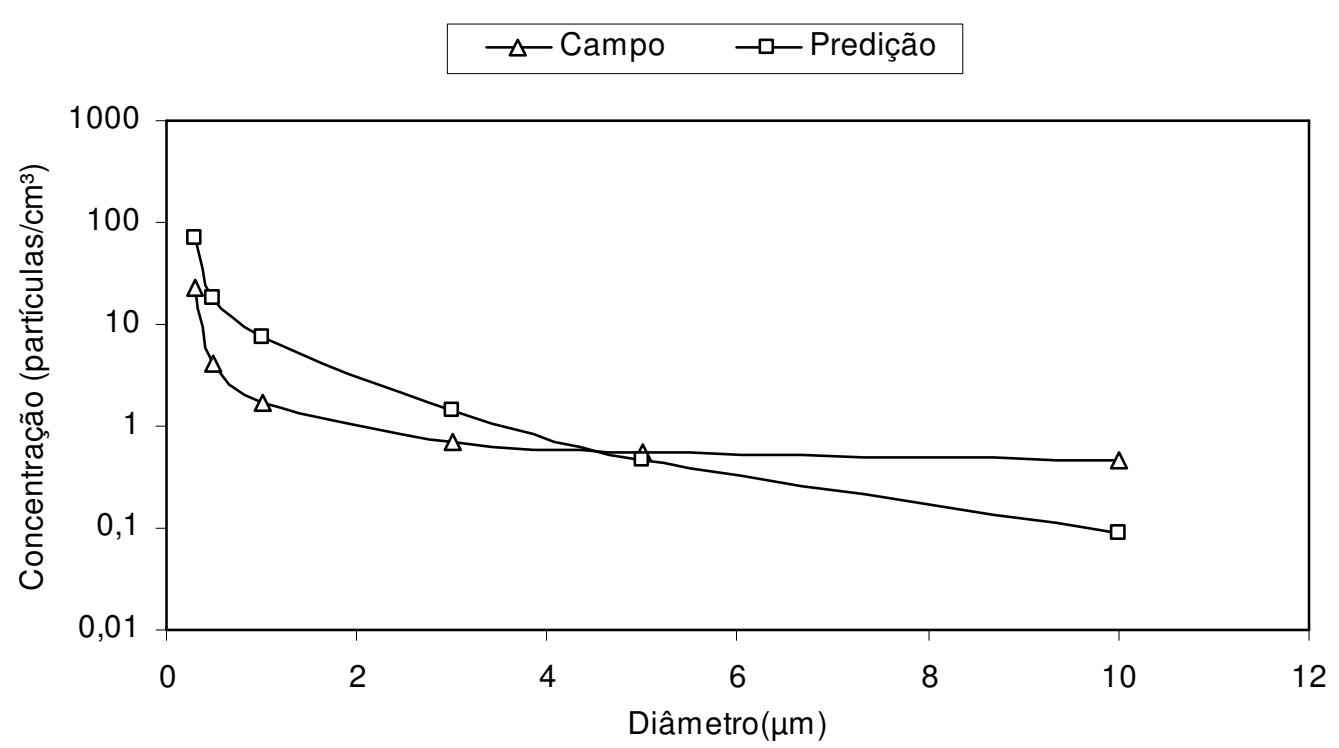

Figura 9.12 - Comparação das concentrações de partículas medidas no interior da sala com as concentrações preditas pelo modelo, para diferentes diâmetros, para o sistema A, com condicionamento de ar desligado e portas abertas.

\subsubsection{Condicionamento de ar ligado e portas fechadas}

A Figura 9.13 apresenta uma comparação entre as concentrações de partículas medidas no interior da sala e as concentrações preditas pelo modelo, para o caso onde o sistema de condicionamento de ar permaneceu ligado e as portas fechadas.

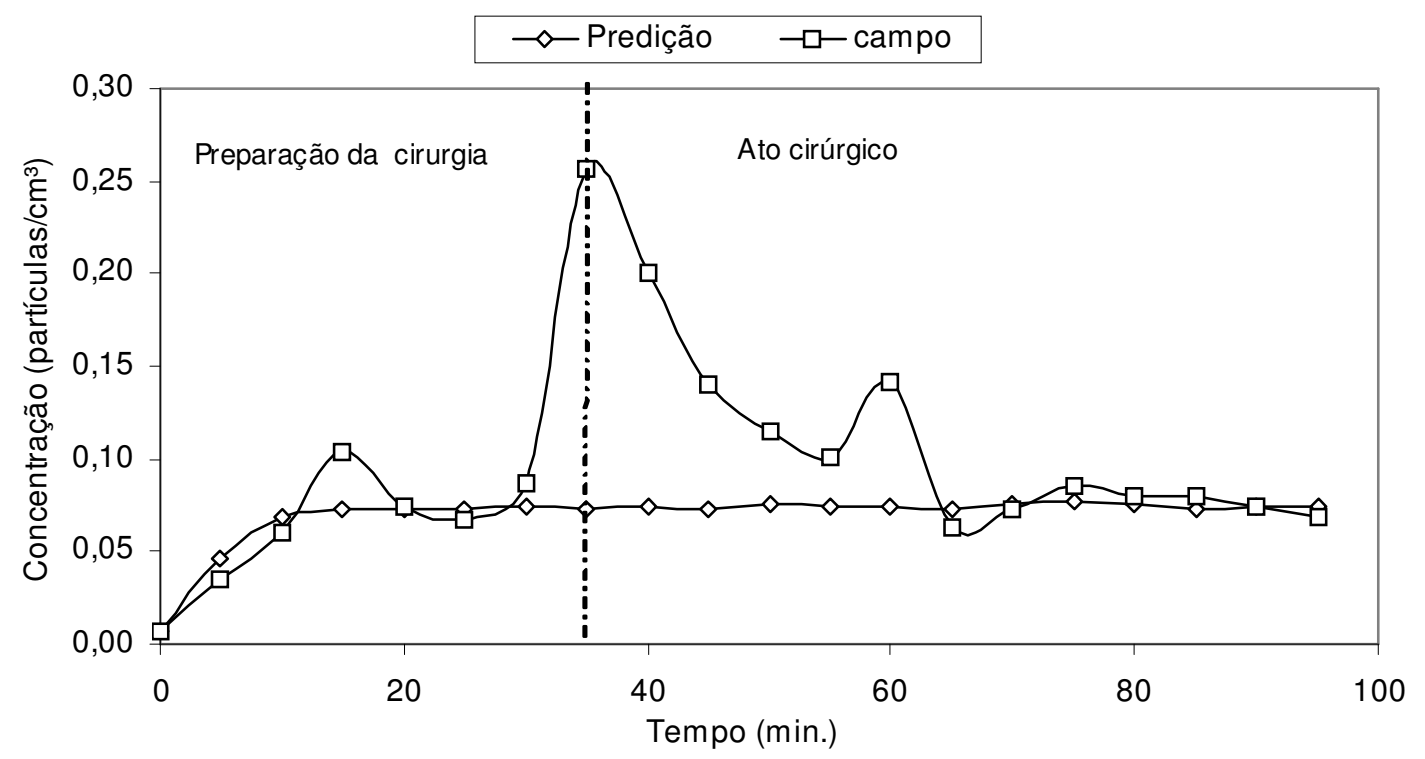

Figura 9.13 - Comparação entre os dados de campo e o modelo, para o sistema A, com condicionamento de ar ligado e portas fechadas. 
A Figura 9.14 apresenta uma comparação entre as concentrações de partículas medidas no interior da sala e as concentrações preditas pelo modelo, sem considerar as partículas geradas na colocação dos campos cirúrgicos.

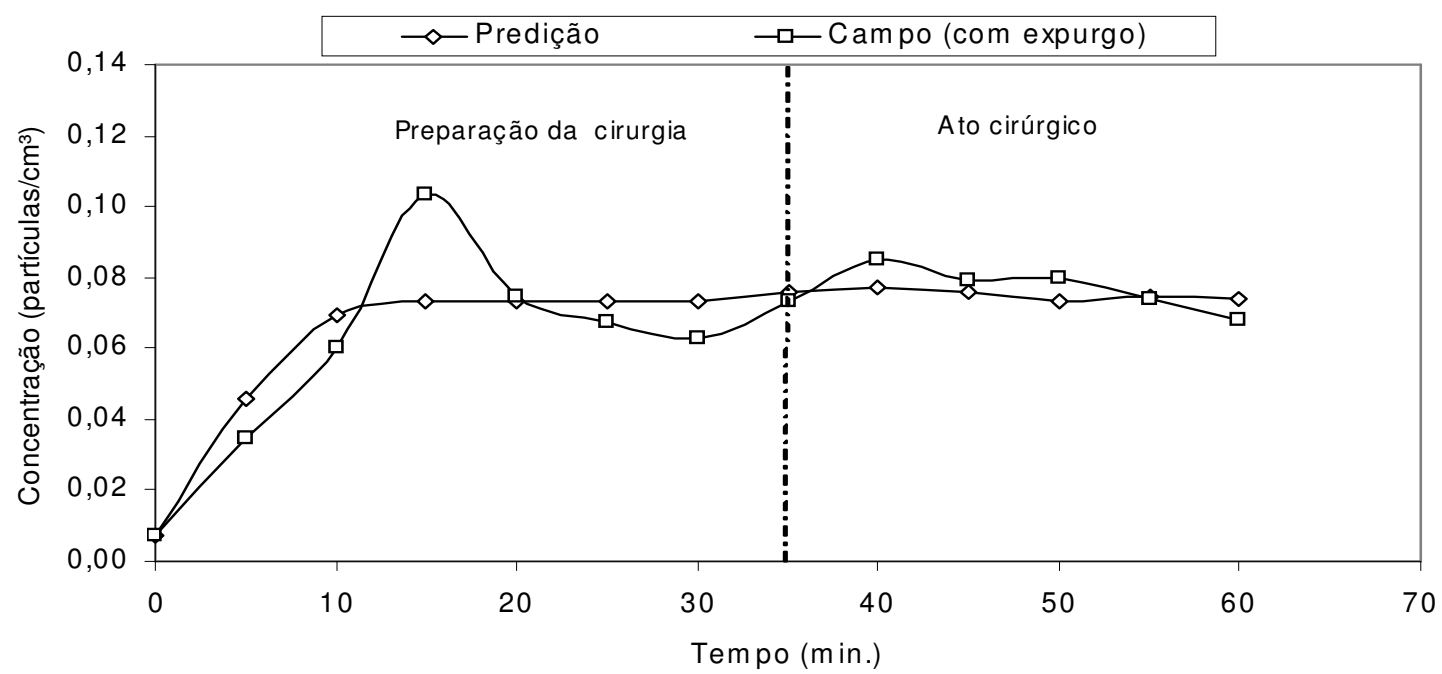

Figura 9.14 - Comparação entre os dados de campo e os resultados de predição, sem considerar os efeitos dos campos cirúrgicos, para o sistema A, com condicionamento de ar ligado e portas fechadas.

Tem-se, na Figura 9.15, uma comparação entre as concentrações de partículas medidas no interior da sala e as concentrações preditas pelo modelo, considerando um fator de multiplicação, que leva em consideração o efeito das partículas geradas na colocação dos campos cirúrgicos. 


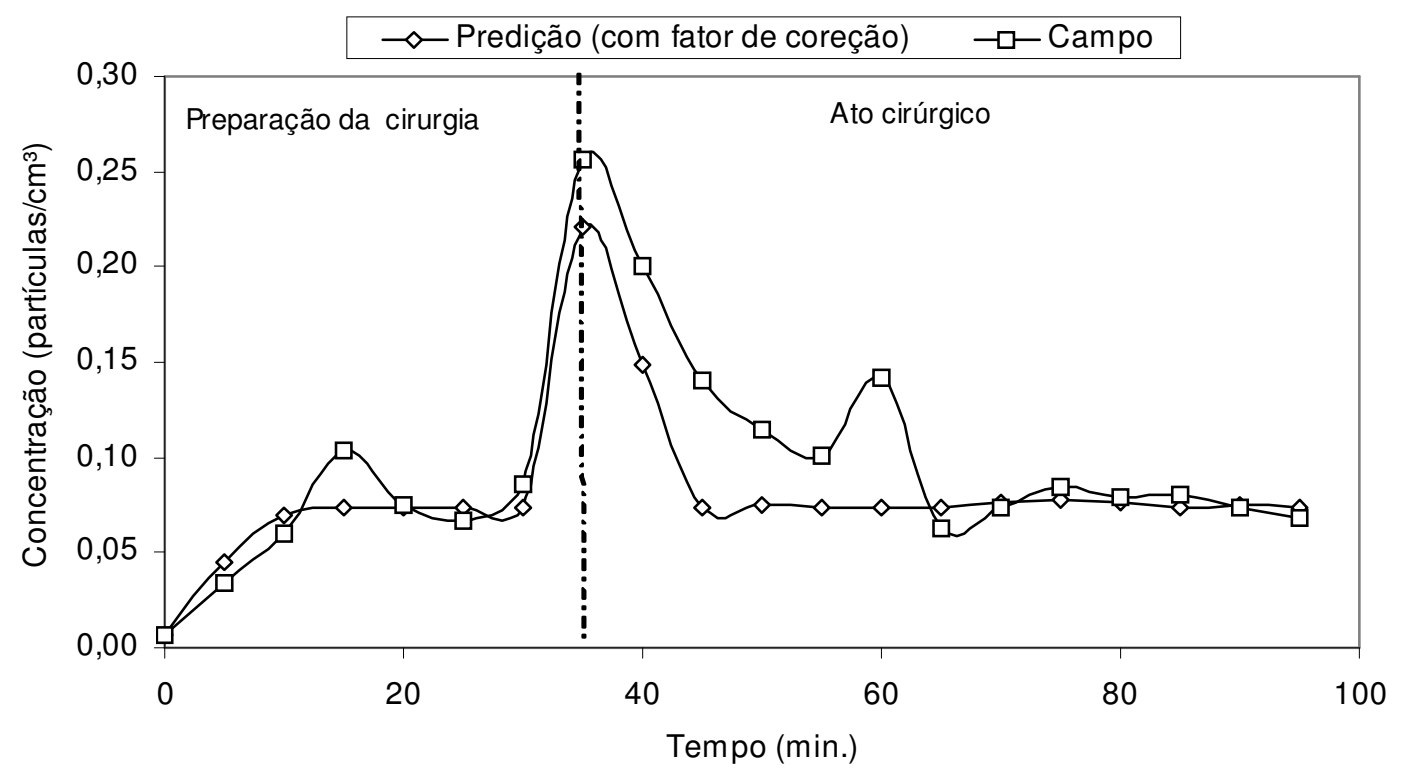

Figura 9.15 - Comparação entre os dados de campo e os resultados de predição, considerando um fator para os campos cirúrgicos, para o sistema A, com condicionamento de ar ligado e portas fechadas.

É mostrada, na Figura 9.16, uma comparação entre as concentrações de partículas medidas no interior da sala e as concentrações preditas pelo modelo para diferentes diâmetros.

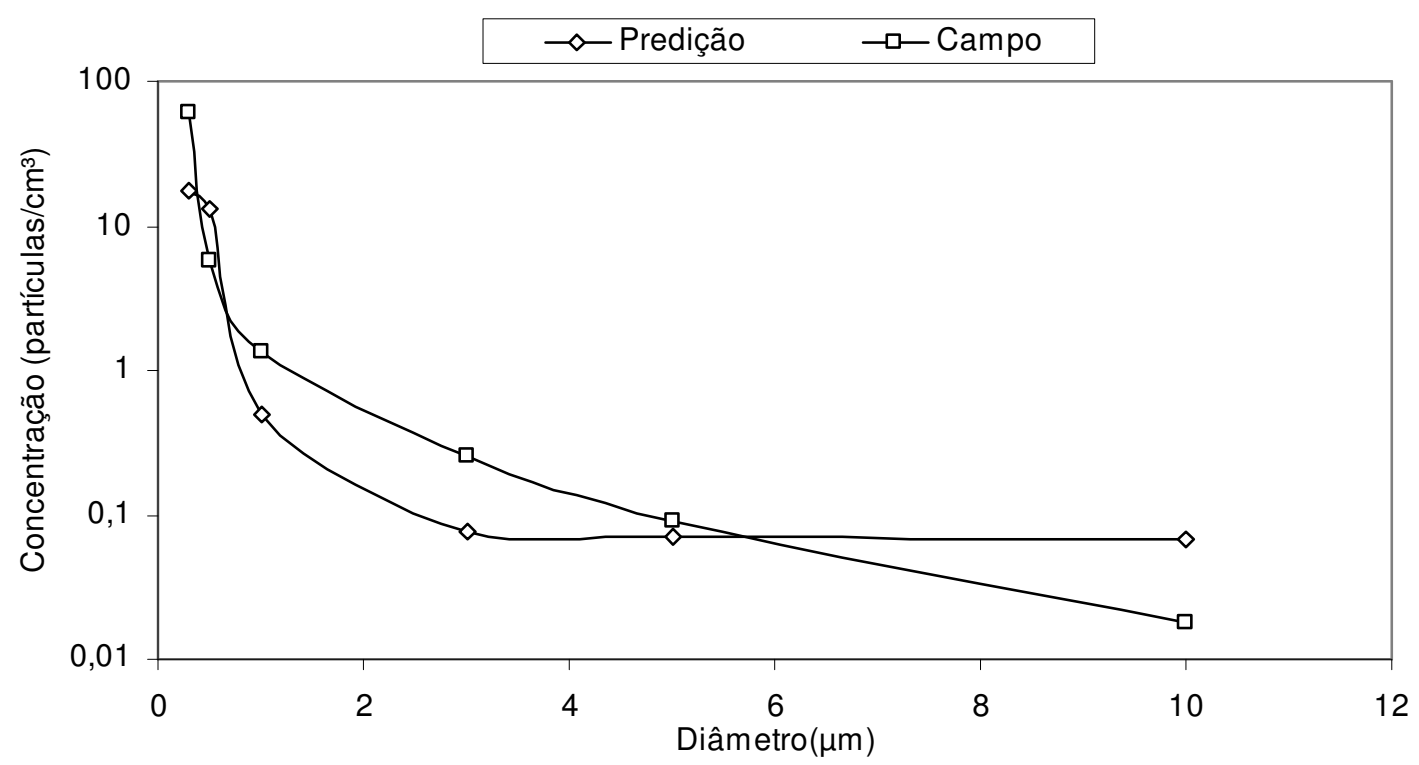

Figura 9.16 - Concentração de partículas em função do diâmetro, para o sistema A, com condicionamento de ar ligado e portas fechadas. 
Como é mostrado na Figura 9.17, para este caso, as pessoas representam a principal fonte de geração de partículas no interior da sala, contribuindo com 95,55\%. Os campos cirúrgicos participam com $3,27 \%$, e o sistema de condicionamento de ar com 1,16\%.

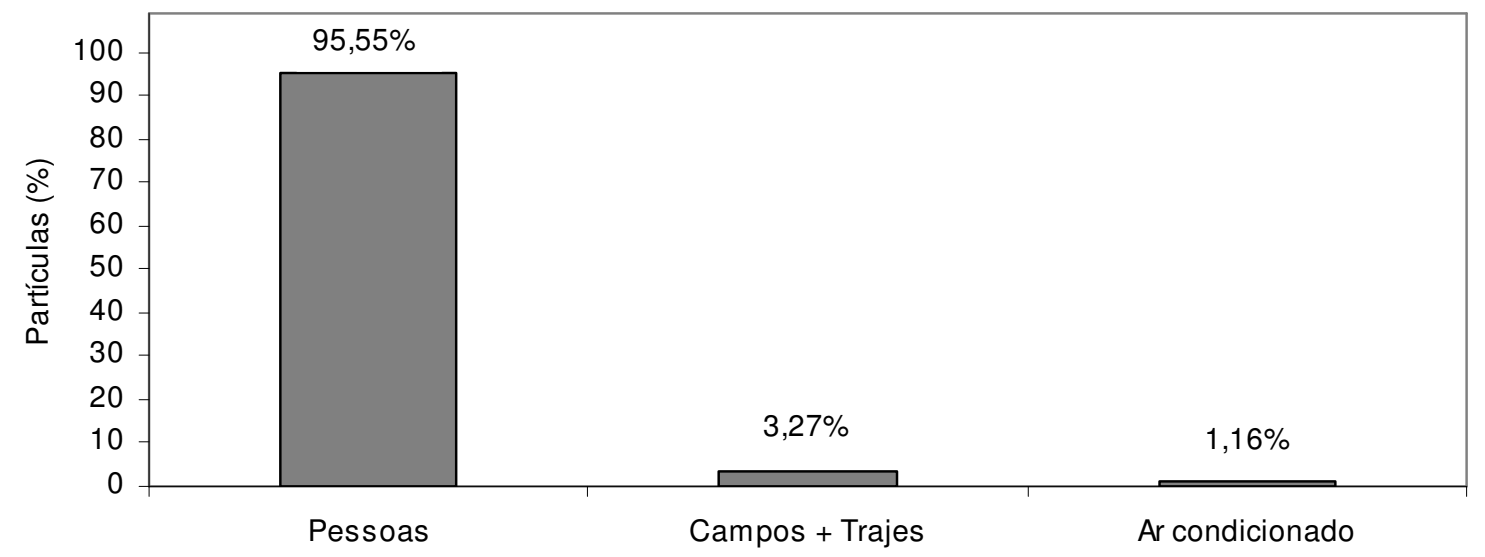

Figura 9.17 - Contribuição de diferentes fatores na geração de partículas, para o A, com condicionamento de ar ligado e portas fechadas.

Como se pode ver na Figura 9.18, o retorno do ar é o principal parâmetro na remoção das partículas do interior da sala, representando $88,62 \%$ do total, e a deposição sobre as superfícies participa com uma parcela de $11,37 \%$.

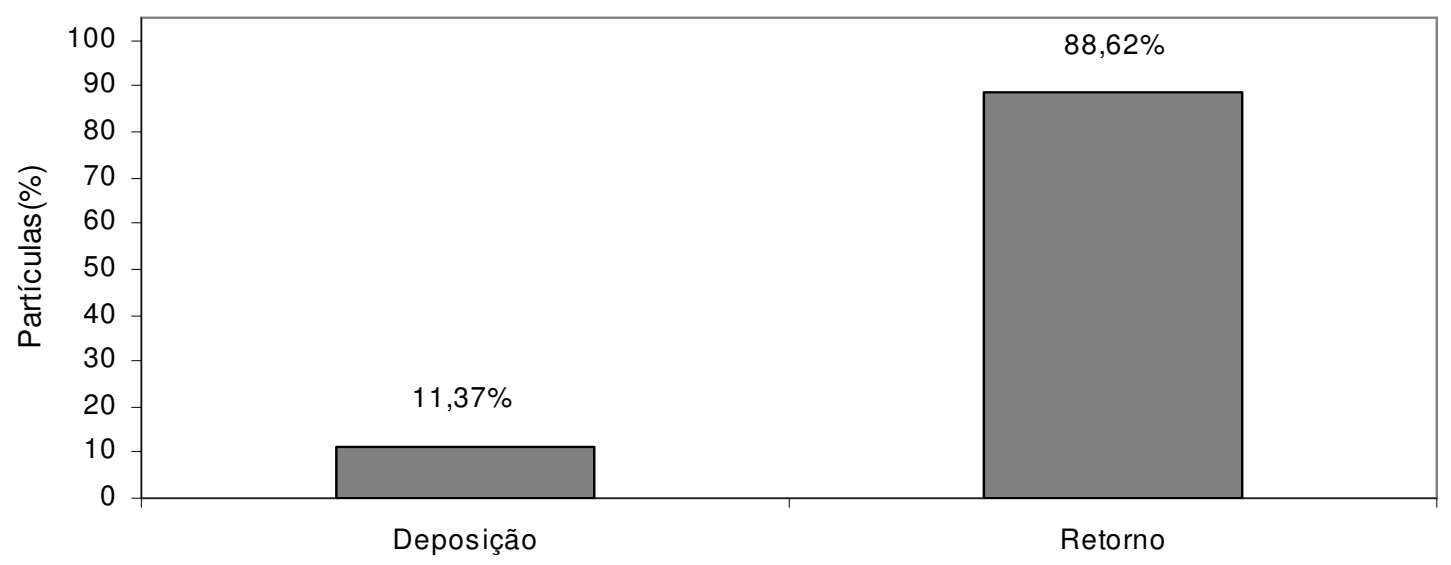

Figura 9.18 - Contribuição de diferentes fatores na remoção de partículas, para o sistema A, com condicionamento de ar ligado e portas fechadas. 


\subsubsection{Condicionamento de ar ligado e portas abertas}

Tem-se, na Figura 9.19, uma comparação das concentrações de partículas medidas no interior da sala com as concentrações preditas pelo modelo, para o caso onde o sistema de condicionamento de ar permaneceu ligado e as portas abertas.

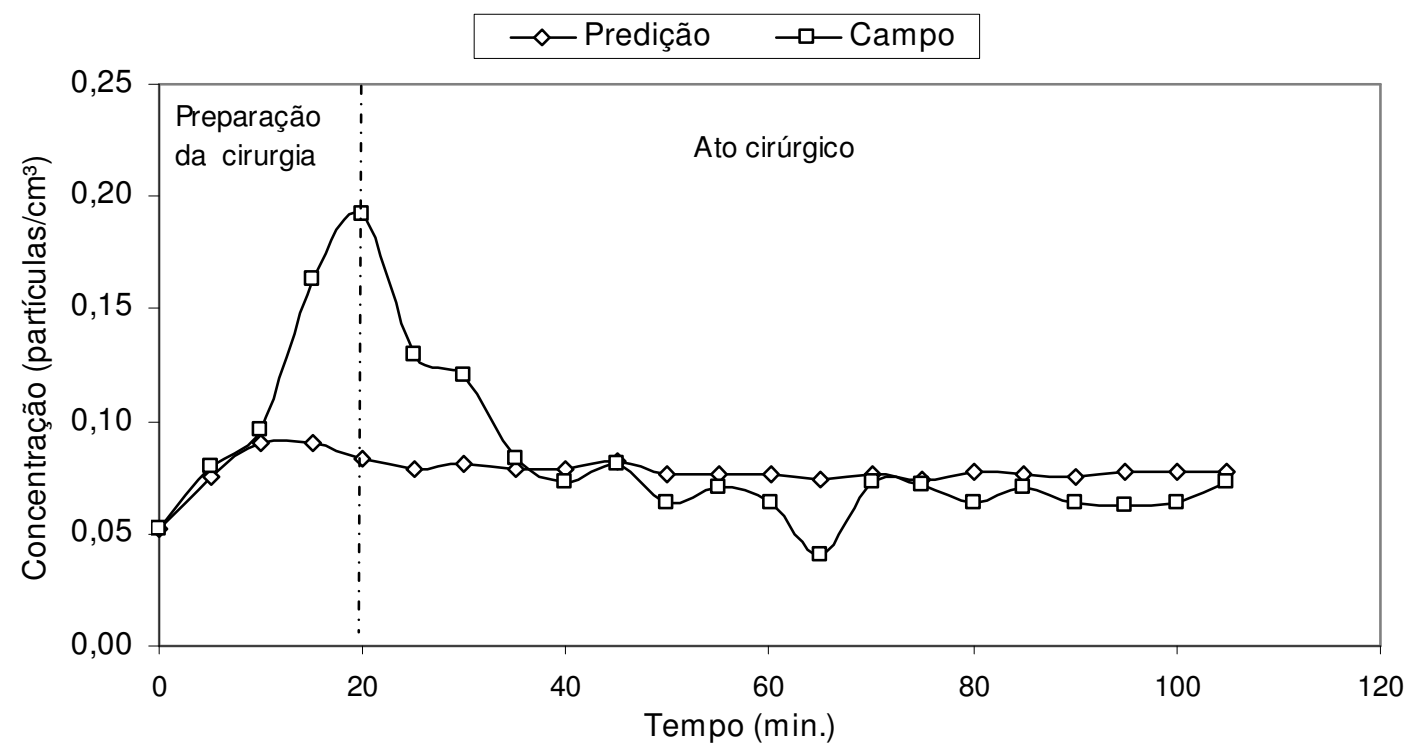

Figura 9.19 - Comparação entre os dados de campo e o modelo, para o sistema A, com condicionamento de ar ligado e portas abertas.

Na Figura 9.20, é apresentada uma comparação das concentrações de partículas medidas no interior da sala com as concentrações preditas pelo modelo, sem considerar as partículas geradas na colocação dos campos cirúrgicos. 


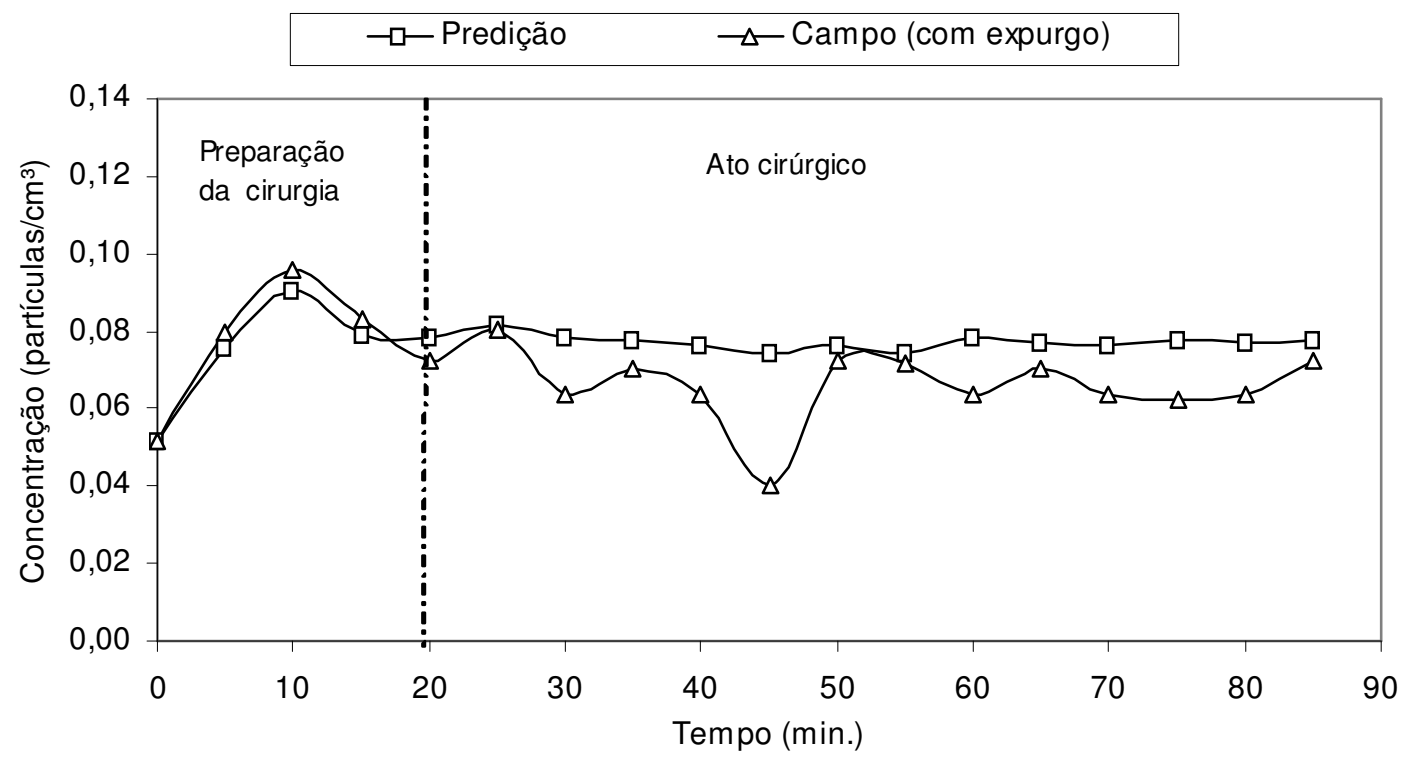

Figura 9.20 - Comparação entre os dados de campo e os resultados de predição, sem considerar o efeito dos campos cirúrgicos, para o sistema $\mathrm{A}$, com condicionamento de ar ligado e portas abertas.

Na Figura 9.21, é apresentada uma comparação entre as concentrações de partículas medidas no interior da sala e as concentrações preditas pelo modelo, considerando um fator de multiplicação, que leva em conta o efeito das partículas geradas na colocação dos campos cirúrgicos.

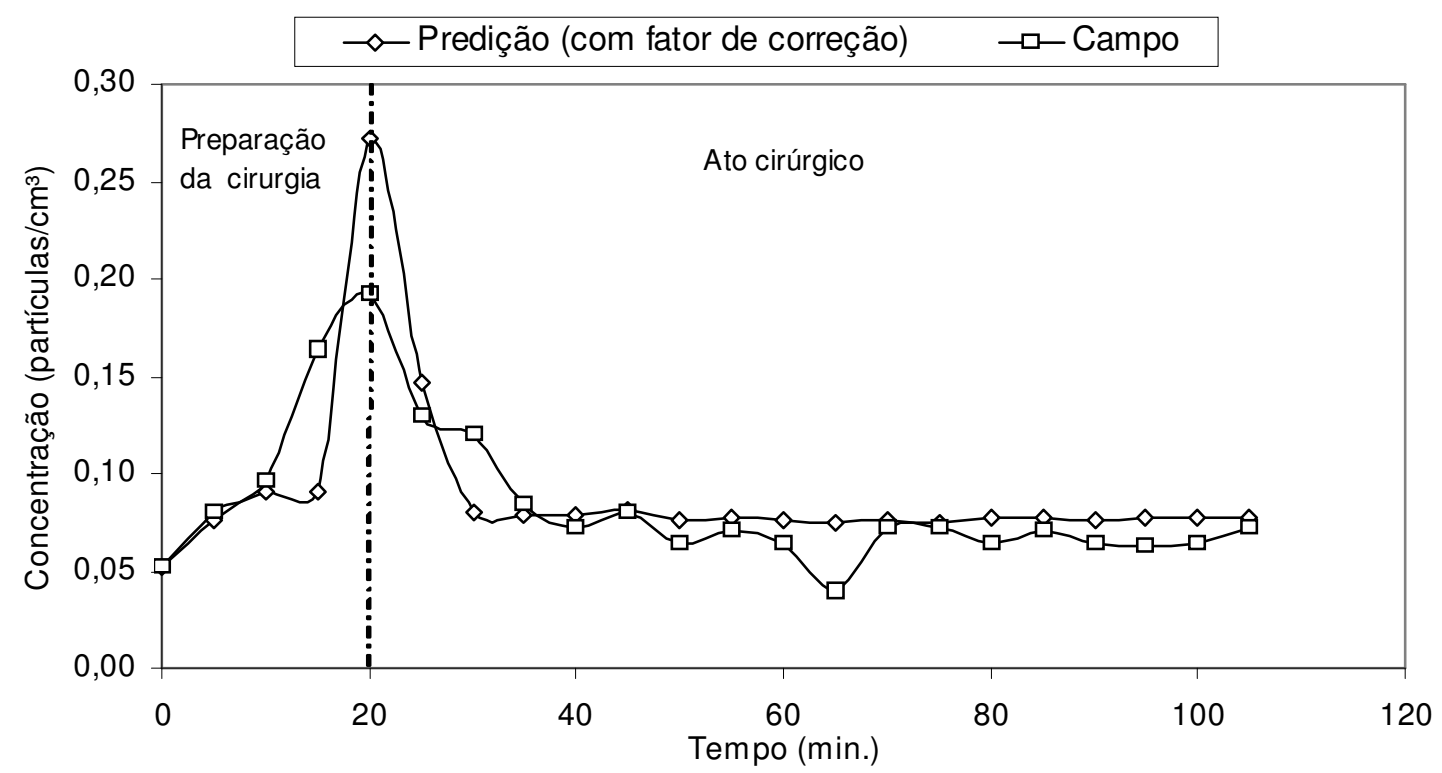

Figura 9.21 - Comparação entre os dados de campo e os resultados de predição, considerando um fator para dos campos cirúrgicos, para o sistema A, com condicionamento de ar ligado e portas abertas. 
A Figura 9.22 apresenta as concentrações médias das partículas (dados de campo e valores preditos) em função do tamanho (diâmetro) das mesmas.

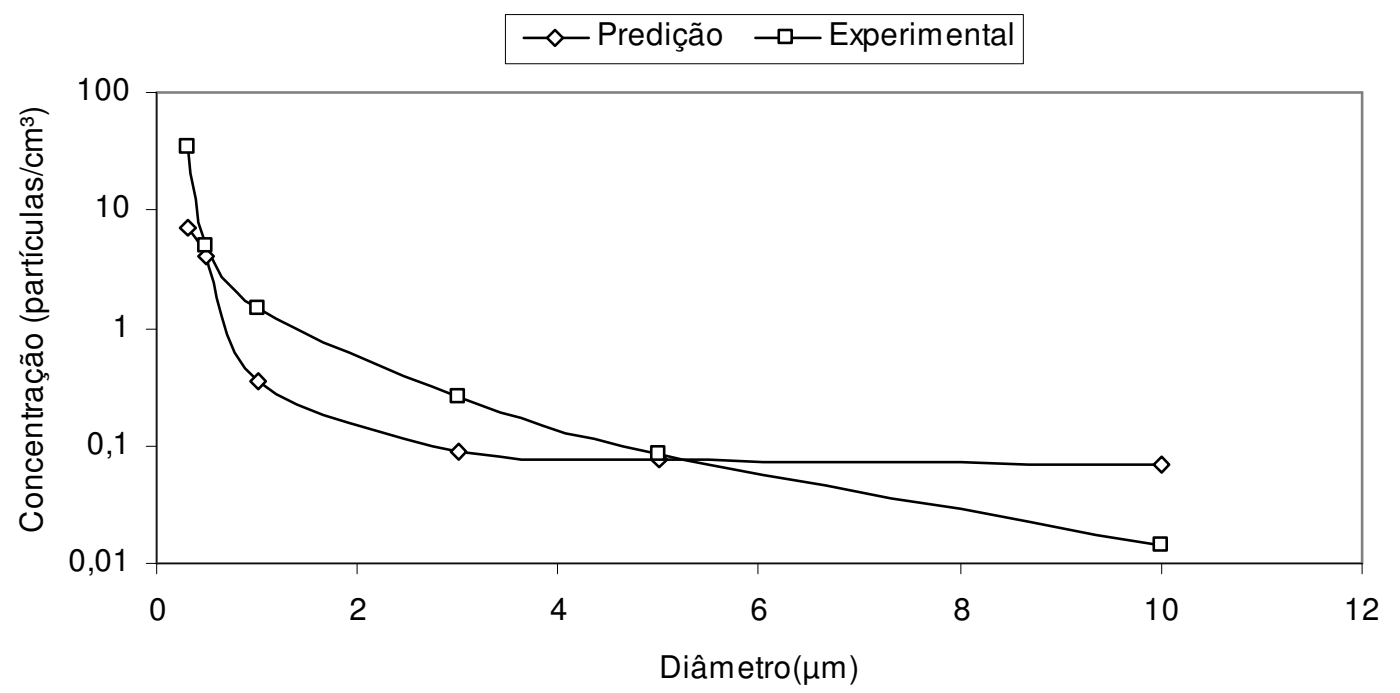

Figura 9.22 - Concentração de partículas em função do diâmetro, para o sistema A, com condicionamento de ar ligado e portas abertas.

Também neste caso, como se vê na Figura 9.23, as pessoas são os principais fatores que geram partículas no interior da sala, com $75,91 \%$ do total. A infiltração pelas portas é o segundo maior fator, com $21,80 \%$. Os demais fatores, como colocação e remoção dos campos cirúrgicos e sistema de condicionamento de ar participam com parcelas menores, $1,25 \%$ e $1,02 \%$, respectivamente.

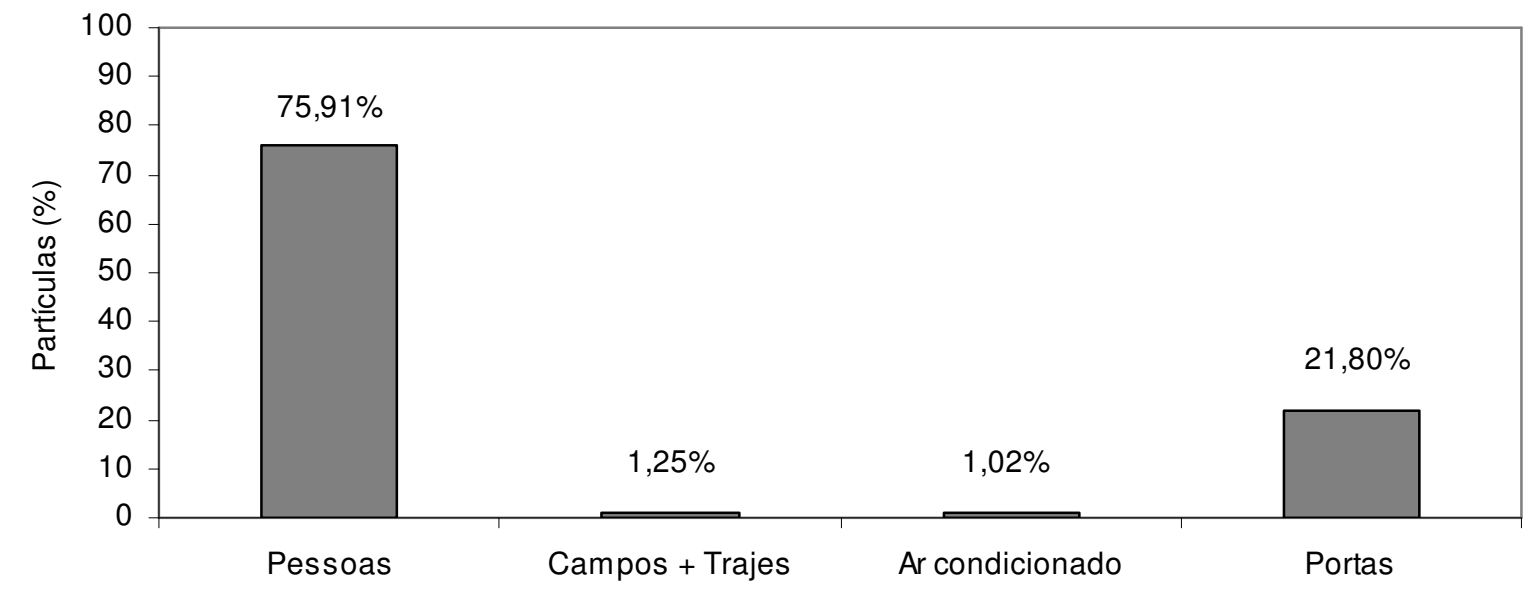

Figura 9.23 - Contribuição de diferentes fatores na geração de partículas, para o sistema A, com condicionamento de ar ligado e portas abertas. 
Da mesma forma, como mostrado na Figura 9.24, o retorno de ar é o principal fator de remoção de partículas do interior da sala, com 72,73\% do total. As portas abertas representam o segundo maior fator, com 16,35\%. A colocação e a remoção dos campos cirúrgicos participam com uma parcela menor, $10,90 \%$.

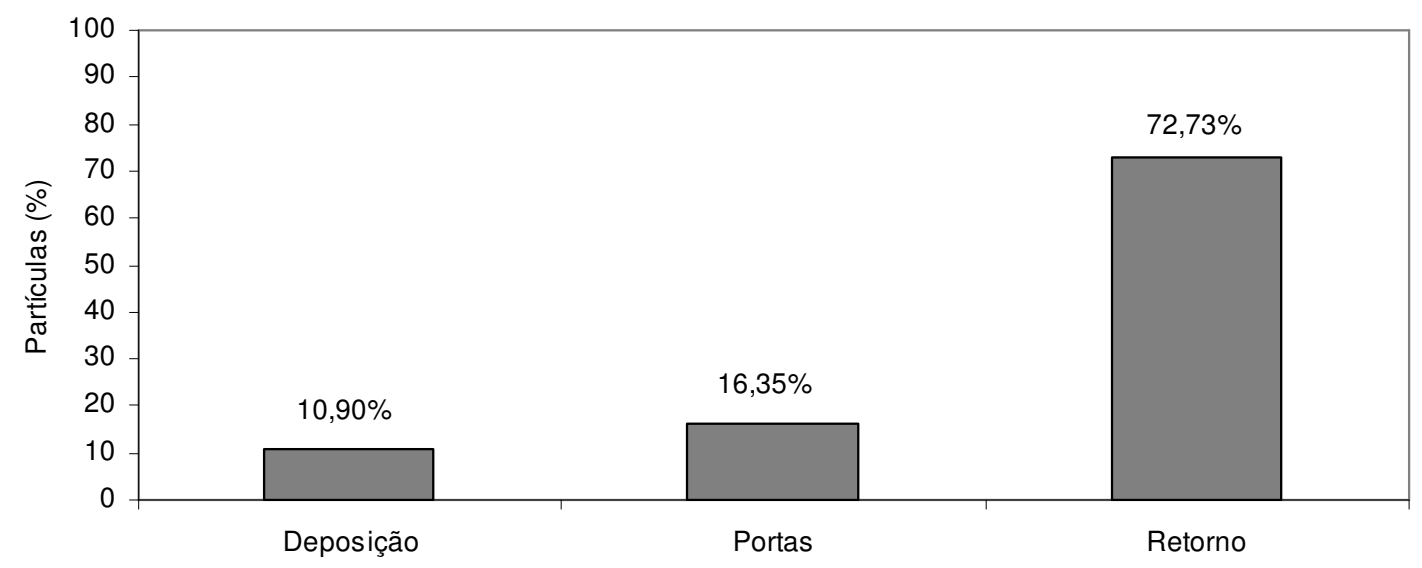

Figura 9.24 - Contribuição de diferentes fatores na remoção de partículas, para o sistema A, com condicionamento de ar ligado e portas abertas.

\subsection{SISTEMA COM INSUFLAMENTO E RETORNO PELO TETO (SISTEMA B)}

\subsubsection{Condicionamento de ar ligado e portas fechadas}

Na Figura 9.25, é mostrada uma comparação entre as concentrações de partículas medidas no interior da sala (próximo ao campo cirúrgico) e as concentrações preditas pelo modelo, para o caso em que o sistema de condicionamento de ar permaneceu ligado e as portas fechadas. 


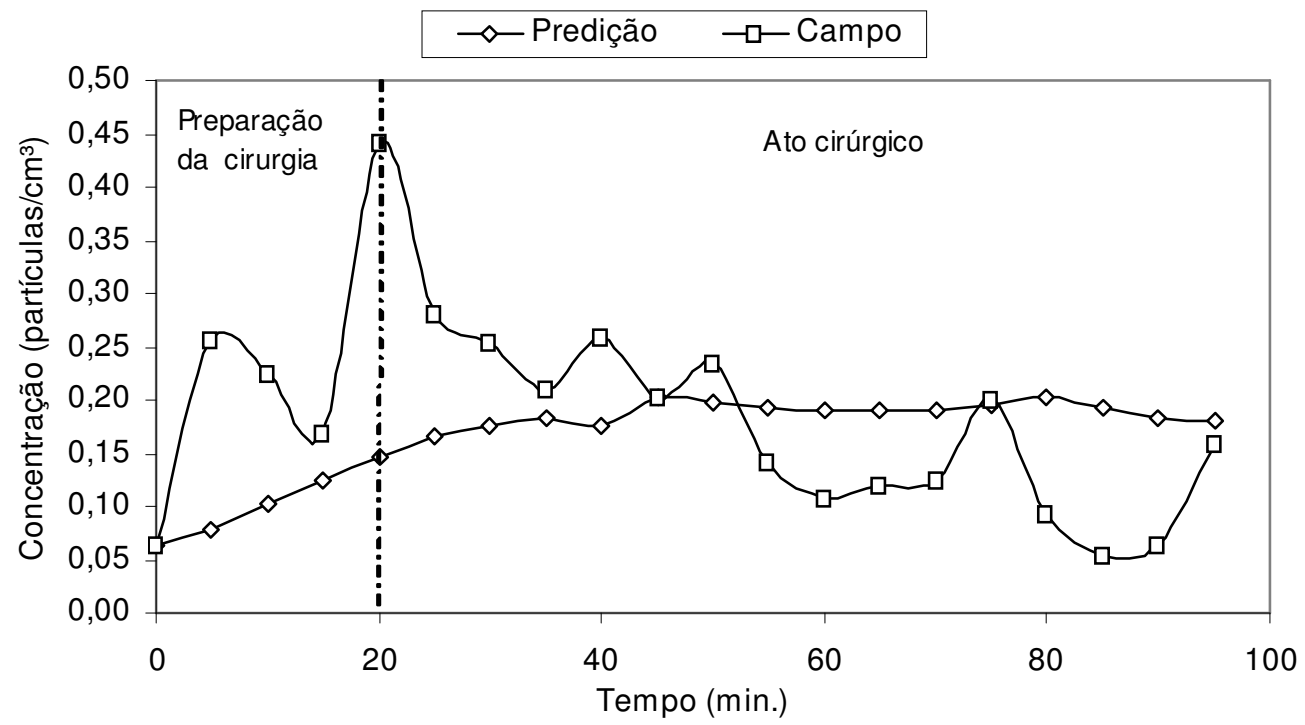

Figura 9.25 - Comparação entre os dados de campo e de predição, para o sistema B, com condicionamento de ar ligado e portas fechadas.

A Figura 9.26 apresenta uma comparação das concentrações de partículas medidas no interior da sala com as concentrações preditas pelo modelo, sem considerar as partículas geradas na colocação dos campos cirúrgicos.

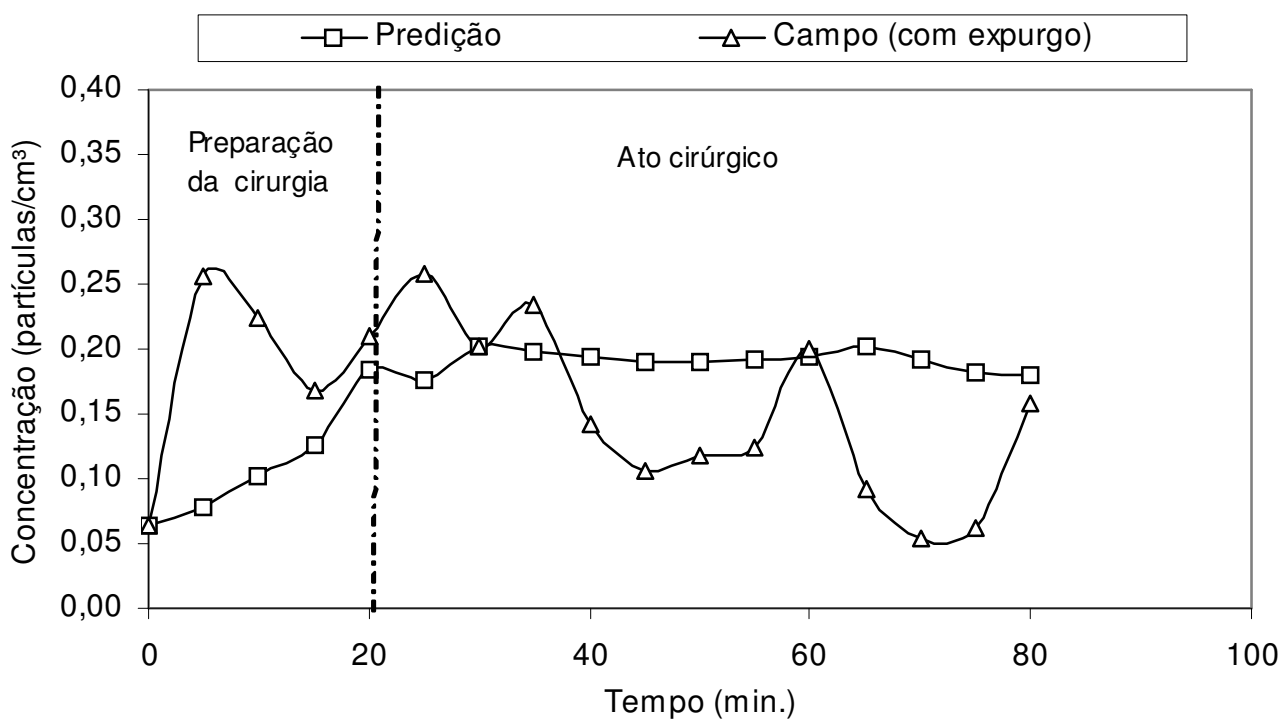

Figura 9.26 - Comparação entre os dados de campo e os resultados de predição, sem considerar o efeito dos campos cirúrgicos, para o sistema $\mathrm{B}$, com condicionamento de ar ligado e portas fechadas. 
Na Figura 9.27, é apresentada uma comparação entre as concentrações de partículas medidas no interior da sala com as concentrações preditas pelo modelo, considerando um fator de multiplicação, que leva em conta o efeito das partículas geradas na colocação dos campos cirúrgicos.

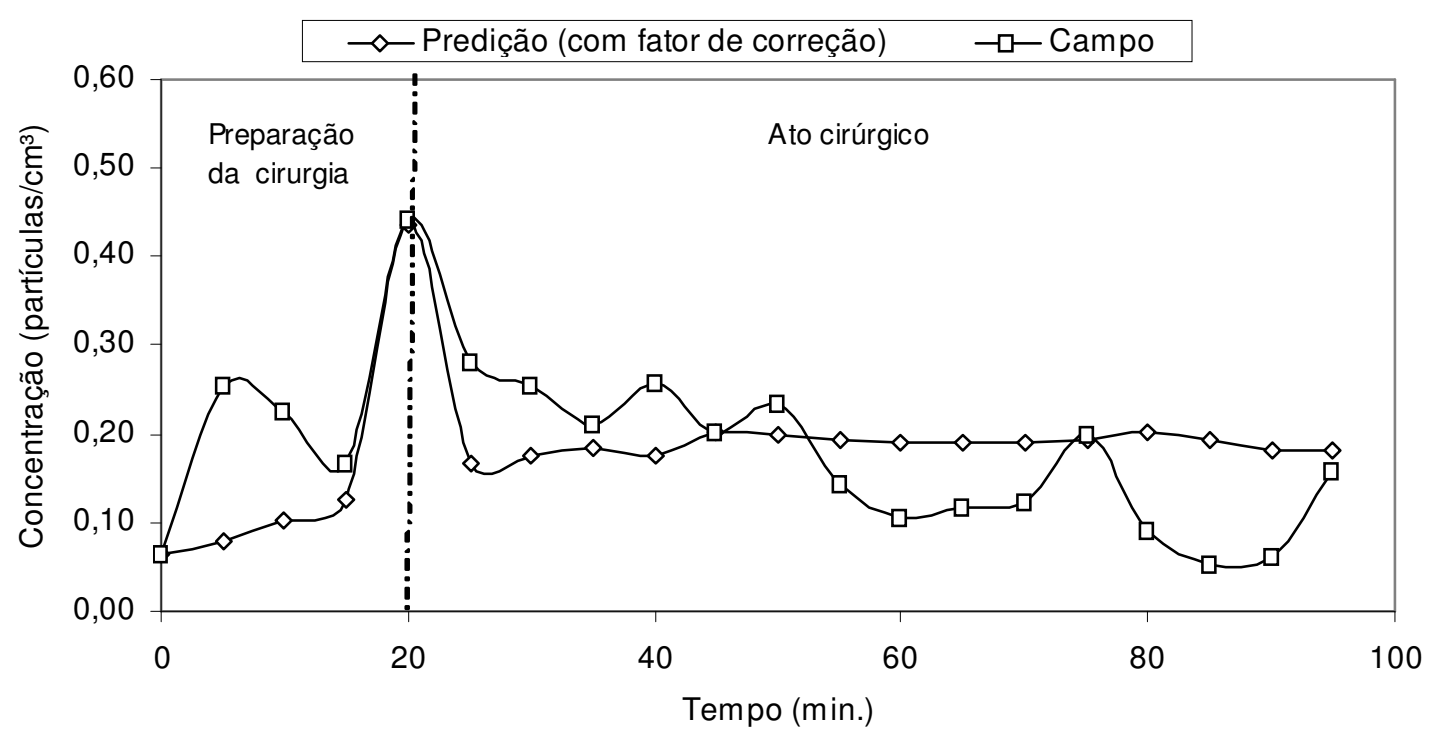

Figura 9.27 - Comparação entre os dados de campo e os resultados de predição, considerando um fator para os campos cirúrgicos, para o sistema $\mathrm{B}$, com condicionamento de ar ligado e portas fechadas.

Na Figura 9.28, tem-se uma comparação entre as concentrações medidas com as concentrações preditas pelo modelo, para diferentes tamanhos (diâmetros) de partículas.

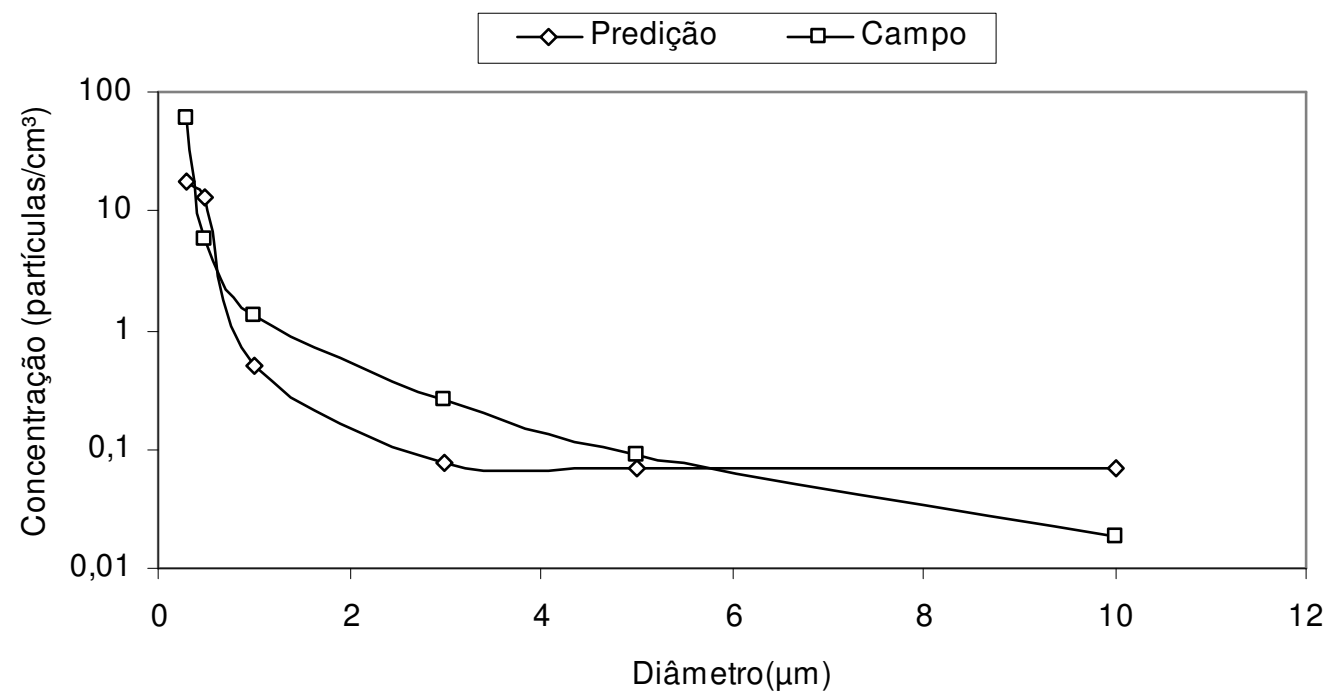

Figura 9.28 - Concentração de partículas em função do diâmetro, para o sistema B, com condicionamento de ar ligado e portas fechadas. 
A Figura 9.29 mostra que o sistema de condicionamento de ar contribui com apenas $1,16 \%$ no processo de geração de partículas no interior da sala. As pessoas contribuem com a maior parcela, 95,55\%, e a colocação e remoção dos campos cirúrgicos contribui como apenas $3,27 \%$.

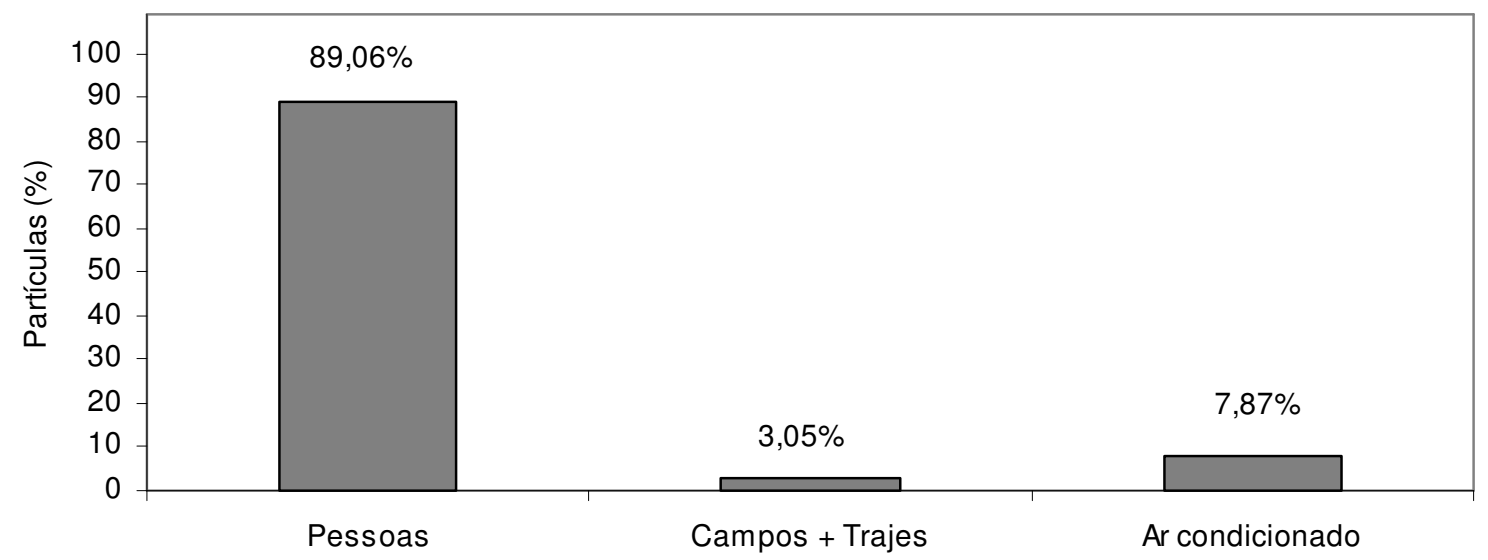

Figura 9.29 - Contribuição de diferentes fatores na geração de partículas, para o sistema B, com condicionamento de ar ligado e portas fechadas.

O retorno é o fator que mais contribui para a eliminação das partículas do ar no interior da sala cirúrgica, com 88,62\% do total, como mostrado na Figura 9.30. A deposição sobre as superfícies contribui com uma parcela menor, $11,37 \%$.

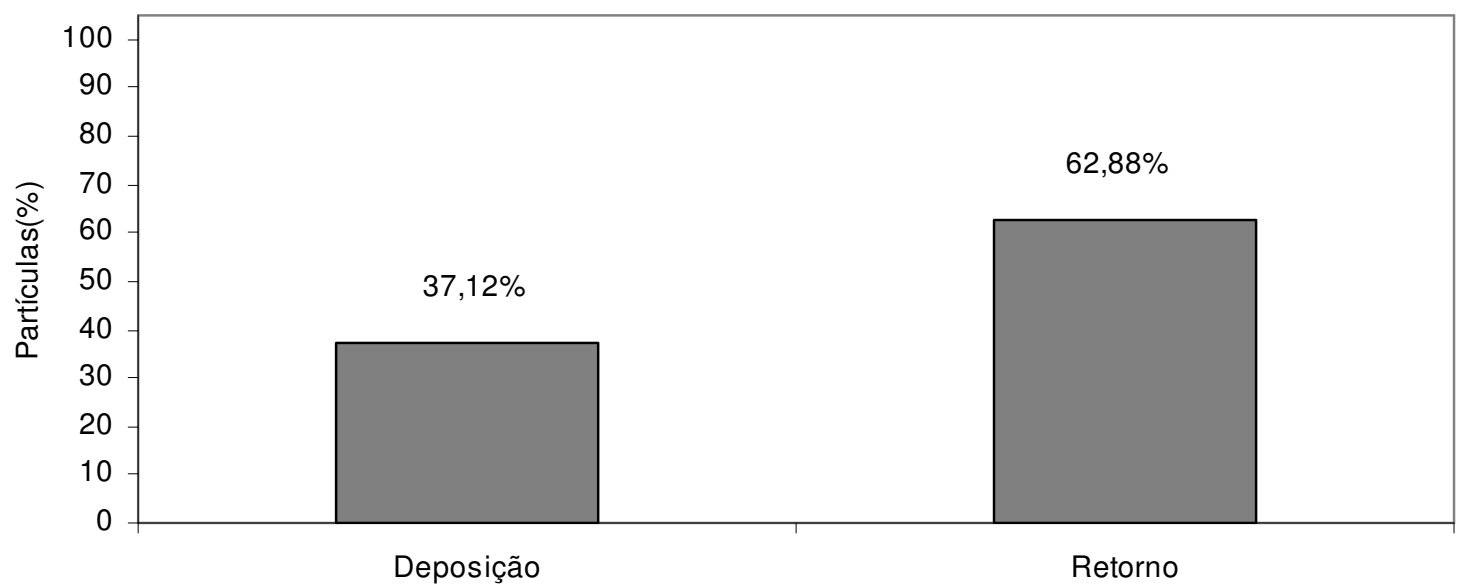

Figura 9.30 - Contribuição de diferentes fatores na remoção de partículas, para o sistema $\mathrm{B}$, com condicionamento de ar ligado e portas fechadas. 


\subsubsection{Condicionamento de ar ligado e portas abertas}

Na Figura 9.31, apresenta-se uma comparação entre as concentrações de partículas medidas no interior da sala (próximo ao campo cirúrgico) com as concentrações preditas pelo modelo para o caso onde o sistema de condicionamento de ar permaneceu ligado e as portas abertas.

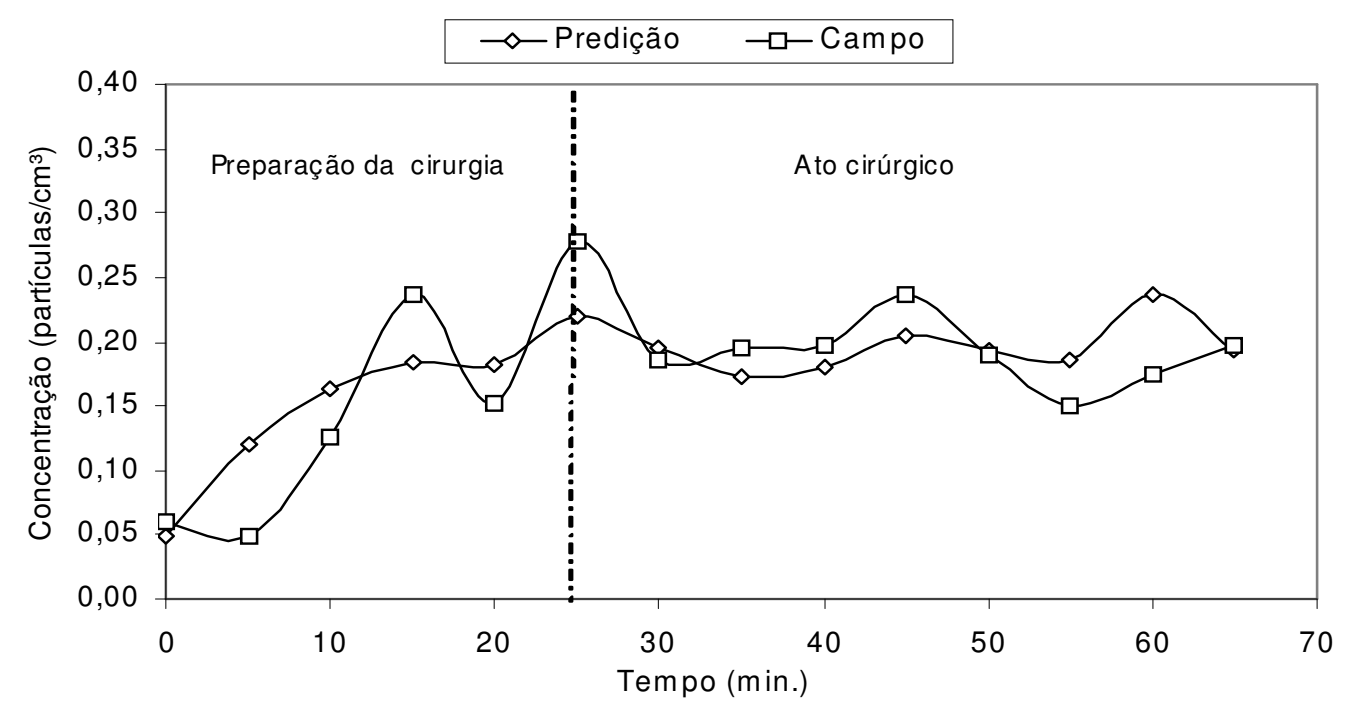

Figura 9.31 - Comparação entre os dados de campo e o modelo, para o sistema B, com condicionamento de ar ligado e portas abertas.

Na Figura 9.32, é apresentada uma comparação das concentrações de partículas medidas no interior da sala com as concentrações preditas pelo modelo, sem considerar as partículas geradas na colocação dos campos cirúrgicos. 


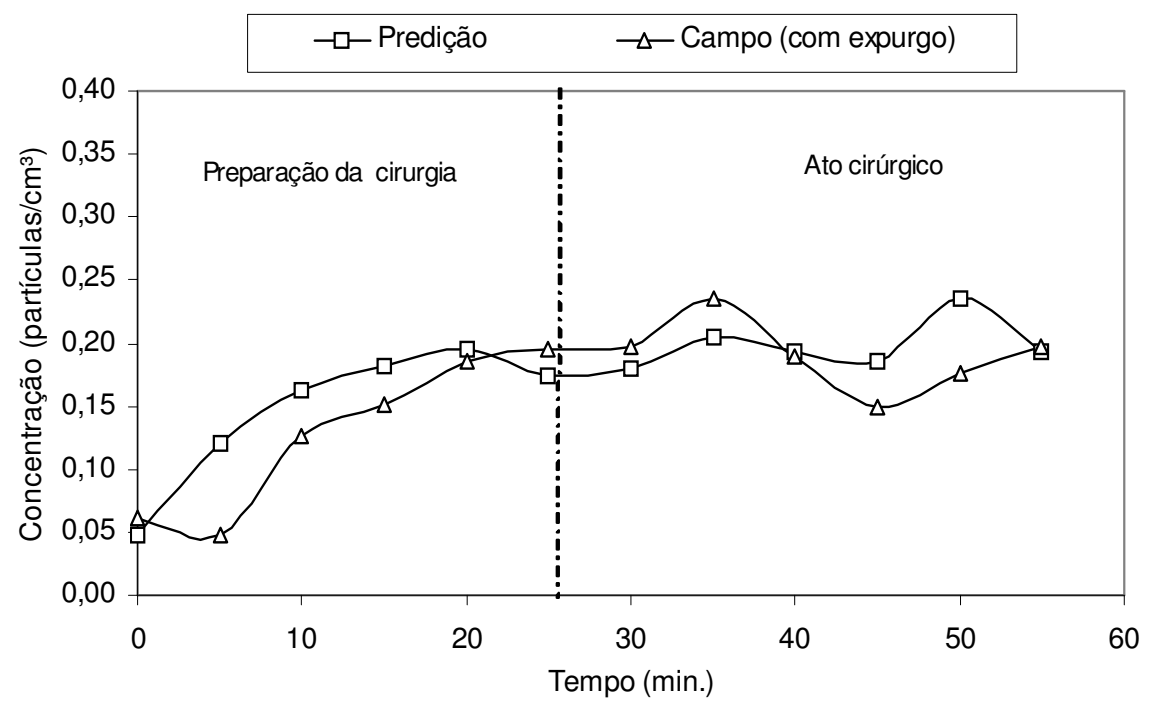

Figura 9.32 - Comparação entre os dados de campo e os resultados de predição, sem considerar os efeitos dos campos cirúrgicos, para o sistema $\mathrm{B}$, com condicionamento de ar ligado e portas abertas.

Na Figura 9.33, é apresentada uma comparação entre as concentrações de partículas medidas no interior da sala com as concentrações preditas pelo modelo, considerando um fator de multiplicação, que leva em consideração o efeito das partículas geradas na colocação dos campos cirúrgicos.

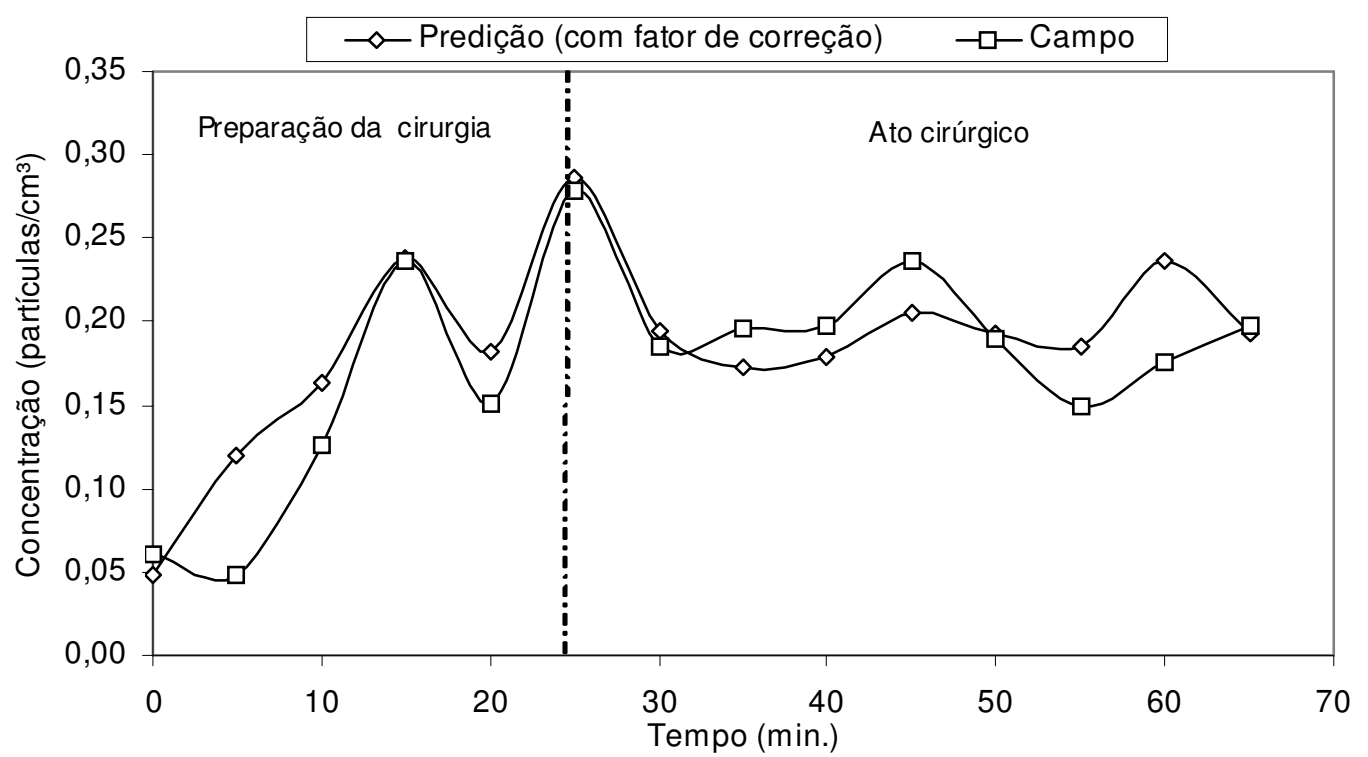

Figura 9.33 - Comparação entre os dados de campo e os resultados de predição, considerando um fator para os campos cirúrgicos, para o sistema B, com condicionamento de ar ligado e portas abertas. 
A Figura 9.34 apresenta uma comparação entre as concentrações medidas com as concentrações preditas pelo modelo para diferentes tamanhos (diâmetros) de partículas.

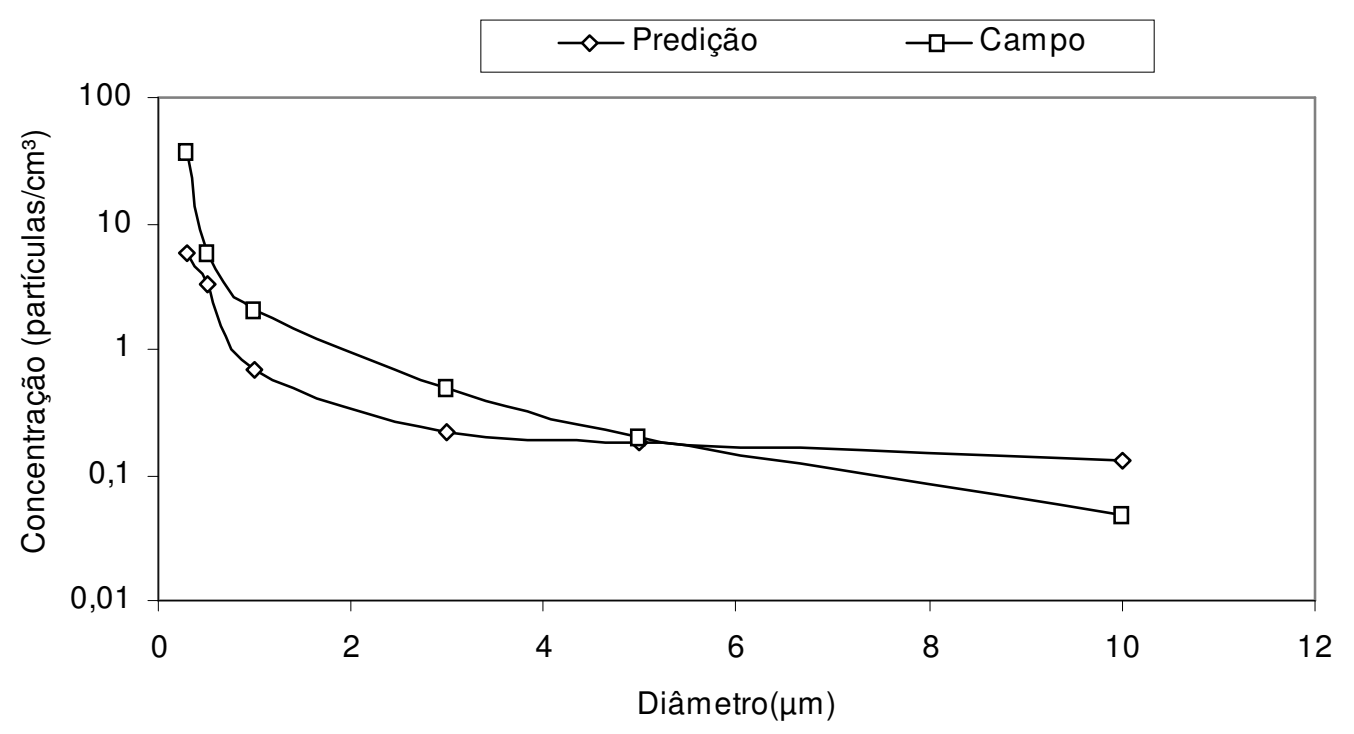

Figura 9.34 - Concentração de partículas em função do diâmetro, para o sistema B, com condicionamento de ar ligado e portas abertas

Como se pode ver na Figura 9.35, observa-se que as pessoas são o principal fator entre aqueles que contribuem para a geração de partículas dentro da sala, com 69,21\% do total gerado. A infiltração pelas portas abertas contribui com 17,66\%. Já as partículas provenientes do insuflamento do sistema de condicionamento de ar contribuem com 9,91\%, e a colocação e remoção dos campos cirúrgicos contribuem com apenas 3,20\%.

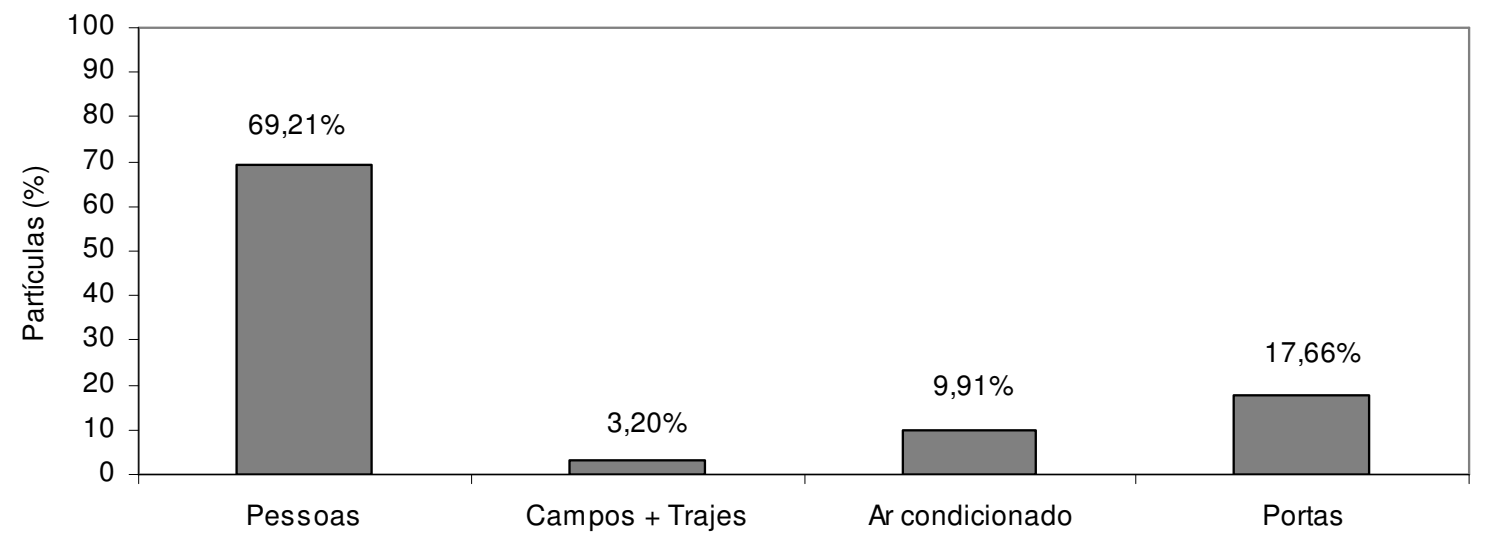

Figura 9.35 - Contribuição de diferentes fatores na geração de partículas, para o sistema $\mathrm{B}$, com condicionamento de ar ligado e portas abertas. 
O retorno de ar, como é mostrado na Figura 9.36, é o fator que mais contribui na remoção de partículas, 43,49\%. A remoção pelas portas e o processo de deposição nas superfícies contribuem com $39,90 \%$ e $22,60 \%$, respectivamente.

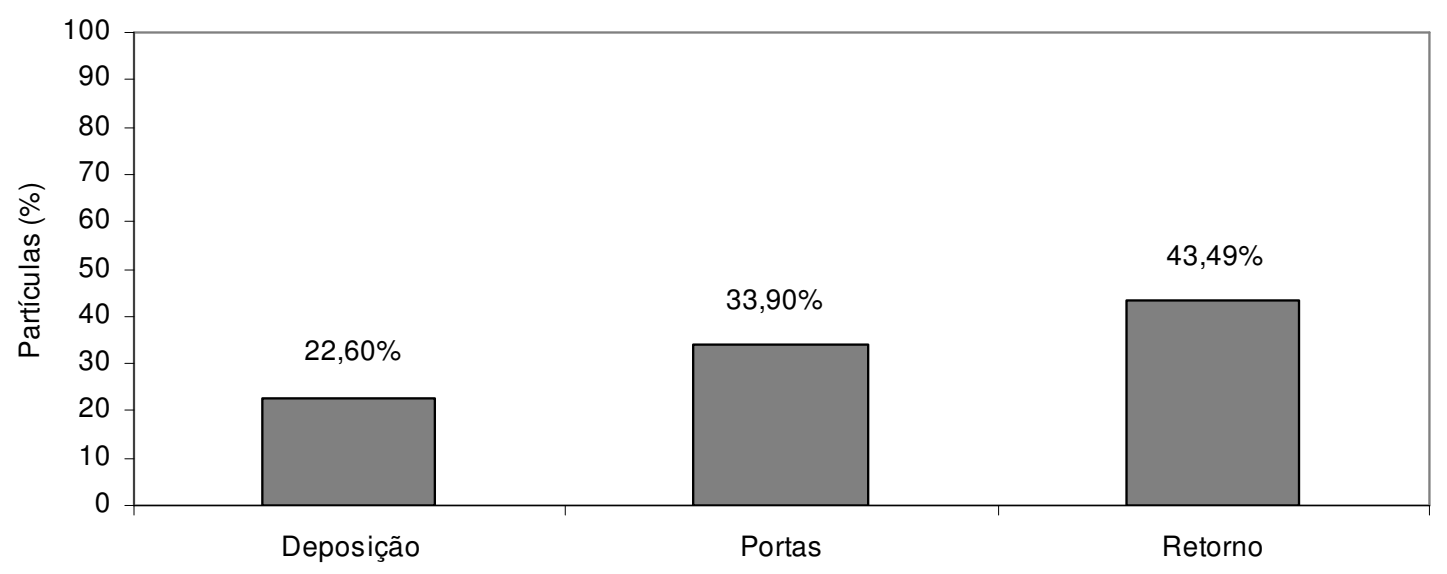

Figura 9.36 - Contribuição de diferentes fatores na remoção de partículas, para o sistema B, com condicionamento de ar ligado e portas abertas.

\subsection{SISTEMA COM INSUFLAMENTO PELO TETO E RETORNO PRÓXIMO AO PISO (SISTEMA C)}

\subsubsection{Condicionamento de ar ligado e portas fechadas}

A Figura 9.37 mostra uma comparação entre as concentrações medidas no interior da sala com as concentrações preditas pelo modelo, para o caso em que o sistema de condicionamento de ar permaneceu ligado e as portas fechadas. 


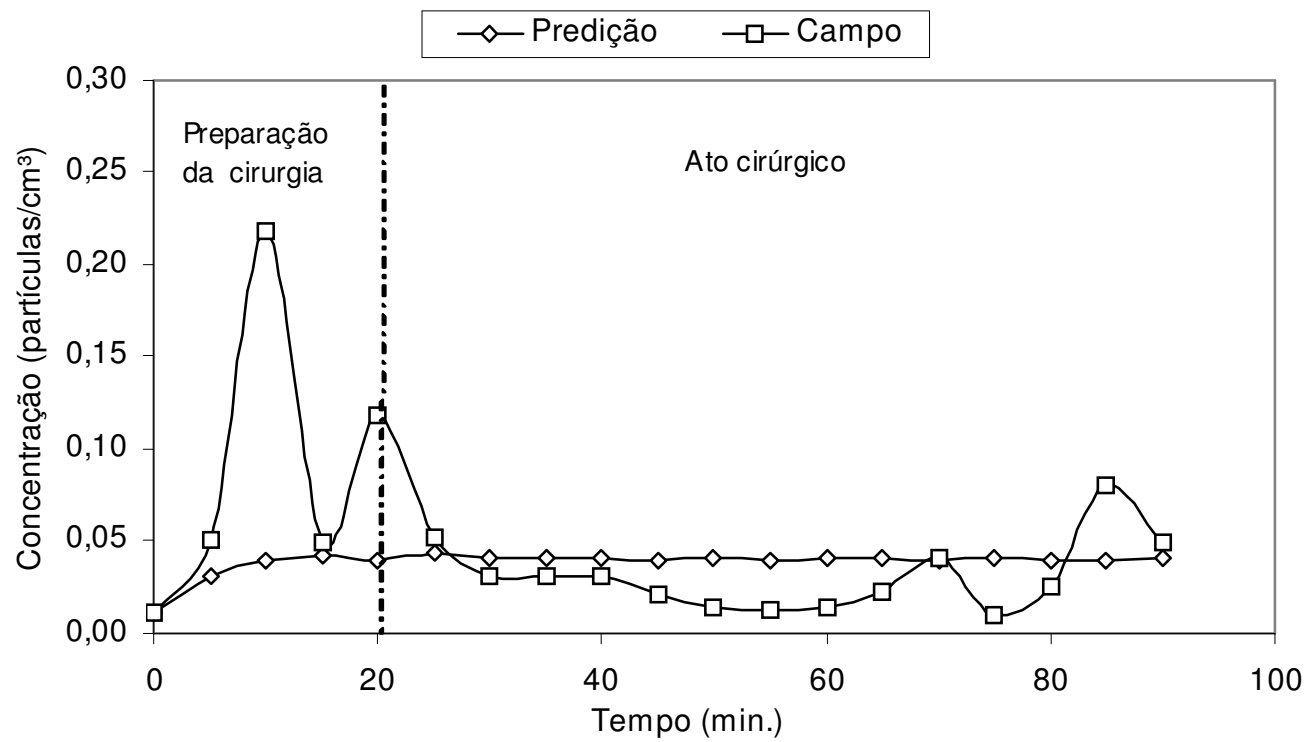

Figura 9.37 - Comparação entre os dados de campo e de predição, para o sistema C, com condicionamento de ar ligado e portas fechadas.

Tem-se, na Figura 9.38, uma comparação das concentrações de partículas medidas no interior da sala com as concentrações preditas pelo modelo, sem considerar as partículas geradas na colocação dos campos cirúrgicos.

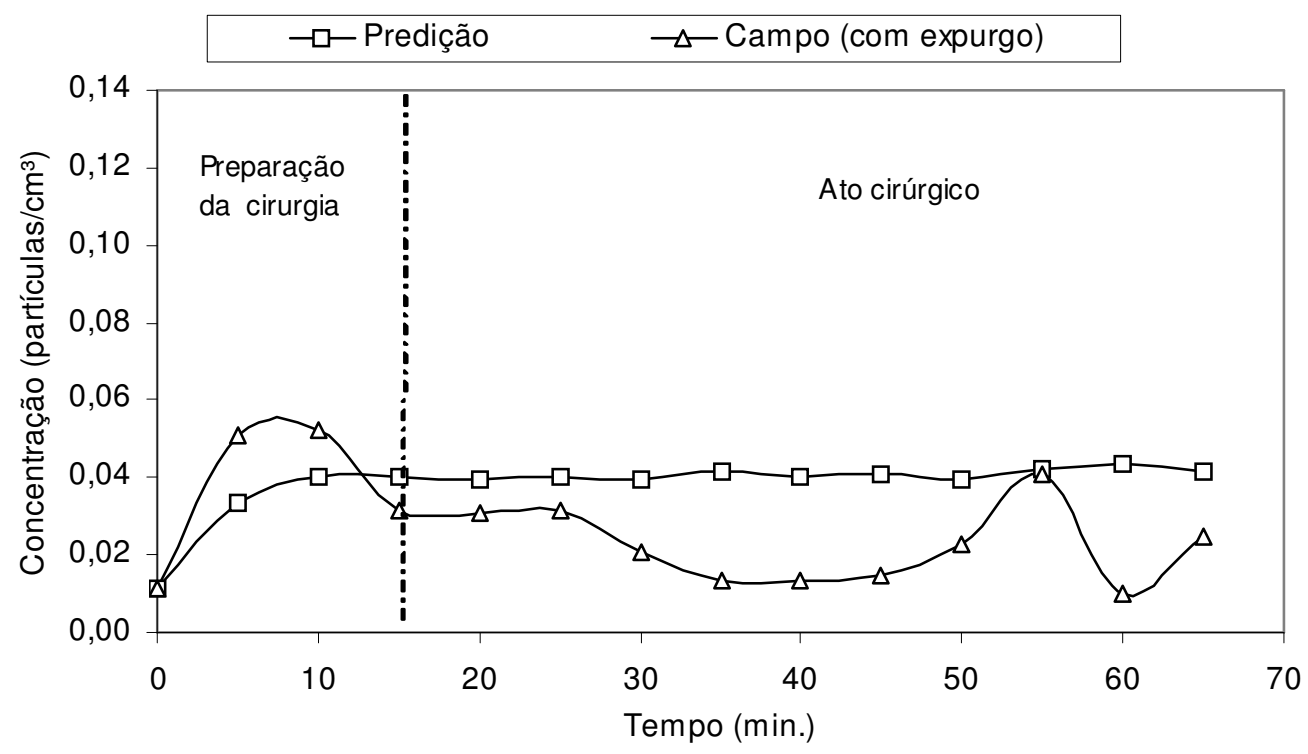

Figura 9.38 - Comparação entre os dados de campo e os resultados de predição, sem considerar os efeitos dos campos cirúrgicos, para o sistema com insuflamento $\mathrm{C}$, com condicionamento de ar ligado e portas fechadas. 
Na Figura 9.39, é apresentada uma comparação entre as concentrações de partículas medidas no interior da sala com as concentrações preditas pelo modelo, considerando um fator de multiplicação, que leva em conta o efeito das partículas geradas na colocação dos campos cirúrgicos.

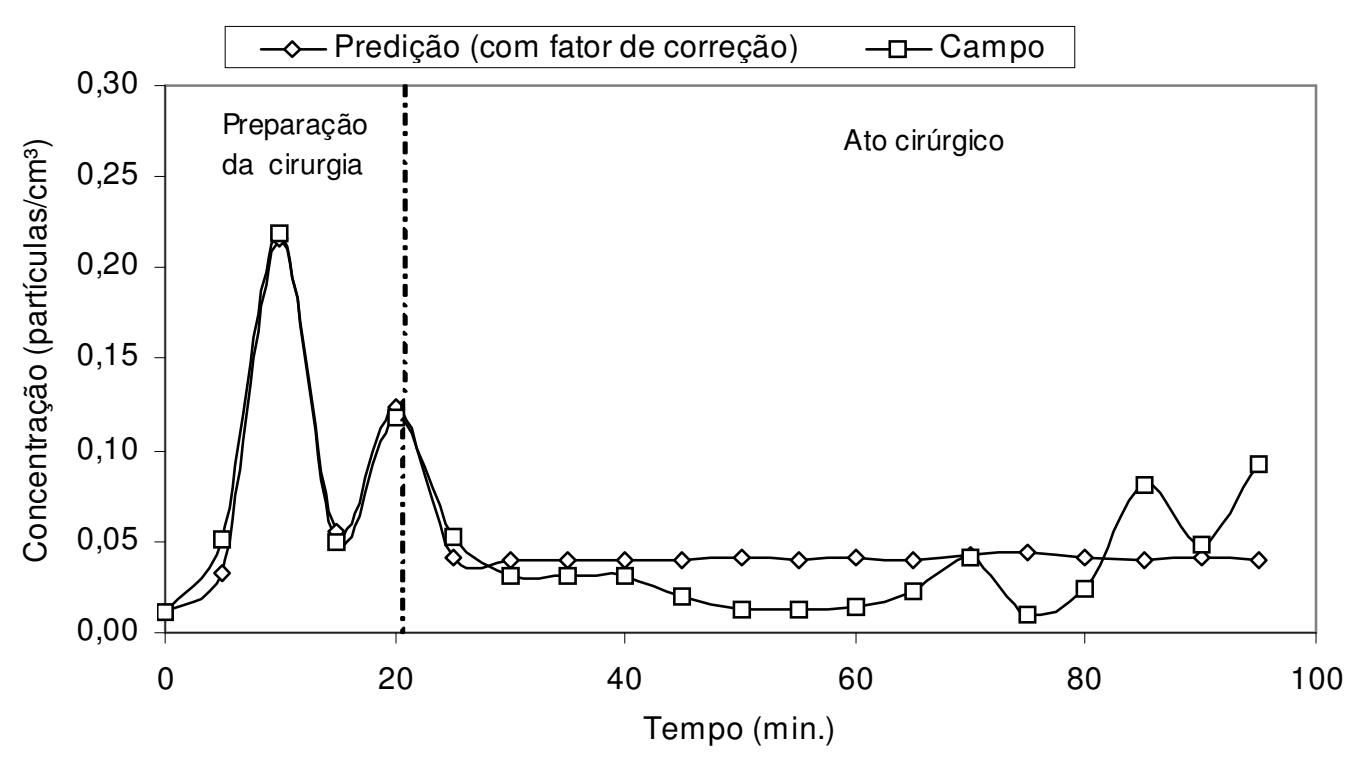

Figura 9.39 - Comparação entre os dados de campo e os resultados de predição, considerando um fator para o gesso e os campos cirúrgicos, para o sistema $\mathrm{C}$, com condicionamento de ar ligado e portas fechadas.

Na Figura 9.40, tem-se uma comparação entre as concentrações das partículas (dados de campo e valores preditos) para diferentes tamanhos (diâmetros) de partículas. 


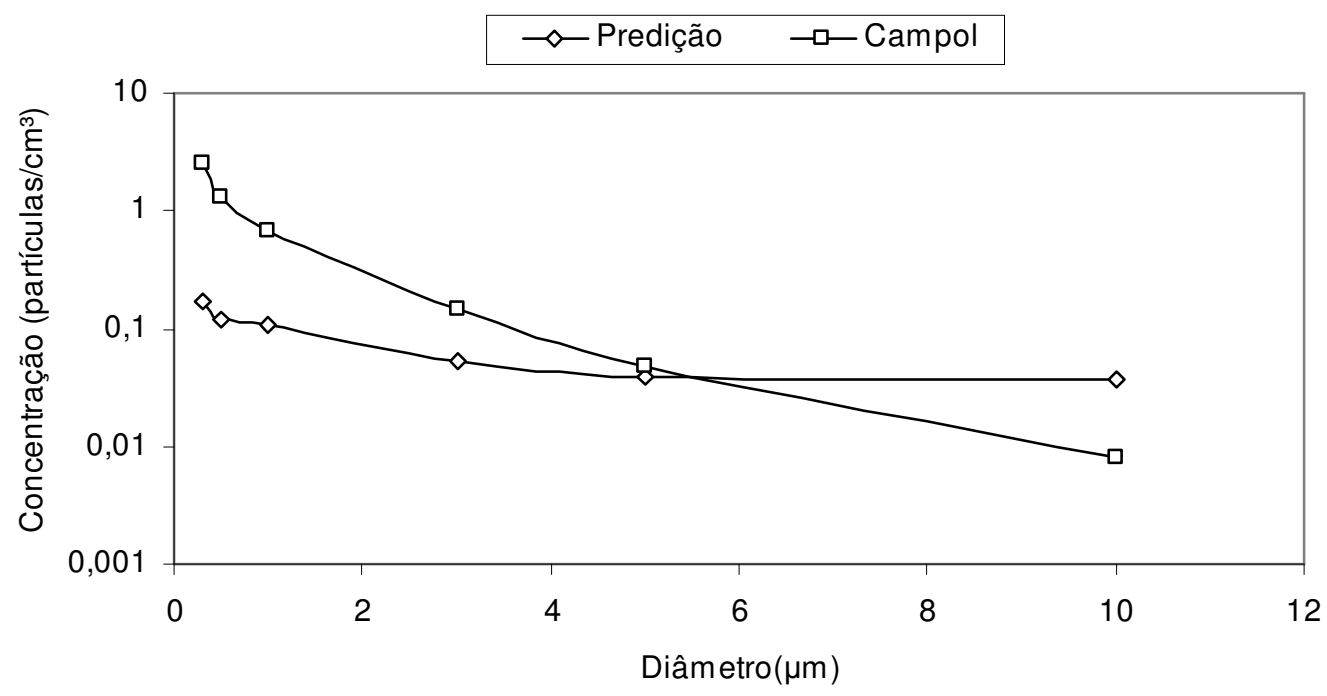

Figura 9.40 - Concentração de partículas em função do diâmetro, para o sistema $\mathrm{C}$, com condicionamento de ar ligado e portas fechadas.

As pessoas contribuem com 94,02\% no processo de geração de partículas no interior da sala, como é mostrado na Figura 9.41. Os campos cirúrgicos contribuem com 1,27\%, e o sistema de condicionamento de ar com 4,70\%.

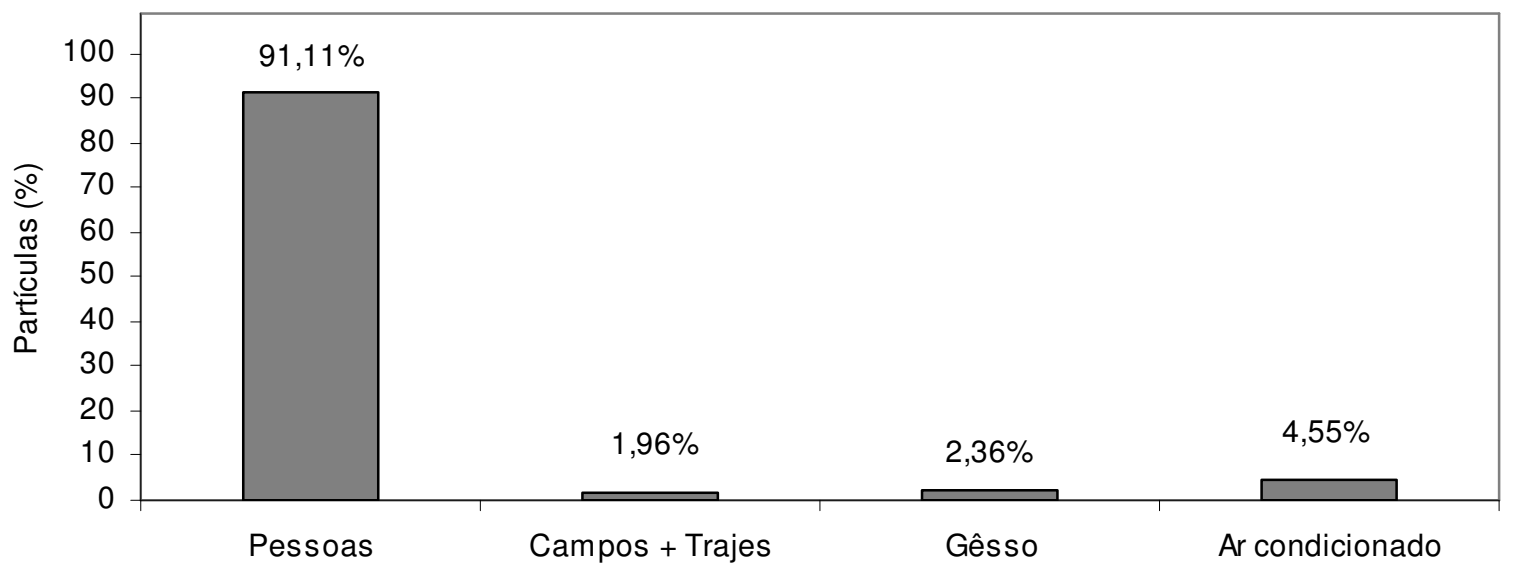

Figura 9.41 - Contribuição de diferentes fatores na geração de partículas, para o sistema C, com condicionamento de ar ligado e portas fechadas.

Como se pode ver na Figura 9.42, no processo de remoção, o retorno do condicionamento de ar contribui com a maior parcela, 92,24\% enquanto que o processo de deposição contribui com $7,75 \%$. 


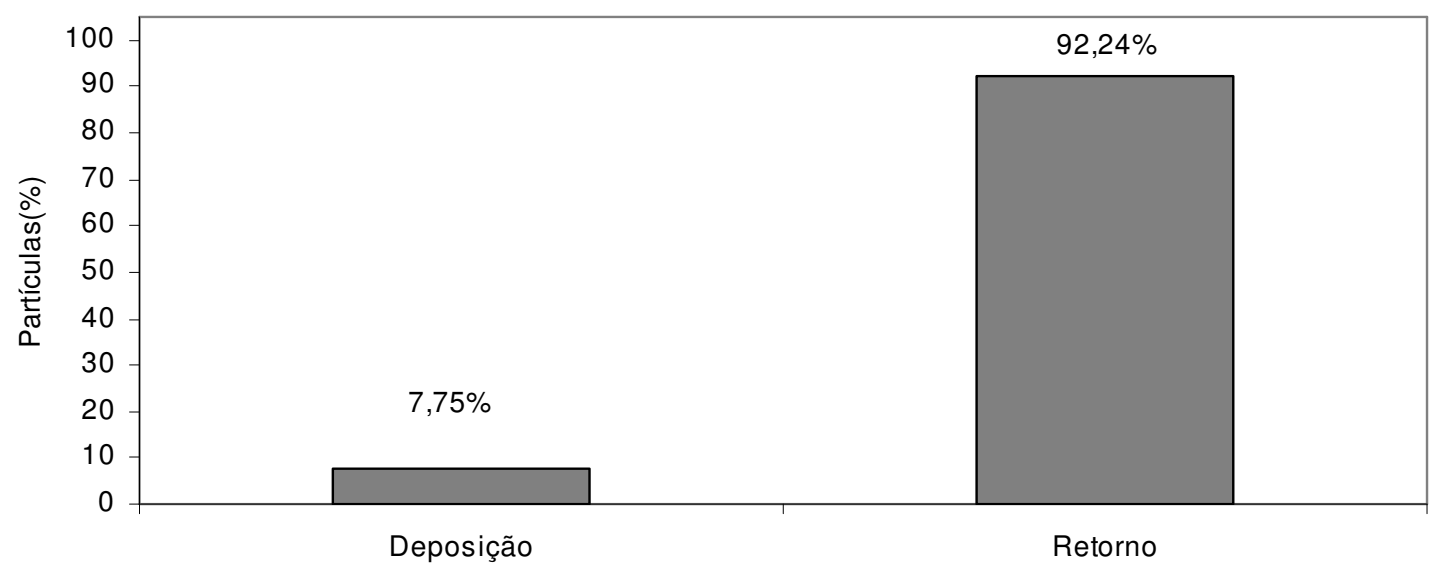

Figura 9.42 - Contribuição de diferentes fatores na remoção de partículas, para o sistema $\mathrm{C}$, com condicionamento de ar ligado e portas fechadas.

\subsubsection{Condicionamento de ar ligado e portas abertas}

Tem-se, na Figura 9.43, uma comparação das concentrações de partículas medidas no interior da sala com as concentrações preditas pelo modelo, para o caso em que o sistema de condicionamento de ar permaneceu ligado e as portas abertas.

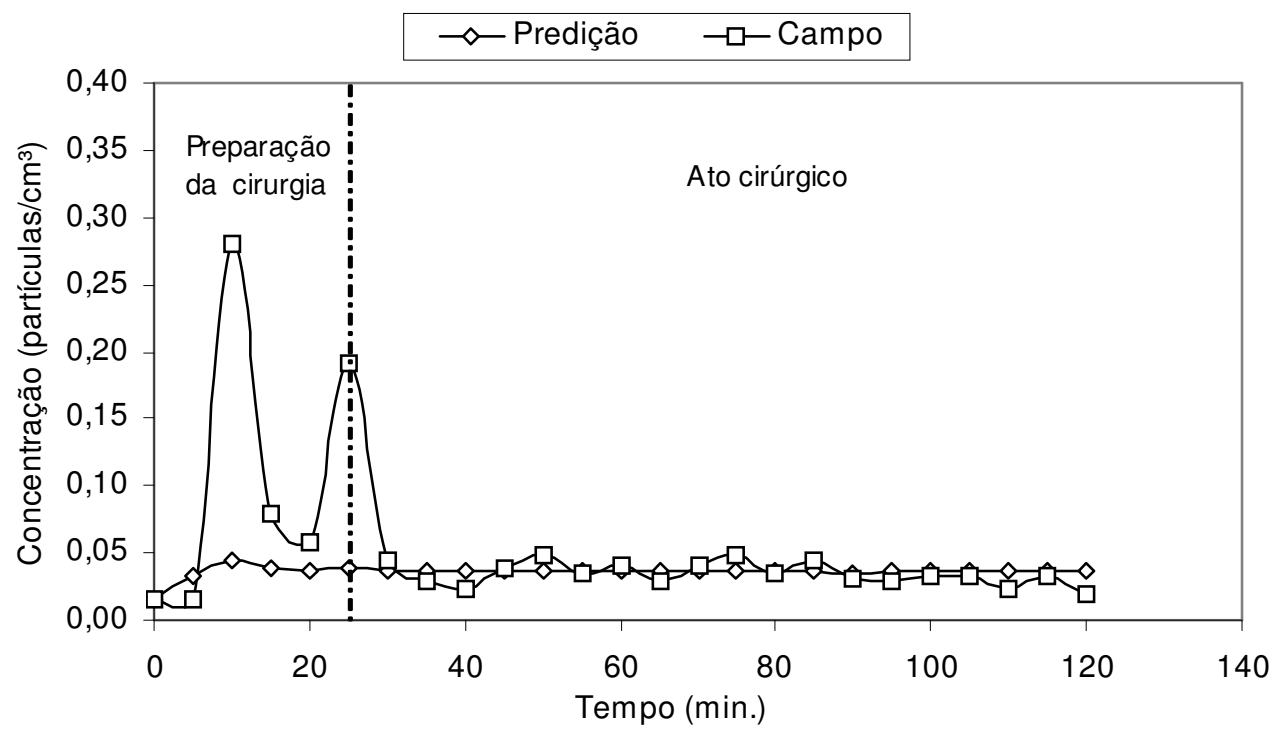

Figura 9.43 - Comparação entre os dados de campo e de predição, para o sistema $C$, com condicionamento de ar ligado e portas abertas.

Da mesma forma, na Figura 9.44, é apresentada uma comparação das concentrações de partículas medidas no interior da sala com as concentrações preditas pelo modelo, sem considerar as partículas geradas na colocação dos campos cirúrgicos. 


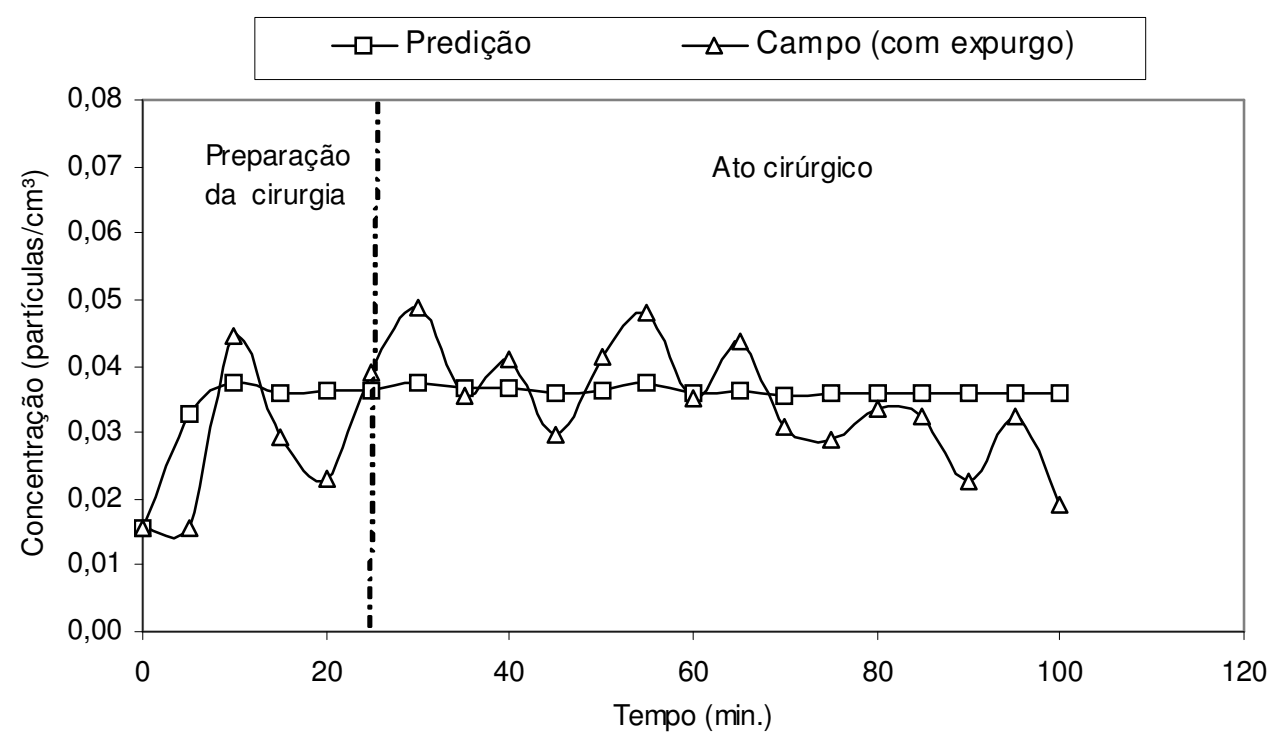

Figura 9.44 - Comparação entre os dados de campo e os resultados de predição, sem considerar o efeito dos campos cirúrgicos, para o sistema $\mathrm{C}$, com condicionamento de ar ligado e portas abertas.

A Figura 9.45 também apresenta uma comparação entre as concentrações de partículas medidas no interior da sala com as concentrações preditas pelo modelo, considerando um fator de multiplicação que leva em conta o efeito das partículas geradas na colocação dos campos cirúrgicos.

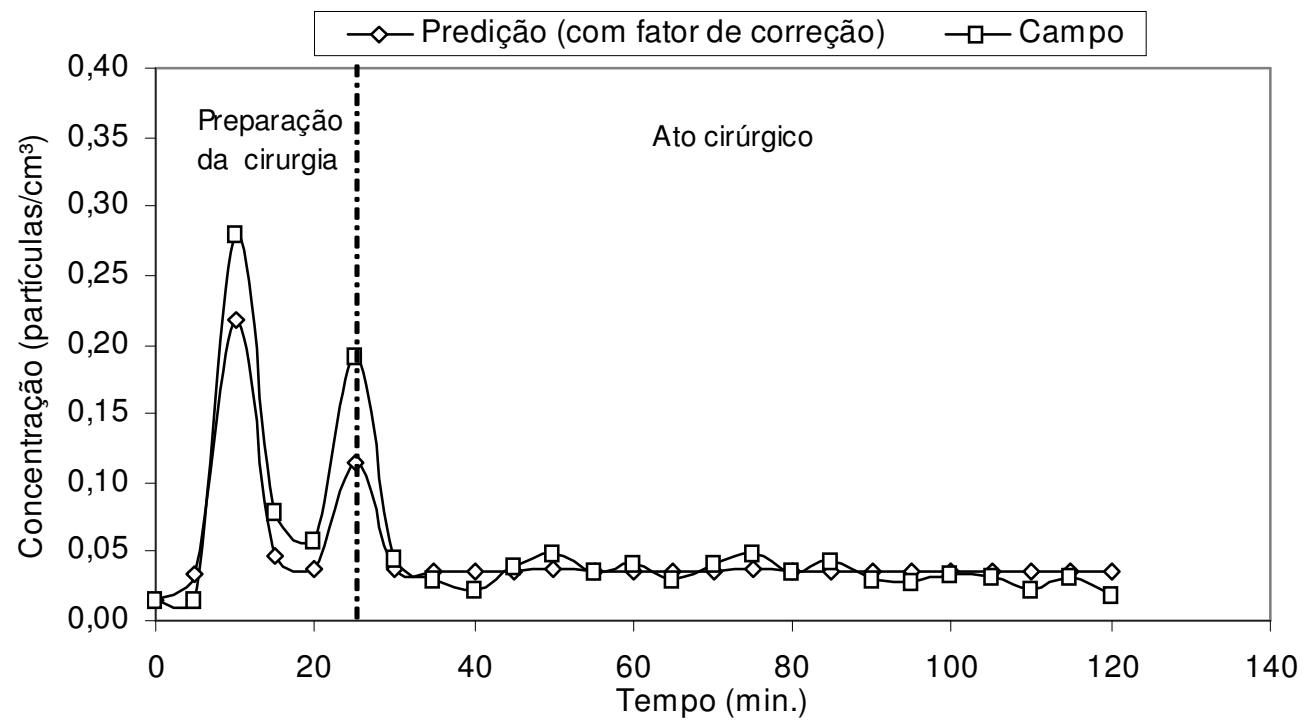

Figura 9.45 - Comparação entre os dados de campo e os resultados de predição, considerando um fator para os campos cirúrgicos, para o sistema $\mathrm{C}$, com condicionamento de ar ligado e portas abertas. 
Na Figura 9.46, tem-se uma comparação entre as concentrações das partículas (dados de campo e valores preditos) para diferentes tamanhos (diâmetros) de partículas.

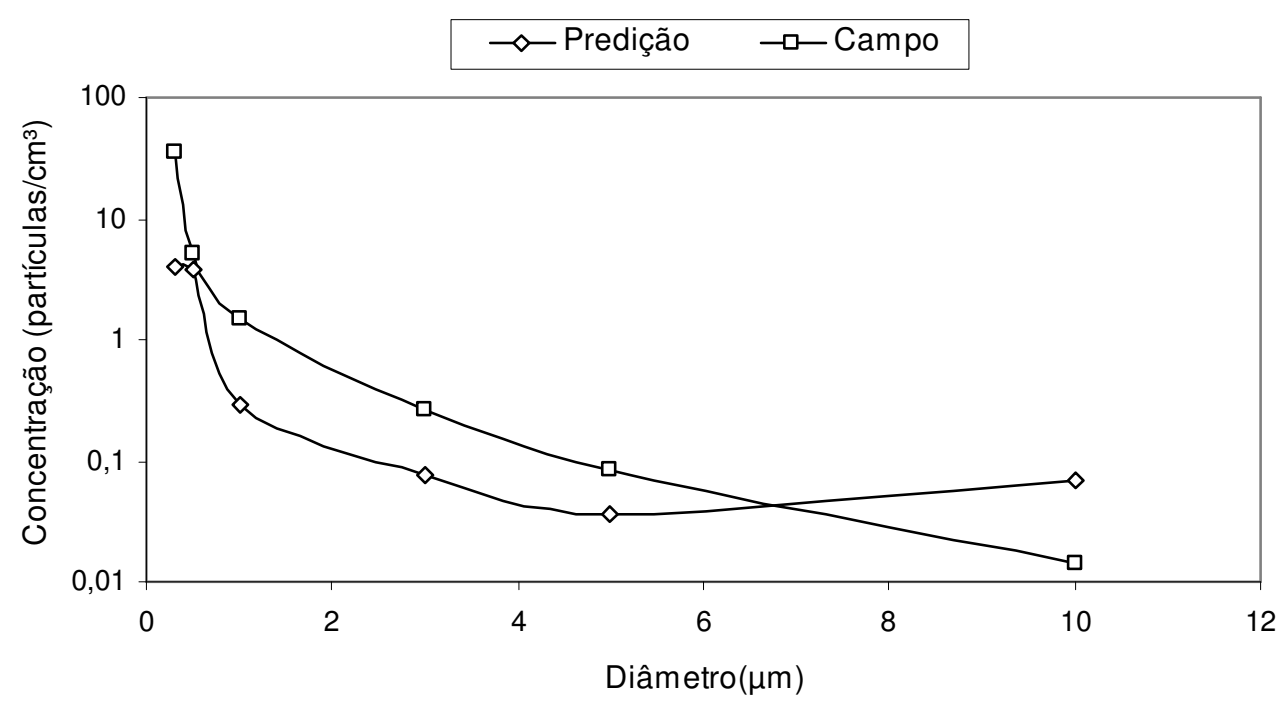

Figura 9.46 - Concentração de partículas em função do diâmetro, para o sistema C, com condicionamento de ar ligado e portas fechadas.

Como se pode ver na Figura 9.47, as pessoas constituem o fator que mais contribui para a geração de partículas dentro da sala, participando com 92,66\%. A infiltração pelas portas contribui com 4,65\%. Os demais fatores, como a colocação de gesso e dos campos cirúrgicos e o sistema de condicionamento de ar, contribuem com uma parcela muito pequena, $2,13 \%, 0,43 \%$ e $0,11 \%$, respectivamente.

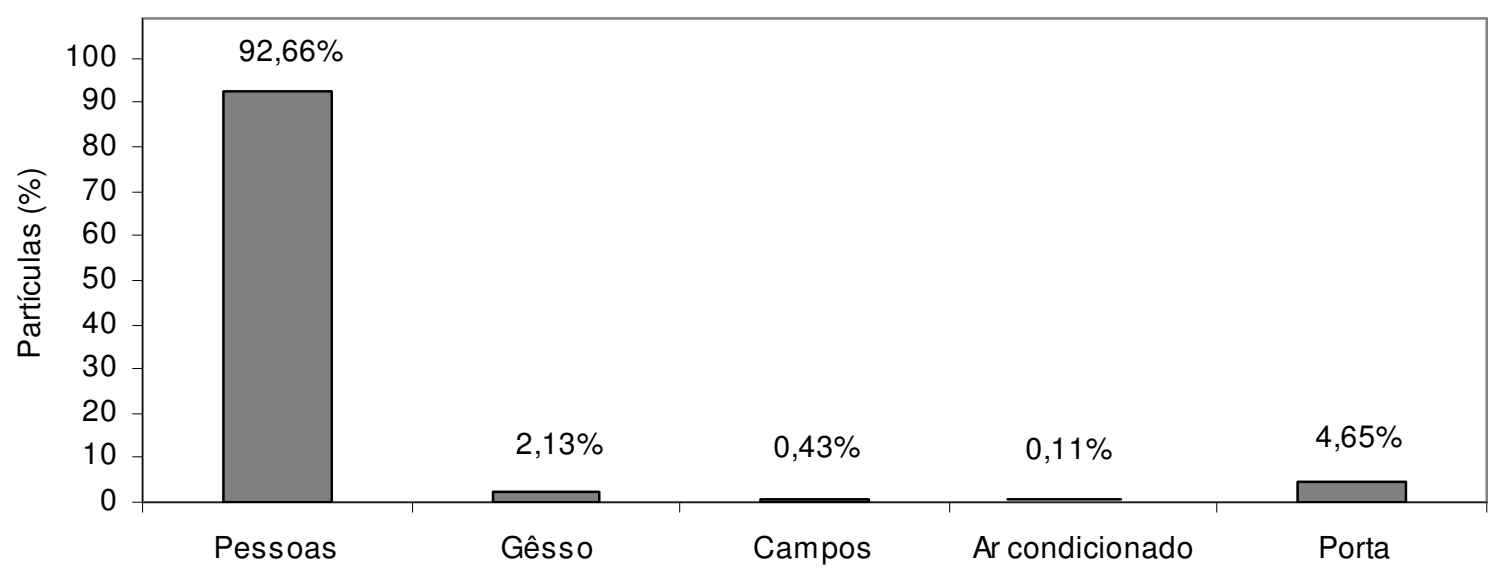

Figura 9.47 - Contribuição de diferentes fatores na geração de partículas, para o $\mathrm{C}$, com condicionamento de ar ligado e portas abertas. 
Com relação à remoção das partículas, a Figura 9.48 mostra que o retorno é o fator que mais contribui na remoção das partículas do interior da sala, com 80,28\%. A fuga pelas portas e o processo de deposição contribuem com parcelas menores, 11,82\% e 7,88\%, respectivamente.

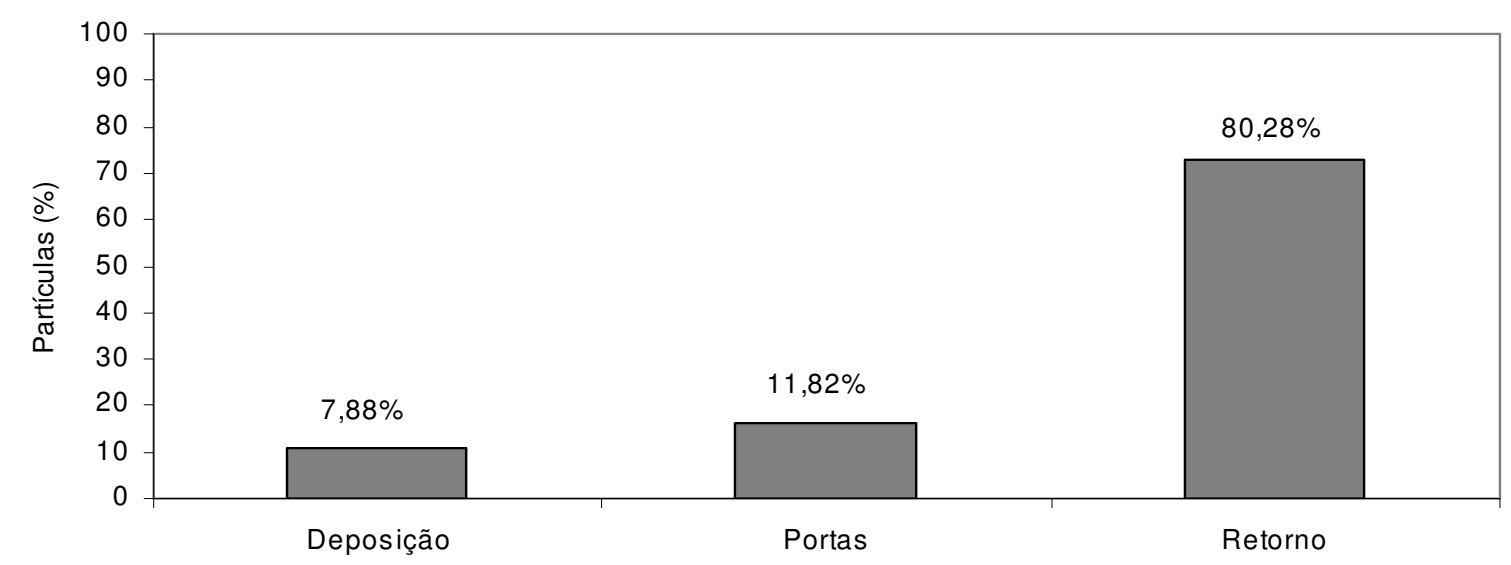

Figura 9.48 - Contribuição de diferentes fatores na remoção de partículas, para o sistema $C$, com condicionamento de ar ligado e portas abertas.

\subsection{AR CONDICIONADO DE JANELA (SISTEMA D)}

\subsubsection{Condicionamento de ar ligado e portas fechadas}

Figura 9.49 mostra uma comparação entre as concentrações de partículas medidas no interior da sala com as concentrações preditas pelo modelo para o caso em que o ar condicionado de janela permaneceu ligado e as portas fechadas. 


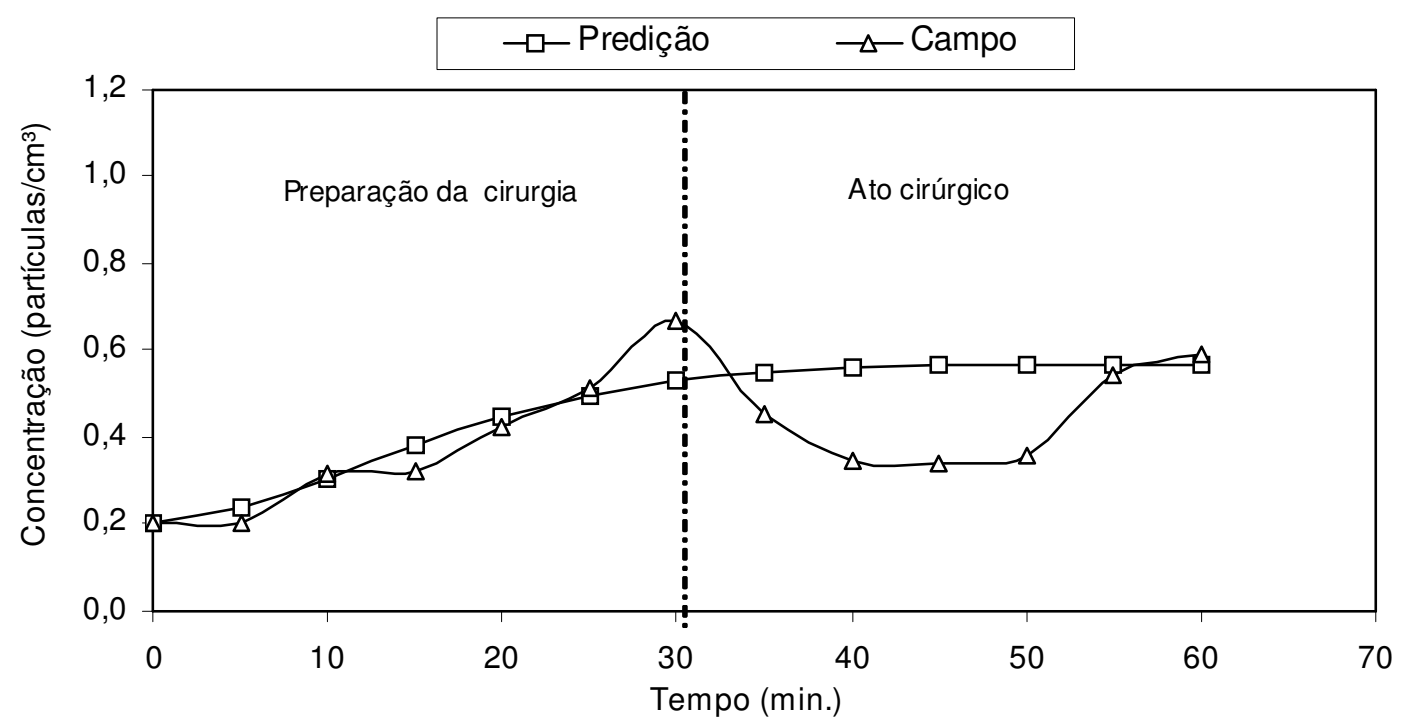

Figura 9.49 - Comparação entre os dados de campo e de predição, para o sistema D, com condicionamento de ar ligado e portas fechadas.

Na Figura 9.50, é apresentada uma comparação das concentrações de partículas medidas no interior da sala com as concentrações preditas pelo modelo, sem considerar as partículas geradas na colocação dos campos cirúrgicos.

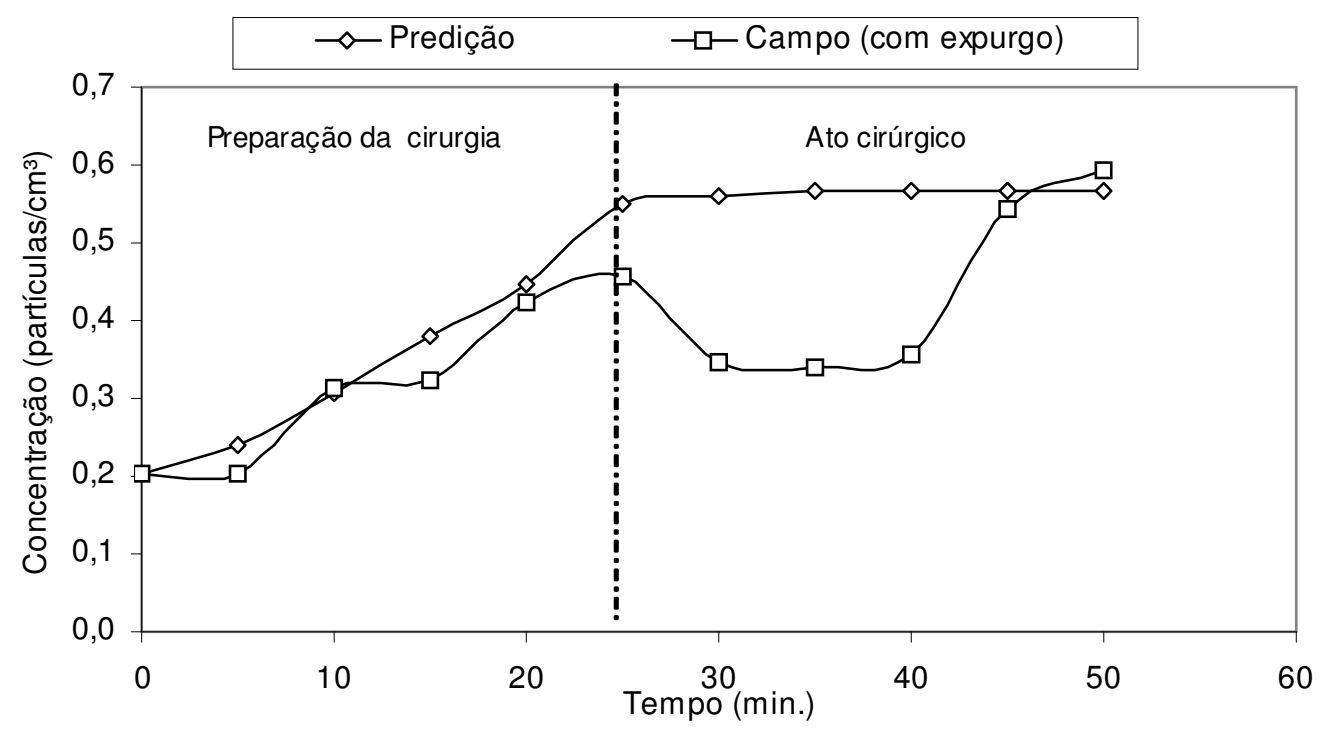

Figura 9.50 - Comparação entre os dados de campo e os resultados de predição, sem considerar os efeitos dos campos cirúrgicos, para o sistema $\mathrm{D}$, com condicionamento de ar ligado e portas fechadas. 
Tem-se, na Figura 9.51, uma comparação entre as concentrações de partículas medidas no interior da sala com as concentrações preditas pelo modelo, considerando um fator de multiplicação, que leva em conta o efeito das partículas geradas na colocação dos campos cirúrgicos.

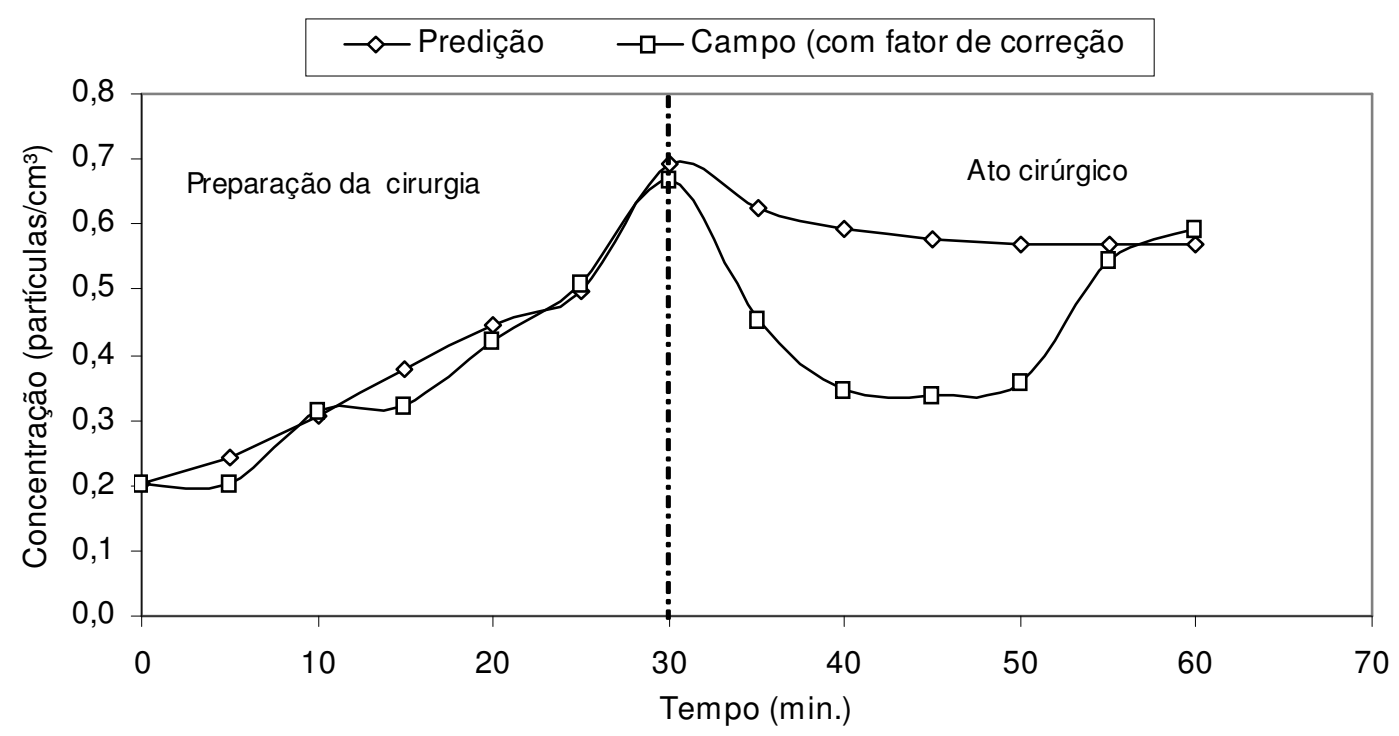

Figura 9.51 - Comparação entre os dados de campo e os resultados de predição, considerando um fator para os campos cirúrgicos, para o sistema D, com condicionamento de ar ligado e portas fechadas.

A Figura 9.52 apresenta uma comparação entre as concentrações medidas das partículas com as concentrações preditas pelo modelo para diferentes tamanhos (diâmetros) de partículas. 


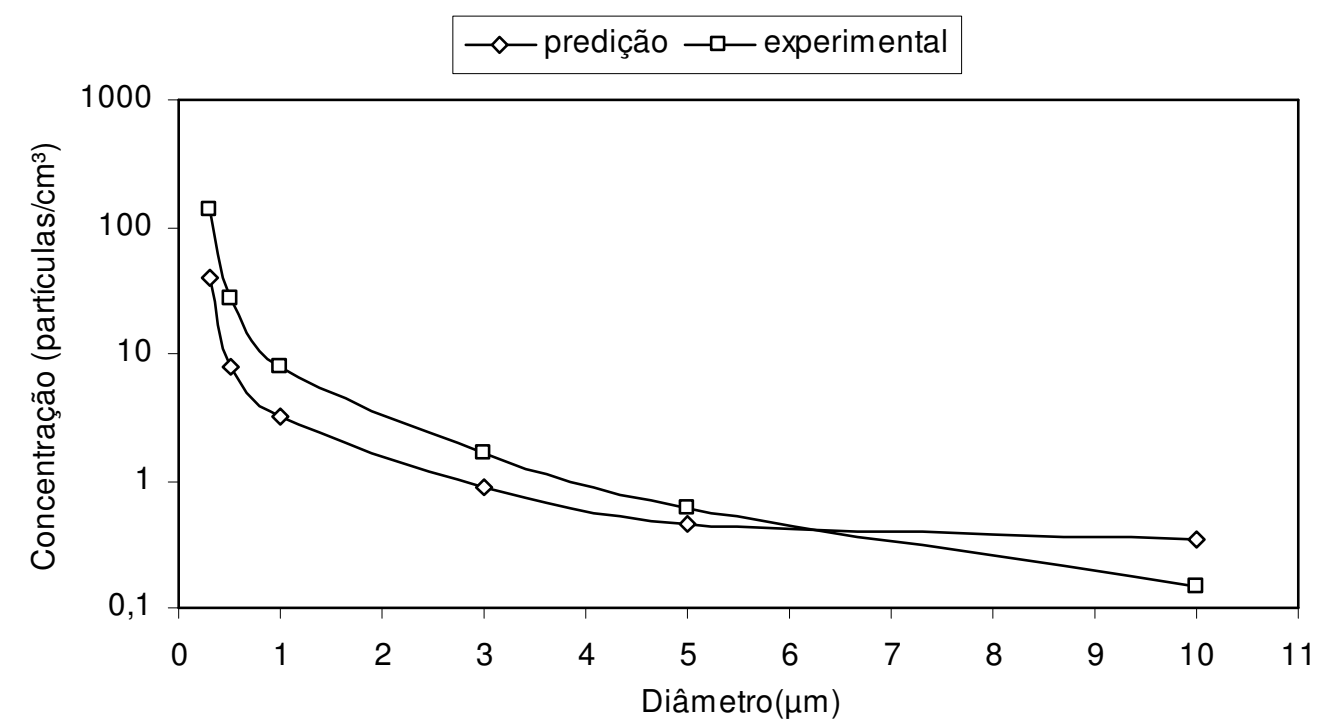

Figura 9.52 - Concentração de partículas em função do diâmetro, para o sistema D, com condicionamento de ar ligado e portas fechadas.

A Figura 9.53 mostra que a colocação e a remoção dos campos cirúrgicos contribuem com uma parcela muito pequena no processo de geração de partículas no interior da sala $(0,77 \%)$. Todo o restante $(99,22 \%)$ é gerado pelas pessoas.

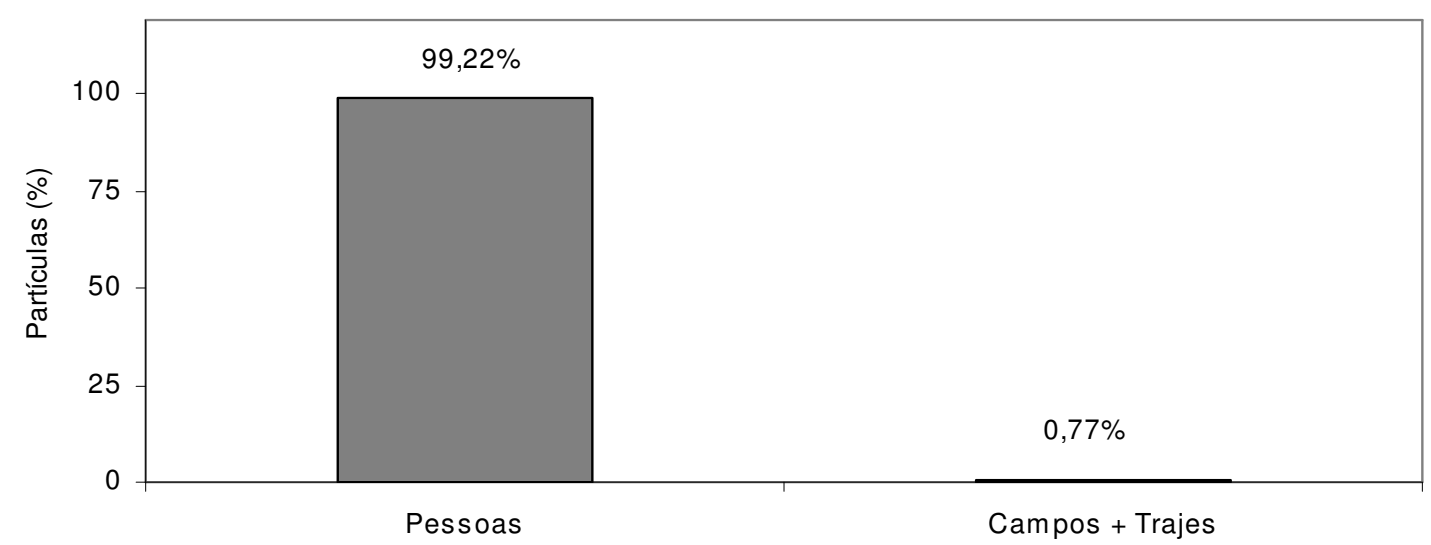

Figura 9.53 - Contribuição de diferentes fatores na geração de partículas, para o sistema D, com condicionamento de ar ligado e portas fechadas.

Neste caso, a única fonte de remoção de partículas no interior da sala é o processo de deposição. 


\subsubsection{Condicionamento de ar ligado e portas abertas}

A Figura 9.54 mostra uma comparação das concentrações de partículas medidas no interior da sala (próximo ao campo cirúrgico) com as concentrações preditas pelo modelo, para o caso em que ar condicionado de janela permaneceu ligado e as portas abertas.

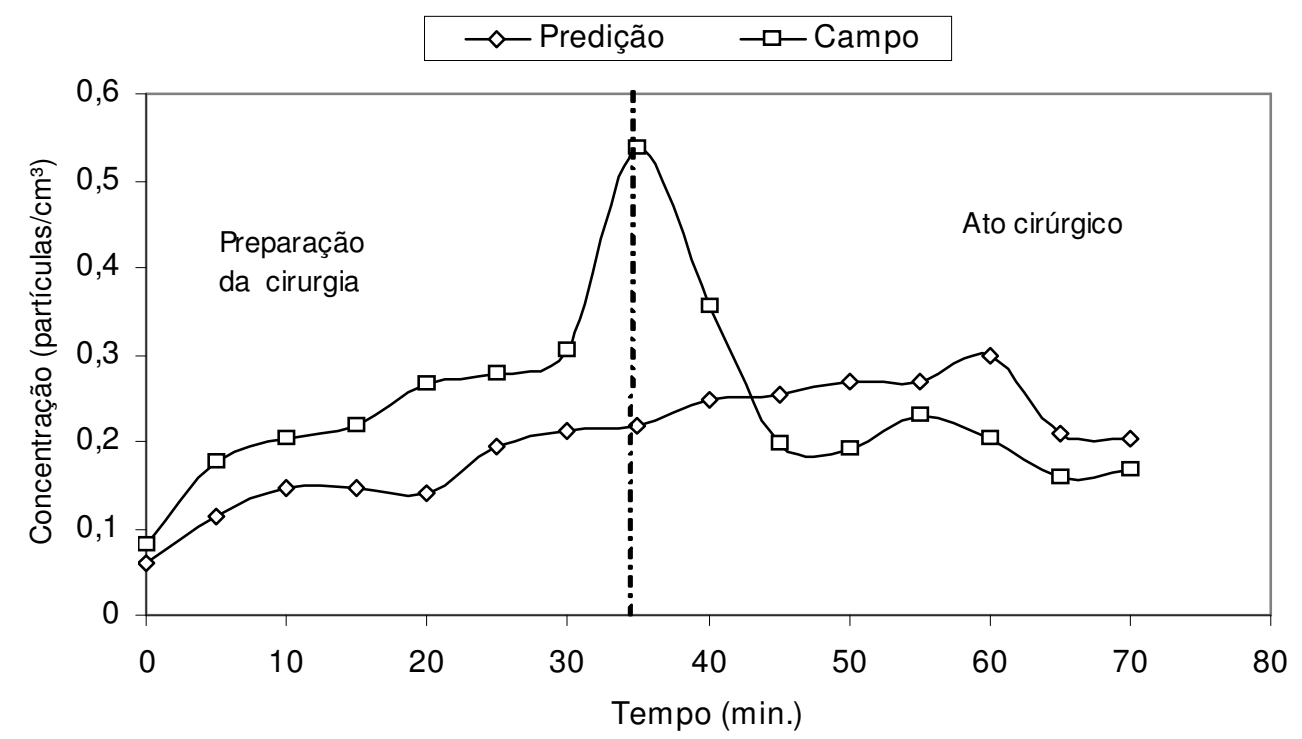

Figura 9.54 - Comparação entre os dados de campo e o modelo, para o sistema D, com condicionamento de ar ligado e portas abertas.

Na Figura 9.55, é apresentada uma comparação das concentrações de partículas medidas no interior da sala com as concentrações preditas pelo modelo, sem considerar as partículas geradas na colocação dos campos cirúrgicos.

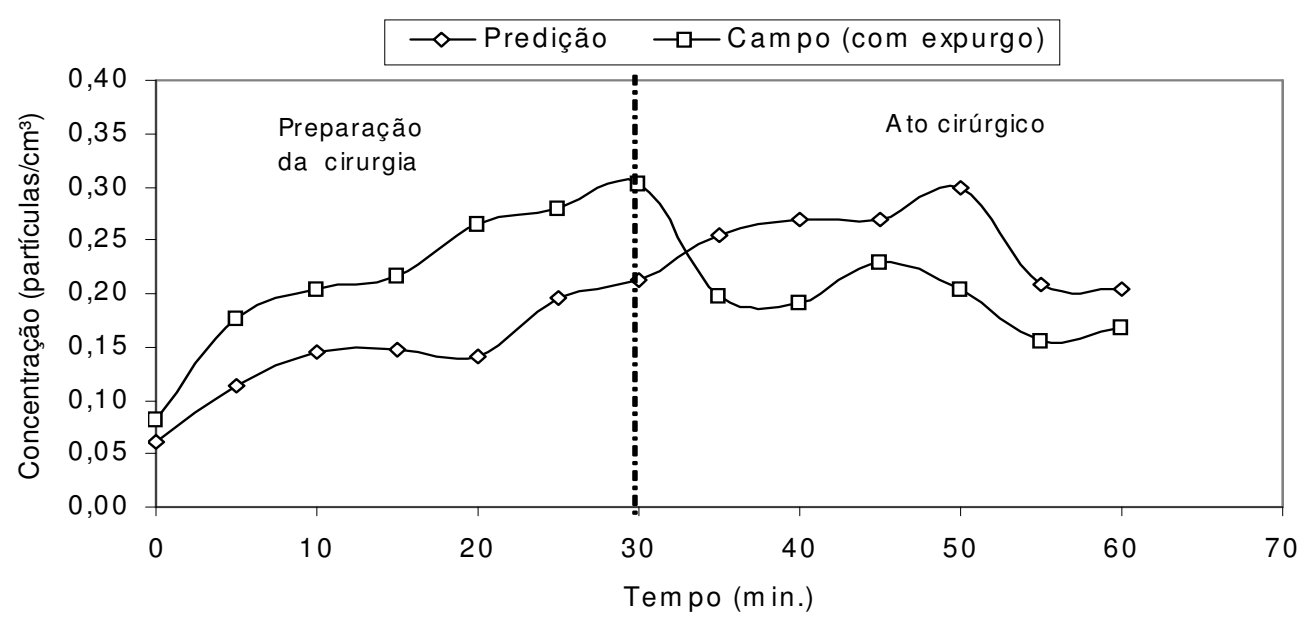

Figura 9.55 - Comparação entre os dados de campo e os resultados de predição, sem considerar os efeitos dos campos cirúrgicos, para o sistema $\mathrm{D}$, com condicionamento de ar ligado e portas abertas. 
A Figura 9.56 apresenta uma comparação entre as concentrações de partículas medidas no interior da sala com as concentrações preditas pelo modelo, considerando um fator de multiplicação, que leva em conta o efeito das partículas geradas na colocação dos campos cirúrgicos.

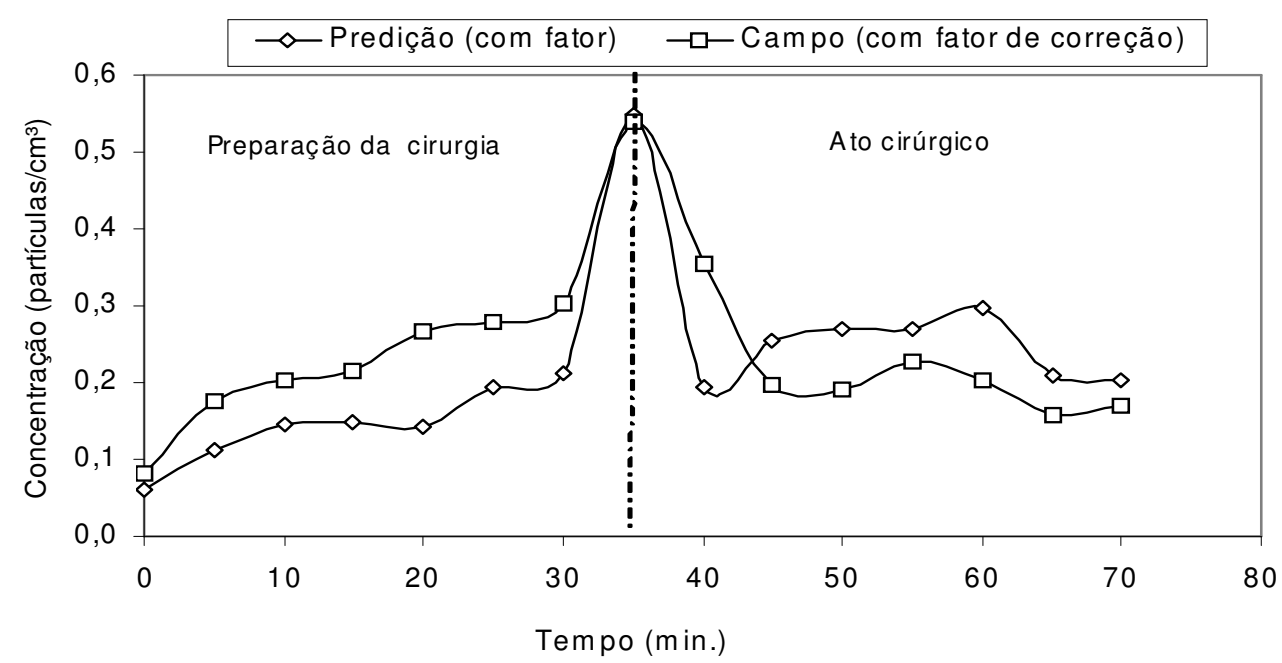

Figura 9.56 - Comparação entre os dados de campo e os resultados de predição, considerando um fator para os campos cirúrgicos, para o sistema $\mathrm{D}$, com condicionamento de ar ligado e portas abertas.

A Figura 9.57 apresenta as concentrações médias das partículas (dados de campo e valores preditos) para diferentes tamanhos (diâmetros) das mesmas.

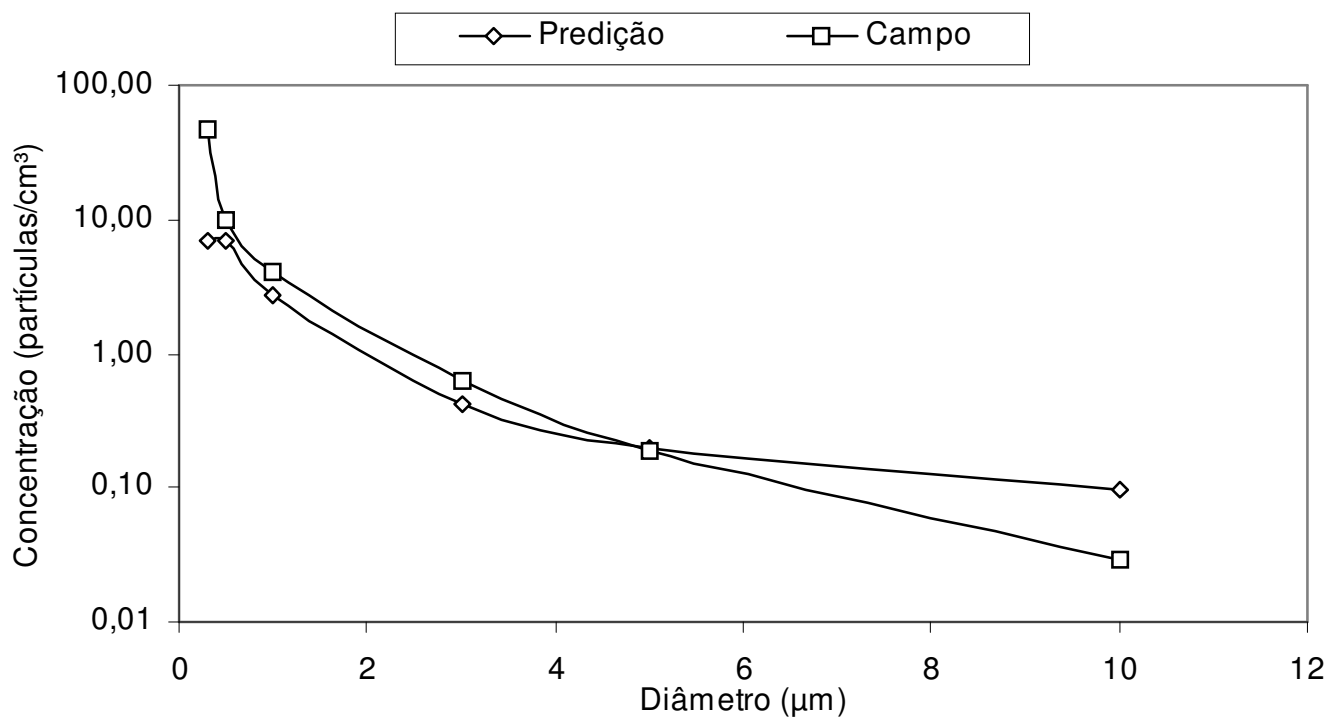

Figura 9.57 - Concentração de partículas em função do diâmetro, para o sistema D, com condicionamento de ar ligado e portas abertas. 
Na Figura 9.58, observa-se que a colocação e a remoção dos campos cirúrgicos contribuem com uma pequena parcela no processo de geração de partículas no interior da sala $(1,89 \%)$. Outros fatores, como as pessoas $(80,11 \%)$ e infiltrações pelas portas $(17,98 \%)$, contribuem com um percentual mais significativo.

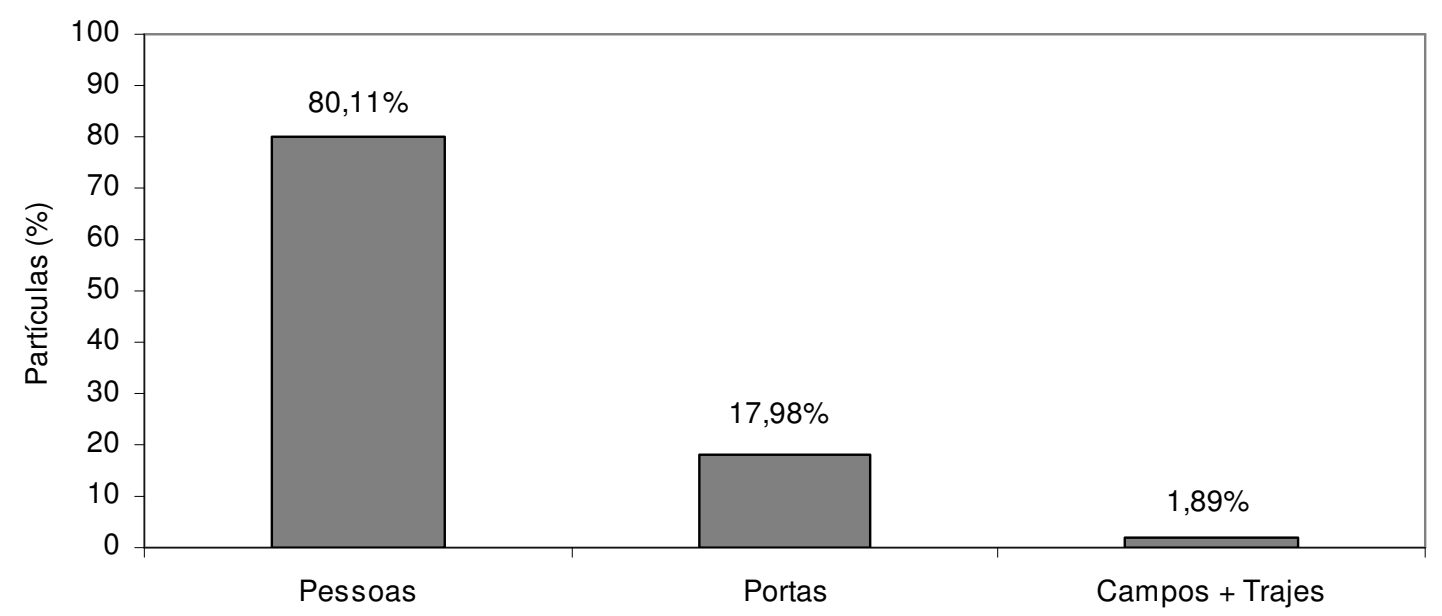

Figura 9.58 - Contribuição de diferentes fatores na geração de partículas, para o sistema D, com condicionamento de ar ligado e portas abertas.

A remoção pelas portas é o fator que mais contribui para a diminuição das partículas do ar no interior da sala cirúrgica, participando com 85,54\%. Isso é mostrado na Figura 9.59 A deposição sobre as superfícies contribui com 11,45\%.

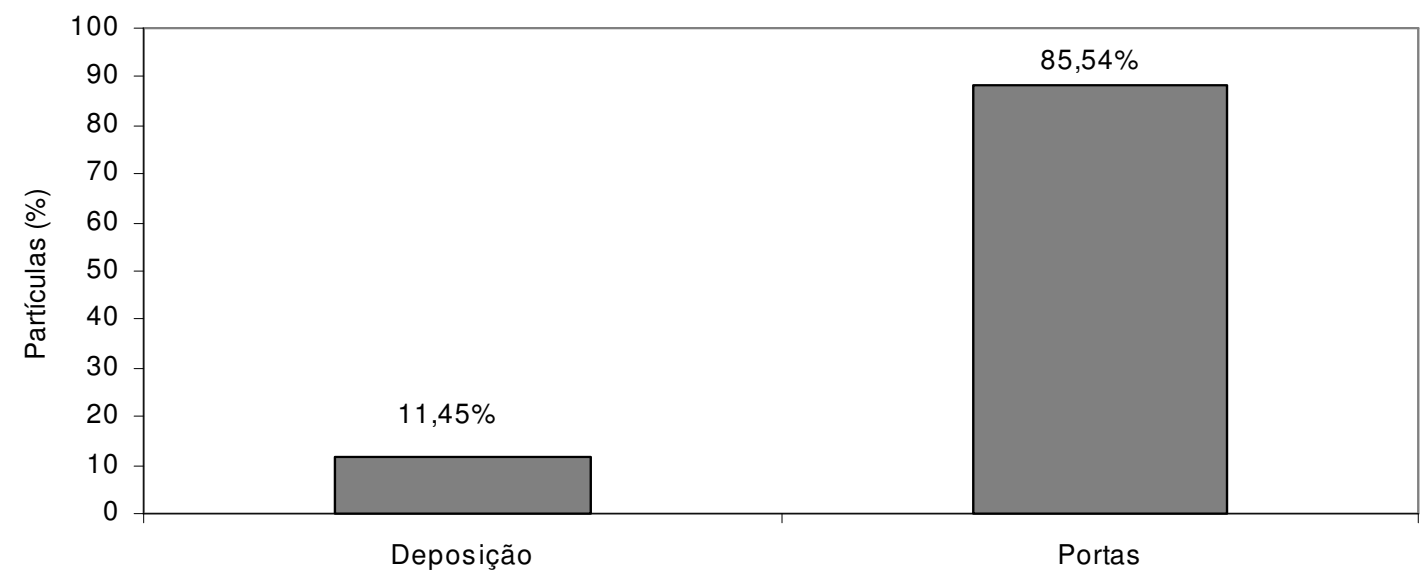

Figura 9.59 - Contribuição de diferentes fatores na remoção de partículas, para o sistema D, com condicionamento de ar ligado e portas abertas. 


\section{CAPÍTULO 10}

\section{ANÁLISE DOS RESULTADOS EXPERIMENTAIS}

Neste capítulo são apresentadas as análises dos resultados experimentais, compreendendo a análise da:

- Distribuição de temperaturas e velocidades do ar nas salas cirúrgicas;

- Caracterização da concentração das partículas no interior das salas cirúrgicas;

- Influência da atividade humana na concentração de partículas;

- Influência do diâmetro das partículas sobre a concentração;

- Influência da abertura das portas na concentração de partículas;

- Influência do sistema de condicionamento de ar na concentração de partículas;

- Influência das vazões de insuflamento e retorno do ar na concentração de partículas.

\subsection{DISTRIBUIÇÃO DA TEMPERATURA E VELOCIDADE DO AR NAS SALAS CIRÙRGICAS}

O estudo da distribuição de temperatura e de velocidade do ar é uma importante estratégia para verificar se o comportamento da distribuição do ar no interior da sala é homogêneo, pois este é o principal critério para a utilização dos modelos propostos.

Em todos os casos analisados, as condições de distribuição de temperatura e velocidade do ar (Anexo A) indicam um comportamento estável no interior das salas cirúrgicas. Isso garante para todos os casos analisados a utilização dos modelos para a predição da concentração de partículas na sala, pois por meio da obtenção do campo de distribuição de velocidade e temperatura, percebe-se que não existem no interior da sala pontos de estagnação de ar ou regiões com grandes turbulências, que possam formar correntes de convecção, descaracterizando a homogeneidade na distribuição das partículas. 


\subsection{CARACTERIZAÇÃO DA CONCENTRAÇÃO DAS PARTÍCULAS NO INTERIOR DAS SALAS CIRÚRGICAS}

Essa análise desempenha um papel importante para se verificar quais os fatores preponderantes na geração e remoção de partículas e durante quais momentos e atividades ocorre maior ou menor geração de partículas.

Os resultados das medições mostram que a variação na concentração das partículas no interior de uma sala cirúrgica normalmente apresenta comportamento típico, Inicialmente, quando a sala está vazia, a concentração das partículas é baixa, comparativamente às demais etapas do procedimento cirúrgico. Com a entrada do paciente e, conseqüentemente, a preparação do procedimento cirúrgico, ocorre um aumento da concentração de partículas, por ser o nível de atividade no interior da sala mais intenso, devido ao processo de indução anestésica, à colocação de trajes e campos cirúrgicos e, em certas cirurgias ortopédicas, à remoção da tala (gesso).

Na etapa de preparação do procedimento cirúrgico, durante a colocação dos aventais e campos cirúrgicos, observa-se uma forte inclinação nos gráficos que mostram a variação da concentração das partículas de 5 a $10 \mu \mathrm{m}$ ao longo do tempo, devido à intensa geração de partículas de fibra de algodão que ocorre durante essas atividades. Nas cirurgias ortopédicas, observam-se dois picos de geração de partículas, o primeiro devido à remoção da tala de gesso, mediante serragem, e o segundo devido à colocação dos aventais e campos cirúrgicos. Percebe-se que a geração de partículas devido à remoção de tala é mais intensa.

Com o início do ato cirúrgico, o nível de atividade no interior da sala vai diminuindo e, conseqüentemente, a geração de partículas é menos intensa. Na maioria dos casos, nessa região, as partículas geradas durante a preparação do ato cirúrgico se estabilizam após um determinado tempo. No final do ato cirúrgico, com a retirada dos campos cirúrgicos, observa-se novamente um aumento da concentração de partículas no interior da sala.

\subsection{INFLUÊNCIA DA CONCENTRAÇÃO INICIAL}

Observou-se que, nas cirurgias que ocorrem no início do turno de trabalho, as concentrações iniciais (sala vazia) são baixas. Por outro lado, as cirurgias realizadas em outros momentos podem sofrer os efeitos da contaminação gerada nas cirurgias anteriores. Essa contaminação tende a ser eliminada pelo sistema de condicionamento de ar, como mostrado na Figura 8.9. Mas, quando o sistema está desligado, não há uma eficiente remoção dos contaminantes, como se pode observar na Tabela 8.5 e nas Figuras 8.7 e 8.8. Desta forma, 
destaca-se a importância de ligar o sistema de condicionamento de ar algum tempo antes da cirurgia para eliminação da contaminação residual. Destaque-se também que, como mostram a Tabela 8.5 e a Figura 8.12, o sistema de ar condicionado de janela, por não promover filtragem adequada e nem renovação de ar, mostra-se ineficiente para remover a contaminação residual.

\subsection{INFLUÊNCIA DA ATIVIDADE HUMANA NA CONCENTRAÇÃO DE PARTÍCULAS}

Com as análises realizadas em todos os casos estudados, comprovou-se que o aumento da concentração de partículas ocorre essencialmente em função da atividade humana: variação no número de pessoas, aumento do nível de atividade, colocação dos aventais e campos cirúrgicos. As maiores variações ocorreram na faixa de diâmetro de 5 a $10 \mu \mathrm{m}$, devido à grande geração de partículas de pele e fibras de algodão. Essa comprovação é de particular interesse, uma vez que é justamente nessa faixa que as partículas de escamas de pele representam as principais fontes de contaminação, pois têm usualmente diâmetro médio de 7,5 $\mu \mathrm{m}$ (Woods, 1986). A importância dessa observação é que as partículas viáveis nessa faixa de tamanho, geradas pelas atividades humanas, podem ser as mais propensas a causar infecção bacteriana na ferida cirúrgica, uma vez que oferecem maior possibilidade de servir como meio para transporte de patógenos. Além disso, o tempo de permanência no ar das partículas nessa faixa de tamanho é relativamente longo. De acordo com Liu et al. (2002), o tamanho das partículas que contêm bactérias numa sala cirúrgica normalmente está na faixa de 0,5 a $10 \mu \mathrm{m}$.

Dois dos casos estudados, referidos na Tabela 8.5 como B1 e B2, comprovam a importância do número de pessoas na geração de partículas. Trata-se, em ambos os casos, de partos cesáreos, um tipo de procedimento que gera essencialmente partículas muito pequenas, produzidas pelo uso do bisturi elétrico, que não são detectadas pelo sistema de aquisição de dados utilizado no presente estudo. Nesses dois casos, percebe-se que a sala apresenta baixas concentrações iniciais de partículas. Entretanto, durante o procedimento cirúrgico, ocorre um aumento significativo nas concentrações de partículas na faixa de $5 \mu \mathrm{m}$. Essas altas concentrações de partículas, que o sistema de condicionamento de ar não foi capaz de eliminar eficientemente, são explicáveis pelo grande número de pessoas na sala, especialmente estudantes de medicina. Em alguns momentos houve até 12 pessoas ao mesmo tempo na sala. 
Um exemplo do impacto do número de pessoas na geração de partículas no interior de uma sala cirúrgica é mostrado na Figura 10.1. Observa-se que a concentração de partículas no interior da sala praticamente obedece à mesma tendência do número de pessoas.

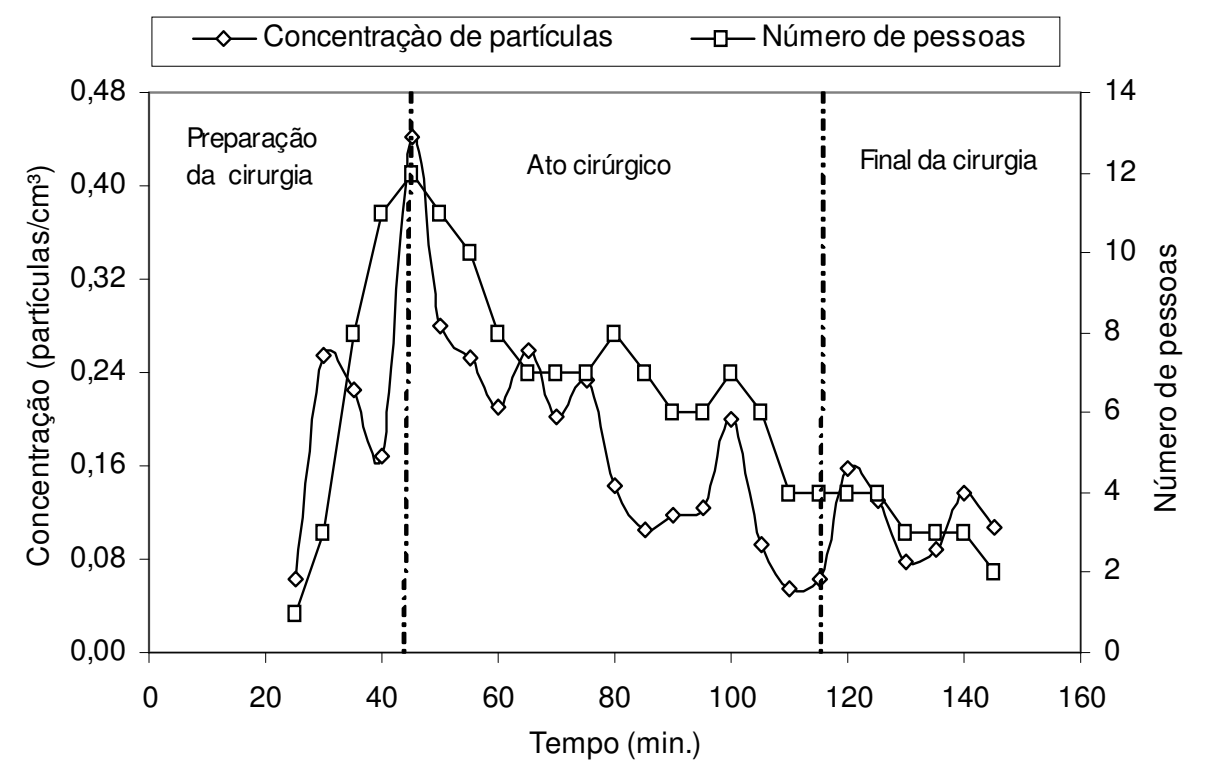

Figura 10.1 - Influência da atividade humana sobre a concentração de partículas no interior da sala cirúrgica, com sistema de condicionamento de ar ligado; Sistema B.

A fim de avaliar a correlação estatística entre o número de pessoas na sala e a geração de partículas, utilizaram-se os dados acima em uma análise com correlação de Pearson, representada graficamente na Figura 10.2. Nesta análise obteve-se um nível de correlação significante, $\mathrm{R}^{2}=0,7028$, o que indica que cerca de $70 \%$ das partículas em suspensão na sala cirúrgica são geradas pelas pessoas, especialmente partículas de pele. Os demais $30 \%$ são partículas geradas principalmente devido à colocação e à retirada dos campos cirúrgicos e das vestimentas da equipe cirúrgica. 


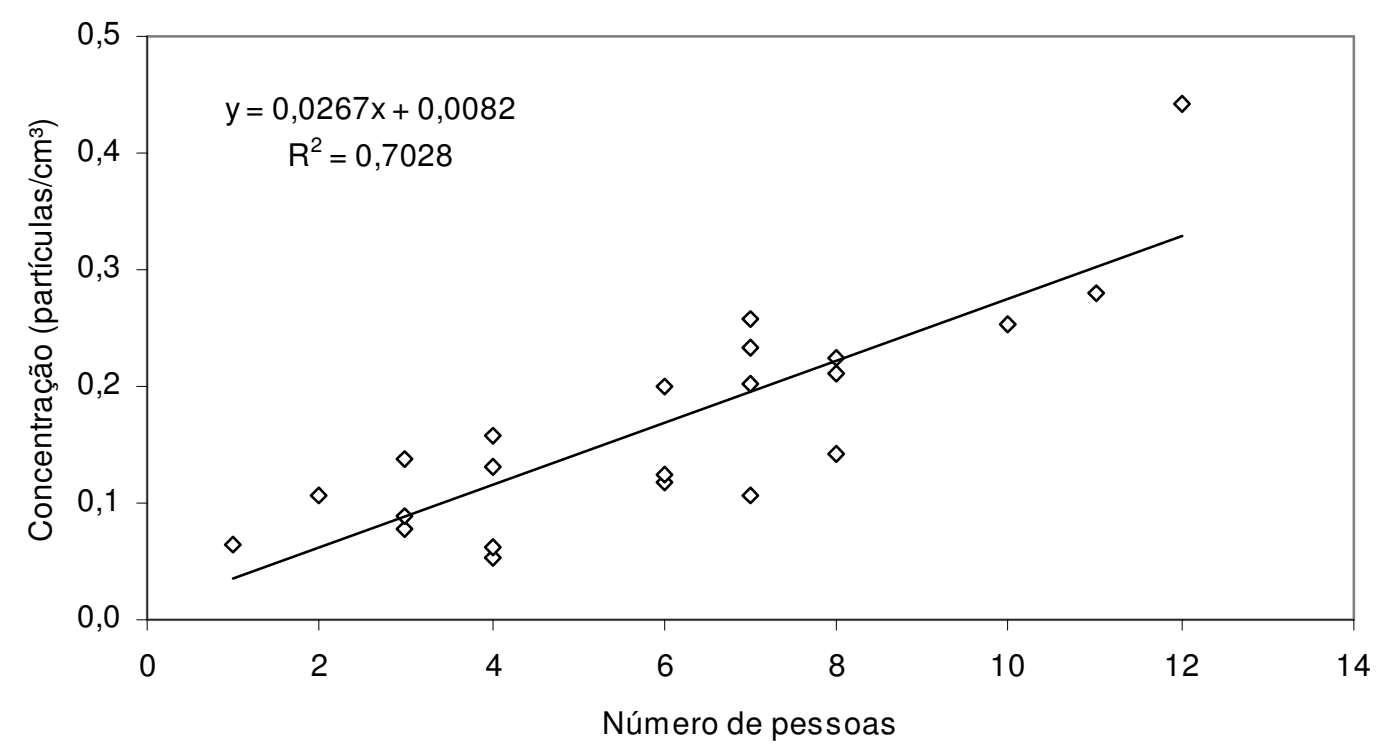

Figura 10.2 - Correlação entre o número de pessoas e a concentração de partículas na sala cirúrgica, com o sistema de condicionamento de ar ligado; Sistema B

\subsection{INFLUÊNCIAS DO DIÂMETRO DAS PARTÍCULAS SOBRE A CONCENTRAÇÃO}

Também foram desenvolvidas medições e análises da concentração das partículas no interior das salas cirúrgicas para diferentes diâmetros, conforme apresentado no item 8.6. Observou-se, de forma geral, comportamento já descrito na literatura (Morawska et al., 1998), que indica um decréscimo das concentrações de partículas com o aumento do tamanho destas. Pôde-se observar que, na maioria dos casos, as curvas de distribuição dos tamanhos das partículas em função da concentração assemelham-se bastante. As partículas de maior tamanho tendem a exibir uma maior flutuação que as partículas menores. Isso ocorre porque as atividades humanas no interior da sala cirúrgica geram um maior número de partículas nas maiores faixas de tamanho analisadas neste estudo, 5 a $10 \mu \mathrm{m}$, que são representadas especialmente por fibras de algodão, oriundas dos trajes e campos cirúrgicos, e por descamações de pele. Houve alguns resultados atípicos, que estão em desacordo com essa tendência geral, cuja explicação exigiria estudos específicos. Entretanto, isso fugiria ao escopo do presente trabalho. 


\subsection{INFLUÊNCIA DA ABERTURA DAS PORTAS NA CONCENTRAÇÃO DE PARTÍCULAS}

Outra análise importante diz respeito à influência da situação das portas da sala cirúrgica (abertas ou fechadas) sobre a concentração de partículas no interior da sala. Nesse estudo, foi analisada a influência da abertura das portas para as seguintes situações: sistema de condicionamento desligado e portas abertas ou fechadas; sistema ligado e portas abertas ou fechada. Entretanto, como já foi destacado anteriormente, só foi possível manter desligado o sistema de condicionamento de ar em um único centro cirúrgico.

Objetivando comparar as diferentes situações, analisou-se a concentração de partículas em cirurgias semelhantes, realizadas no mesmo centro cirúrgico e envolvendo o mesmo número de pessoas no interior da sala. Dada a natureza diversa dos procedimentos cirúrgicos, das salas cirúrgicas e dos sistemas de condicionamento de ar, optou-se por comparar o aumento relativo nas concentrações e não os valores absolutos. Ou seja, como apresentado na Tabela 8.5, para cada caso, obteve-se a diferença entre o valor da concentração média durante o ato cirúrgico e a concentração inicial. As considerações que seguem baseiam-se nessa diferença.

Quando se mantém o condicionamento de ar desligado, casos A1 e A2, a abertura das portas propicia uma redução na concentração, uma vez que a diferença aludida acima cai de 0,648 para 0,548 partícula/ $\mathrm{cm}^{3}$ (decréscimo de 15,4\%). Nessa situação, a abertura das portas favorece a eliminação das partículas produzidas próximas à área cirúrgica, pois, devido à diferença de temperatura entre o interior da sala e o corredor, ocorrem correntes de convecção que provocam uma maior movimentação do ar no interior da sala. Assim, as partículas produzidas próximo à área cirurgia podem ser mais rapidamente dissipadas. E também pode ocorrer sua diluição pelo ar que provém do corredor. Diferentemente, quando as portas são mantidas fechadas, a baixa movimentação do ar no interior da sala cria uma região de quase estagnação do ar próximo a área cirúrgica, o que pode dificultar a dissipação das partículas dessa região.

Nos dois casos com o sistema de insuflamento pela parede e retorno próximo ao piso, A3 e A4, também há redução na concentração, uma vez que a diferença nas concentrações cai de 0,067 para 0,029 partícula/ $\mathrm{cm}^{3}$ (decréscimo de 56,7\%). Novamente, com as portas abertas, as correntes de convecção podem ter contribuído para remoção de partículas da região próxima à área cirúrgica. Além disso, as vazões de insuflamento e de retorno desta sala são 
ajustadas de forma a que ela opere com pressão positiva. E isso também favorece a remoção de partículas do interior da sala quando as portas estão abertas.

Quando se realizaram medições com o sistema de insuflamento e retorno pelo teto, B1 e B2, também se constatou uma redução na concentração de partículas, ainda que mais discreta, quando as portas foram mantidas abertas. A diferença caiu de 0,182 para 0,163 partícula/ $\mathrm{cm}^{3}$ (decréscimo de 10,4\%). Aparentemente, o efeito combinado das correntes de convecção e da pressão positiva novamente provocou a remoção de partículas da sala.

Com o sistema de insuflamento pelo teto e retorno próximo ao piso, casos $\mathrm{C} 1$ e C2, ao contrário dos demais casos, a abertura das portas pareceu provocar um aumento na concentração interna de poluentes. A diferença entre as concentrações subiu de 0,013 para 0,016 partícula $/ \mathrm{cm}^{3}$ (acréscimo de 23\%). Curiosamente, apesar de a sala operar também com pressão positiva e ser a sala com a maior vazão de insuflamento, parece que a eficiência do retorno é prejudicada, havendo entrada de partículas do corredor quando as portas são mantidas abertas. Isso pode ser causado por algum tipo de turbulência gerada pela alta vazão de insuflamento, combinada às correntes de convecção geradas pela diferença de temperatura entre a sala e o corredor.

Por fim, com sistema de ar condicionado de janela, casos D1 e D2, a abertura das portas também propiciou uma redução na concentração interna de poluentes, com a diferença de concentrações caindo de 0,223 para 0,123 partícula/ $\mathrm{cm}^{3}$ (decréscimo de 44,8\%). Esse tipo de sistema, como já mencionado, não provê renovação nem filtragem eficiente do ar. Assim, tende a haver uma elevação na concentração de poluentes ao longo do procedimento cirúrgico. A abertura das portas permite que haja trocas de ar entre o ambiente da sala e o corredor, por meio de convecção e dispersão. Isso provoca remoção de partículas da região próxima à área cirúrgica.

\subsection{INFLUÊNCIA DO SISTEMA DE CONDICIONAMENTO DE AR SOBRE A CONCENTRAÇÃO DE PARTÍCULAS}

A Figura 10.3 mostra o impacto do sistema de condicionamento de ar sobre a concentração de partículas no interior da sala cirúrgica, com as portas fechadas. A cirurgia analisada foi uma herniorrafia inguinal, e o número médio de pessoas no interior da sala foi 4. Observa-se, na figura 10.3, que, durante o ato cirúrgico, quando o sistema de condicionamento de ar está ligado, a concentração de partículas diminui rapidamente. Situação oposta ocorre quando o sistema de condicionamento de ar é desligado, com 
concentração de partículas aumentando continuamente. Ao final da cirurgia, a queda acentuada na concentração de partículas não poderia ser atribuída meramente ao processo de deposição. Comprova-se, portanto, a importância do sistema de condicionamento de ar na eliminação das partículas do interior da sala.

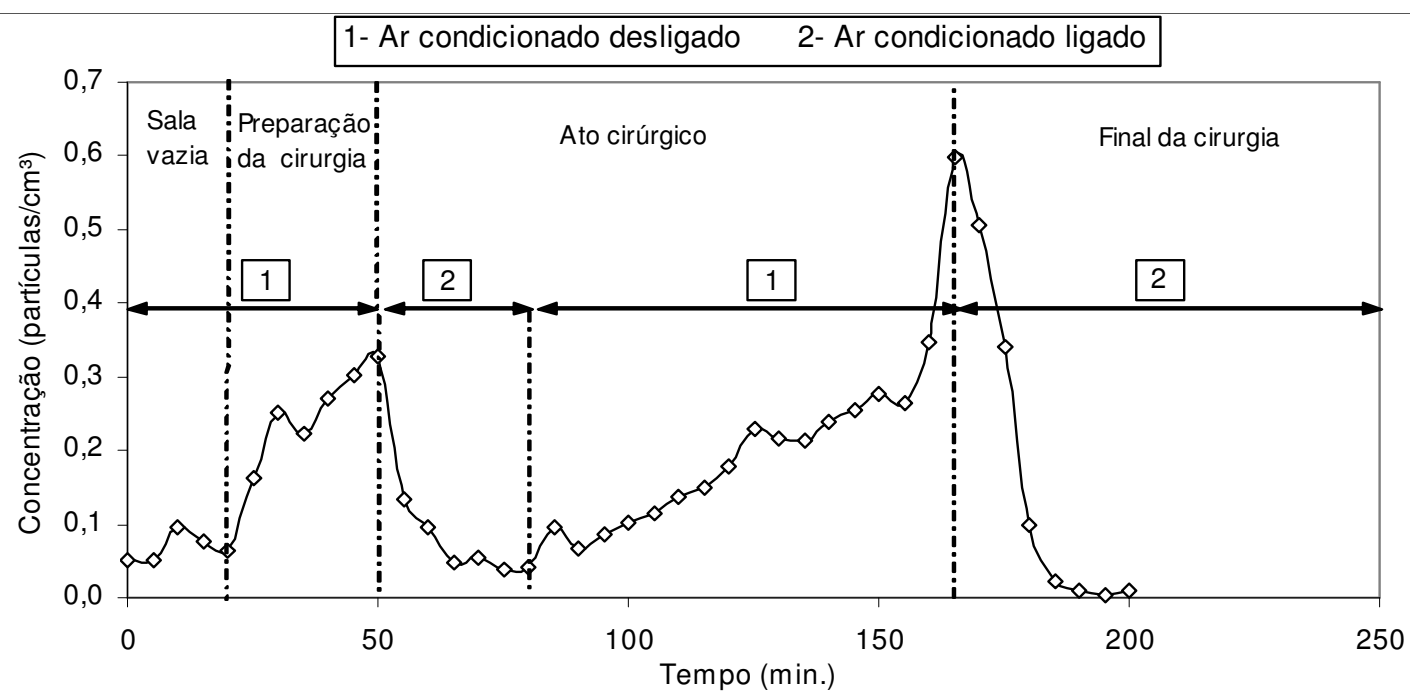

Figura 10.3 - Impacto do sistema de condicionamento de ar sobre a concentração de partículas; sistema com insuflamento pela parede e retorno próximo ao piso.

Ainda investigando a influência do sistema de condicionamento de ar sobre a concentração de partículas, compararam-se duas cirurgias semelhantes, realizadas com as portas fechadas, com concentrações iniciais semelhantes (Figura 10.4). Em uma delas, o sistema de condicionamento de ar estava desligado; na outra, ligado. Observa-se que na cirurgia realizada com o sistema de condicionamento desligado, a concentração de partículas eleva-se acentuadamente e mantém-se elevada ao longo do procedimento cirúrgico. Por outro lado, na cirurgia realizada com o condicionamento de ar ligado, a concentração de partículas reduz-se rapidamente e mantém-se baixa. 


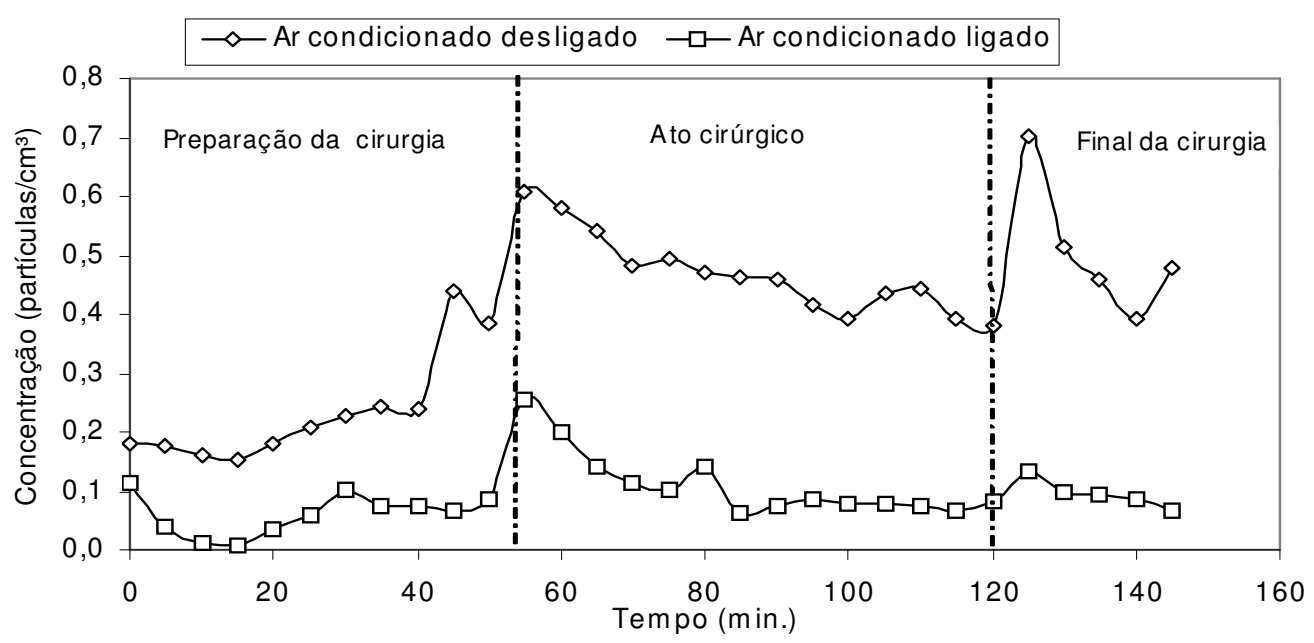

Figura 10.4 - Impacto do sistema de condicionamento de ar sobre a concentração de partículas no interior da sala cirúrgica, com as portas fechadas; sistema A

Na Figura 10.5 são comparadas duas cirurgias semelhantes, realizadas com as portas abertas. Como anteriormente, em uma das cirurgias, o sistema de condicionamento de ar estava desligado; na outra, ligado. Novamente, observa-se que, ao longo de todo o procedimento cirúrgico, a concentração de partículas é maior quando o sistema de condicionamento de ar está desligado.

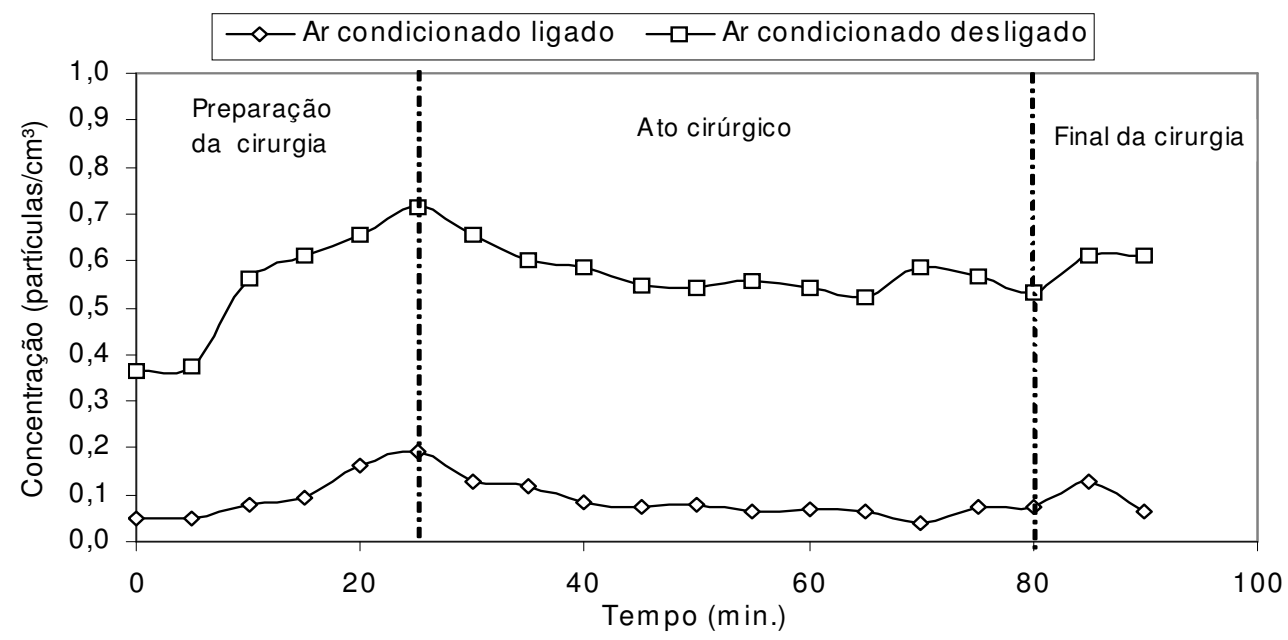

Figura 10.5 - Impacto do sistema de condicionamento de ar sobre a concentração de partículas no interior da sala cirúrgica, com as portas abertas; sistema A.

Os resultados obtidos nessas duas comparações, apresentadas nas Figuras 10.7 e 10.8, reforçam a conclusão inicial (Figura 10.6) de que o sistema de condicionamento de ar é de fundamental importância para a remoção das partículas geradas no interior da sala ao longo de um procedimento cirúrgico. 


\subsection{INFLUÊNCIA DAS VAZÕES DE INSUFLAMENTO E RETORNO NA CONCENTRAÇÃO DE PARTÍCULAS}

As Figuras 10.6 e 10.7 mostram a variação da concentração de partículas no interior de uma sala cirúrgica em função das vazões de insuflamento e retorno, respectivamente. Ajustou-se a vazão de insuflamento para os valores 446, 970, 1342, 1580, 1675 e 1760 m³/h, enquanto a vazão de retorno permaneceu constante $\left(995 \mathrm{~m}^{3} / \mathrm{h}\right)$. Observa-se na Figura 10.6 que, para as partículas com diâmetros de 0,3 e 0,5 $\mu \mathrm{m}$, a concentração aumenta com o aumento da vazão de insuflamento. Provavelmente, isso ocorre porque, com o aumento dessa vazão, o sistema de condicionamento de ar insufla na sala uma maior quantidade de partículas nessas faixas de tamanho, pois a filtragem não se mostra eficiente para partículas dessas dimensões, e o retorno não consegue eliminá-las na mesma taxa em que são insufladas no ambiente.

Observa-se ainda que, o maior impacto do sistema de condicionamento de ar ocorreu para partículas com diâmetro de $3 \mu \mathrm{m}$. Ou seja, para esse tamanho, a concentração de partículas reduziu 58 vezes quando se variou a vazão de insuflamento de 446 até $1760 \mathrm{~m} 3 / \mathrm{h}$. Para os diâmetros de $1 \mu \mathrm{m}, 5 \mu \mathrm{m}$ e $10 \mu \mathrm{m}$, a concentração de partículas reduziu aproximadamente 8 vezes, 42 vezes e 26 vezes, respectivamente. Isso ocorre porque, para as partículas com diâmetro igual ou superior a $1 \mu \mathrm{m}$, o sistema de filtragem atua de forma mais eficiente.

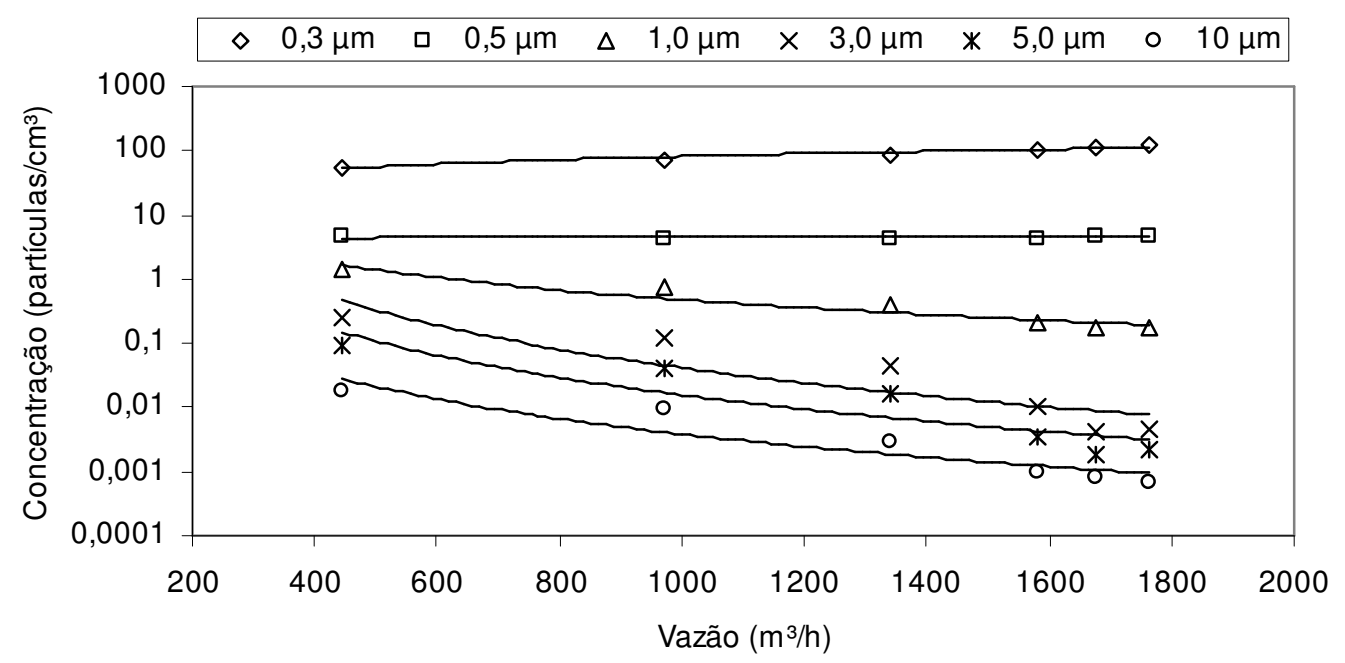

Figura 10.6 -Variação da concentração de partículas em função da vazão de insuflamento; Sistema A. 
A vazão de retorno (Figura 10.7) foi ajustada para os valores 260, 400, 650, 880, 970 e $1007 \mathrm{~m} / \mathrm{h}$, e a vazão de insuflamento permaneceu constante $(1760 \mathrm{~m} / \mathrm{h})$. Para esse caso, observa-se que a variação da concentração de partículas com diâmetros de 0,3 e $0,5 \mu \mathrm{m}$ foi praticamente a mesma, ou seja, com o aumento da vazão de retorno ocorreu uma redução de 1,8 vezes. Da mesma forma que ocorreu no caso anterior, o maior impacto do sistema de condicionamento de ar foi para partículas com diâmetro de $3 \mu \mathrm{m}$. Para esse tamanho, a concentração de partículas reduziu 63 vezes enquanto se aumentou a vazão de retorno de 260 até $1007 \mathrm{~m} / \mathrm{h}$. Para os diâmetros de $1 \mu \mathrm{m}, 8 . \mu \mathrm{m}$ e $10 \mu \mathrm{m}$, a concentração de partículas reduziu aproximadamente 5 vezes, 58 vezes e 36 vezes, respectivamente.

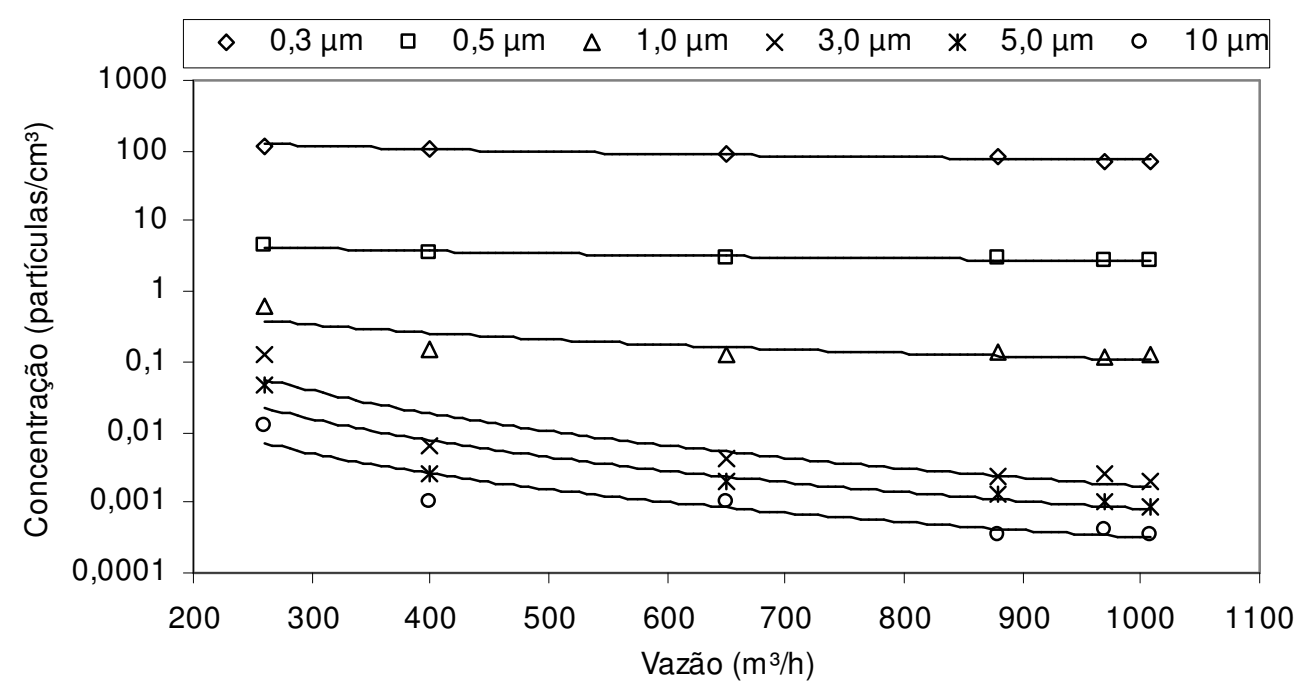

Figura 10.7 - Variação da concentração de partículas com a vazão de retorno; sistema A.

Assim, com esses resultados conclui-se que, para a eliminação do interior da sala de partículas menores - no caso do presente estudo, com diâmetros de 0,3 e 0,5 $\mu \mathrm{m}$-, o aumento da vazão da insuflamento não parece ser o meio mais adequado. Também, de forma geral, conclui-se que a vazão de retorno tem um forte efeito na redução das partículas no interior de uma sala cirúrgica, principalmente na faixa de tamanho onde ocorre a maior geração de partículas no interior da sala, ou seja, nos diâmetros da faixa de 3 a $10 \mu \mathrm{m}$.

Nos procedimentos cirúrgicos acompanhados no presente trabalho, percebe-se também a relevância da renovação de ar, através da vazão de insuflamento, para eliminação de poluentes aéreos. Na Tabela 8.5 (casos A1 e A2) e nas Figuras 8.7 e 8.8, pode-se observar como, com o sistema de condicionamento de ar desligado, a concentração de partículas aumenta rapidamente e praticamente não diminui ao longo de todo o procedimento cirúrgico. 
Da mesma forma, o sistema de ar condicionado de janela, que não promove uma adequada renovação do ar, também não se mostrou capaz de reduzir a concentração de partículas geradas durante o procedimento cirúrgico (v. Tabela 8.5, casos D1 e D2, e Figuras 8.12 e 8.16), especialmente quando as portas da sala cirúrgica estão fechadas.

Por outro lado, os casos C1 e C2 (v. Tabela 8.5 e Figuras 8.11 e 8.15), nos quais se utilizou um sistema com alta taxa de renovação de ar, observa-se que a concentração de partículas permanece baixa, especialmente durante o ato cirúrgico, mesmo se tratando de cirurgias ortopédicas, que geram grande quantidade de partículas na faixa de tamanhos de partículas analisada.

\subsection{INFLUÊNCIA DO TIPO DE SISTEMA DE CONDICIONAMENTO DE AR NA CONCENTRAÇÃO DE PARTÍCULAS}

As Figuras 10.8 e 10.9 mostram uma comparação da variação da concentração de partículas no interior da sala cirúrgica ao longo do tempo para dois tipos de sistemas de condicionamento de ar, sistema convencional e de janela, em duas condições diferentes: portas fechadas e portas abertas. Lembre-se que o sistema convencional é aquele em que ar insuflado no interior da sala retorna para o equipamento de condicionamento de ar que esta fora da sala cirúrgica para remoção das partículas, por meio do sistema de filtragem, enquanto que o sistema de janela esta localizado na própria sala e não possui filtros adequados para remoção das partículas.

Observa-se que, para ambos os casos, as salas que operam com ar condicionado de janela possuem as maiores concentrações de partículas. Isso ocorre pelo fato de o ar condicionado de janela não realizar renovação e filtragem do ar do interior da sala, por não possuir retorno de ar.

Para as salas que utilizam esse tipo de equipamento, poder-se-ia esperar concentrações cada vez maiores ao longo do procedimento cirúrgico. Entretanto, a turbulência provocada pelo ar condicionado de janela também causa elevada deposição sobre as superfícies da sala, percebida principalmente durante o ato cirúrgico, mantendo a concentração em níveis mais baixos do que seria esperado se não houvesse essa deposição. Essa é uma observação importante, porque comprova a maior possibilidade de contaminação das superfícies, inclusive dos instrumentos e da ferida cirúrgica, por partículas, no caso de adoção desse sistema de condicionamento de ar. 


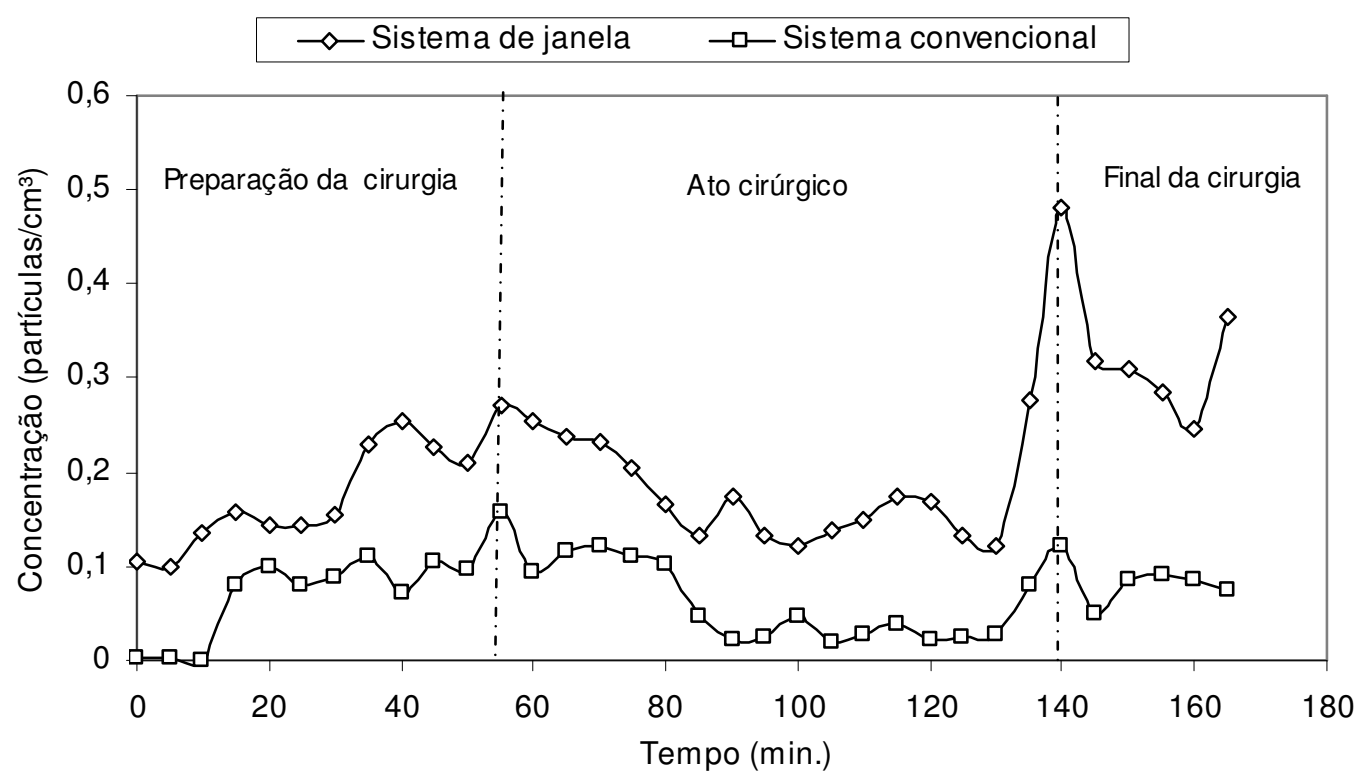

Figura 10.8 - Comparação entre as concentrações de partículas para um sistema convencional (Sistema A) e sistema de ar condicionado de janela (Sistema D); portas fechadas.

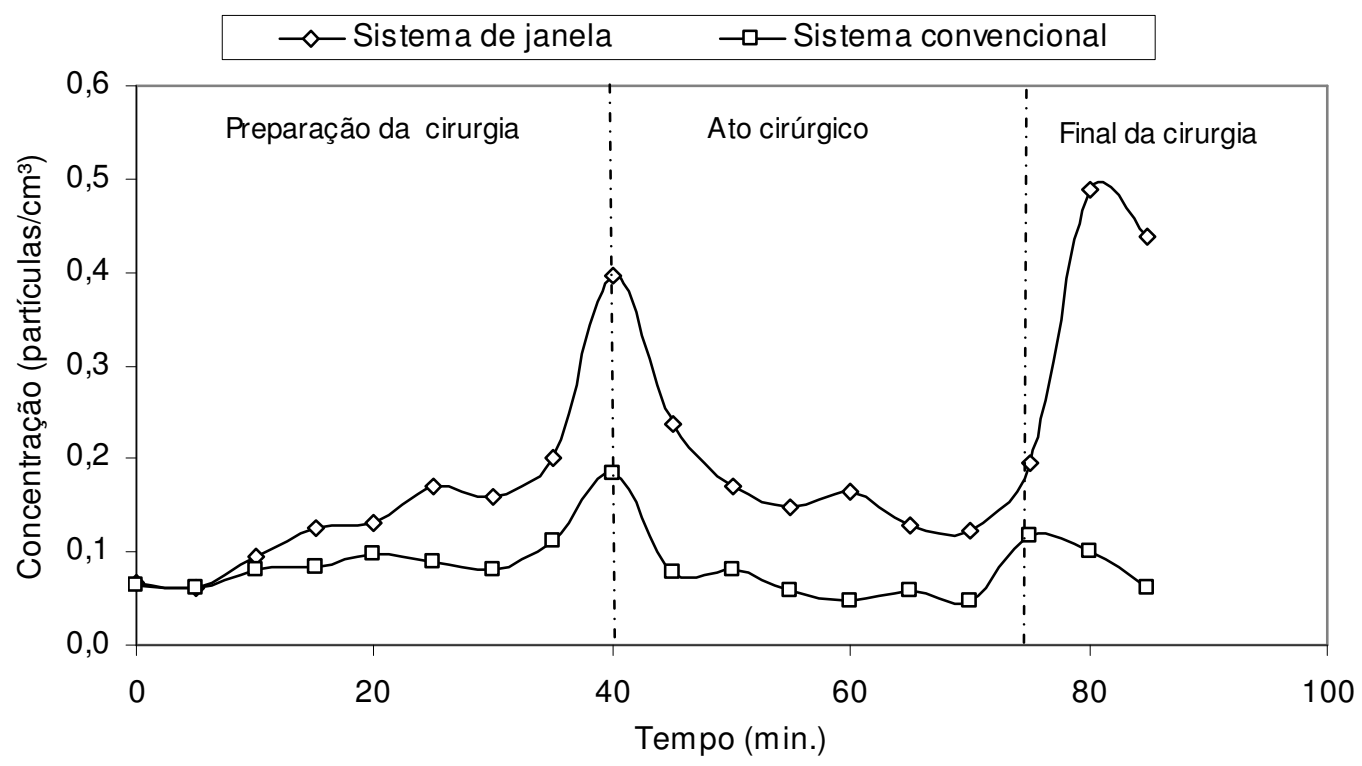

Figura 10.9 - Comparação entre as concentrações de partículas para um sistema convencional (Sistema A) e sistema de ar condicionado de janela (Sistema D); portas abertas. 


\section{CAPÍTULO 11}

\section{ANÁLISE DOS RESULTADOS DE PREDIÇÃO DE PARTÍCULAS}

Este capítulo visa analisar os resultados de predição de partículas para os diferentes sistemas e casos estudados. As análises são feitas comparando os dados de campo com os valores preditos pelo modelo proposto neste estudo. Essas comparações já foram apresentadas graficamente no Capítulo 7. Além disso, no presente capítulo, para se avaliar a precisão do modelo, realizam-se análises estatísticas conforme dois procedimentos sugeridos pela norma ASTM D5157-97 (ASTM, 1997): coeficiente de correlação (r) e erro quadrado médio normalizado (NMSE).

As três formas de comparação são realizadas (normal, com expurgo de dados e com fator de correção) são analisadas no item 11.2.

Também foi analisada, para os diferentes sistemas e casos estudados, a contribuição de cada fator no processo de geração e remoção das partículas no interior da sala cirúrgica. Para isso, nos diferentes casos estudados, retiraram-se das equações de regime permanente os valores totais das concentrações geradas e removidas por cada um dos parâmetros utilizados nas mesmas, relativos aos diversos fatores considerados. Os resultados desse procedimento são analisados no item 11.3.

O modelo foi desenvolvido tomando por base as partículas de 5 a $10 \mu \mathrm{m}$. Desejando observar sua precisão para todas as faixas de tamanhos consideradas neste estudo, realizaram-se comparações entre os dados de campo e os valores preditos pelo modelo, para partículas de $0,3 \mu \mathrm{m}, 0,5 \mu \mathrm{m}, 1 \mu \mathrm{m}, 3 \mu \mathrm{m}, 5 \mu \mathrm{m}$ e $10 \mu \mathrm{m}$. Para isso, foi utilizada a média das concentrações. No item 11.4, analisam-se os resultados dessas comparações. 


\subsection{ANÁLISES ESTATÍSTICAS}

A Tabela 11.1 mostra os resultados dos cálculos do coeficiente de correlação (r) e do erro médio quadrado normalizado (NMSE), para avaliar o desempenho dos modelos, conforme sugerido pela norma ASTM D5157-97 (ASTM, 1997).

Tabela 11.1 - Comparações estatísticas entre os valores preditos pelo modelo e os valores obtidos em campo, para os diferentes procedimentos de análise adotados.

\begin{tabular}{|c|c|c|c|c|c|c|c|}
\hline \multirow{2}{*}{ Sistema } & \multirow{2}{*}{ Caso } & \multicolumn{2}{|c|}{ Normal } & \multicolumn{2}{|c|}{$\begin{array}{c}\text { Com expurgo de } \\
\text { dados }\end{array}$} & \multicolumn{2}{|c|}{$\begin{array}{l}\text { Com fator de } \\
\text { correção }\end{array}$} \\
\hline & & $\mathbf{r}$ & NMSE & $\mathbf{r}$ & NMSE & $r$ & NMSE \\
\hline \multirow{4}{*}{ A } & A1 & 0,96 & 0,01 & 0,97 & 0,01 & 0,97 & 0,01 \\
\hline & A2 & 0,84 & 0,02 & 0,86 & 0,02 & 0,90 & 0,02 \\
\hline & A3 & 0,46 & 0,13 & 0,89 & 0,02 & 0,91 & 0,11 \\
\hline & A4 & 0,71 & 0,09 & 0,71 & 0,011 & 0,90 & 0,07 \\
\hline \multirow{2}{*}{ B } & B1 & 0,09 & 0,35 & 0,25 & 0,19 & 0,32 & 0,18 \\
\hline & B2 & 0,84 & 0,04 & 0,90 & 0,037 & 0,91 & 0,03 \\
\hline \multirow{2}{*}{ C } & C1 & 0,21 & 1,27 & 0,36 & 0,26 & 0,90 & 0,18 \\
\hline & C2 & 0,87 & 1,77 & 0,87 & 0,05 & 0,95 & 0,22 \\
\hline \multirow{2}{*}{ D } & D1 & 0,74 & 0,69 & 0,77 & 0,10 & 0,83 & 0,06 \\
\hline & D2 & 0,39 & 0,13 & 0,42 & 0,12 & 0,91 & 0,13 \\
\hline
\end{tabular}

A - Insuflamento pela parede e retorno próximo ao piso;

B - Insuflamento e retorno pelo teto;

C - Insuflamento pelo teto e retorno próximo ao piso;

D - Ar condicionado de janela.

A1 - Sistema de condicionamento de ar desligado e as portas da sala cirúrgica fechadas;

A2 - Sistema de condicionamento de ar desligado e as portas da sala cirúrgica abertas;

A3, B1, C1, D1 - Sistema de condicionamento de ar ligado e as portas da sala cirúrgica fechadas;

A4, B2, C2, D2 - Sistema de condicionamento de ar ligado e as portas da sala cirúrgica abertas.

Observa-se que, ao se adotar o procedimento de comparação normal, obtém-se apenas quatro valores de $\mathrm{r}$ superiores a 0,75 e apenas um valor superior a 0,9 . Além disso, em quatro dos dez casos, o valor de NMSE é superior a 0,25. Portanto, comparando os dados brutos com os resultados de predição, sem o expurgo de dados e sem o fator de correção, observa-se que o modelo não apresenta uma boa precisão.

Quando se expurgam os dados relativos às partículas geradas na colocação de campos e trajes cirúrgicos e, no caso das cirurgias ortopédicas, pela remoção da tala, observa-se que o modelo proposto ajusta-se bem melhor aos dados de campo. Agora, são seis os casos em que 
r é superior a 0,75 e dois os casos em que $\mathrm{r}$ é maior que 0,9. E apenas em um dos casos NMSE é superior a 0,25 .

Quando se utiliza o fator de correção, o modelo fica ainda mais preciso. Em apenas dois casos $\mathrm{r}$ é inferior a 0,9 e em apenas um único caso $r$ é inferior a 0,75. E em nenhum dos casos NMSE ficou acima do valor 0,25 , sugerido pela norma.

Situações nas quais ocorrem oscilações intensas e bruscas nas concentrações reduzem a precisão do modelo. Isso pode ser observado no caso B1. A saída e entrada de pessoas (alunos) da sala cirúrgica durante as diferentes etapas do procedimento cirúrgico fizeram com que as concentrações de partículas tivessem grandes variações, que não poderiam ser previstas no modelo. Da mesma forma, no caso $\mathrm{C} 1$, houve grande geração de partículas, produzidas durante a retirada da tala, seguida de uma brusca redução, devido ao ato cirúrgico (uma cirurgia ortopédica) implicar em um nível de atividade bastante baixo.

\subsection{ANÁLISES GRÁFICAS}

Os gráficos construídos segundo as três formas de comparação propostas ilustram os mesmos fatos evidenciados pela análise estatística. Primeiro, percebe-se que a maioria das curvas construídas com os dados brutos, sem expurgo, não se ajustam com os resultados preditos pelo modelo, sem o fator de correção, como se pode verificar nas Figuras 9.13, 9.19, 9.25, 9.37, 9.49, 9.54. É interessante observar que, embora as curvas relativas ao caso C2 (Figura 9.43) tenham um bom ajuste para quase todos os pontos, há dois momentos de notável discrepância quando são colocados os campos e trajes cirúrgicos e é retirada a tala de gesso. $\mathrm{O}$ coeficiente de correlação dessas curvas é elevado $(\mathrm{r}=0,86)$, porém o erro médio quadrado normalizado é também bastante alto (NMSE $=1,77)$. Isso ressalta a necessidade de que a análise de correlação seja associada a uma verificação do erro médio quadrado normalizado, para evidenciar os casos em que curvas com bom ajuste apresentam grandes discrepâncias em poucos pontos.

Em segundo lugar, quando se constroem as curvas expurgando dos dados de campo as concentrações registradas na colocação dos trajes e campos e na remoção das talas de gesso, obtém-se um melhor ajuste entre essas curvas e aquelas construídas pela aplicação do modelo teórico. Houve somente três casos nos quais as curvas prática e teórica mostraram-se bastante discrepantes (Figuras 9.26, 9.38, 9.55).

Em terceiro lugar, quando se utiliza o fator de correção, as curvas teóricas obtidas apresentam grande ajuste com as curvas oriundas dos dados de campo. Em somente um caso, 
B1, isso não ocorre (Figura 9.27). Porém, como já discutido anteriormente, trata-se de um caso atípico em que houve saída e entrada de grande número de pessoas da sala durante o procedimento cirúrgico.

\subsection{ANÁLISE DA CONTRIBUIÇÃO DOS FATORES NA GERAÇÃO E REMOÇÃO DE PARTÍCULAS}

\begin{tabular}{|c|c|c|c|c|c|c|c|c|c|c|}
\hline \multirow{2}{*}{ Sistema } & \multirow{2}{*}{ Caso } & \multicolumn{5}{|c|}{ Geração (\%) } & \multicolumn{4}{|c|}{ Remoção (\%) } \\
\hline & & Pessoas & $\begin{array}{c}\text { Campos e } \\
\text { Trajes }\end{array}$ & $\begin{array}{l}\text { Insufla- } \\
\text { mento }\end{array}$ & Portas & Gesso & Deposição & Portas & Retorno & Outros \\
\hline \multirow{4}{*}{ A } & A1 & 99,10 & 0,89 & - & - & - & 84,68 & - & - & 15,31 \\
\hline & $\mathrm{A} 2$ & 62,76 & 0,48 & - & 36,75 & - & 4,96 & 95,04 & - & - \\
\hline & A3 & 95,55 & 3,27 & 1,16 & - & - & 11,37 & - & 88,62 & - \\
\hline & A4 & 75,91 & 1,25 & 1,02 & 21,80 & - & 10,90 & 16,35 & 72,73 & - \\
\hline \multirow{2}{*}{ B } & B1 & 89,06 & 3,05 & 8,87 & - & - & 37,12 & - & 62,88 & - \\
\hline & B2 & 69,21 & 3,20 & 9,91 & 17,66 & - & 22,60 & 33,90 & 43,49 & - \\
\hline \multirow{2}{*}{ C } & C1 & 91,11 & 1,96 & 4,57 & - & 2,36 & 7,75 & - & 92,24 & - \\
\hline & $\mathrm{C} 2$ & 92,89 & 0,43 & 0,11 & 4,65 & 2,13 & 7,88 & 11,82 & 80,28 & - \\
\hline \multirow{2}{*}{ D } & D1 & 99,22 & 0,77 & - & - & - & 100,00 & - & - & - \\
\hline & D2 & 80,11 & 1,89 & - & 17,98 & - & 51,64 & 48,35 & - & - \\
\hline
\end{tabular}

A - Insuflamento pela parede e retorno próximo ao piso;

B - Insuflamento e retorno pelo teto;

C - Insuflamento pelo teto e retorno próximo ao piso;

D - Ar condicionado de janela.

A1 - Sistema de condicionamento de ar desligado e as portas da sala cirúrgica fechadas;

A2 - Sistema de condicionamento de ar desligado e as portas da sala cirúrgica abertas;

A3, B1, C1, D1 - Sistema de condicionamento de ar ligado e as portas da sala cirúrgica fechadas;

A4, B2, C2, D2 - Sistema de condicionamento de ar ligado e as portas da sala cirúrgica abertas.

As pessoas tendem a ter uma participação proporcional bastante elevada no processo de geração de partículas (Fitzgerald,1979; Roy, 1997; Blakemore et al., 1979; Ritter, 1999). No presente estudo, essa contribuição foi sempre maior que as contribuições somadas de todos os demais fatores. Quando as portas são abertas, a contribuição proporcional das pessoas diminui, em função das partículas provenientes do corredor.

A participação proporcional das partículas geradas na colocação dos campos e trajes cirúrgicos é discreta, quando considerado o total de partículas geradas durante todo o procedimento cirúrgico. Entretanto, é preciso lembrar que as partículas oriundas desse 
processo são produzidas em um curto intervalo de tempo e pode ser muito intensa. Portanto, a contribuição da colocação de campos e trajes não pode ser menosprezada.

A parcela de partículas insufladas pelo sistema de condicionamento de ar, de forma geral, não é elevada. As contribuições mais altas ocorrem nos casos B1 e B2, provavelmente devido a problemas de filtragem de ar, uma vez que esse sistema (insuflamento e retorno pelo teto) tem uma vazão baixa, comparativamente aos dois outros sistemas convencionais. Também chama a atenção a contribuição do sistema de condicionamento de ar no caso $\mathrm{C} 1$, a qual, ainda que não seja muito elevada, é muitas vezes superior ao do caso $\mathrm{C} 2$, com dados obtidos na mesma sala. Essa diferença significativa deve-se, muito provavelmente, às condições do ar exterior, que têm grande impacto sobre a qualidade do ar interior (Morawska et al., 1998).

A infiltração pelas portas representa, no presente estudo, a segunda maior fonte de geração de partículas. Quando as portas estiveram abertas, sua contribuição foi bastante significativa (casos A2, A4, B2, D2), exceto pelo caso C2. Nesse caso, tinha-se um corredor climatizado, com baixa concentração de partículas, e uma vazão de insuflamento elevada. Combinados, esses fatores parecem ter contribuído decisivamente para minimizar a infiltração de partículas pelas portas.

Estes resultados, à primeira vista, parecem conflitar com os dados medidos em campo, porque, justamente no caso $\mathrm{C} 2$, a abertura das portas produziu um aumento na concentração de partículas, comparativamente ao caso $\mathrm{C} 1$, quando as portas foram mantidas fechadas. Porém, como já discutido no item 6.6, os resultados mostram que a eficiência do retorno é afetada pela abertura das portas. Assim, apesar de a contribuição proporcional da infiltração pelas portas ser menor que nos casos outros casos de portas abertas, as portas aqui efetivamente proporcionam aumento na concentração interna de partículas, porque comprometem a remoção pelo sistema de condicionamento de ar das partículas geradas no interior da sala cirúrgica.

A participação proporcional das partículas geradas pela remoção da tala de gesso (casos $\mathrm{C} 1$ e C2) também é discreta, quando considerado o processo cirúrgico como um todo. Entretanto, da mesma forma que ocorre na colocação de campos e trajes cirúrgicos, tem-se um processo intenso, com muitas partículas geradas em um curto espaço de tempo. Portanto, novamente, ainda que, proporcionalmente as partículas geradas pela remoção da tala não sejam muitas, elas podem ter muita importância no transporte de patógenos para a ferida cirúrgica. Na verdade, as partículas resultantes da remoção da tala podem ter importância muito maior que aquelas geradas pelos campos e trajes, uma vez que os mesmos são 
submetidos previamente a processo de esterilização, diferentemente da tala de gesso, que é um material cujas superfícies interna e externa são altamente contaminadas.

Quando o sistema de condicionamento de ar está desligado e as portas estão fechadas (caso A1), é intensa a perda por deposição. Porém, por meio do balanço de massa, percebe-se que nem todas as partículas são removidas por deposição, pois intervêm fatores que não são apreendidos pelo modelo (genericamente denominados "outros"). Já quando o sistema de condicionamento de ar permanece desligado, mas as portas estão abertas (caso A2), percebese que a perda por deposição cai acentuadamente, uma vez que a remoção pelas portas tornase agora o principal fator de eliminação de partículas.

Quando o sistema de condicionamento de ar está ligado, o retorno de ar passa a ser o principal fator de remoção de partículas, exceto para o sistema de janela. Entretanto, observase que a abertura das portas interfere sobre a eficiência do retorno. Sempre que as portas são abertas (casos A4, B2 e C2), diminui a remoção de partículas pelo retorno. E essa redução na eficiência do retorno, quando as portas são abertas, é tanto mais acentuada quanto menor a vazão de insuflamento e de retorno. Da mesma forma, quando se abrem as portas, também cai a perda por deposição.

Com o sistema de ar condicionado de janela, quando as portas estão fechadas (caso D1), a perda de partículas dá-se exclusivamente por deposição. Quando as portas são mantidas abertas, as perdas dividem-se, quase que igualmente, entre deposição e eliminação pelas portas (caso D2).

\subsection{ANÁLISE DAS CONCENTRAÇÕES EM FUNÇÃO DO DIÂMETRO}

Também foram desenvolvidas predições da concentração das partículas para diferentes diâmetros. Observou-se o mesmo comportamento relatado na literatura, que indica um decréscimo das concentrações de partículas com o aumento do seu tamanho (Morawska et al., 1998). Pôde-se observar que, na maioria dos casos, as curvas de distribuição dos tamanhos das partículas em função da concentração são muito semelhantes. Entretanto, os valores absolutos diferenciam-se bastante.

O principal motivo para isso é que, apesar de as taxas de geração de partículas pelas pessoas variarem com o diâmetro, foi utilizado no modelo, para todas as faixas de diâmetro, o valor da taxa de geração de partículas de $5 \mu \mathrm{m}$, obtido na literatura (Woods, 1986). Outro fator que pode ter causado as diferenças entre as curvas teóricas e as curvas dos dados de 
campo é a imprecisão na medição e cálculo das taxas de deposição e de infiltração, para as faixas de diâmetro diferentes de $5 \mu \mathrm{m}$.

Portanto, a partir das semelhanças e diferenças entre as curvas teóricas e práticas, evidencia-se que a predição pode ser feita para qualquer faixa de tamanho. Mas é necessário ajustar os parâmetros de entrada no modelo para a faixa de tamanho cuja concentração se deseja predizer. 


\section{CAPÍTULO 12}

\section{CONCLUSÕES}

Neste capítulo, apresentam-se as principais conclusões a que se chegou com o desenvolvimento deste trabalho de pesquisa. Discute-se a precisão e aplicabilidade do modelo matemático proposto, apresentam-se algumas constatações baseadas nos resultados experimentais, destaca-se a relevância do estudo bem como as suas limitações e, finalmente, apresentam-se sugestões para outros estudos.

\subsection{O MODELO MATEMÁTICO PROPOSTO}

O objetivo principal do presente trabalho foi o estabelecimento de uma modelagem matemática para previsão da concentração de partículas em suspensão em salas cirúrgicas. Inicialmente, buscou-se compreender quais os fatores que afetam a concentração das partículas no interior de uma sala cirúrgica. Foram realizadas observações e medições no interior de salas cirúrgicas e nos corredores adjacentes. Buscou-se, no Centro Cirúrgico do Hospital Universitário da USP, analisar diferentes tipos de salas cirúrgicas quanto ao tamanho, número de portas e sistema de tratamento de ar. Isso permitiu a realização de ensaios e simulações em um número significativo de combinações e com o levantamento de um número ainda mais significativo de dados. Determinaram-se, assim, quais fatores são potencialmente importantes no problema. Posteriormente, com a compreensão dos fatores que afetam a variação das partículas no interior de uma sala cirúrgica, foi possível definir as variáveis utilizadas no modelo e a metodologia de coleta de dados. Após essa etapa, iniciou-se o processo de medição em diferentes centros cirúrgicos. Em seguida efetuou-se a predição e análise das concentrações de partículas no interior das salas, por meio de modelos obtidos por balanço de massa.

Destaca-se de forma geral, que em todos os casos analisados, as condições de distribuição de temperatura e velocidade do ar indicaram um estado estável no interior da sala 
cirúrgica, o que sugeria uma distribuição homogênea das partículas. Isso garantiu, para todos os casos analisados, a utilização do modelo proposto para a predição da concentração de partículas nas salas cirúrgicas.

Com base nos resultados coletados em campo e nas análises estatísticas, verificou-se que, na maioria dos casos considerados, o modelo proposto consegue predizer com boa precisão a concentração de partículas no interior das salas cirúrgicas ao longo tempo, nas diferentes situações estudadas. Da mesma forma, foi possível prever com suficiente precisão a contribuição de todos os fatores no processo de geração e remoção das partículas no interior da sala, utilizando as equações de regime transiente e regime permanente.

As discrepâncias obtidas podem ser facilmente justificadas. Inicialmente pode-se dizer que um dos fatores que podem estar produzindo essas diferenças advém do fato de que o modelo foi alimentado de forma a considerar que a geração de partículas no ambiente é contínua, com a mesma quantidade de pessoas no interior da sala cirúrgica. Contudo, observou-se, durante a análise da concentração das partículas no interior das salas cirúrgicas, que isso não ocorre na prática. A concentração varia com o tempo em função das diferentes atividades que ocorrem na sala e também em função do número de pessoas, ocorrendo picos de geração de partículas em momentos característicos.

Outro fato que também pode ter provocado discrepância entre os resultados numéricos e os resultados experimentais é a estimativa da quantidade de partículas dispersas por uma pessoa no interior da sala. O modelo utiliza o valor sugerido na literatura, que é de 14.000 .000 partículas/hora. Em uma sala cirúrgica, o tipo de vestimenta utilizada e o nível de atividade influenciam na quantidade de partículas dispersadas por uma pessoa. Assim, a quantidade sugerida na literatura pode ser bastante diferente da quantidade real gerada no interior da sala.

Devido a essas questões práticas, quando o modelo foi aplicado, inicialmente, percebeu-se que os valores de concentração preditos pelo modelo, em muitos casos, não se ajustaram adequadamente aos dados coletados em campo, mesmo quando expurgados os valores de concentração relativos aos momentos em que havia intensa geração de partículas. Daí a adoção de um fator de correção para melhor considerar as grandes variações de concentração produzidas por atividades que geram grandes quantidades de partículas, especialmente na etapa de preparação do ato cirúrgico. Esse fator de correção foi um importante procedimento para que o modelo proposto melhor se ajustasse à situação real. Sua adoção, conforme as análises gráficas e estatísticas, conferiu ao modelo grande robustez, permitindo sua aplicação, com boa precisão, para as diferentes situações na rotina de salas cirúrgicas. 
O modelo também se mostrou uma importante ferramenta para auxiliar na análise dos fatores que afetam tanto a geração como a remoção de partículas. Quando o modelo foi utilizado para esse tipo de estudo, evidenciou-se que o principal fator de geração de partículas no interior de uma sala cirúrgica são as pessoas e que o principal fator de remoção, quando o sistema de condicionamento de ar está ligado, é o retorno.

Com base nas observações anteriores, pode-se afirmar que o objetivo de propor um modelo para previsão da concentração de partículas no interior de salas cirúrgicas com diferentes sistemas de condicionamento de ar foi alcançado, produzindo-se uma base teórica que pode ter grande valor para o desenvolvimento de futuros trabalhos. Para todos os casos analisados, as predições demonstraram a sua potencialidade em gerar informações detalhadas sobre o comportamento dos parâmetros em estudo e a sua contribuição para geração e remoção das partículas no interior da sala. Considera-se assim que a modelação da concentração das partículas é viável para análise dos riscos de contaminação, permitindo quantificar o impacto que os vários parâmetros têm sobre a geração e a eliminação desses agentes.

\subsection{ALGUMAS CONSTATAÇÕES E RESPECTIVAS IMPLICAÇÕES}

É importante destacar que o enfoque central deste trabalho foi a modelagem matemática, para predição da concentração de partículas ao longo de procedimentos cirúrgicos. Assim, a coleta e análise dos dados representaram aqui um esforço por entender o comportamento geral do ar da sala cirúrgica e de seus contaminantes, muito mais que uma tentativa de determinar com exatidão a contribuição de cada um desses fatores. Portanto, relativamente aos dados coletados em campo, é preciso que se diga que, ainda que, em seu conjunto, de forma geral, eles sugiram certas tendências bastante claras, isoladamente eles devem ser tomados com cautela, porque há interações entre fatores que precisam ser mais bem estudadas. De qualquer forma, a análise dos dados de campo permitiu as seguintes constatações e respectivas implicações:

1. A variação das partículas no interior das salas cirúrgicas estudadas, de forma geral, mostrou-se bastante definida, com padrões característicos e similares para cada etapa do procedimento cirúrgico. Ou seja, revelou-se, nesse comportamento das partículas em salas cirúrgicas uma previsibilidade que faculta a criação de modelos, como o que se propõe neste estudo. 
2. A equipe cirúrgica mostrou ser uma importante fonte de geração de partículas e observou-se que, à medida que aumenta o número de pessoas, ocorre um aumento na concentração de partículas. Isso sugere que o número de pessoas na sala cirúrgica, bem como seu nível de atividade, deva ser mantido tão baixo quanto possível, especialmente nos procedimentos cuja natureza implique maior risco de contaminação aérea.

3. A manipulação de campos cirúrgicos provocou a geração de grande número de partículas, principalmente na faixa de 5 a $10 \mu \mathrm{m}$. Apesar de geradas por material esterilizado, essas partículas, em contato com superfícies contaminadas podem tornar-se viáveis e oferecer risco quando ressuspensas. Então, parece recomendável que se utilizem campos cirúrgicos descartáveis, pois estes emitem menos partículas.

4. Outra importante fonte de partículas foi a remoção por serragem da tala de gesso em cirurgias ortopédicas. Considerando que as superfícies da tala podem estar muito contaminadas, parece recomendável que a mesma seja removida fora da sala cirúrgica e que seja feita uma limpeza da pele do paciente.

5. O diâmetro das partículas resultantes da atividade humana nos ambientes estudados concentrou-se principalmente na faixa de 5 a $10 \mu \mathrm{m}$. Nessa faixa, as partículas de escamas de pele representam a principal fonte de contaminação, pois têm usualmente diâmetro médio de 7,5 $\mu \mathrm{m}$. E partículas nesse tamanho têm tempo de suspensão relativamente longo. Isso implica a necessidade de que o controle das partículas em salas cirúrgicas dê-se especialmente nessa faixa de diâmetro.

6. Os dados de campo sugerem que a concentração das partículas no início de um procedimento, oriundas da cirurgia anterior e/ou do processo de limpeza da sala, podem ser um fator importante para a contaminação da ferida cirúrgica. Portanto, parece recomendável ligar-se o sistema de condicionamento de ar alguns minutos antes da entrada do paciente na sala cirúrgica e não apenas quando as condições de conforto térmico o exigirem. Também parece aconselhável manter o condicionamento de ar ligado após o ato cirúrgico, durante a limpeza da sala, para remover partículas geradas tanto pela cirurgia quanto pela própria atividade de limpeza.

7. O retorno do ar foi o fator que mais contribuiu para a eliminação das partículas no interior da sala cirúrgica. Desta forma, é importante que as grelhas de retorno 
sejam mantidas livres de obstruções, como mobílias e equipamentos à sua frente, que podem comprometer severamente o fluxo de ar de retorno.

8. A abertura das portas, em quase todos os casos analisados, resultou na queda da concentração das partículas no interior da sala. Assim, manter as portas abertas parece, à primeira vista, ser uma boa alternativa para remoção de partículas quando não há sistema de retorno ou quando este se mostra insuficiente para manter a concentração de partículas em níveis adequados. Isso pode ser especialmente verdadeiro para o caso do sistema de ar condicionado de janela, no qual a abertura da porta provocou sensível redução na concentração de partículas. Entretanto, esses resultados devem ser tomados com muita cautela, por várias razões. Primeiro, ainda que a abertura da porta favoreça a eliminação de partículas do interior da sala, por processos de convecção e dispersão, também propicia que o ar do corredor entre na sala por convecção. Com isso, podem penetrar partículas carregadas de patógenos, especialmente quando a sala cirúrgica localiza-se na proximidade de áreas contaminadas. Em segundo lugar, deve-se levar em conta que a remoção de partículas do interior da sala cirúrgica para o corredor implica piorar a qualidade do ar neste último. Assim, partículas contaminadas geradas em uma sala cirúrgica podem vir a atingir salas cirúrgicas próximas. Por fim, também se constatou neste estudo que a eficiência do retorno pode ser sensivelmente prejudicada pela abertura das portas. Diante desses fatos, a abertura da porta como forma de remover partículas só se justificaria naqueles casos em que o sistema de condicionamento de ar mostra-se claramente inadequado e os riscos da contaminação gerada internamente são elevados. A melhor situação é ter-se um sistema de condicionamento eficiente e manterem-se fechadas as portas.

9. À exceção do sistema de ar condicionado de janela, os demais sistemas estudados, quando ligados ao longo de todo o procedimento cirúrgico, conseguiram manter a concentração de partículas no interior das salas em níveis aceitáveis. Isso reforça que o sistema de ar condicionado de janela é inadequado para uso em salas cirúrgicas, pois não propicia adequada remoção das partículas geradas pelos procedimentos cirúrgicos.

10. Devido à baixa eficiência dos sistemas de filtragem, o aumento da vazão de insuflamento diminuiu a concentração das partículas maiores, porém provoca um aumento das partículas de pequeno diâmetro. Portanto, é preciso estar atento aos pontos de captação do ar externo pois, se este sofrer contaminação por partículas 
pequenas e viáveis, como vírus, o sistema de filtragem poderá não ser capaz de eliminar esses elementos, e o aumento da vazão poderá resultar no aumento de sua concentração no interior da sala.

\subsection{RELEVÂNCIA DO ESTUDO}

Uma das contribuições mais relevantes do presente trabalho é que ele foi desenvolvido a partir de situações reais. Situações de laboratório, ainda que mais precisas, podem afastar-se consideravelmente das situações cotidianas, devido à eliminação de fatores importantes. Desta forma, a partir deste estudo, pôde-se:

(a) analisar a importância relativa dos fatores considerados sobre a quantidade de partículas em suspensão e, por extensão, sobre o risco de infecções hospitalares;

(b) criar uma ferramenta prática para a avaliação de novos sistemas de condicionamento de ar utilizados em salas cirúrgicas.

(c) criar uma ferramenta prática para a avaliação dos sistemas de condicionamento de ar existentes em salas cirúrgicas.

(d) obter um modelo matemático para auxiliar na avaliação e previsão da eficiência de sistemas de condicionamento de ar utilizados em salas cirúrgicas, para o controle de partículas em suspensão;

Assim, produziu-se uma melhor compreensão da forma como os contaminantes particulados aerotransportados são gerados e se movimentam no interior de uma sala cirúrgica. E também se propôs e avaliou uma ferramenta para determinar, de forma rápida, eficiente e econômica, a importância relativa dos vários fatores envolvidos na contaminação do ar sobre o campo cirúrgico, identificando aqueles que têm maior peso relativo. A partir desse conhecimento, pode-se propor formas mais adequadas de controle sobre a geração e dispersão desses contaminantes, buscando evitar que atinjam a ferida cirúrgica. Isso propiciará que se reduzam as taxas de infecção pós-cirúrgica por partículas aéreas e todos os malefícios dela decorrentes, como o aumento no tempo de internação e nas taxas de óbito, assim como os acréscimos nos custos de tratamento. 


\subsection{LIMITAÇÕES DO ESTUDO}

Apesar de o estudo estar muito próximo do cotidiano de uma sala cirúrgica, algumas simplificações tiveram que ser feitas, devido a limitações materiais (falta de tempo e de equipamentos, necessidade de reduzir ao mínimo a intervenção no ambiente cirúrgico etc.) e teóricas, uma vez que se desejava um modelo tão simples e prático quanto possível. Por sua vez, as medições no interior da sala foram feitas apenas em um ponto. Seria interessante a medição simultânea em outros pontos para verificar a homogeneidade na distribuição das partículas ao longo do procedimento cirúrgico.

Também não se analisaram os efeitos da turbulência provocada pela movimentação das portas a cada vez que alguém entrava ou saía da sala cirúrgica. Essa turbulência pode ter efeitos bastante significativos sobre a ressuspensão de partículas, fator que também não foi considerado neste estudo. Não se considerou ainda a diferença de temperatura entre a sala cirúrgica e o corredor, fator relevante quando as portas estão abertas, pela formação de correntes de convecção. Por fim, para as pessoas, a única forma de geração de partículas considerada foi a descamação, mas há outras importantes, como falar, tossir e espirrar.

\subsection{SUGESTÕES PARA A CONTINUIDADE DO PRESENTE TRABALHO}

Para a obtenção de predições mais precisas, é necessário estudar alguns aspectos, que não foram possíveis de serem analisados com mais detalhes em campo. Alguns deles são:

- a quantidade de partículas geradas pelas pessoas no interior da sala cirúrgica;

- a contribuição da perda por deposição sobre as superfícies;

- a contribuição da infiltração a partir das áreas adjacentes;

- a contribuição da ressuspensão.

Portanto, sugere-se a realização de estudos mais detalhados com relação a esses aspectos. 


\section{REFERÊNCIAS BIBLIOGRÁFICAS}

AHL, N.; DALÉN, T.; JÖRBÄCK; HOBORN, J. Air contamination during hip and knee arthroplasties. Acta Orthop Scand, 66, p. 17-20, 1995.

ANVISA. Curso Básico de Controle de Infecção Hospitalar. Brasília: Agência Nacional de Vigilância Sanitária, 2000.

ASHRAE. ASHRAE Handbook: Fundamentals. Atlanta: American Society of Heating, Refrigerating and Air-Conditioning Engineers, 2005.

ASHRAE. Standard 62. Ventilation for acceptable indoor air. Atlanta: American Society of Heating, Refrigerating and Air-Conditioning Engineers, 1998.

ASTM. D5157-97. Standard Guide for Statistical Evaluation of Indoor Air Quality Models. American Society for Testing and Materials, 1997.

AYLIFFE, G. A. J. Role of the environment of the operating suite in surgical wound infections. Rev Infect Dis, 13 (Suppl. 10), S800-4VIII-52, 1991.

BECK, W. C.; FRANK, F. The open door in the operating room. Am J Surg, v. 125, p. 592-5, May 1973.

BEGGS, C. B. The airborne transmission of infection in hospital buildings: fact or fiction? Indoor Built Environ, v. 12, p. 9-18, 2003.

BELKIN, L. N. Laminar Airflow and Surgical Wound Infections. AORN Journal, Aug. 1998.

BLAKEMORE, W. S.; MCGARRITY, G. J.; THURER, R. J. et al. Infection by air-borne bacteria with cardio-pulmonary bypass. Surg, v. 70, p. 830-838,1979.

CHAO, C. Y. H.; WAN, M. P.; CHENG, E. C. K. Penetration coefficient and deposition rate as a function of particle size in non-smoking naturally ventilated residences. Atmospheric Environment, v. 37, n. 30, p. 4233-4241, 2003. 
CHEN, Q.; JIANG, Z.; MOSER, A. Control of airborne particle concentration and draught risk in an operating room. Indoor Air, v. 2, p. 154-167, 1992.

CHOW, T.; YANG, X. Performance of ventilation system in a non-standard operating room. Hong Kong: Division of Building Science and Technology. City University of Hong Kong, 2003.

COSTA, S. F. Introdução ilustrada à estatística. 2 ed. São Paulo: Harbra, 1992.

COTERILL, S.; EVANS, R.; FRAISE, A. P. An unusual source of an outbreak of methicillinresistant Staphylococcus aureus on an intensive therapy unit. J. Hosp Infect, v. 32, p. 207-16, 1996.

COX, R. N.; CLARK, R. P. Particle transport within the human microenvironment. Medical and Biological Engineering, p. 275-278, May 1974.

DANKERT, J.; ZIJLSTRA, J. B.; LUBBERDING, H. A garment for use in the operating theatre: the effect upon bacterial shedding. J Hyg , v. 82, n. 1, p. 7-14. Feb 1979.

DGKH. Sociedade Alemã de Higiene Hospitalar / SGSH. Sociedade Suíça de Higiene Hospitalar / ÖGHMP. Sociedade Austríaca de Higiene Hospitalar. Grupo de Trabalho em Microbiologia e Medicina Preventiva em Sistemas de Aquecimento, Ventilação e Ar Condicionado. Guidelines (draft): designing and operating heating, ventilation and airconditioning (HVAC) in hospitals. Hyg Med, v. 27, Jah. 2002.

DHARAN, S.; PITTET, D. Environmental controls in operating theatres. J Hosp Infect, v. 51, n. 2, p. 79-84. Jun 2002.

EDMISTON, C.E.; SINSKI, S.; SEABROOK G.R.; SIMONS, D.; GOHEEN, M. Airborne particulates in the OR environment. AORN Journal, v. 69, n. 6, Jun 1999.

ESMEN, N. A. Characterization of Contaminant Concentrations in Enclosed Spaces. American Chemical Society, v. 12, n. 3, March 1978.

EVERETT, W. D.; KIPP, H. Epidemiologic observations of operating room infections resulting from variations in ventilation and temperature. Am J Infect Control, 19, p. 277-282, 1991.

FAVAROLO, P. A.; MANZ, H. Temperature-driven single-sided ventilation through rectangular opening. Building and Environment, May 2005. 
FEIGLEY, C. E.; BENNETT, J. S.; LEE, E.; KHAN, J. Improving the use of mixing factors in dilution ventilation design. Appl Occup Environ Hyg, v. 17, p. 333-43, 2002.

FERRAZZI, P.; ALLEN, R.; CRUPI, G.; REYES, I.; PARENZAN, L.; MAISONNET, M. Reduction of infection after cardiac surgery: a clinical trial. Ann Thorac Surg, n. 42, p. 321-325. Sep. 1986.

FITZGERALD JR, R. H. Microbiologic environment of the conventional operating room, Arch Surg, v. 114(7), p. 772-5, Jul. 1979.

FLUCKIGER, U.; WIDMER, A. F. Epidemiology of Methicillin-Resistant Staphylococcus aureus. Chemotherapy, v. 45, p. 121-134, 1999.

FOGH, C. L.; BYRNE, M. A.; ROED, J.; GODDARD, A. J. H. Size-specific indoor aerosol deposition measurements and derived I/O concentrations ratios. Atmospheric Environment 31, p. 2193-2203, 1997.

FOSTER, J. T. The Staphylococcus aureus "superbug”. J. Clin. Invest., v. 114, p. 1693-96, 2004.

FRIBERG, B. E. E.; BURMAN, L.G.; FRIBERG, S. Zoned Exponential, Vertical and horizontal ultra-clean laminar airflows. Acta Orthop Scand, 69 (2), p. 169-172, 1998.

GADGIL, A. J.; LOBSCHEID, C.; ABADIE, M. O.; FINLAYSON, E. U. Indoor pollutant mixing time in an isothermal closed room: an investigation using CFD. Atmospheric Environment, v. 37, n. 39-40, p. 5577-5586, 2003.

GOSDENA, P. E.; MACGOWANA, A. P.; BANNISTER, G. C. Importance of air quality and related factors in the prevention of infection in orthopedic implant surgery. Journal of Hospital Infection, v. 39, p. 173-180, Jul. 1998.

HAMBRAEUS, A.; BENGTSSON, S.; LAURELI, G. Bacterial contamination in a modern operating room. 3. Importance of floor contamination as a source of airborne bacteria. J. Hyg. Camb., 80, 169, 1978.

HARTUNG, C.; KUGLER, J. Perturbations affecting the performance of laminar flow in operating theatres. In IFHE CONGRESS, 15, 1998. Proceedings..., p. 88-92.

HAYS, S. M.; GOBBELL, R. V.; GANICK, N. R. Indoor air quality: solutions and strategies. New York: McGraw-Hill, 1995. 
HE, C.; MORAWSKA, L.; HITCHINS, J.; GILBERT, D. Particle deposition rates in residential houses. Atmospheric Environment, 39, p. 3891-3899, 2005.

HEISELBERG, P.; SVIDT, K.; NIELSEN, P. V. Characteristics of airflow from open windows. Building and Environment, Aug 2001.

HINDS, W. C. Aerosol technology: properties, behavior, and measurement of airborne particles. New York: Wiley, 1999.

HORAN, T. C, CULVER, D. H.; GAYNES, R. P.; JARVIS, W. R.; EDWARDS, J. R.; REID C. R. Nosocomial infections in surgical patients in the United States, January 1986 - June 1992. National Nosocomial Infections Surveillance (NNIS) System. Infect Control Hosp Epidemiol. n. 14, p. 73-80, 1993.

HOWARD-REED, C.; WALLACE, L.A.; EMMERICH, S. J. Effect of ventilation systems and air filters on decay rates of particles produced by indoor sources in an occupied. Atmospheric Environment, 37, p. 5295-5306, Dec. 2003.

HOWORTH, F. H. Prevention of airborne infection during surgery. The Lancet, v. 1, n. 8425, p. 386-388, Feb 16, 1985.

HOWORTH, F. Prevention of airborne infection during surgery. ASHRAE Transaction, 99(1), 1993.

HUMPHREYS, H.; TAYLORB, E. W. Operating theatre ventilation standards and the risk of postoperative infection. Journal of Hospital Infection, 50, p. 85-90, 2002.

JAMARISKA, M.; MORAWSKA, L.; CLARK, B. A. Effect of ventilation and filtration on submicrometer particles in an indoor environment, Indoor Air 10 (1), p. 19-26, 2000.

JONES, R. K.; LUNDGREN, D.; MUGGENBURG, B.; SMITH, J. P.; TURNER, R.; YEH, H. Characterization of aerosols produced during surgical-procedures in hospitals. Aerosol science and technology, v. 22, n. 2, 1995.

JOSEPHE, P. E. A re-evaluation of laminar air flow in hospital operating rooms. ASHRAE Transaction, 87 (2), 1981.

KALMEIJER, M. D.; COERTJENS, H.; VAN NIEUWLAND-BOLLEN, P. M.; BOGAERSHOFMAN, D.; DE BAERE, G. A. J, STUURMAN, A.; VAN BELKUM, A.; KLUYTMANS, J. A. J. W. Surgical site infections in orthopedic surgery: the effect of 
mupirocin nasal ointment in a double-blind, randomized, placebo-controlled study. Clinical Infectious Diseases, v. 35, p. 353-8. 2002.

KAMEEL, R.; KHALIL, E. Predictions of turbulence behavior using k- $\varepsilon$ model in operating theatres. Cairo: Mechanical Power Engineering Dpt. Cairo University, Egypt, 2003.

KLUYTMANS, J. J. W.; MOUTON, J. W.; IJZERMAN, E. F.; MAAT, W. M.; VERBRUGH, H. Nasal carriage of Staphylococcus aureus as a major risk factor for wound infections after cardiac surgery. JID, 171, Jan. 1995.

KULKARNI, M. M.; PATIL, R. S. An empirical model to predict indoor NO2 concentrations. Atmospheric Environment, v. 36, n. 30, p. 4777-4785, 2002.

LACERDA, R. A. Infecções Hospitalares no Brasil. São Paulo, 1995. Tese (Doutorado em Enfermagem). Departamento de Enfermagem, Universidade de São Paulo.

LEWIS, H. E.; FOSTER, A. R.; MULLAN, B. J.; COX, R. N; CLARK, R. P. Aerodynamics of the human microenvironment. Lancet, p.1273-1277, Jun. 1969.

LEWIS, J. R. Operating room air distribution effectiveness. ASHRAE Transactions, 93 (2), 1993.

LIDWELL, O. M. Air exchange through doorways, J. H. Camb. 79, p. 141- 155, 1977.

LIDWELL, O. M. Air, antibiotics and sepsis in replacement joints. Journal of Hospital Infection. v. 11 (Supplement C), p.18-40, 1988.

LIDWELL, O. M.; LOWBURY, E. J. L.; WHYTE, W.; BLOWERS, R.; STANLEY, S. J.; LOWE, D. Ultraclean air and antibiotics for prevention of postoperative infection: a multicenter study of 8052 joint replacement operations. Acta Orthop. Scand, 58, p. 4-13, 1987.

LIDWELL, O. M.; LOWBURY, E. J. L.; WHYTE, W.; BLOWERS, R.; STANLEY, S. J.; LOWE, D. Infection and sepsis after operating for total hip or knee-joint replacement: influence of ultraclean air, prophylactic antibiotics and other factors. Journal of Hygiene. p. 505-29, 1993.

LIDWELL, O. M.; LOWBURY, E. J. L.; WHYTE, W.; BLOWERS, R.; STANLEY, S. J.; LOWE, D. Airborne contamination of wounds in joint replacement operations: the relationship to sepsis rates. J. Hosp Infect, v. 4, p. 111- 131, 1983. 
LIDWELL, O. M; LOWBURY, E. J. L.; WHYTE, W.; BLOWERS, R.; STANLEY, S. J.; LOWE, D. Effect of ultraclean air in operating rooms on deep sepsis in the joint after total hip or knee replacement: a randomised study. Br Med J, v. 285, p. 10-4, 1982.

LIU, Y.; MOSER, A. Airborne particle concentration control for an operating room, Roomvent, Denmark, 2002.

MANGRAM, A. J.; HORAN, T. C.; PEARSON, M. L.; SILVER, L. C.; JARVIS, W. R. Guideline for prevention of surgical site infection. Centers for Disease Control and Prevention (CDC). Hospital Infection Control Practices Advisory Committee. Am J Infect Control, 27, p. 97-132, 1999.

MEMARZADEH, F.; MANNING, A. Comparison of operating room ventilation systems in the protection of the surgical site. ASHRAE Transactions, 108(2), 2002.

MEMARZADEH, F.; MANNING, A. P. Comparison of operating room ventilation systems in the protection of the surgical site. ASHRAE Transactions, v. 108, Part 2, p. 3-15, 2002.

MILNER, J. T.; DIMITROULOPOULOU, C.; APSIMON H. M. Indoor concentrations in buildings from sources outdoors. UK Atmospheric Dispersion Modeling Liaison Committee. ADMLC/2004/2. 2004.

MORAWSKA, L.; JAMRISKA, M.; FRANCIS, P. Particulate matter in the hospital environment. Indoor Air, v. 8, p. 285-294, 1998.

MOSLEY, R. B.; GREENWELL, D. J.; SPARKS, L. E.; GUO, Z.; TUCKER, W. G.; FORTMANN, R.; WHITFIELD, C. Penetration of ambient fine particles into the indoor environment. Aerosol Science and Technology 34, p. 127-136, 2001.

NAZARO, W. W. Indoor Particle Dynamics. Indoor Air, v. 14 (Supplement 7), p. 175-183, 2004.

NAZAROFF, W. W.; CASS, G. R. Mathematical modeling of indoor aerosol dynamics. Environmental Science e Technology, 23, p. 157-166, 1989.

NOBLE, W. C.; DAVIES, R. R.; PLACE-DOREEN, A. Studies on the dispersal of staphylococci. J Clin Pathol. v. 18, n. 1, p. 16-19. Jan. 1965.

Noble, W.C.; Dispersal of skin microorganisms, Br J Dermatol. Oct 1975; 93(4):477-85. 
ÖZKAYNAK, H.; XUE, J.; WEKER, R.; BUTLER, D.; KOUTRAKIS, P, SPENGLER, J. The particle team (PTEAM) study: analysis of the data. v. 3. Research Triangle Park, NC, 1996.

PEREIRA, M. L.; TRIBESS, A. Sistemas de tratamento de ar em salas cirúrgicas: estudo da distribuição de partículas na avaliação da contaminação aérea. VIII Congreso Iberoamericano de Aire Acondicionado y Refrigeración - CIAR. Montevideo, 2005.

PEREIRA, M. L. Sistemas de refrigeração e condicionamento de ar. Curso Técnico de Refrigeração e Ar Condicionado - CEFET-SC, Florianópolis, 75p, 2002.

PERL, T. M.; ROY, M. C. Postoperative wound infections: risk factors and role of Staphylococcus aureus nasal carriage. J Chemother, Suppl, n. 3, p. 29-35, Jul. 1995.

PITTET, D.; DUCEL, G. Infectious risk factors related to operating rooms. Infect Control Hosp Epidemiol, v. 15, n. 7, p. 456-62, Jul 1994.

QURAISHI, Z.; BLAIS, F. X.; SOTTILE, W.; ADLER, L. M. Movement of personnel and wound contamination. AORN Journal, v. 38, n. 1, Jul. 1983.

RITTER, M. A. Operating room environment. Clinical Orthopaedics \& Related Research, v. 369, p. 103-109, Dec. 1999.

RILEY, W. J.; MCKONE, T. E.; LAI, A. C. K.; NAZAROFF, W. W. Indoor Particulate Matter of Outdoor Origin: Importance of size-dependent removal mechanisms, Environ. Sci. Technol. V. 36, p. 200-207, 2002.

ROY, M. C. The operating theater: a special environmental area. In: WENZEL, R.P. Prevention and control of nosocomial infections. Baltimore: Williams \& Wilkins, 1997.

SAlVATI, E. A.; ROBINSON, R. P.; ZENO, S. M.; KOSLIN, B. L.; BRAUSE, B. D.; WILSON, P. D. Infection rates after 3175 total hip and total knee replacements performed with and without a horizontal unidirectional filtered airflow system. Journal of Bone and Joint Surgery, v. 64A (4), p. 525-535, 1982.

SALVIGNI, S.; PIVA, S.; MAZZACANE, S. On the assessment of ventilation requirements for hospital operating rooms. v. 1. In INTERNATIONAL CONFERENCE INDOOR AIR, 7, 21-26 July 1996. Nagoya, Japan. Proceedings..., 1996. p. 393-398.

SBCC. Sociedade Brasileira de Controle de Contaminação. Recomendação Normativa 005. Controle de Contaminação. Testes em Áreas Limpas. 1997. 
SCOTT, C. C.; SANDERSON, J. T.; GUTHRIE, T. D. Choice of ventilation system for operating-theatres: comparison of turbulent versus laminar/linear flow systems in operatingrooms and industrial clean rooms, The Lancet, 297(7712), p. 1288-1291, Jun. 1971.

SCOTTISH QUALITY ASSURANCE SPECIALIST INTEREST GROUP. Guidelines on environmental monitoring for aseptic dispensing facilities. 3 ed. Nov. 2002.

SETTLES, G. S.; MCGANN, W. J. Potential for portal detection of human chemical and biological contamination. SPIE Aerosense. v. 4378, Apr. 2001.

SOFTAH, A.; BEDARD, A.; HENDRY, P.; MASTER, R.G, GOLDSTEIN, W.; BRAIS, M.; KEON, W. Wound Infection in cardiac surgery. Annal of Saudi Medicine, v. 22, 2002.

SOHN, M. D.; SMALL, M. J. Parameter estimation of unknown air exchange rates and effective mixing volumes from tracer gas measurements for complex multi-zone indoor air models. Building and Environment, v. 34, n. 3, p. 293-303, 1999.

SOLBERG, C. O. Spread of Staphylococcus aureus in hospitals: causes and prevention. Scandinavian Journal of Infectious Diseases, v. 6, p. 587-95, 2000.

TAT. Technology Assessment Team. Policy Coordination Unit. An overview of laminar flow ventilation for operating theatres. 1997.

THATCHER, T. L.; LAYTON, D. W. Deposition, resuspension, and penetration of particles within a residence. Atmospheric Environment, v. 29, p. 1487-1497, 1995.

THORNBURG, J.; ENSOR, D. S.; RODOS, C. E.; LAWLESS, P. A.; SPARKS, L. E.; MOSLEY, R. B. Penetration of particles into buildings and associated physical factors. Part I: Model development and computer simulations. Aerosol Science and Technology, v 34, p. 284-296, 2001.

TORREIRA, R. P. Salas limpas: projeto, instalação, manutenção. São Paulo: Behar/Hemus, 1991.

TURPIN, I. M. Laminar Airflow Systems, AORN Journal. Sep. 1998.

VERKKALA,K.; EKLUND, A.; OJAJÄRVI, J.; TIITTANEN, L.; HOBORN, J.; MÄKELÄ, $P$. The conventionally ventilated operating theatre and air contamination control during cardiac surgery--bacteriological and particulate matter control garment options for low level contamination. Eur J Cardiothorac Surg, v. 14, n. 2, p. 206-10, Aug. 1998. 
VETTE, A. F.; REA, A. W.; LAWLESS, P. A.; RODES, C. E.; EVANS, G.; HIGHSMITH, V. R.; SHELDON, L. Characterization of indoor-outdoor aerosol concentration relationships during the Fresno PM exposure studies. Aerosol Science and Technology, 34, p. 118-126, 2001.

WALLACE, L.; Indoor particles: a review. Journal of the Air e Waste Management Association, v. 46, p. 98-126, 1996.

WALTER, C. W.; KUNDSIN, R. B. The airborne component of wound contamination and infection. Arch Surg, v. 107, p. 588-595, 1973.

WHITE, W.; HODGSON, R.; TINKLER, J. The importance of airborne bacterial contamination of wounds. J Hosp Infect, v. 3(2), p. 123-135, 1982.

WHYTE, W. Operating theatre clothing - a review. Surg Infect, 1991, n. 3, p. 14-17.

WHYTE, W. The role of clothing and drapes in the operating room. Journal of Hospital Infection, 11, supplement C, p. 2-17, 1988.

WHYTE, W.; VESLEY, D.; HODGSON, R. Bacterial dispersion in relation to operating room clothing. J Hyg, v. 76, n. 3, p. 367-78, Jun 1976.

WHYTE, W; HAMBRAEUS, A; LAURELL, G; HOBORN, J. The relative importance of the routes and sources of wound contamination during general surgery: II. Airborne. J. Hosp. Infect. v. 22, p. 41-54, 1992.

WILEY, W. Cleanroom Technology. New York: J Wiley \& Sons, 2001.

WILLIAMS, R. E. Epidemiology of airborne staphylococcal infection. Bacteriol Rev, v. 30, n. 3, p. 660-74. Sep. 1966.

WOLOSZYN, M.; RUSAOUËN, G. Airflow through large vertical openings in multizone modeling. Disponível em: http://www.ibpsa.org/proceedings/bs99/papers/D-09.pdf. Acesso em 15/3/2007.

WOODS, J. E.; BRAYMEN, D. T.; RASMUSSEN, R. W.; REYNOLDS, P. E.; MONTAG, G. M. Ventilation requirements in hospital operating rooms. Part I: Control of airborne particles. ASHRAE Transactions, 92 (2), 1986.

XU, M.; NEMATOLlAHI, M.; SEXTRO, R. G.; GADGIL, A. J. Deposition of tobacco smoke particles in a low ventilation room. Aerosol Science and Technology, 20, p. 194-206, 1994. 


\section{ANEXO A}

\section{PERFIS DE TEMPERATURAS E VELOCIDADES DO AR}

Neste anexo são apresentados os resultados das medições da temperatura e da velocidade do ar para os diferentes sistemas e casos estudados.

\section{SISTEMA A}

\subsection{Condicionamentos de ar desligado e portas fechadas}

Nas figuras A.1 e A.2 são apresentados perfis de temperatura e velocidade, respectivamente. Lembrando que os índices "b", "c", "d" e "e" referem-se, respectivamente, às alturas de 0,$66 ; 1,24 ; 1,83$ e 2,43 m com relação ao piso.

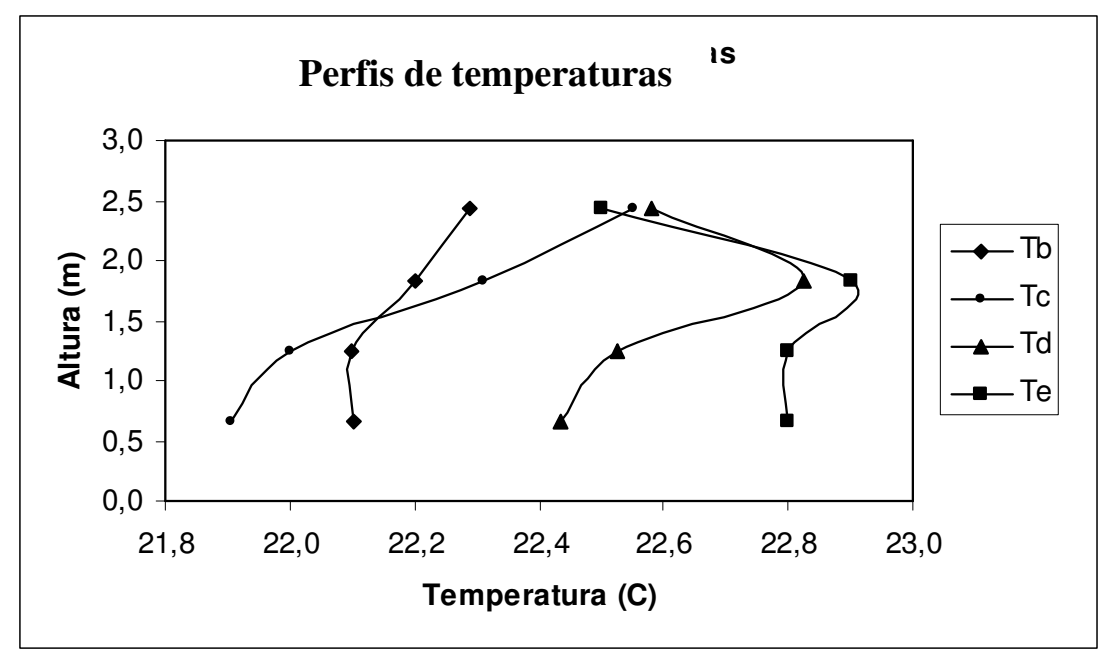

Figura A.1 - Perfis de temperatura 


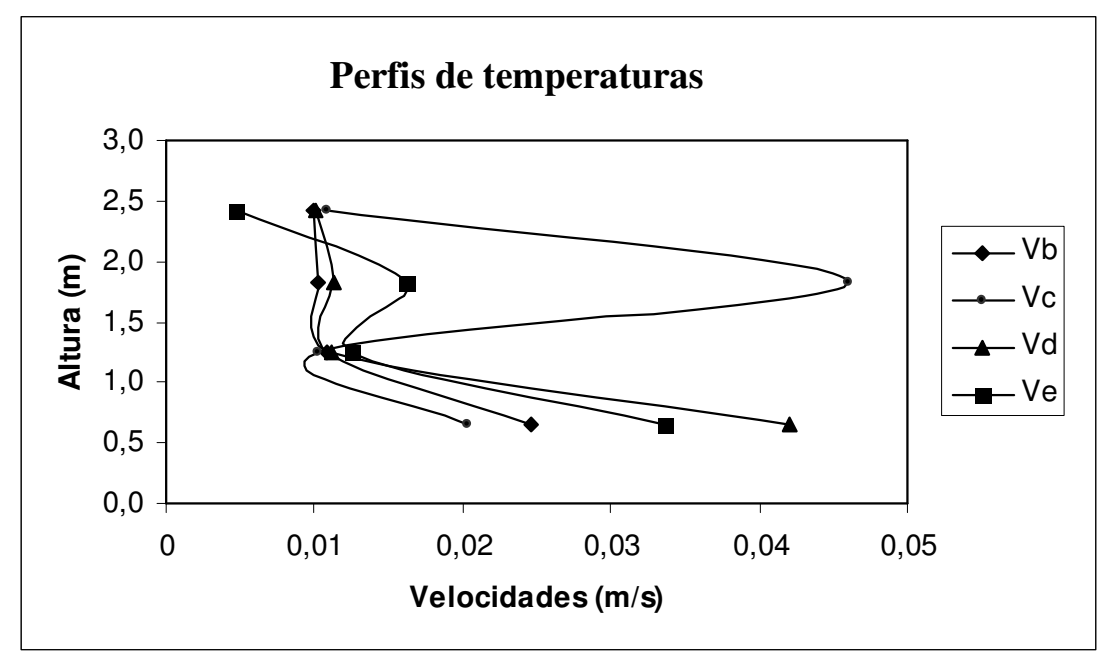

Figura A.2 - Perfis de velocidade

\subsection{Sistema de condicionamento de ar desligado e portas abertas}

Nas figuras A.3 e A.4 são apresentados perfis de temperatura e velocidade, respectivamente.

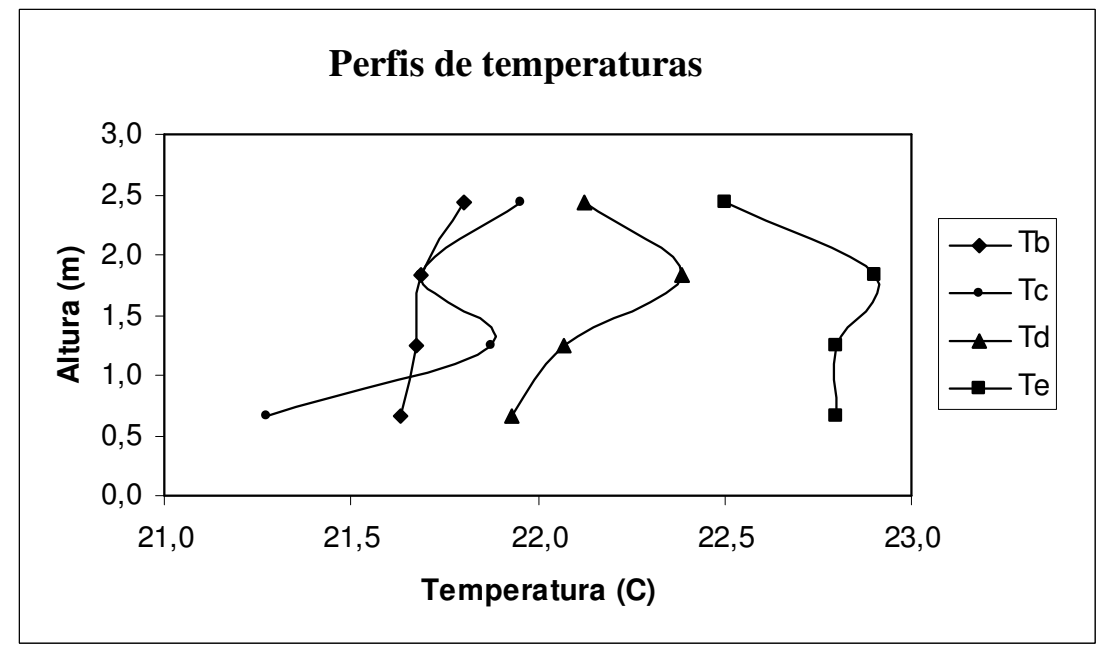

Figura A.3 - Perfis de temperaturas 


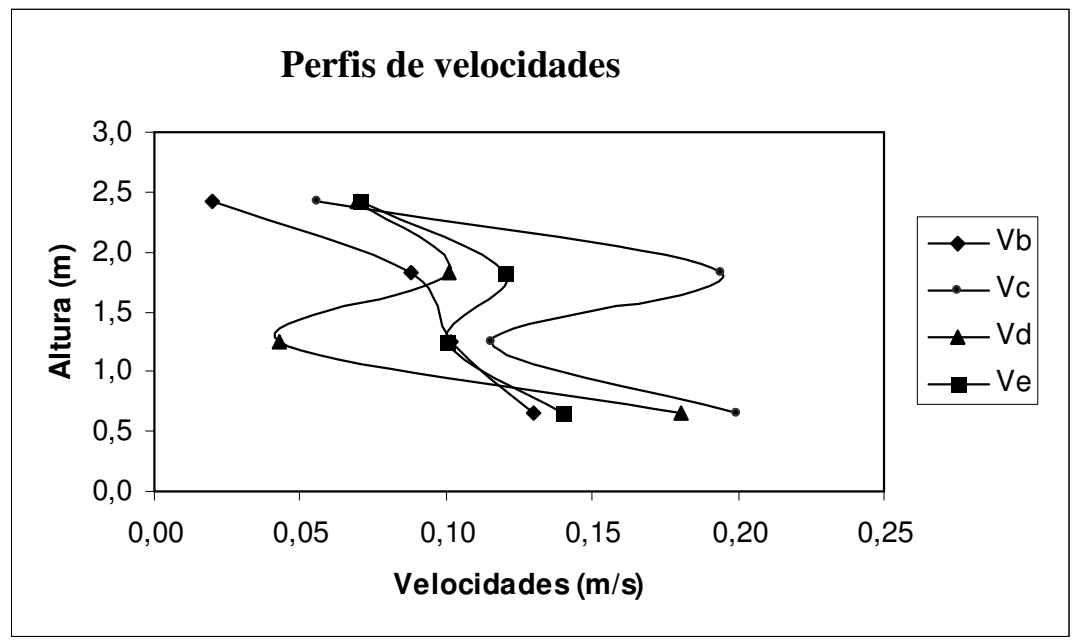

Figura A.4 - Perfis de velocidades

\subsection{Sistema de condicionamento de ar ligado e portas fechadas}

Para esse caso as figuras A.5 e A.6 apresentam os perfis de temperatura e velocidade, respectivamente.

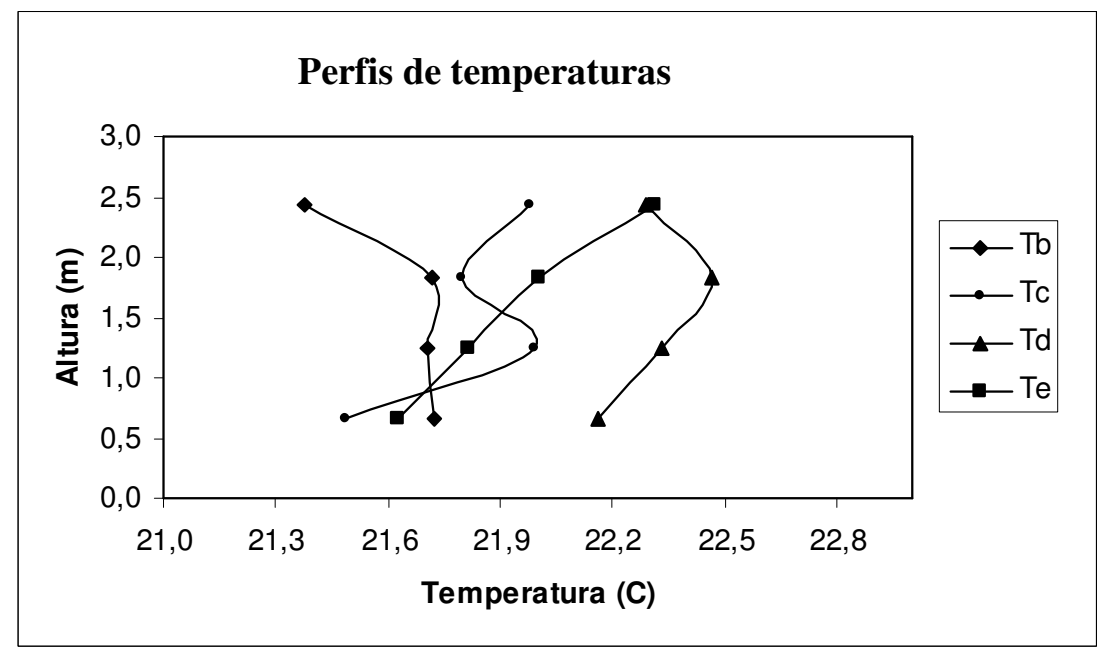

Figura A.5 - Perfis de temperaturas 


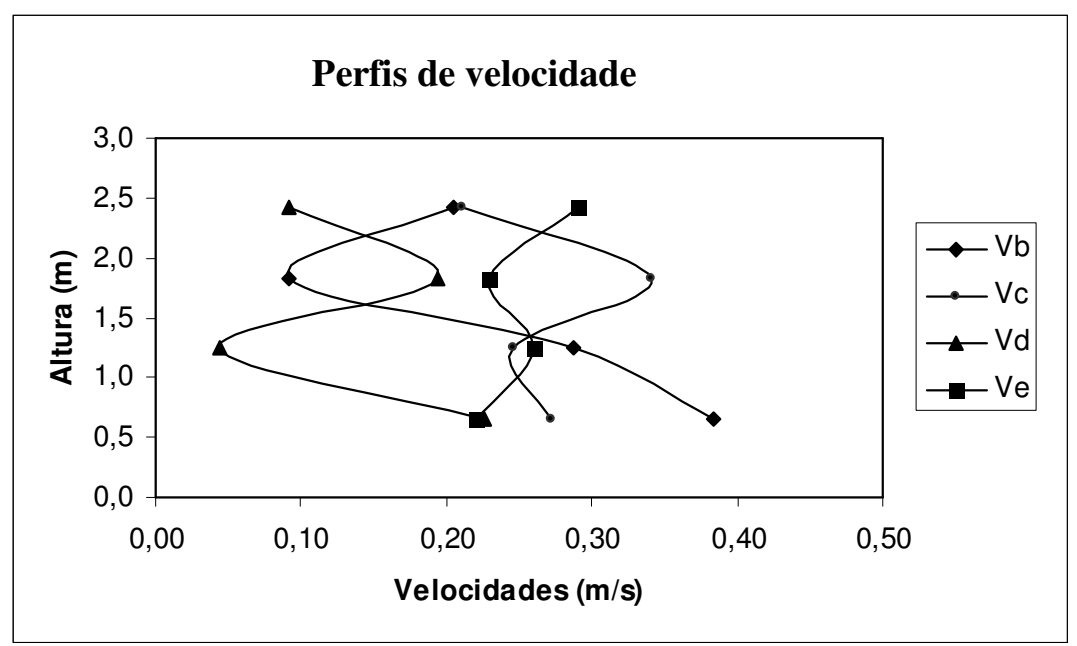

Figura A.6 - Perfis de velocidades

\subsection{Sistema de condicionamento de ar ligado e portas abertas}

Nas figuras A.7 e A.8 são apresentados perfis de temperatura e velocidade, respectivamente.

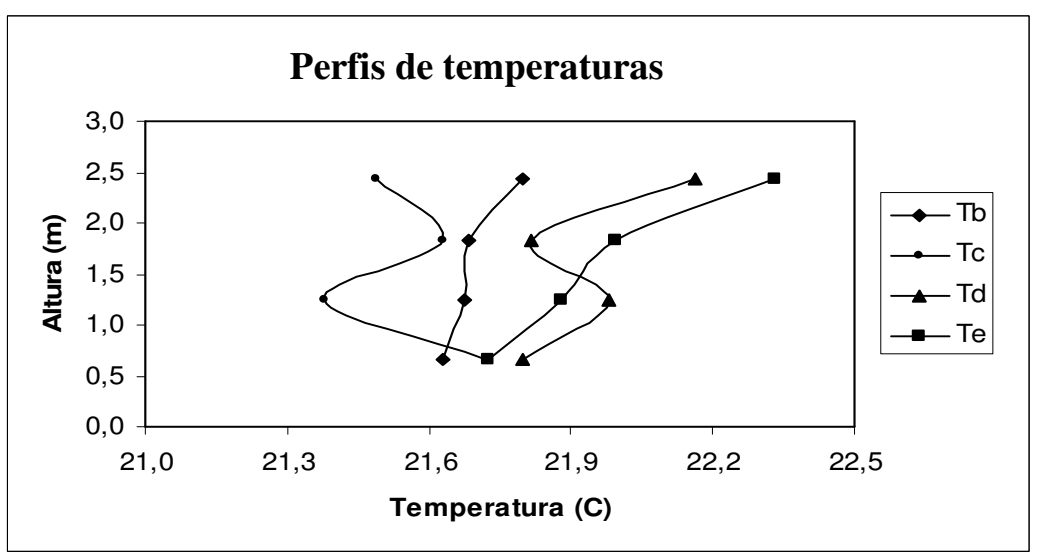

Figura A.7 - Pefis de temperaturas 


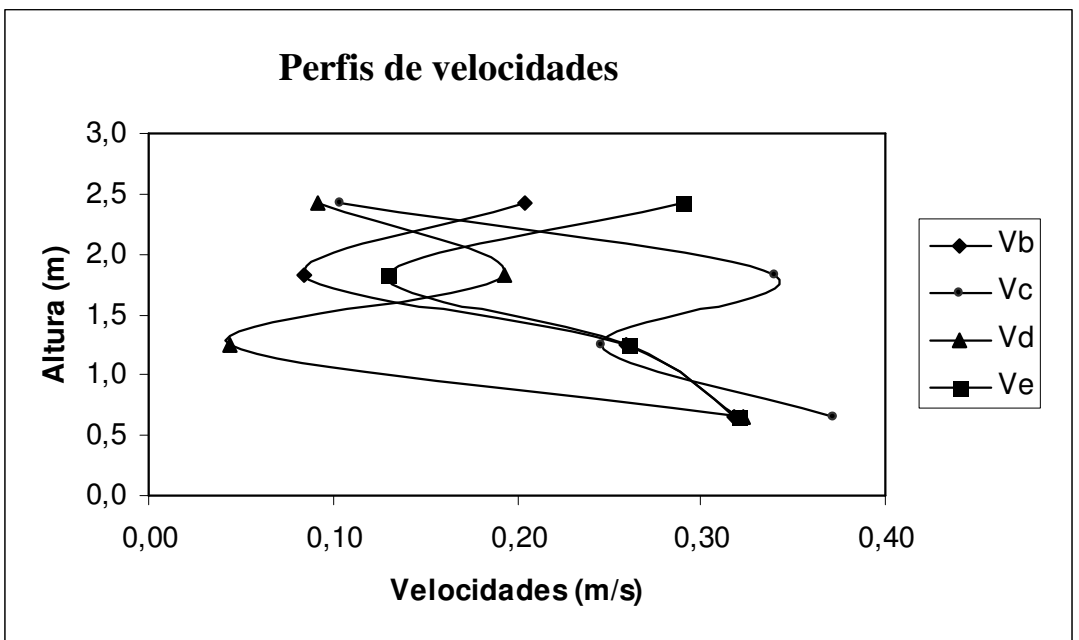

Figura A.8 - Perfis de velocidades

\section{SISTEMA B}

\subsection{Sistema de condicionamento de ar ligado e portas fechadas}

Nas figuras A.9 e A.10 são apresentados perfis de temperatura e velocidade, respectivamente.

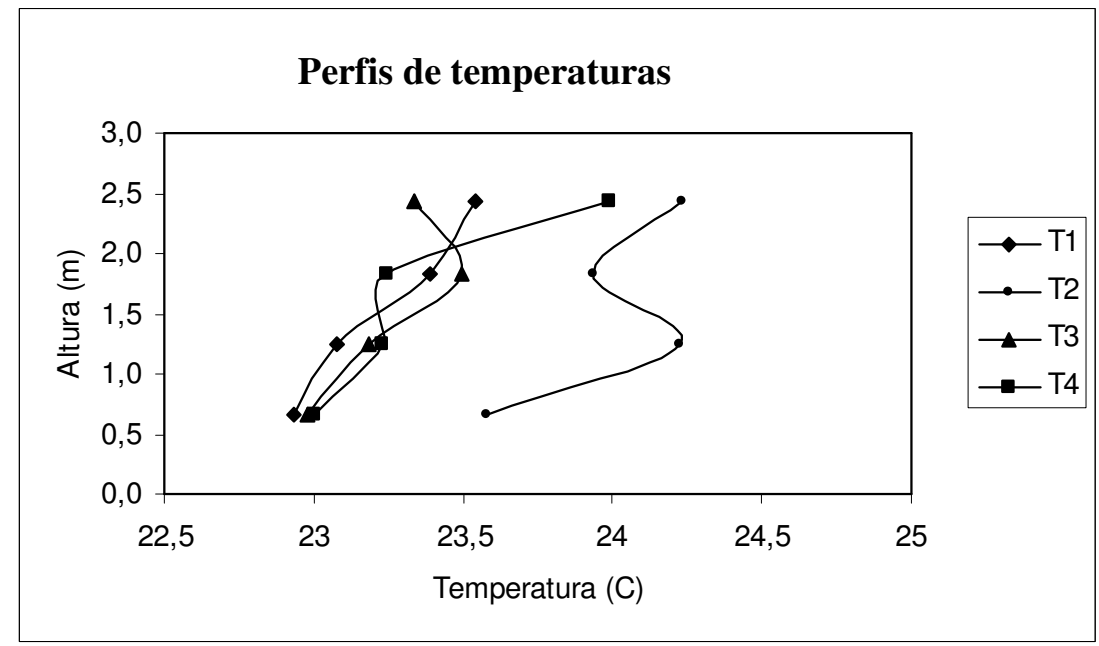

Figura A.9 - Perfis de temperaturas 


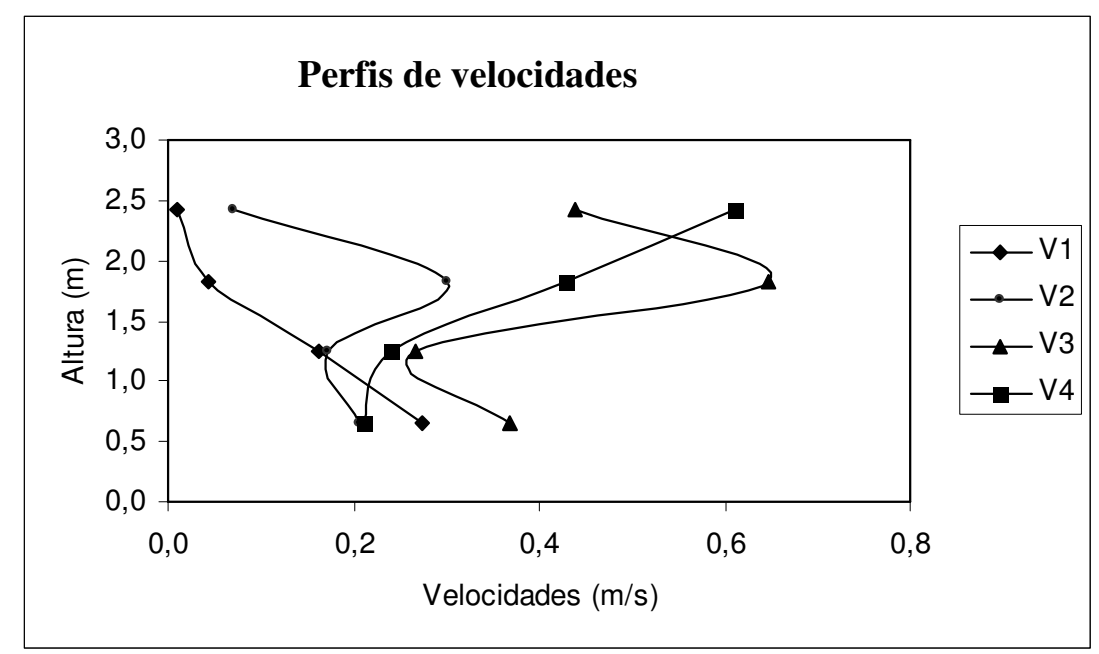

Figura A.10 - Perfis de velocidades

\subsection{Sistema de condicionamento de ar ligado e portas abertas}

Nas figuras A.11 e A.12 são apresentados perfis de temperatura e velocidade, respectivamente.

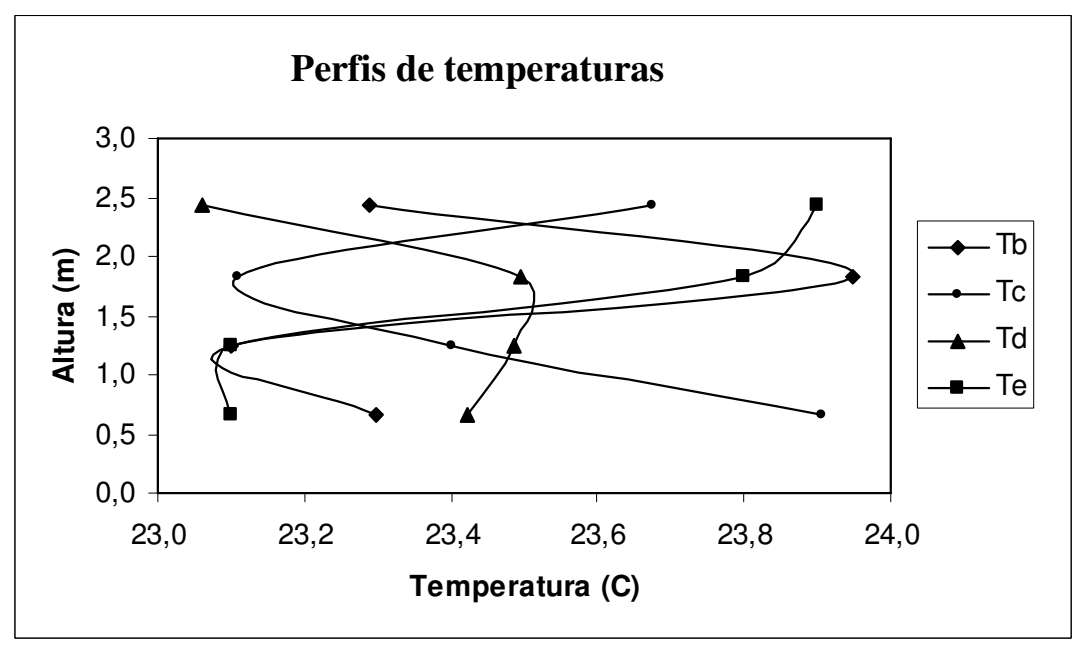

Figura A.11 - Perfis de temperaturas 


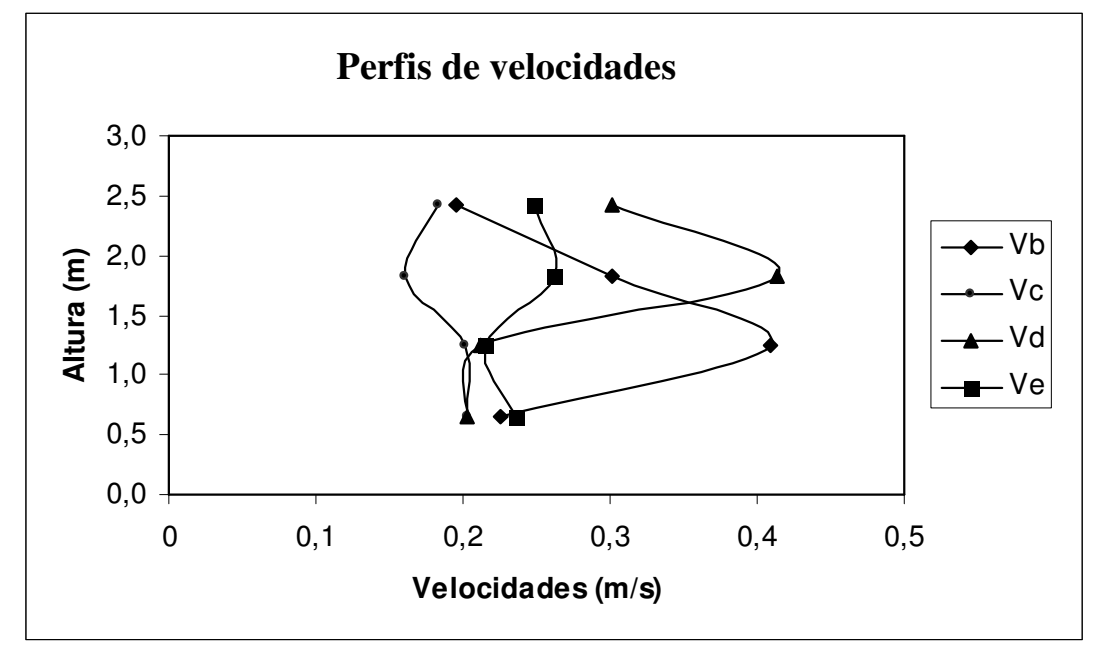

Figura A.12 - Perfis de velocidades

\section{SISTEMA C}

\subsection{Sistema de condicionamento de ar ligado e portas fechadas}

Para este caso nas figuras A.13 e A.14 são apresentados perfis de temperatura e velocidade, respectivamente.

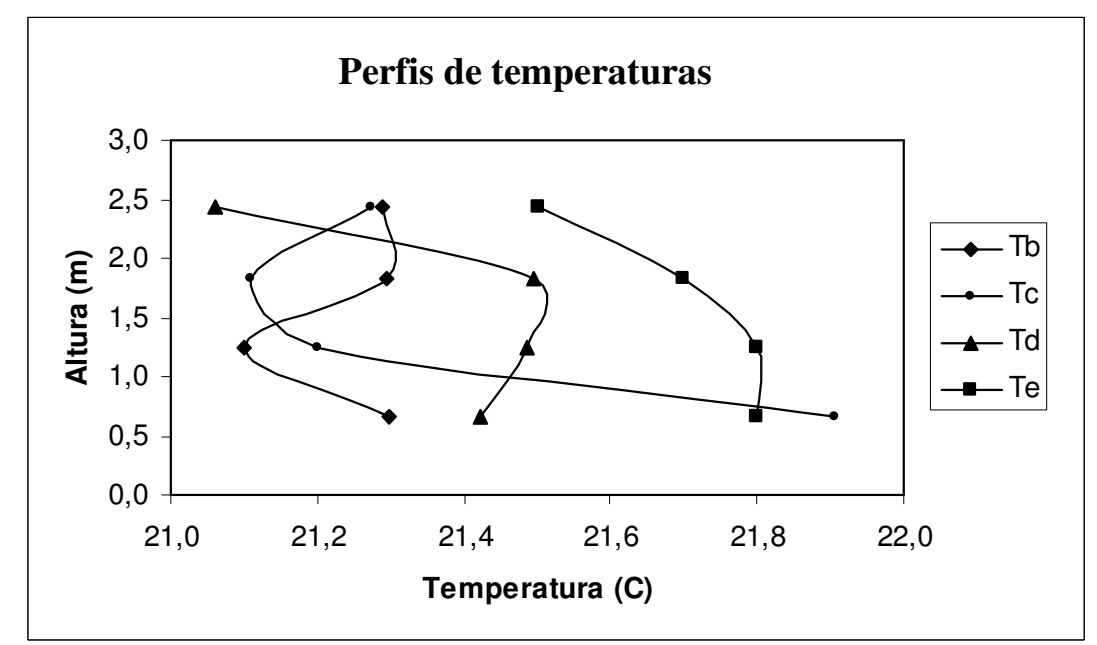

Figura A.13 - Perfis de temperaturas 


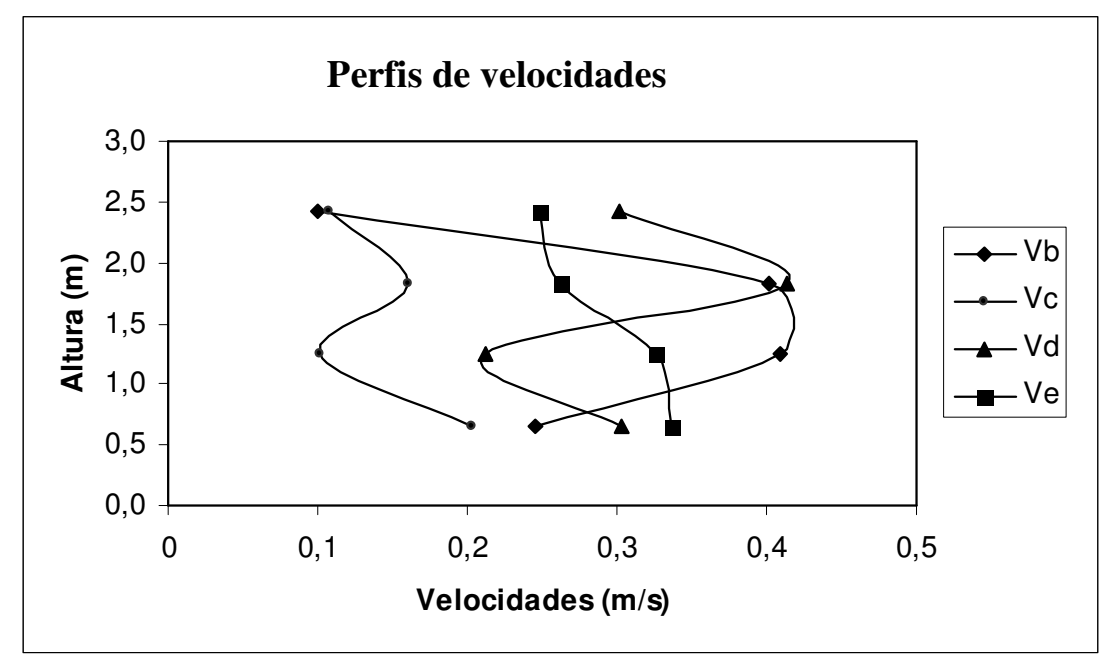

Figura A.14 - Perfis de velocidades

\subsection{Sistema de condicionamento de ar ligado e portas abertas}

Para este caso onde o sistema de condicionamento de ar ligado e portas abertas as figuras A.15 e A.16 mostram os perfis de temperatura e velocidade, respectivamente.

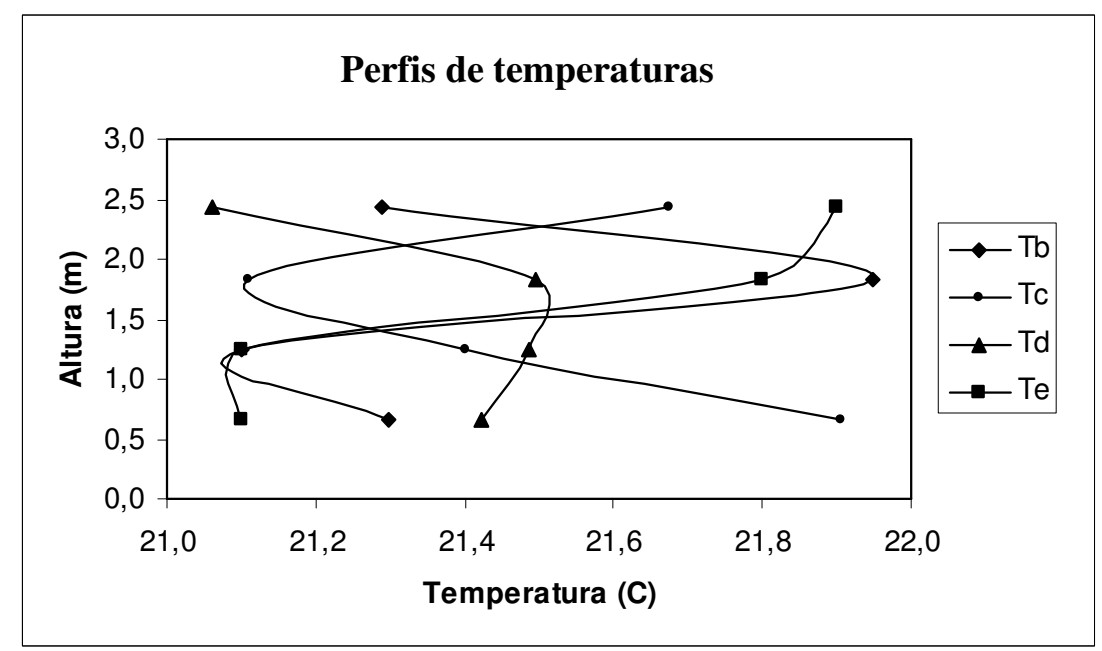

Figura A.15 - Perfis de temperaturas 


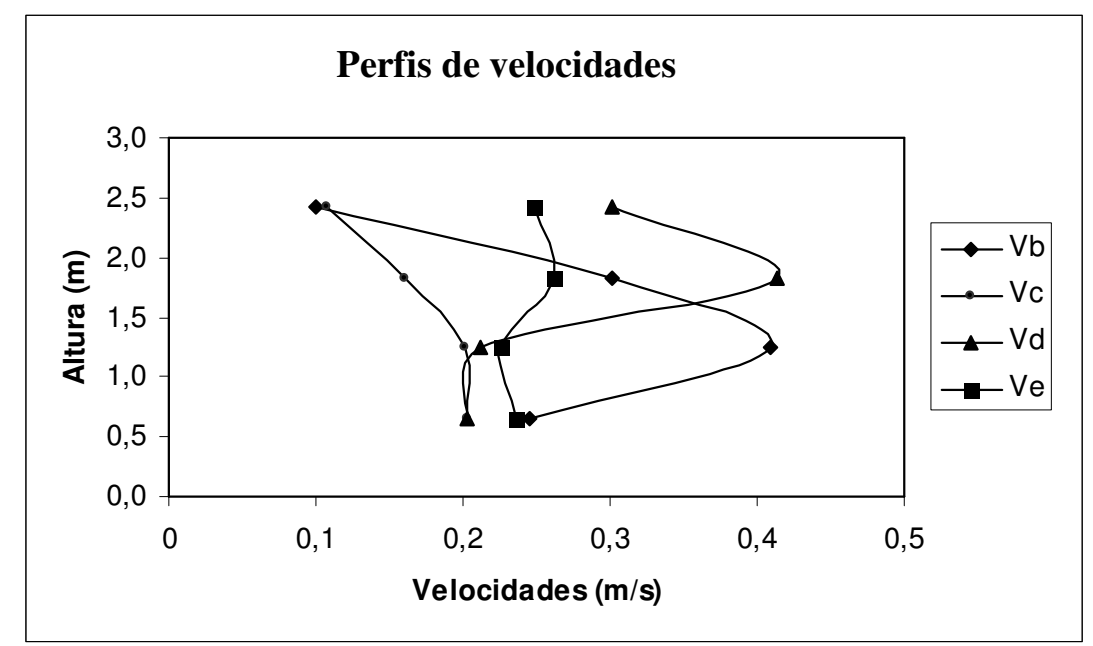

Figura A.16 - Perfis de velocidades

\section{SISTEMA D}

\subsection{Sistema de condicionamento de ar ligado e portas fechadas}

Nas figuras A.17 e A.18 são apresentados perfis de temperatura e velocidade, respectivamente.

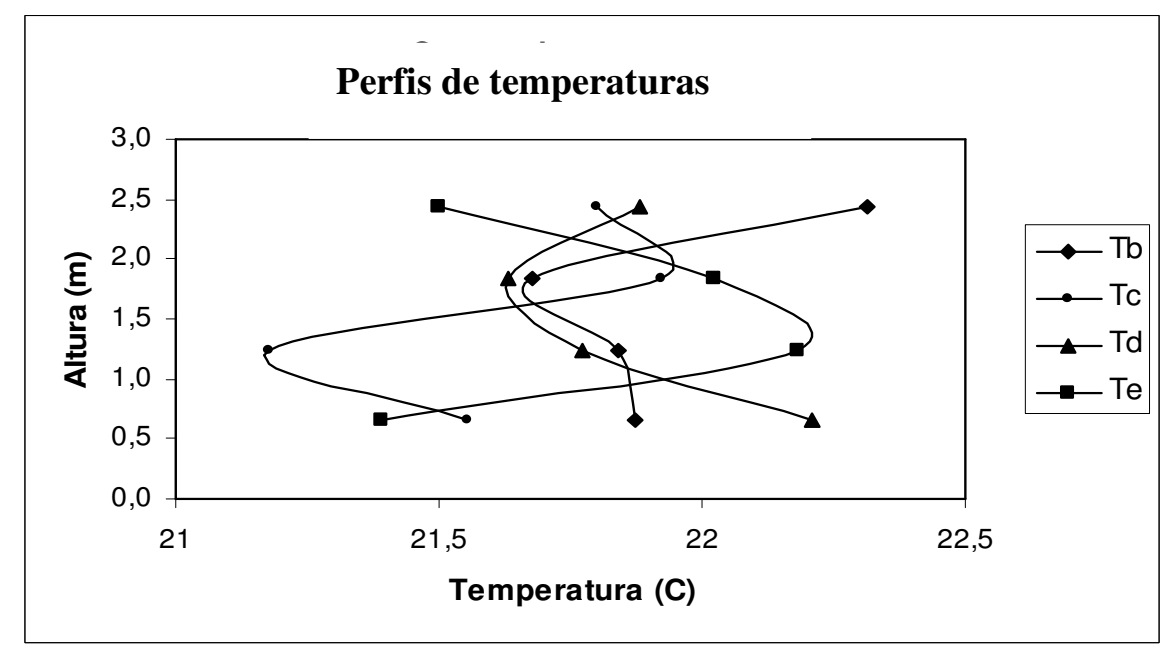

Figura A.17 - Perfis de temperaturas 


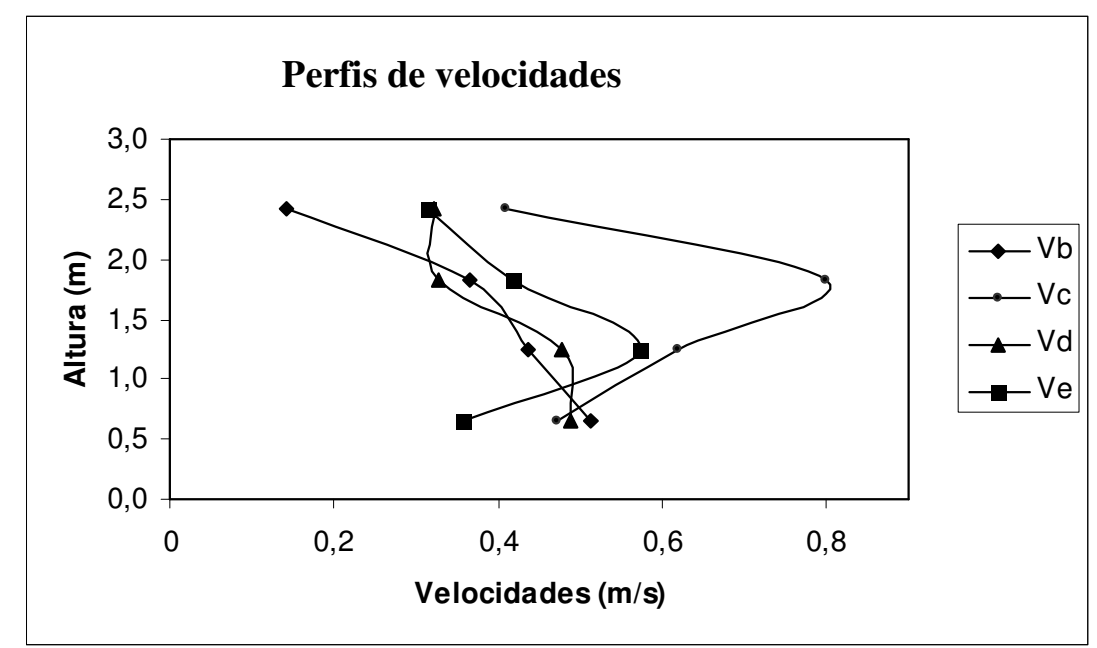

Figura A.18 - Perfis de velocidades

\subsection{Sistema de condicionamento de ar ligado e portas fechadas}

Nas figuras A.19 e A.20 são apresentados perfis de temperatura e velocidade, respectivamente.

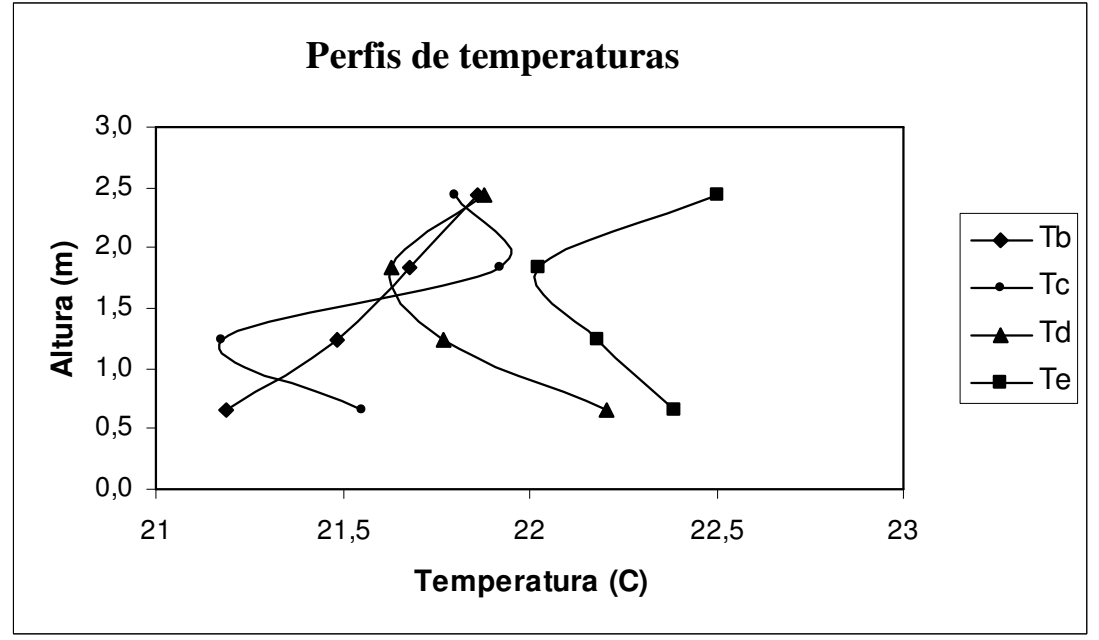

Figura A.19 - Perfis de temperaturas 


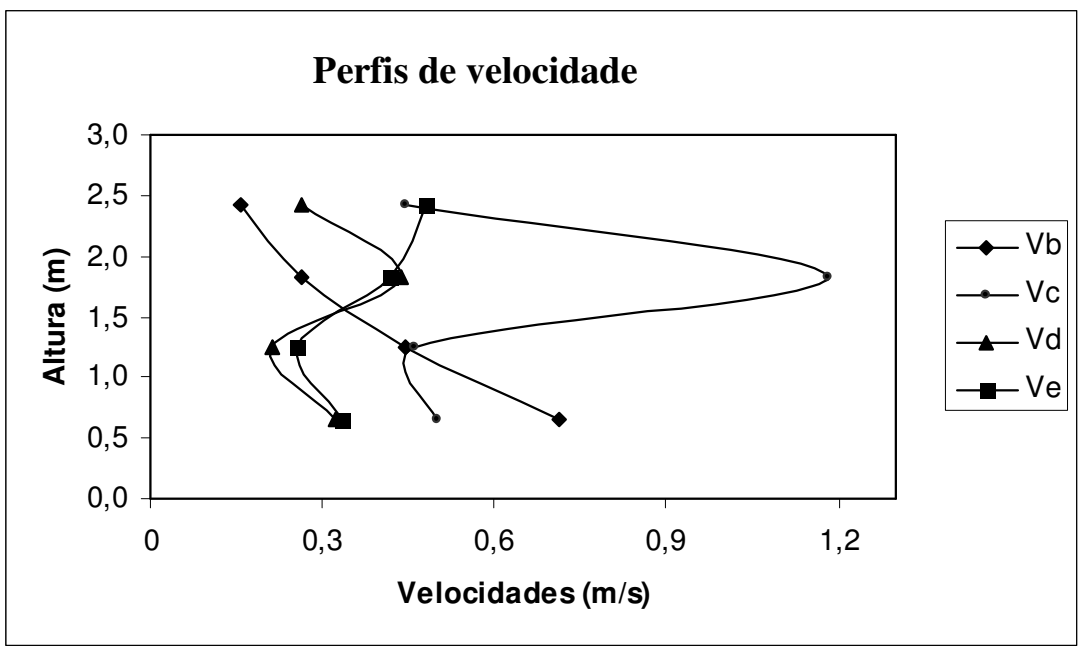

Figura A.20 - Perfis de velocidades 